UNIVERSIDADE DE SÃO PAULO/ESCOLA DE ENGENHARIA DE SÃO CARLOS PROGRAMA DE PÓS-GRADUAÇÃO EM ENGENHARIA MECÂNICA

\title{
“ANÁLISE TEÓRICA DE VIGAS PRÉ-MOLDADAS DE CONCRETO COM ARMADURA DE AÇO E DE POLÍMERO REFORÇADO COM FIBRA DE VIDRO EM MEIO ALTAMENTE AGRESSIVO"
}

Dissertação apresentada à Escola de Engenharia de São Carlos da Universidade de São Paulo, como parte dos requisitos para a obtenção do Título de Mestre em Engenharia Mecânica.

Orientador: Prof. Dr. Jonas de Carvalho

Aluno: Roberto Mauricio Micali 


\section{DEDICATÓRIA}

Dedico este trabalho primeiramente ao "Senhor" nosso criador, que me permitiu executá-lo.

Em segundo, a minha família, a minha esposa Rosângela, minhas filhas Natália e Lara è à minha mãe Maria Amélia, que sempre me incentivaram.

Em terceiro aos meus amigos de trabalho e ao meu orientador Dr. Jonas de Carvalho que sempre me apoiou e me incentivou nas horas dificeis.

também dedico aos meus colegas da pós-graduação Altibano e Lucas.

Não poderia esquecer de alguns professores do Departamento de Engenharia de Estruturas da EESC, entre eles o Prof. Libânio Miranda Pinheiro e o Prof. João Baptista de Paiva, que muito me ajudaram na minha formação, aos quais devo minha gratidão. 


\section{AGRADECIMENTOS}

Ao amigo e Prof. Dr. Jonas de Carvalho, Coordenador da Pós-graduação em Engenharia Mecânica da EESC-USP, que me aceitou como seu orientando no mestrado, sempre me apoiando nas horas difíceis;

Ao Altibano Ortenzi, que sempre se mostrou disposto a colaborar, e pelo seu notável bom humor.

À CAPES, pela bolsa concedida ao mestrado.

Aos professores e funcionários do Departamento de Engenharia Mecânica, não tenho como expressar o quanto estou grato, por tudo o que aprendi e pelo que ainda irei aprender, a cada vez que voltar a encontrá-los. 


\section{SUMÁRIO}

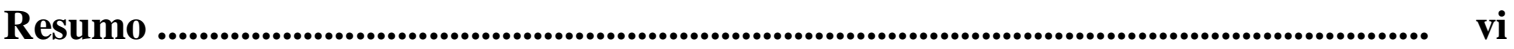

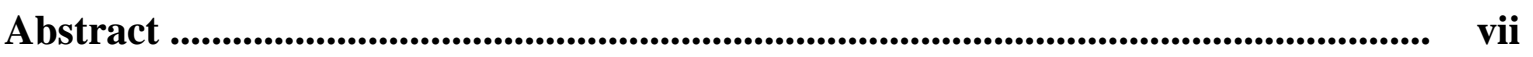

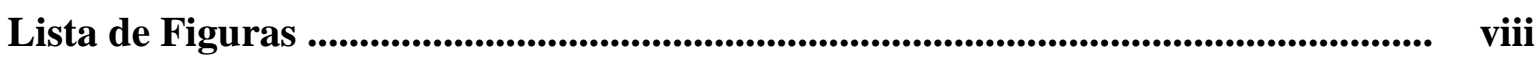

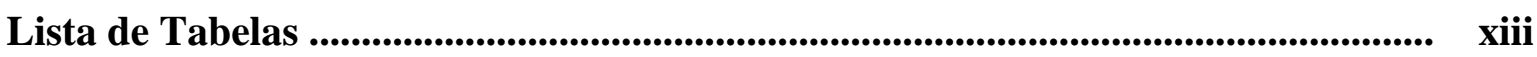

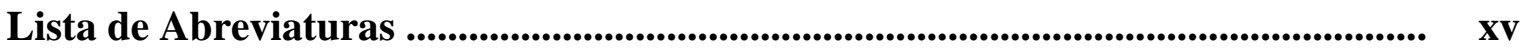

1. INTRODUÇÃO COM CONTRIBUIÇÃO BIBLIOGRÁFICA .......... 1

1.1 Motivação para a pesquisa ….............................................................. 2

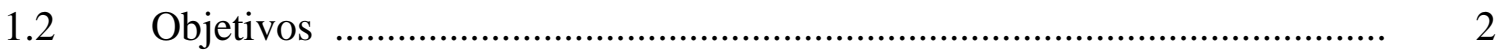

1.3 Desenvolvimento do Trabalho ……........................................................ 2

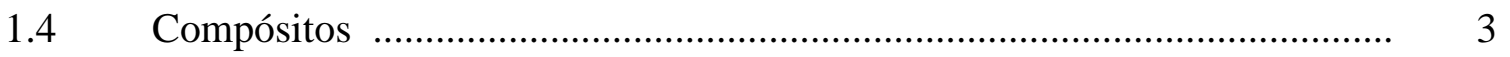

1.4.1 Polímeros e Fibras ...................................................................................... 8

1.4.2 Vantagens e Desvantagens da utilização de FRP ......................................... 14

1.4.3 Processo de Fabricação das fibras de vidro .................................................... 16

1.4.4 Principais processos de Fabricação de FRP …................................................ 19

2. REVISÃO BIBLIOGRÁFICA ............................................................... 25 
2.1 Fabricação das barras em GFRP

2.2 Características das barras em FRP

2.3 Flexão em peças com aço e com FRP 34

2.3.1 Tensão deformação no aço e em barras de FRP ……..................................... 34

2.3.2 Propriedades mecânicas do concreto simples ............................................ 37

2.3.3 Agressividade ambiental segundo a ABNT NBR 6118:2003 ....................... 39

2.3.4 Estádios de tensão e Domínios de deformação do concreto armado com aço

2.3.5 Equacionamento para flexão simples no concreto armado com aço................. 44

2.3.6 Equacionamento para flexão simples no concreto armado com FRP.............. 46

2.3.7 Considerações importantes sobre peças fletidas com FRP ............................. 52

2.4 Estados limites de serviço para vigas de concreto …............................... 57

2.4.1 Estados limites de serviço para vigas armadas com aço ........................... 58

2.4.2 Estados limites de serviço para vigas armadas com FRP ........................... 62

2.5 Cisalhamento em vigas de concreto ...................................................... 71

2.5.1 Cisalhamento em vigas de concreto armadas com aço .............................. 73

2.5.2 Cisalhamento em vigas de concreto armadas com FRP............................ 76

2.5.3 Verificação da ancoragem nas barras com FRP........................................ 82

3. MODELOS DE CÁLCULO _............................................................. 86

3.1 Modelo 1- Cálculo de acordo com a NBR 6118:2003 ….......................... 86

3.2 Modelo 1- Cálculo de acordo com o ACI 440.1R-06 …............................ 89

3.3 Modelo 2- Cálculo de acordo com a NBR 6118:2003 …........................... 95 
3.4 Modelo 2- Cálculo de acordo com o ACI 440.1R-06

3.5 Análise dos modelos pelo método dos elementos finitos ............................. 104

3.5.1 Resultados obtidos nos modelos de flexão ................................................... 106

3.5.2 Resultados obtidos nos modelos de cisalhamento ...................................... 114

4.1 Modelo de flexão

4.1.1 Através das equações................................................................................. 121

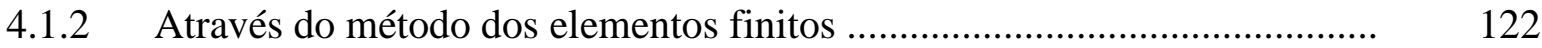

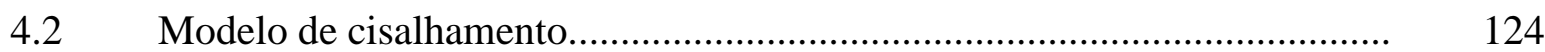

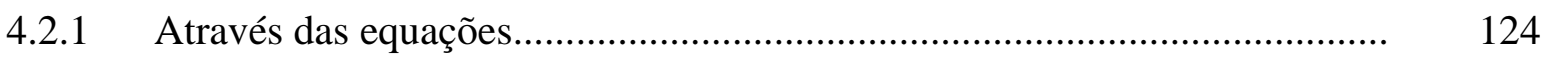

4.2.2 Através do método dos elementos finitos.................................................... 125

5. CONSIDERAÇÕES FINAIS ..................................................................... 127

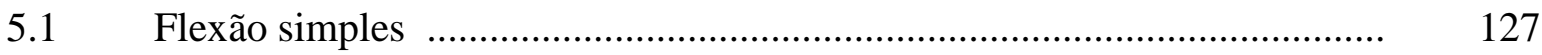

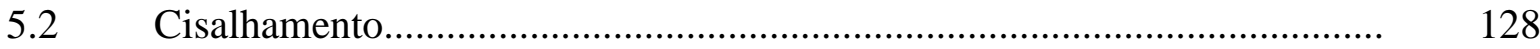

REFERÊNCIAS BIBLIOGRÁFICAS ....................................................... 129 


\section{RESUMO}

MICALI, R. M. "Análise teórica de vigas pré-moldadas de concreto com armadura de aço e de polímero reforçado com fibra de vidro em meio altamente agressivo". Dissertação de Mestrado. Universidade de São Paulo, Escola de Engenharia de São Carlos, Departamento de Engenharia Mecânica, 2010.

Este trabalho analisou o comportamento estrutural de polímeros reforçados com fibra de vidro - PRFV em elementos pré-moldados de concreto, com aplicações específicas em vigas de concreto. Realizou-se um estudo comparativo do comportamento de vigas pré-moldadas reforçadas com armadura convencional, segundo a norma brasileira NBR 6118:2003, e reforçadas com armadura de barras pultrudadas de PRFV, segundo o ACI 440.1R-06. O estudo visa obter subsídios para a aplicação de barras de reforço de PRFV, em relação ao Estado Limite de Serviço - ELS, em obras realizadas em regiões de alta agressividade ambiental. Posteriormente fez-se os mesmos modelos de cálculo em elementos finitos, onde foram comparados e analisados os resultados obtidos com o cálculo prescrito pelas normas. Nem todos os parâmetros da norma americana foram inseridos, uma vez que alguns coeficientes internos que contam com efeitos sísmicos e com a neve estão embutidos nos cálculos. Os resultados obtidos, principalmente no cisalhamento, foram altamente satisfatórios, validando a aplicação do PRFV nas vigas consideradas.

Palavra-Chave: FRP, GFRP, vigas de concreto armado com GFRP, Cisalhamento em vigas com GFRP 


\section{ABSTRACT}

MICALI, R. M. "Theoretical analysis of precast concrete beams with steel bars and polymer reinforced with glass fiber in aggressive environmental sites”. M.Sc. Dissertation. Universidade de São Paulo, Campus de São Carlos, Departamento de Engenharia Mecânica, 2010.

This work studied the behavior of precast beams when subjected to shear stress according to the Brazilian Standard NBR 6118:2003 reinforced with steel bar compared to the American Standard ACI 440.1R-06 when the structural member was reinforced with glass fiber reinforced polymer - GFRP pultruded bars. The goal of this work is to acquire subsidies to apply the GFRP in aggressive environmental sites. Also the same model calculations were performed by using Finite Element Method and compared to the results of the calculation prescribed by the standards. Some parameters indicated in the ACI standard were not followed since they are related to seismic and snow effects. The obtained results mainly in shear loading were highly satisfactory which validates the use of GFRP in the considered beams. 


\section{LISTA DE FIGURAS}

Figura 1.1- Materiais Compósitos Poliméricos Reforçados 04

Figura 1.2- Classificação dos Compósitos (adaptado de DANIEL e ISHAI, 1994) ............. 04

Figura 1.3- Classificação dos Compósitos Reforçados - Adaptado: CALLISTER (2002) .... 05

Figura 1.4 - Evolução do mercado de compósitos no Brasil de 2003 a 2006- Fonte: ABMACO -Associação Brasileira de Materiais Compósitos (2007) 06

Figura 1.5 - Volume relativo de venda de diferentes fibras - Adaptado: Tsai, Stephen W. et al. (2003) 07

Figura 1.6 - Distribuição mundial por continente da produção de compósitos. ACMA-2003..

Figura 1.7- Representação esquemática de compósito unidirecional .................................. 11

Figura 1.8- Elemento de volume de fibra unidirecional ............................................... 11

Figura 1.9- Representação esquemática de compósito bidirecional .................................... 12 Figura 1.10 - Representação esquemática de compósito bidirecional em uma única lâmina 13

Figura 1.11- Resistência específica à tração de diferentes compósitos com o aumento de temperatura. Adaptado: Tsai, Stephen W. et al. (2003) ...................................................... 16

Figura 1.12- Manta de Superfície. Fonte: SAINT GOBAIN VETROTEX (2000) ............... 16 Figura 1.13 - Roving contínuo para enrolamento ou filamento Winding, pultrusão e

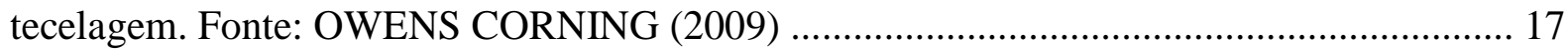

Figura 1.14- Roving para laminação à pistola. Fonte: OWENS CORNING (2009) ............. 18 Figura 1.15- Tecido em fibra de vidro.Fonte: SAINT-GOBAIN-VETROTEX (2000) ......... 18 Figura 1.16- Tensão última de alguns compósitos resina/fibra de vidro de acordo com a porcentagem em volume de fibras. Adaptado: Tsai, Stephen W. et al. (2003) .....

Figura 1.17 - Distribuição Brasileira por processos de fabricação. Fonte: ABMACO Associação Brasileira de Materiais Compósitos (2009) ......................................................... 20

Figura 1.18- Laminação manual. Fonte: SAINT-GOBAIN-VETROTEX (2000) .................. 21

Figura 1.19- Processo de Filament Winding. Adaptado: Tsai, Stephen W. et al. (2003) ....... 22 
Figura 1.20 - Esquema do processo de Pultrusão. Adaptado: Handbook of Composites.

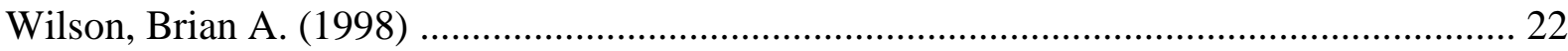

Figura 1.21- Processo de moldagem a vácuo. Adaptado: Tsai, Stephen W. et al. (2003) .... 24 Figura 2.1 - Máquina de Pultrusão.Fonte: Handbook of Composites. Wilson, Brian A. (1998)

Figura 2.2 - Material de reforço dos rovings sendo introduzidos na máquina de pultrusão. Fonte: Handbook of Composites. Wilson, Brian A. (1998) 27

Figura 2.3- Barras de reforço em GFRP comercialmente disponíveis. Fonte: ACI440.1R06

Figura 2.4 - Barras de FRP com conformações superficiais diferentes, comercialmente disponíveis. Fonte: ACI440.1R-06 28

Figura 2.5- Barras de GFRP usadas na Winery in British Columbia em 1998. Fonte: ACI440.1R-06 30

Figura 2.6- Esquema de deformação isotrópica e anisotrópica. Adaptado: Tsai, Stephen W. et al. (2003)

Figura 2.7- Digrama de cálculo (tensão-deformação) para o aço. Adaptado: NBR6118:2003

Figura 2.8- Diagrama tensão-deformação do aço e GFRP. Adaptado: Pilakoutas, K. et al. (2002) 35

Figura 2.9- Distribuição de deformações e tensões para duas seções transversais de concreto armada com FRP e aço respectivamente. Adaptado: Pilakoutas, K. et al. (2007).. 36 Figura 2.10- Tensão na ruptura do concreto reforçado em relação à taxa de armadura de reforço. Adaptado: Pilakoutas e Guadagnini (2007)

Figura 2.11- Ensaio de tração na flexão de uma viga de concreto de acordo com a ABNT NBR 12142:1991 38

Figura 2.12- Módulo de deformação tangencial inicial do concreto. Adaptado: ABNT NBR 6118:2003 38

Figura 2.13- Diagrama tensão deformação no estado limite. Fonte: ABNT NBR 6118:2003

Figura 2.14- Diagrama de deformação e de tensão no concreto na ruptura. Adaptado ABNT NBR 6118:2003

Figura 2.15- Domínios de deformação na ruína. Fonte: ABNT NBR 6118:2003................. 43

Figura 2.16- Equilíbrio de forças e de momentos da viga na flexão simples .45 
Figura 2.17- Ruína governada pela ruptura da barra de FRP (tensão no concreto pode ser não linear). Adaptado: ACI440.1R-06

Figura 2.18- Ruína governada pelo esmagamento do concreto. Adaptado: ACI440.1R06

Figura 2.19- Condição balanceada de ruína: ACI440.1R-06 47

Figura 2.20- Fator de redução de resistência em função da taxa de armadura de reforço FRP Adaptado: ACI440.1R-06 50

Figura 2.21- Relação teórica momento- curvatura para seções de concreto usando reforço em aço e GFRP. Adaptado: ACI440.1R-06 52

Figura 2.22- Situação com mais de uma camada de reforço FRP. Adaptado: ACI440.1R06

Figura 2.23- Modelo proposto otimizado para viga com vão reduzido reforçada em FRP. Adaptado: Nehdi et al. (2008) 53

Figura 2.24 - Tipos de métodos de ensaio para testes de aderência entre barras de FRP e o concreto. Adaptado: Fico (2007) 55

Figura 2.25- Reforço interno hiperestático em FRP em vigas de concreto. Adaptado: ACI Structural Journal (2003) 55

Figura 2.27- Concreto de envolvimento da armadura. Fonte: ABNT NBR 6118:2003 61

Figura 2.28- Previsão de controle de fissuras da equação 2.52 segundo Frosch (1999) Adaptado: ACI 318M-05

Figura 2.29- Modelo proposto para controle de fissuras para o reforço GFRP em elementos de concreto. Adaptado: Bakis e Ospina (2006) 67

Figura 2.30- Modelo clássico de analogia com a treliça segundo Ritter e Mörsch .72

Figura 2.31- Viga submetida a esforços de cisalhamento .73

Figura 2.32- Componentes de $\mathrm{V}_{\mathrm{n}}$ para a viga de concreto reforçada com aço. Adaptado Kong e Evans (2001) .78

Figura 2.33- Ruptura no cisalhamento pelo esmagamento do concreto. Fonte: Pilakoutas et al. (2007) 81

Figura 2.34- Transferência de força através da aderência. Fonte: ACI440.1R-06 83

Figura 3.1- Viga 200 mm x 300 mm submetida à flexão em ambiente altamente agressivo 
Figura 3.2- Detalhamento final da viga submetida à flexão simples, com armadura convencional para um carregamento de $\mathrm{F}=33,42 \mathrm{kN}$ (domínio 2) em ambiente altamente agressivo

Figura 3.3- Detalhamento final da viga submetida à flexão simples, com armadura em GFRP e um carregamento $\mathrm{F}=33,42 \mathrm{kN}$ em ambiente altamente agressivo 94

Figura 3.4- Viga $200 \mathrm{~mm}$ x $300 \mathrm{~mm}$ submetida ao cisalhamento em ambiente altamente agressivo 96

Figura 3.5- Detalhamento final da viga submetida ao cisalhamento, com armadura convencional para um carregamento de $\mathrm{F}=77,33 \mathrm{kN}$ (domínio 2) em ambiente altamente agressivo .98

Figura 3.6- Detalhamento final da viga submetida ao cisalhamento, com armadura em GFRP e um carregamento $\mathrm{F}=77,33 \mathrm{kN}$ em ambiente altamente agressivo 103

Figura 3.7- Malha de elementos finitos para os elementos do concreto da viga na flexão .. 107

Figura 3.8- Malha de elementos finitos para os elementos da armadura na flexão 107

Figura 3.9a- Deslocamento máximo na viga armada com aço na flexão 108

Figura 3.9b- Deslocamento máximo na armadura em aço na flexão . 108

Figura 3.10a- Deslocamento máximo na viga armada com GFRP na flexão 109

Figura 3.10b - Deslocamento máximo na armadura em GFRP na flexão 109

Figura 3.11.a- Deformação máxima na viga armada com aço na flexão 110

Figura 3.11.b- Deformação máxima na armadura em aço na flexão 110

Figura 3.12.a- Deformação máxima na viga armada com GFRP na flexão 111

Figura 3.12.b- Deformação máxima na armadura em GFRP na flexão 111

Figura 3.13- Tensão máxima de tração e compressão da viga armada com aço na flexão ... 112 Figura 3.14a- Tensão máxima de tração e compressão da viga armada com GFRP na flexão ...

Figura 3.14b- Análise mais detalhada do ponto de máxima tensão na viga armada em GFRP 113

Figura 3.15- Malha de elementos finitos para os elementos do concreto da viga no cisalhamento

Figura 3.16- Malha de elementos finitos para os elementos da armadura no cisalhamento...115

Figura 3.17a- Deslocamento máximo na viga armada com aço no cisalhamento ................ 115

Figura $3.17 b$ - Deslocamento máximo na armadura em aço no cisalhamento...................... 116

Figura 3.18.a- Deslocamento máximo na viga armada com GFRP no cisalhamento ........... 116

Figura 3.18.b- Deslocamento máximo na armadura em GFRP no cisalhamento ................. 117 
Figura 3.19.a- Deformação máxima na viga armada com aço no cisalhamento 117

Figura 3.19.b- Deformação máxima na armadura em aço no cisalhamento 118

Figura 3.20a- Deformação máxima na viga armada com GFRP no cisalhamento 118

Figura 3.20b- Deformação máxima na armadura em GFRP no cisalhamento 119 Figura 3.21 - Tensão máxima de tração e compressão da viga armada com aço no cisalhamento 119

Figura 3.22 - Tensão máxima de tração e compressão da viga armada com GFRP no cisalhamento 120

Figura 4.1- Comparação tensão x deformação entre o aço e GFRP na flexão 123

Figura 4.2- Comparação tensão x deformação entre o aço e GFRP no cisalhamento 126 


\section{LISTA DE TABELAS}

Tabela 1.1 - Tipos de polímeros mais utilizados. Adaptado de Quinn (2002) e Mazumdar (2001)

Tabela 1.2 - Propriedades mecânicas de polímeros curados sem reforço. Fontes: REICHHOLD (2006); SHACKELFORD (2001) 09

Tabela 1.3 - Propriedades das fibras mais utilizadas em compósitos. Fonte: UOMOTO (2002)

Tabela 1.4 - Vantagens e Desvantagens de FRP. Fonte: ACI440.1R (2006) 15

Tabela 2.1 - Padrão ASTM - Barras Reforçadas. Fonte: ACI440.1R-06 29

Tabela 2.2 - Propriedades das barras de FRP comparadas com as de aço. Fonte: ACI440.1R-06 30

Tabela 2.3- Fator de redução ambiental. Fonte: ACI440.1R-06. 32

Tabela 2.4- Mínimo módulo de elasticidade para diferentes tipo de FRP. Fonte: ACI440.1R06 33

Tabela 2.5 - Classe de agressividade ambiental. Adaptado: NBR 6118:2003 40

Tabela 2.6 - Correspondência entre classe de agressividade e qualidade do concreto Adaptado: NBR 6118:2003.

Tabela 2.7 - Correspondência entre classe de agressividade ambiental e cobrimento nominal Adaptado: NBR 6118:2003

Tabela 2.8 - Valores típicos da taxa de armadura balanceada para uma seção retangular com $f_{c}^{\prime}=34,5 \mathrm{MPa}$. Fonte: ACI440.1R-06

Tabela 2.9 - Resumo dos resultados dos experimentos em elementos finitos. Adaptado: ACI Structural Journal (2003)

Tabela 2.10 - Valores do coeficinete $\xi$ em função do tempo. Fonte: ABNT NBR 6118:2003 (2006)

Tabela 2.11 - Exigências de durabilidade relacionadas à fissuração e à proteção da armadura, em função das classes de agressividade ambiental. Fonte: ABNT NBR 6118:2003 .62

Tabela 2.12 - Altura mínima recomendada de viga. Adaptado: ACI 440.1R-06. 68

Tabela 2.13- Limites de tensão de ruptura do reforço FRP. Adaptado: ACI 440.1R-06. 70 
Tabela 2.14- Valores da taxa de armadura mínima. Adaptado ABNT NBR 6118:2003........ 75 Tabela 3.1- Resultados obtidos da viga (flexão simples) no centro do vão através das

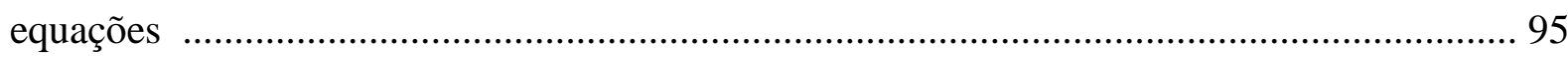

Tabela 3.2- Resultados obtidos da viga (cisalhamento) através das equações .................... 104

Tabela 3.3- Entrada de dados para a simulação em elementos finitos dos modelos das

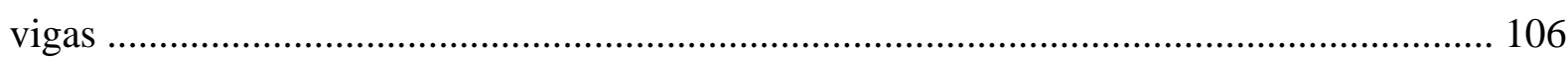

Tabela 4.1- Resultados pelo método dos elementos finitos na flexão em aço e GFRP....... 122 Tabela 4.2- Resultados pelo método dos elementos finitos no cisalhamento em aço e GFRP... 


\section{LISTA DE ABREVIATURAS}

ABNT: Associação Brasileira de Normas Técnicas

ACI: American Concrete Institute (Instituto Americano do Concreto)

ACMA American Composites Manufactures Association (Associação Americana de Compósitos Manufaturados)

AFRP: Aramida Fiber Reinforced Polymer (Polímero Reforçado com Fibra de Aramida)

ASTM: American Standards for Testing and Materials (Norma Americana para Testes e Materiais)

BMC: Bulk Molding Compound (Moldagem por Compressão do Compósito)

CAA: Classe de Agressividade Ambiental

CFRP: Carbon Fiber Reinforced Polymer (Polímero Reforçado com Fibra de Carbono)

CSA: Canadian Standards Association (Associação de Normas Canadense)

EC2: Eurocode 2

ELS: $\quad$ Estado Limite de Serviço

FIB: Federation Internationale du Béton (Federação Internacional do Concreto)

FRP: $\quad$ Fiber Reinforced Polymer (Polímero Reforçado com Fibra)

GFRP: Glass Fiber Reinforced Polymer (Polímero Reforçado com Fibra de Vidro)

JSCE: Japan Society of Civil Engineers (Sociedade Japonesa de Engenheiros Civis)

RTM: Resin Transfer Molding (Moldagem por Transferência de Resina)

SMS: Sheet Molding Compound (Moldagem por compressão de folhas pré impregnadas submetidas à compressão e calor) 


\section{1- INTRODUÇÃO COM CONTRIBUIÇÃO BIBLIOGRÁFICA}

Este trabalho comparou os procedimentos de dimensionamento de vigas de concreto armado quando submetidas a ambientes agressivos, pelas normas ABNT NBR 6118:2003 e o ACI 4401R-06.

As vigas foram calculadas com armadura interna em aço e em Glass Fiber Reinforced Polymer - GFRP, respectivamente. Posteriomente, foi realizado um modelo numérico para comparar com os resultados analíticos baseados nas duas normas.

$\mathrm{Na}$ literatura são estudadas várias tipologias de elementos pré-moldados de concreto reforçados com GFRP. Ainda que alguns estudos desta natureza já tenham sido realizados anteriormente no Brasil, esse tema requer maior aprofundamento, especialmente pelas peculiaridades climáticas e geográficas de nosso país, onde não existe ocorrência de neve ou terremotos. Contudo o vasto litoral, o regime de chuvas de regiões tropicais e as variações rápidas de temperatura contribuem para a ocorrência de degradação do concreto, por micro fissuras, lixiviação e outras patologias, que afetam o desempenho da estrutura no decorrer de sua vida útil. Como é possível notar, ainda hoje no Brasil, as fundações e lajes de pisos de áreas laboratoriais de equipamentos médicos de alta sensibilidade carecem de norma que elimine o uso de materiais eletrocondutores como o aço. Este é um dos exemplos de aplicações possíveis, além do uso em ambientes de alta agressividade ambiental.

O principal objetivo do trabalho foi comparar os modelos de cálculo para estruturas utilizadas em ambientes altamente agressivos e comparar os resultados entre o uso da armadura de aço e a armadura de GFRP para uma mesma tipologia de elemento estrutural e para as mesmas solicitações, isto é, momento fletor e força cortante. 


\subsection{Motivação para a pesquisa}

A motivação surgiu devido a alguns trabalhos já publicados na área de reforço interno e externo de vigas de concreto, alguns aqui no Brasil e a sua grande maioria nos Estados Unidos, Canadá, Itália, Portugal e Japão.

No Brasil os estudos estão apenas começando, e nos países citados remontam a aproximadamente um pouco mais de uma década de pesquisas realmente aplicativas na construção civil. Sabe-se que a aplicação de compósitos já é usual na engenharia aeronáutica, naval e automobilística, e também na área médica de próteses e implantes, ou seja, na área de transportes, industrial e também na área da saúde. A construção civil nos últimos anos é um dos setores que mais utiliza compósitos, e este trabalho tem a intenção de contribuir neste sentido.

\subsection{Objetivos}

Este trabalho tem por objetivo estudar o desempenho de vigas de concreto em ambiente altamente agressivo, armadas com barras de Polímero Reforçado com Fibra de Vidro (GFRP), tanto na armadura longitudinal como na armadura transversal. Trata-se de um dos poucos trabalhos desta natureza, pois verifica teoricamente e por elementos finitos o desempenho da armadura transversal em GFRP. O propósito deste trabalho é comparar vigas com a mesma seção transversal e mesmo carregamento, alterando o tipo de armadura, primeiramente calculada com armadura convencional em aço segundo a NBR 6118:2003, e posteriormente com polímero reforçado com fibra de vidro (GFRP) segundo o ACI 440.1R-06.

Após essa análise dos parâmetros, decorrentes de várias equações, é feita uma comparação também com os resultados numéricos obtidos através do Método dos Elementos Finitos.

\subsection{Desenvolvimento do trabalho}

O trabalho se inicia com uma pequena introdução sobre o que são os compósitos poliméricos, seguido da revisão bibliográfica de diversos trabalhos existentes, nacionais e internacionais, sobre reforço estrutural interno em elementos pré-moldados de concreto, através de polímero reforçado com alguns tipos de fibras. 
Posteriormente, em modelos de cálculo e análise de resultados, são comparadas numericamente as duas normas que tratam do tema abordado na pesquisa. Finalmente é realizada a análise por elementos finitos e a comparação final de todos os resultados.

Por se tratar de um trabalho que apresenta os procedimentos de cálculo para estruturas submetidas a ambientes agressivos, a pesquisa foi embasada na literatura que trata de análise numérica e experimental. Pela mesma razão, os cálculos se basearam na NBR 6118:2003 (concreto e aço no Brasil), o ACI 318-05 (concreto e aço nos Estados Unidos) e no ACI 440.1R-06 (concreto e FRP nos Estados Unidos).

\subsection{Compósitos}

Os materiais compósitos estão cada vez mais se tornando uma alternativa altamente viável nos diversos ramos da engenharia, devido a durabilidade a longo prazo aliada a condições de trabalho extremamente exigentes em regiões com alta exposição e agressividade ambiental.

- Hull (1981) define os materiais compósitos utilizados em aplicação estrutural, em escala macroscópica, da seguinte forma:

- Consistem de dois ou mais materiais fisicamente distintos e separáveis mecanicamente;

- Podem ser fabricados de modo a se controlar a proporção de cada um dos componentes utilizados, objetivando-se a obtenção das propriedades desejadas;

- O desempenho obtido no compósito é superior, se comparado ao dos seus componentes separados.

A Figura 1.1 mostra, esquematicamente, a formação de um material compósito polimérico, definido por Hull (1981). 


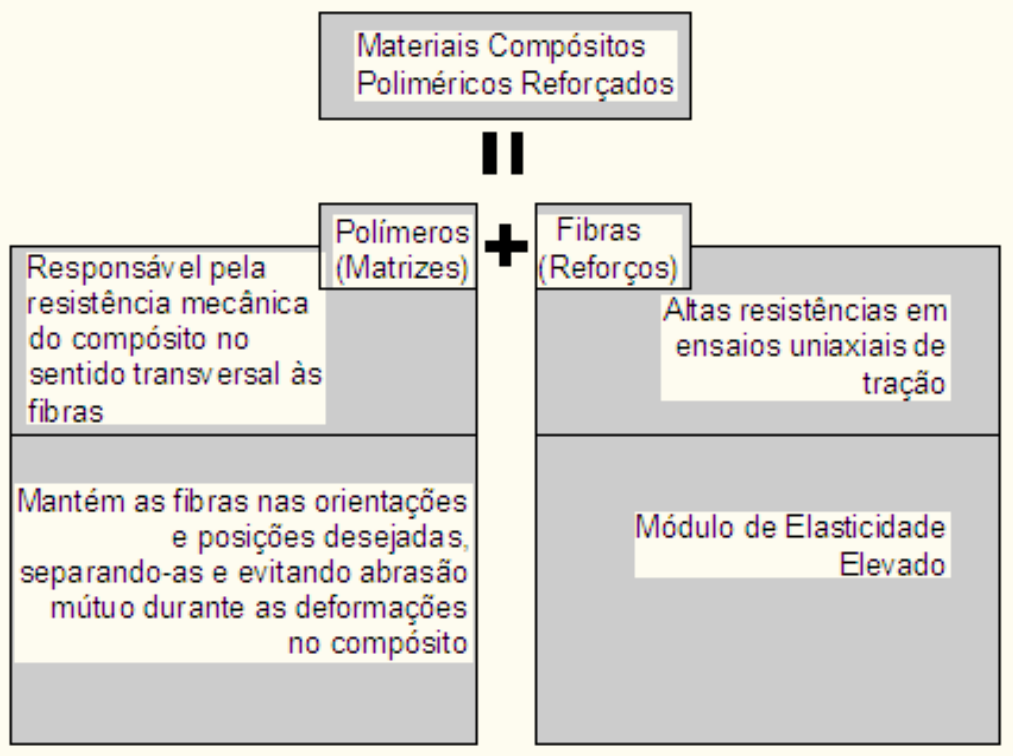

Figura 1.1- Materiais Compósitos Poliméricos Reforçados

Os compósitos podem ser classificados em três categorias, dependendo da geometria, tipo e orientação do reforço (DANIEL e ISHAI, 1994), como mostra a Figura 1.2

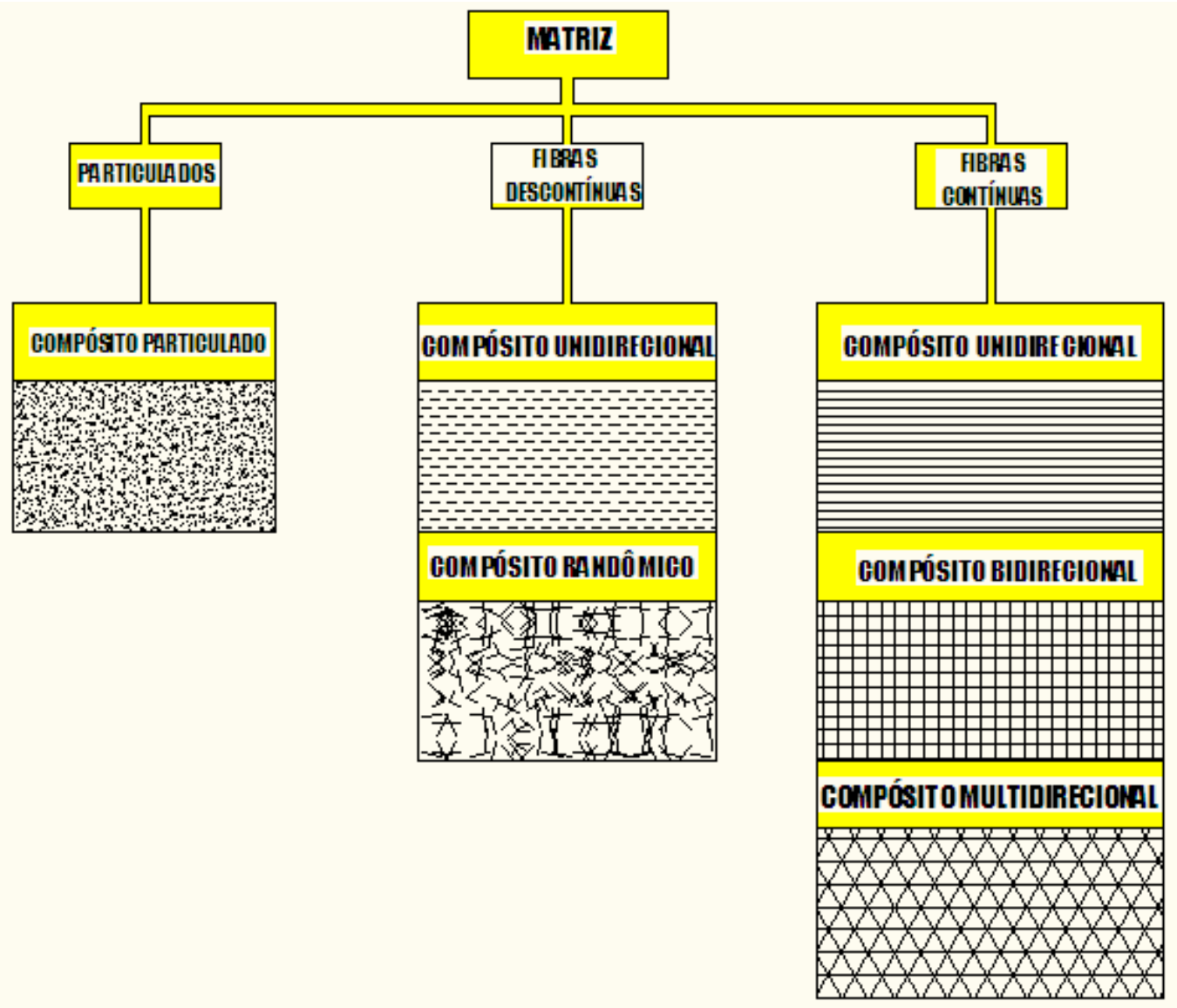

Figura 1.2 - Classificação dos Compósitos (adaptado de DANIEL e ISHAI, 1994)

Cap.1- Introdução com contribuição bibliográfica 
Callister (2002) define o compósito como um material multifase com propriedades superiores a cada fase de sua composição. Uma dessas fases deve ser o material aglomerante (matriz) e outra fase o material de reforço (fibras, partículas ou estrutural). Devido à diversidade de materiais que constituem as diferentes fases dos compósitos, eles podem ser classificados de acordo com o tipo de material de reforço (Figura 1.3):

-Compósitos reforçados com partículas;

-Compósitos reforçados com fibras;

-Compósitos estruturais.

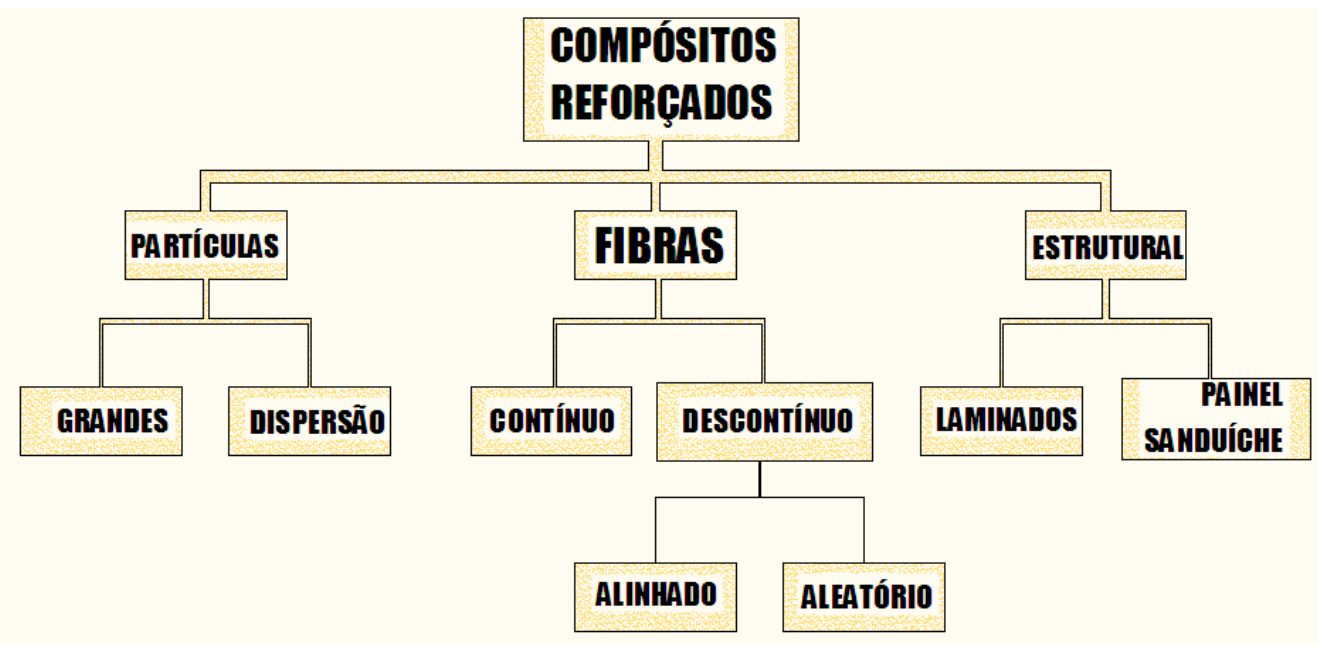

Figura 1.3- Classificação dos Compósitos Reforçados - Adaptado: CALLISTER (2002)

ASTM (2001) define compósito como uma mistura física, de dois ou mais materiais interligados para formar um novo material, com utilização na engenharia e com propriedades diferentes dos componentes puros, podendo ser obtidos por combinação de metais, cerâmicas ou polímeros.

A matriz geralmente é composta por resina termofixa, sendo mais utilizadas as de poliéster insaturada, dissolvida em solvente reativo como estireno ou ainda por resinas éster vinílica, ou epóxi. Resinas especiais como as fenólicas, de poliuretano e de silicone são utilizadas em aplicações especiais. Outras substâncias também são utilizadas na preparação e na 
constituição do compósito, como os materiais do sistema catalisador e aditivos, intitulados cargas ou aditivos especiais, cujo objetivo é fornecer características especiais ao produto final.

Compósitos de polímeros termofixos reforçados com fibras de vidro, também chamados no Brasil como plásticos reforçados com fibra de vidro, ou simplesmente fiberglass, são formados por uma fase contínua polimérica (resina) e uma fase descontínua (fibra de reforço), que se agregam físico-quimicamente após um processo de cura.

A Figura 1.4 mostra o crescimento do mercado de compósitos no Brasil, principalmente na indústria de transporte e civil.

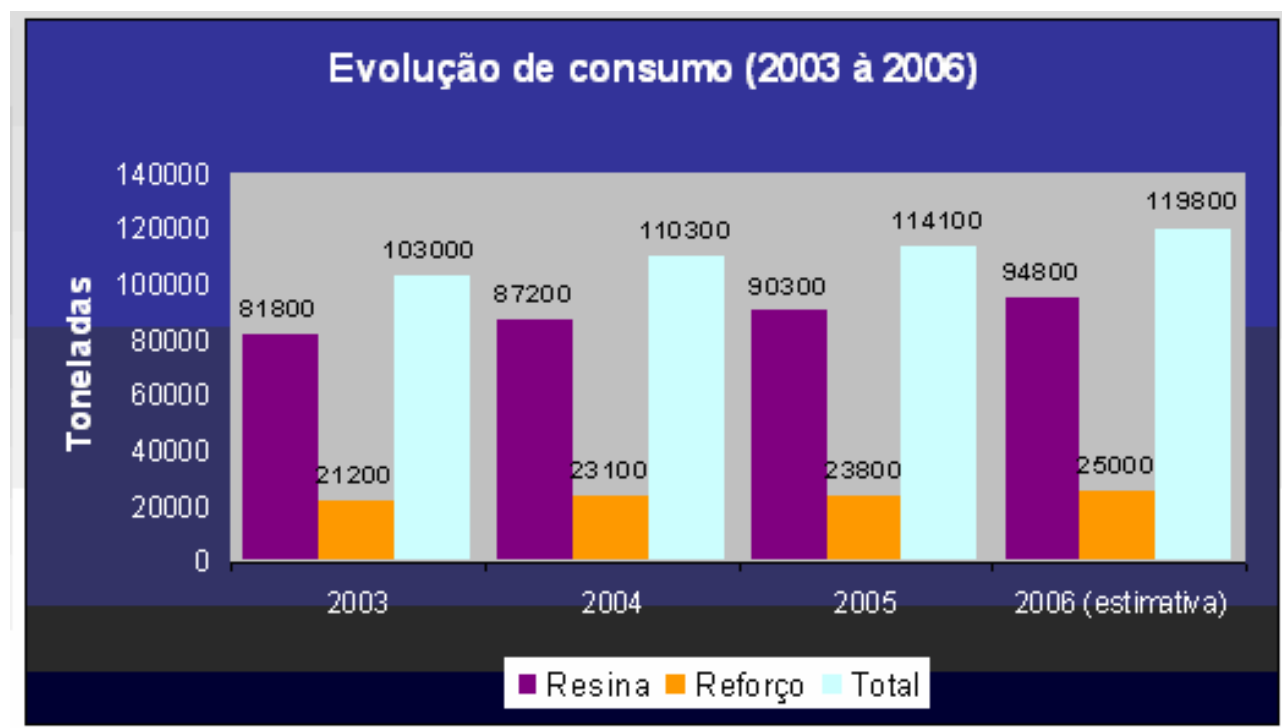

Figura 1.4 - Evolução do mercado de compósitos no Brasil de 2003 a 2006- Fonte: ABMACO -Associação Brasileira de Materiais Compósitos (2007)

No gráfico da Figura 1.5 pode-se comparar a quantidade relativa de fibras comercializadas de 1984 a 1993, e nota-se o crescimento do comércio das fibras de vidro em relação às outras fibras. 


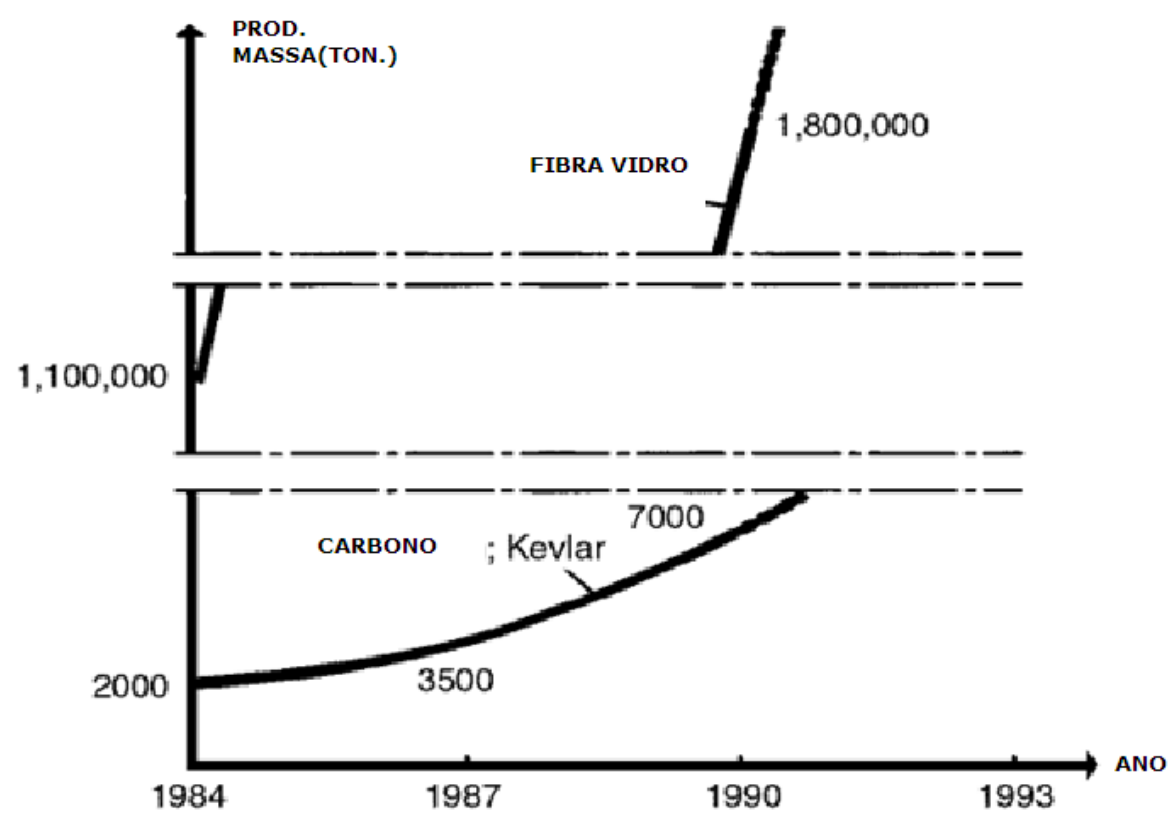

Figura 1.5 - Volume relativo de venda de diferentes fibras - Adaptado: Tsai, Stephen W. et al. (2003)

De acordo com os dados da American Composites Manufacturers Association ACMA, em 2003 a distribuição de produtos fabricados com compósitos são mais utilizados na América do Norte (EUA e Canadá) e Europa. A Figura 1.6 mostra a distribuição da produção mundial de compósitos por continente, tomando como ano-base o de 2003. Pode ser visto que América Central, América do Sul e África representam juntos apenas 3\% do total mundial naquele ano.

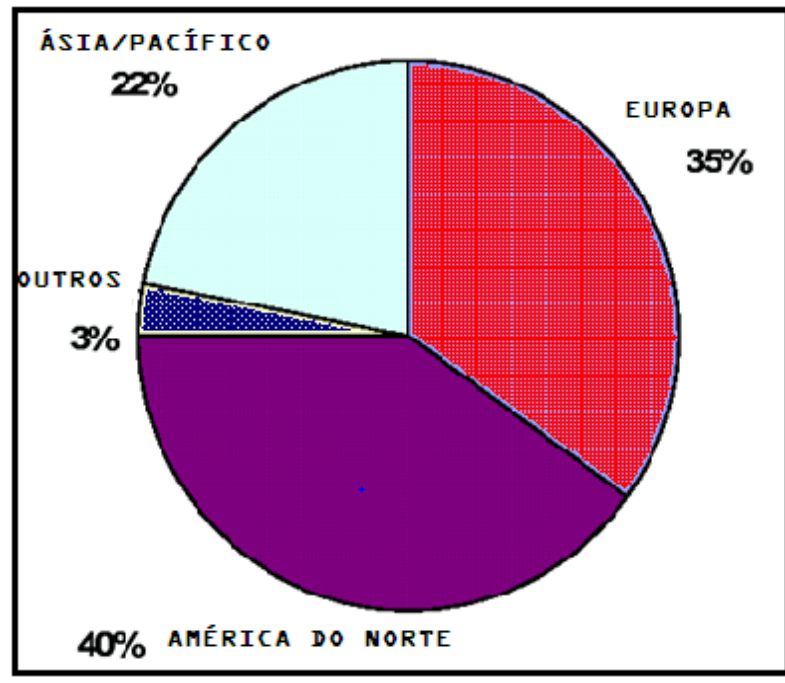

Figura 1.6 - Distribuição mundial por continente da produção de compósitos. Adaptado: ACMA-2003 


\subsubsection{Polímeros e Fibras}

- Os polímeros podem ser classificados em termofixos e termoplásticos (ou termomoldáveis).

- Termofixos: São plásticos insaturados, onde sua cadeia molecular é composta por duplas ligações. São sólidos mantidos em estado líquido viscoso pela adição de algum tipo de solvente para permitir sua trabalhabilidade. Para serem moldados necessitam da adição de algum componente reagente, denominado catalisador, que ativa a polimerização.

- Termoplásticos: São os plásticos saturados, não possuem duplas ligações e seu estado final de equilíbrio é sólido, com variados graus de dureza. Para serem moldados necessitam de aquecimento e confinamento em moldes fechados onde são injetados no estado líquido viscoso. No final do processo o plástico volta ao estado sólido, com a geometria do molde utilizado.

$\mathrm{Na}$ Tabela 1.1 estão presentes os tipos mais comuns de polímeros termofixos e termomoldáveis

Tabela 1.1- Tipos de polímeros mais utilizados. Adaptado de Quinn (2002) e Mazumdar (2001)

\begin{tabular}{|c|c|c|c|}
\hline TERMOFIXOS & USOS COMUNS & TERMOPLASTICOS & USOS COMUNS \\
\hline $\begin{array}{c}\text { Poliéster } \\
\text { Insaturado }\end{array}$ & $\begin{array}{c}\text { Compósitos, adesivo, } \\
\text { peças decorativas. }\end{array}$ & PE - Polietileno & $\begin{array}{l}\text { Embalagens, tubos } \\
\text { flexíveis, utensílios }\end{array}$ \\
\hline Poliuretano & $\begin{array}{l}\text { Compósitos, peças } \\
\text { mecânicas, espumas. }\end{array}$ & $\begin{array}{c}\text { PVC - Policloreto de } \\
\text { Vinila }\end{array}$ & $\begin{array}{c}\text { Tubos e mangueiras } \\
\text { Embalagens de } \\
\text { alimentos }\end{array}$ \\
\hline Fenol & Adesivos diversos. & $\begin{array}{l}\text { PET - Polietileno } \\
\text { Tereftalato }\end{array}$ & $\begin{array}{c}\text { Emb. Diversas e de } \\
\text { alimentos }\end{array}$ \\
\hline Epóxi & $\begin{array}{c}\text { Compósitos especiais e } \\
\text { adesivos. }\end{array}$ & Polipropileno HD & $\begin{array}{c}\text { Peças industriais, } \\
\text { compósitos injetados }\end{array}$ \\
\hline Acrílicos & $\begin{array}{l}\text { Substituto do vidro, } \\
\text { utensílios. }\end{array}$ & Nylon & $\begin{array}{c}\text { Tecidos e peças } \\
\text { mecânicas industriais }\end{array}$ \\
\hline Éster vinílico & $\begin{array}{l}\text { Compósitos de maior } \\
\text { resistência. }\end{array}$ & $\begin{array}{c}\text { EVA - Etileno Vinil } \\
\text { Acetato }\end{array}$ & $\begin{array}{c}\text { Calçados, materiais } \\
\text { esportivos }\end{array}$ \\
\hline Bisfenólico & $\begin{array}{l}\text { Adesivos, abrasivos, } \\
\text { discos de corte. }\end{array}$ & Poliestireno & $\begin{array}{c}\text { Isolamento, } \\
\text { embalagens, constr. } \\
\text { Civil }\end{array}$ \\
\hline
\end{tabular}

Macroscopicamente os polímeros possuem características isotrópicas, mas microscopicamente a maioria deles se constitue de materiais ortotrópicos e anisotrópicos.

$\mathrm{Na}$ Tabela 1.2 tem-se as características mecânicas dos polímeros termofixos mais utilizados na construção civil. 
Tabela 1.2 - Propriedades mecânicas de polímeros curados sem reforço.

Fontes: REICHHOLD (2006); SHACKELFORD (2001)

\begin{tabular}{|c|c|c|c|}
\hline Propriedades & Poliéster & Vinil-Éster & Epóxi \\
\hline Resistência máxima à tração (MPa) & 40 a 105 & 45 a 140 & 60 a 90 \\
\hline Módulo de elasticidade na tração (GPa) & 105 a 450 & 220 a 280 & 330 a 350 \\
\hline Alongamento máximo (\%) & 1,7 a 2,3 & 2 a 8 & 2 a 5 \\
\hline Resistência à flexão (MPa) & 115 a 125 & 110 a 135 & 70 a 100 \\
\hline Módulo de elasticidade na flexão & 3,3 a 3,5 & 3,0 a 4,5 & 3,0 a 5,2 \\
\hline Dureza (ASTM D-785) (ASTM D-676) & 40 a 50 (barcol) & >A95 (shore) & $\begin{array}{l}107 \text { a } 112 \\
\text { (rockwell) }\end{array}$ \\
\hline Contração linear (\%) & 2,0 & 2,0 & 1,2 a 1,8 \\
\hline Temperatura de termodistorção $\left({ }^{\circ} \mathrm{C}\right)$ & 110 a 170 & 100 a 300 & 140 a 290 \\
\hline $\begin{array}{l}\text { Resistência ao impacto; método IZOD } \\
\text { com entalhe }\left(\mathrm{N}^{*} \mathrm{~m} / \mathrm{m}\right)\end{array}$ & 9,6 a 42,8 & 693 a 907 & 16 a 26,7 \\
\hline
\end{tabular}

-As fibras apresentam-se na forma de filamentos com diâmetros microscópicos na ordem de centésimos de milímetro, possuem módulo de elasticidade e resistência à tração elevados, baixa densidade e apresentam comportamento frágil.

Os materiais compósitos de FRP (Polímero Reforçado com Fibras), são constituídos por fibras envoltas em uma matriz polimérica. As fibras contínuas mais utilizadas nos FRP para aplicações em engenharia civil são de vidro (Glass-G), de Aramida (Aramid-A) e Carbono (Carbon-C).

As fibras de carbono inicialmente eram destinadas apenas a projetos aeroespaciais, hoje são utilizadas praticamente por todos os setores industriais. Possuem as melhores características mecânicas, alto módulo de elasticidade, baixo coeficiente de dilatação térmica, são imunes à corrosão, são as mais resistentes à ação de agentes químicos e não absorvem água. Em contrapartida apresentam alguns problemas, como diferença de potencial em contato com outros metais, baixa resistência ao impacto e são as que apresentam maiores custos. 
- As fibras de aramida, mais conhecidas pelo nome comercial como Kevlar, passaram a ser utilizadas na década de 70. Trata-se de um composto orgânico e sua produção segue os padrões têxteis, variam de acordo com o processo de produção em dois tipos: de baixo e de alto módulo de elasticidade. Possuem baixa densidade, alta resistência à tração e possibilita criar estruturas altamente resistentes ao impacto. Utilizadas na fabricação de coletes a prova de balas e em substituição ao aço em pneus radiais, são notáveis também a utilização das fibras de aramida como reforço na produção de compósitos para indústria automobilística, aeronáutica e marítima. Apesar disso possuem baixa resistência à compressão, apresentam dificuldades de moldagem, são susceptíveis a temperaturas elevadas e a raios ultravioletas.

As fibras de vidro são o material mais utilizado como reforço na formação de materiais compósitos, somando aproximadamente $90 \%$ do uso em resinas termofixas. Em consequência de seus aspectos positivos, elas são utilizadas em todos os setores industriais e também na construção civil. As propriedades principais das fibras de vidro são:

-baixo custo;

-boa resistência ao impacto;

-alta resistência à tração;

-alta resistência mecânica;

-baixa absorção de água;

•baixo coeficiente de dilatação térmica;

-boa moldagem das peças;

-incombustibilidade;

•ótimas propriedades eletromagnéticas;

-possibilita a obtenção de materiais translúcidos;

-resistência química a microorganismos.

Como aspectos desfavoráveis as fibras de vidro possuem grande sensibilidade em meios alcalinos e menor resistência quando submetidas a ações de fadiga.

De acordo com a disposição das fibras na matriz polimérica elas podem ser classificadas em:

-FRP unidirecional: A fibra trabalha apenas em uma única direção. 


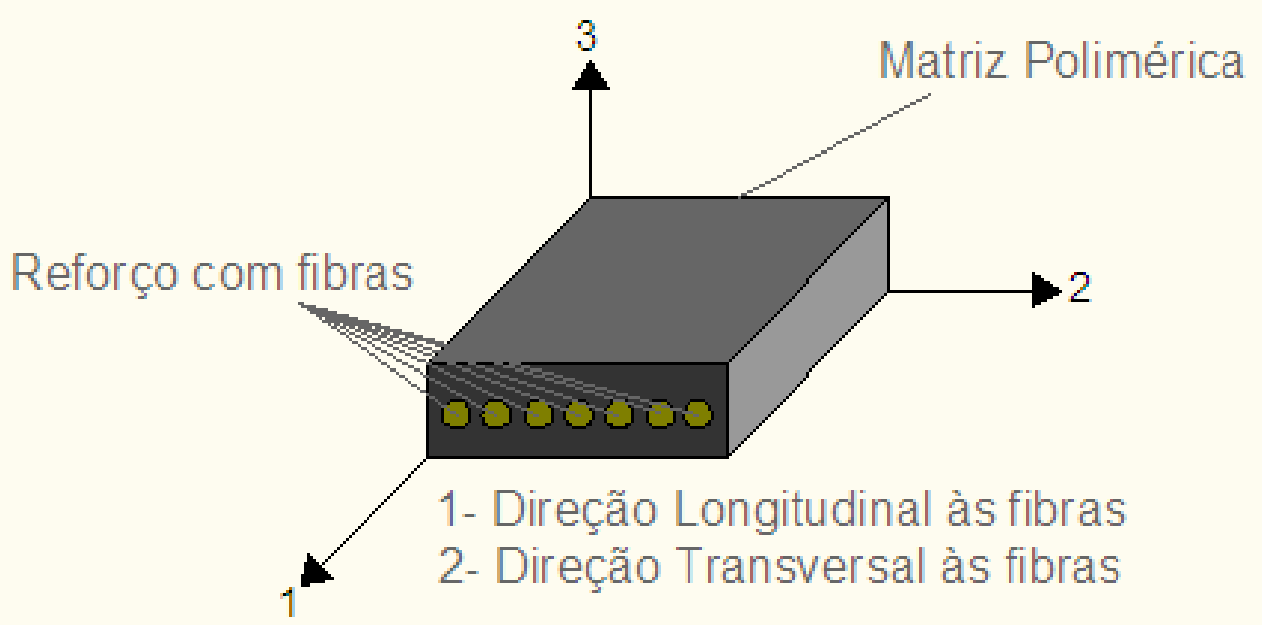

Figura 1.7- Representação esquemática de compósito unidirecional

Analisando um elemento de volume de fibra do compósito unidirecional da Figura 1.7 percebe-se que ela é forte e rígida na direção 1 e fraca e sem resistência nas direções 2 e 3 (Figura 1.8).

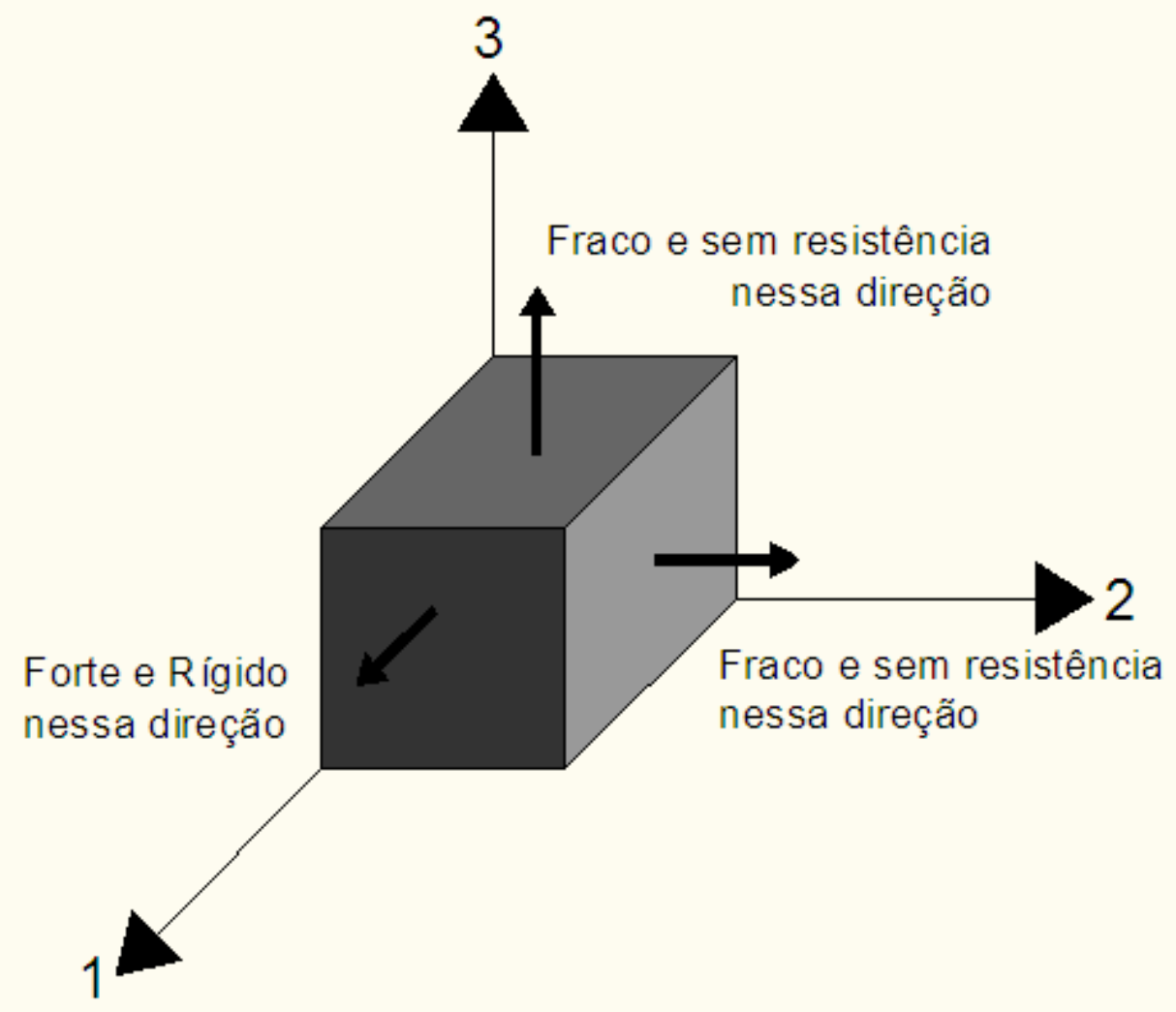

Figura 1.8- Elemento de volume de fibra unidirecional 
-FRP bi ou multidirecional: A fibra trabalha junto com a lâmina em uma única direção, as lâminas podem ser justapostas em duas ou mais direções, formando um polímero reforçado com fibras bi ou multidirecionais.

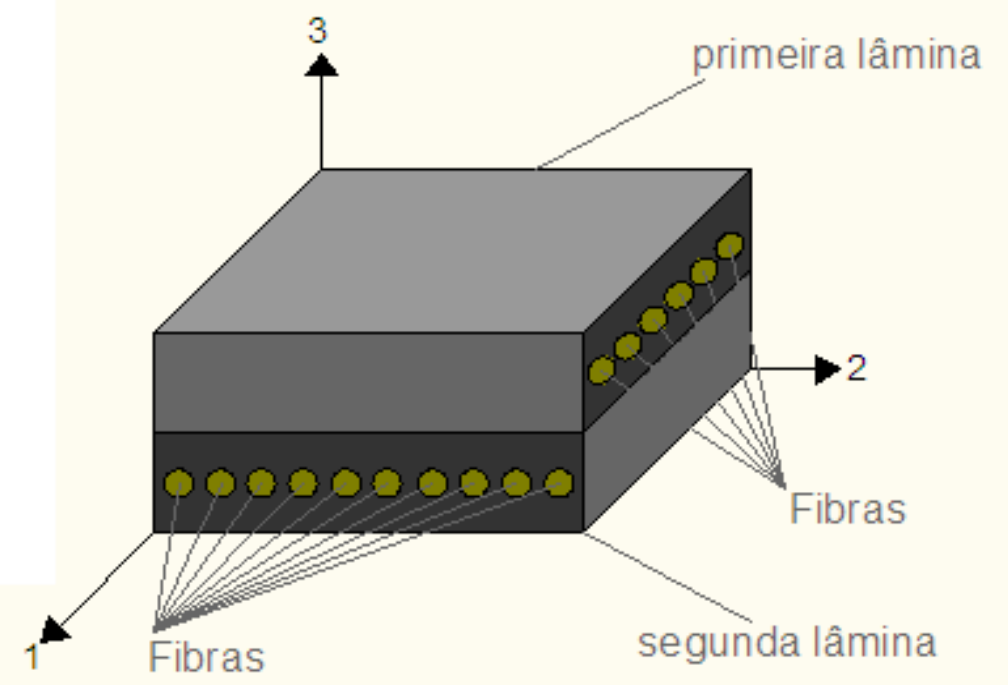

Figura 1.9- Representação esquemática de compósito bidirecional

- FRP bi ou multidirecional em uma mesma lâmina: É possível trabalhar também com compósito bi ou multidirecional por lâmina, ou seja, o compósito é formado por lâminas cujas fibras são bi ou multidirecionais. 


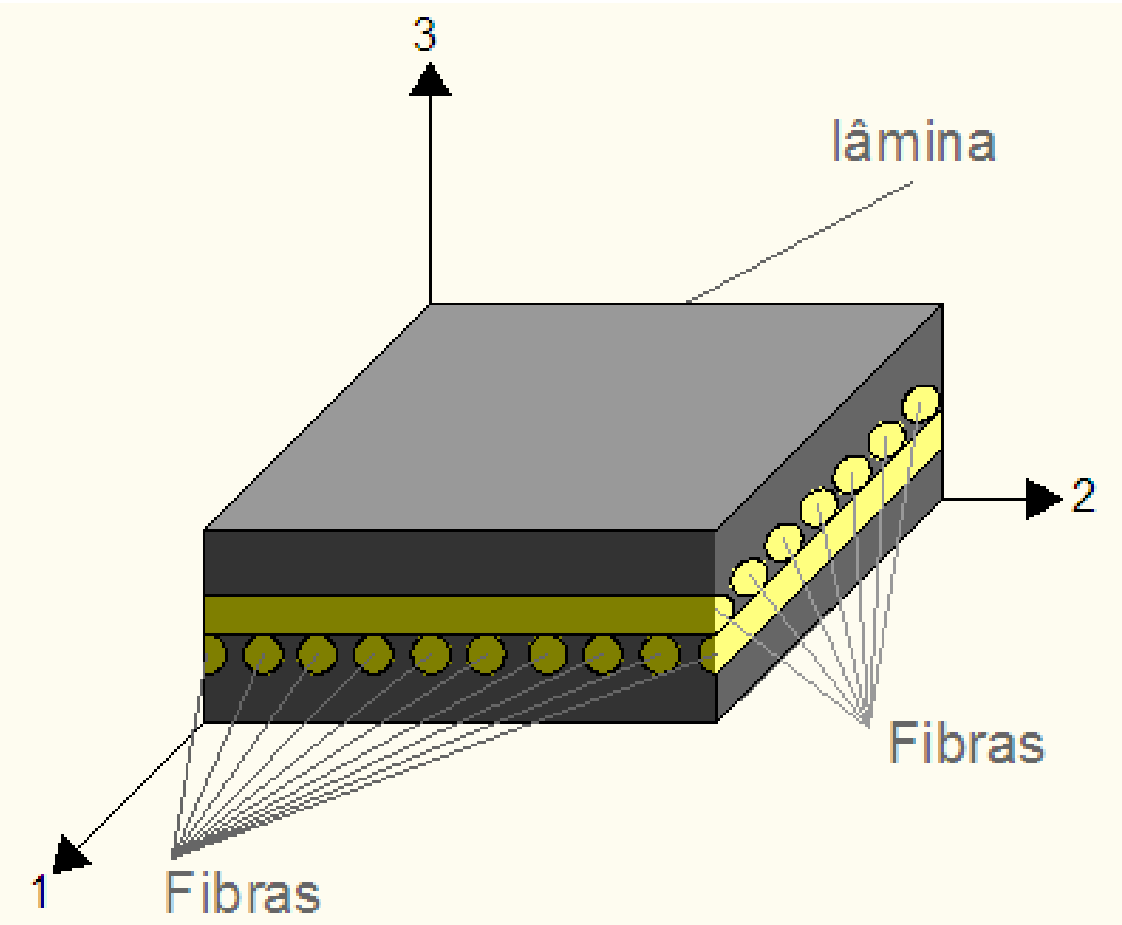

Fig. 1.10- Representação esquemática de compósito bidirecional em uma única lâmina

A Tabela 1.3 apresenta algumas propriedades da fibras mais utilizadas em compósitos, na área da construção civil 
Tabela 1.3 - Propriedades das fibras mais utilizadas em compósitos Fonte: UOMOTO, T. et al. (2002)

\begin{tabular}{|c|c|c|c|c|c|c|c|c|}
\hline & \multicolumn{4}{|c|}{ FIBRA DE CARBONO } & \multirow{2}{*}{\multicolumn{2}{|c|}{$\begin{array}{l}\text { FIBRA DE } \\
\text { ARAMIDA }\end{array}$}} & \multirow{2}{*}{\multicolumn{2}{|c|}{ FIBRA DE VIDRO }} \\
\hline & \multicolumn{2}{|c|}{ Carbono Poliacrílico } & \multicolumn{2}{|c|}{ Carbono Pitch } & & & & \\
\hline & $\begin{array}{c}\text { Alta } \\
\text { Resistência }\end{array}$ & $\begin{array}{c}\text { Alto } \\
\text { Módulo } \\
\text { de } \\
\text { Young } \\
\end{array}$ & Comum & $\begin{array}{c}\text { Alto } \\
\text { Módulo } \\
\text { de } \\
\text { Young } \\
\end{array}$ & $\begin{array}{c}\text { Kevlar } \\
49 \\
\text { Twaron }\end{array}$ & Technora & Vidro-E & $\begin{array}{c}\text { Vidro } \\
\text { Álcali } \\
\text { resistente }\end{array}$ \\
\hline $\begin{array}{c}\text { Resistência a } \\
\text { tração } \\
\text { (MPa) }\end{array}$ & 3430 & $\begin{array}{c}2450 a \\
3920\end{array}$ & $\begin{array}{c}764 a \\
980\end{array}$ & $\begin{array}{c}2940 a \\
3430\end{array}$ & 2744 & 3430 & $\begin{array}{c}3430 a \\
3528\end{array}$ & $\begin{array}{c}1764 \text { a } \\
3430\end{array}$ \\
\hline $\begin{array}{l}\text { Módulo de } \\
\text { Young } \\
\text { (GPa) }\end{array}$ & 196 a 235 & $\begin{array}{c}343 a \\
637\end{array}$ & 37 a 39 & $\begin{array}{c}392 \mathrm{a} \\
784\end{array}$ & 127 & 72,5 & $\begin{array}{c}72,5 \text { a } \\
73,5\end{array}$ & 68,6 a70 \\
\hline $\begin{array}{c}\text { Alongamento } \\
(\%)\end{array}$ & 1,3 a 1,8 & $\begin{array}{c}0,4 \mathrm{a} \\
0,8\end{array}$ & $\begin{array}{c}2,1 \mathrm{a} \\
2,5\end{array}$ & $\begin{array}{c}0,4 \mathrm{a} \\
1,5\end{array}$ & 2,3 & 4,6 & 4,8 & $\begin{array}{l}4 \mathrm{a} 5 \\
2 \mathrm{a} 3\end{array}$ \\
\hline $\begin{array}{c}\text { Densidade } \\
\left(\mathrm{g} / \mathrm{cm}^{3}\right)\end{array}$ & 1,7 a 1,8 & $\begin{array}{c}1,8 \mathrm{a} \\
2,0\end{array}$ & $\begin{array}{c}1,6 \mathbf{a} \\
1,7\end{array}$ & $\begin{array}{c}1,9 a \\
2,1\end{array}$ & 1,45 & 1,39 & 2,6 & 2,27 \\
\hline $\begin{array}{c}\text { Diâmetro } \\
(\mu \mathrm{m})\end{array}$ & \multicolumn{2}{|c|}{5 a 8} & \multicolumn{2}{|c|}{9 a 18} & \multicolumn{2}{|c|}{12} & \multicolumn{2}{|c|}{8 a 12} \\
\hline
\end{tabular}

\subsubsection{Vantagens e Desvatagens da utilização de FRP}

De acordo com o ACI440.1R-06 as vantagens e desvantagens da utilização de Polímero Reforçado com Fibra para reforços estruturais é apresentado na Tabela 1.4. 
Tabela 1.4 - Vantagens e Desvantagens de FRP. Fonte: ACI440.1R (2006)

\begin{tabular}{|c|c|}
\hline Vantagens de Reforço em FRP & Desvantagens de Reforço em FRP \\
\hline Alta resistência à tração longitudinal & Não escoa antes da ruptura frágil \\
\hline $\begin{array}{l}\text { Resistente à corrosão (não depende } \\
\text { do revestimento) }\end{array}$ & Baixa resistência transversal \\
\hline Não magnético & $\begin{array}{l}\text { Baixo módulo de elasticidade (varia } \\
\text { com o tipo de reforço de fibra) }\end{array}$ \\
\hline $\begin{array}{l}\text { Alta tolerância à fadiga (varia com } \\
\text { tipo de fibra) }\end{array}$ & $\begin{array}{l}\text { Suscetibilidade a danos para resinas } \\
\text { poliméricas e fibras sob exposição de } \\
\text { radiação ultravioleta }\end{array}$ \\
\hline $\begin{array}{c}\text { Baixo peso ( } 1 / 5 \text { a } 1 / 4 \text { da densidade } \\
\text { do aço) }\end{array}$ & $\begin{array}{l}\text { Alto coeficiente de expansão térmica } \\
\text { perpendicular às fibras, relativo ao } \\
\text { concreto }\end{array}$ \\
\hline \multirow[t]{3}{*}{$\begin{array}{c}\text { Baixa condutividade térmica e } \\
\text { elétrica (fibras de vidro e aramida) }\end{array}$} & $\begin{array}{l}\text { Susceptível ao fogo, dependendo do } \\
\text { tipo de matriz e do cobrimento livre do } \\
\text { concreto }\end{array}$ \\
\hline & $\begin{array}{l}\text { Baixa durabilidade das fibras de vidro } \\
\text { em ambiente úmido }\end{array}$ \\
\hline & $\begin{array}{c}\text { Baixa durabilidade de algumas fibras } \\
\text { de vidro e aramida em ambiente } \\
\text { alcalino }\end{array}$ \\
\hline
\end{tabular}

Analisando alguns materiais compósitos em relação à temperatura, pode-se observar, de acordo com o gráfico da Figura 1.11, que a relação matriz/reforço que mais resiste às temperaturas elevadas, sem praticamente alterar sua capacidade resistente à tração, é o carbono/carbono, só que sua tensão de tração específica é inicialmente muito baixa à temperatura ambiente, em relação aos demais compósitos poliméricos. Os compósitos Kevlar/Epóxi , vidro ("R”)/epóxi e o Carbono/Epóxi respectivamente são os que possuem maior capacidade resistente à tração à temperatura ambiente, mas também são os que mais perdem resistência com o acréscimo de temperatura. 


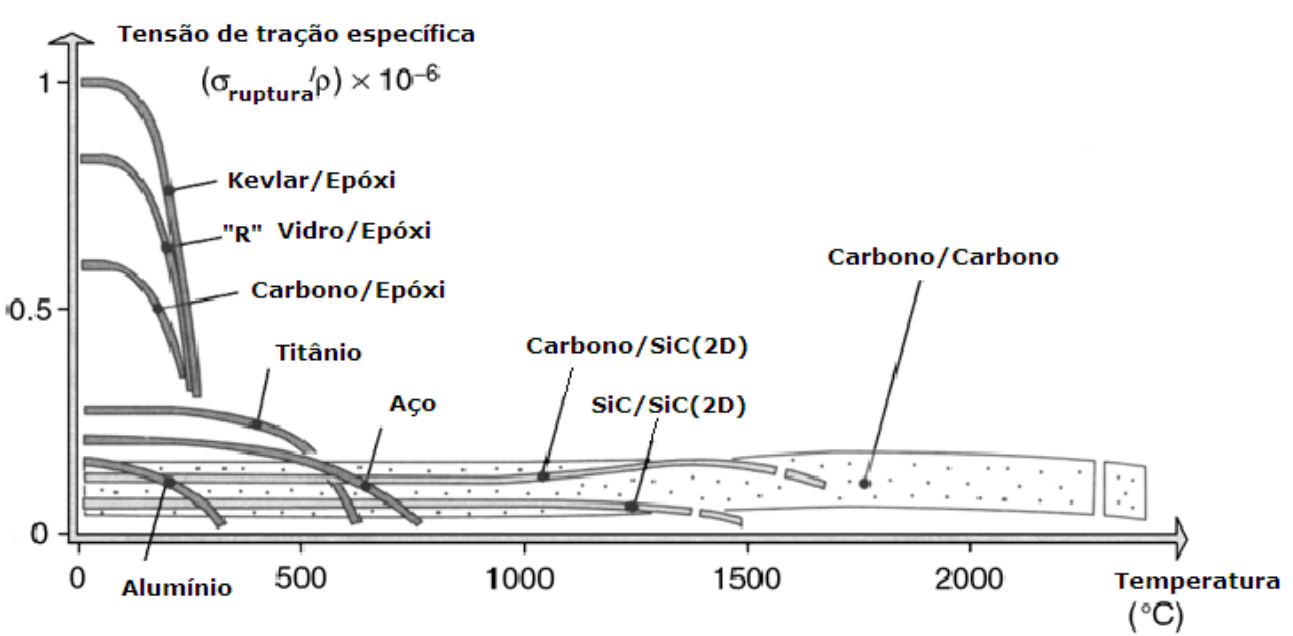

Figura 1.11- Resistência específica à tração de diferentes compósitos com o aumento de temperatura.

Adaptado: Tsai, Stephen W. et al. (2003)

\subsubsection{Processo de fabricação das fibras de vidro}

O processo é dividido em cinco fases: Composição, Fiação, Ensimagem, Bobinagem e Secagem, utilizando como insumos areia, calcário, óxido de alumínio e óxido de magnésio, em proporções adequadas no misturador. Com a fusão desses minerais tem-se a origem de filamentos de vidro. As fibras de vidro podem se apresentar com diferentes configurações. As diferenças variam de acordo com o processo de fabricação e com as características desejadas. As formas e tipos de apresentação de fibra de vidro no mercado são: Manta, Roving e Tecido.

-Manta de Superfície ou Véu de Superfície: Fabricado através de fios cortados, fortemente ligados e calandrados, possibilitando alta resistência (Figura 1.12). A manta de fios contínuos é semelhante à manta de fios cortados; a diferença está no nível de deformabilidade.

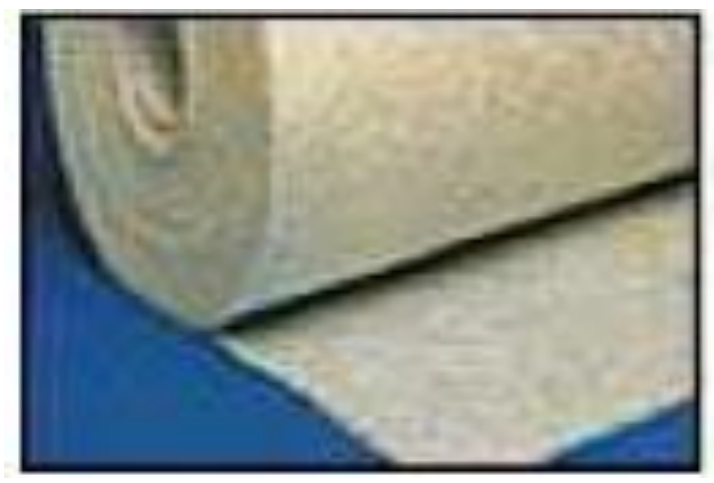

Figura 1.12- Manta de Superfície. Fonte: SAINT GOBAIN VETROTEX (2000) 
-Roving para enrolamento: São filamentos paralelos unidos em uma mecha. Devem receber tratamento químico para que se tornem compatíveis com as resinas empregadas no processo. Esse tipo de roving é apresentado no mercado em diversas gramaturas (Figura 1.13)

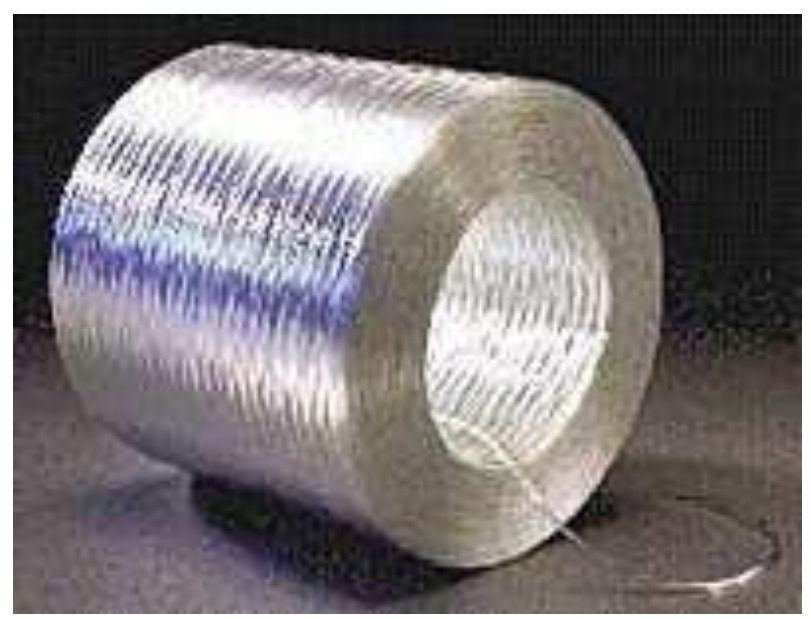

Figura 1.13- Roving contínuo para enrolamento ou filamento Winding, pultrusão e tecelagem. Fonte: OWENS CORNING (2009)

- Spun roving ou roving frisado: Frisos constituintes de um reforço perpendicular à direção principal do roving para enrolamento, visando melhorar a resistência transversal dos materiais compósitos unidirecionais, que são moldados por pultrusão. O spun roving aumenta a resistência contra o cisalhamento interlaminar, que ocorre em função da tendência de deslizamento entre o vidro e a resina.

-Roving de laminação por projeção: São fabricados com o agrupamento dos filamentos e possuem como característica principal a grande facilidade de abertura ao corte (Figura 1.14) 


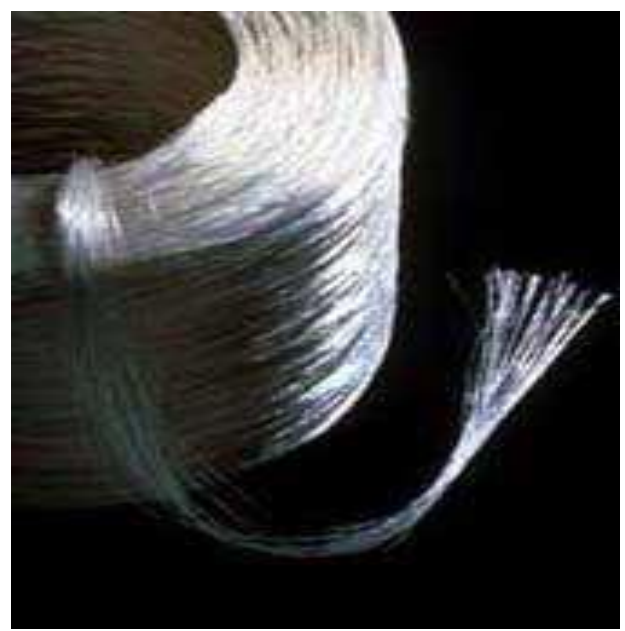

Figura 1.14- Roving para laminação à pistola. Fonte: OWENS CORNING (2009)

-Tecido: A fabricação é feita tecendo-se os rovings de diferente ou igual gramatura (Figura 1.15). Os tecidos podem ser bidirecionais, em telas, sarja ou também unidirecionais.

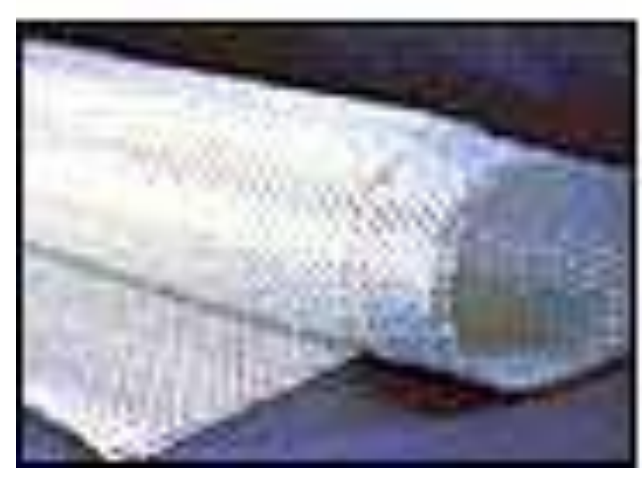

Figura 1.15- Tecido em fibra de vidro. Fonte: SAINT-GOBAIN-VETROTEX (2000)

Como neste trabalho são tratados os polímeros reforçados com fibra de vidro, é interessante salientar que a quantidade em volume de fibras a ser utilizada no compósito é extremamente importante, sendo que quando se chega próximo de $75 \%$ de volume de fibras de vidro a resistência à tração é elevada e consequentemente a tensão última de ruptura também, como mostra o gráfico da Figura 1.16 


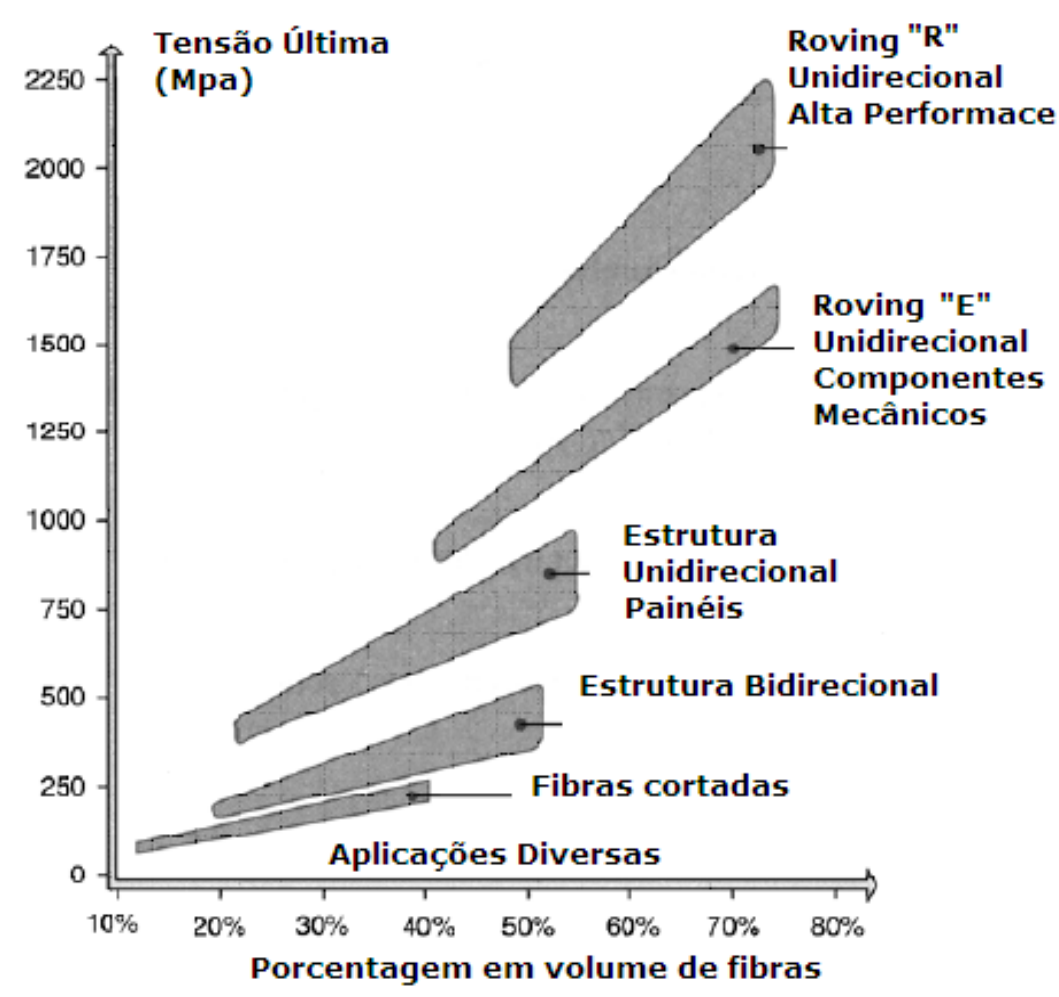

Figura 1.16- Tensão última de alguns compósitos resina/fibra de vidro de acordo com a porcentagem em volume de fibras. Adaptado: Tsai, Stephen W. et al. (2003)

\subsubsection{Principais processos de fabricação de FRP}

Os principais e mais utilizados processos de fabricação de FRP são Hand Lay-up, SMC/BMC, Centrifugação, Vacumm Bag, Spray-up, Pultrusão, Laminação Contínua, RTM, Derramamento (Casting) e Filament Winding.

Segundo a ABMACO (Figura 1.17) o processo mais empregado no Brasil é o sistema spray-up com $59 \%$ de utilização, depois vem o hand-lay-up com 14\%, seguido do Derramamento (Casting) e da laminação contínua, ambos com 7\%. Os processos menos utilisados são o vaccum bag a pultrusão e o filament winding, cada um representando apenas $1 \%$. 


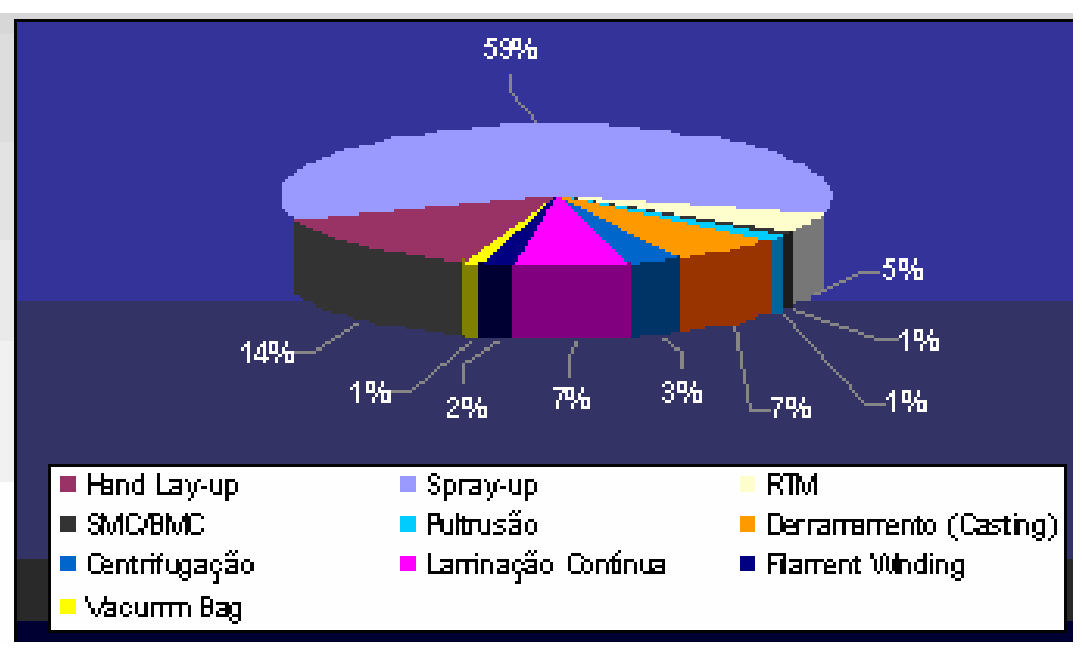

Figura 1.17- Distribuição Brasileira por processos de fabricação. Fonte: ABMACO -Associação Brasileira de Materiais Compósitos (2009)

Laminação manual (Hand-lay-up): Processamento simples e dos mais antigos das fibras de vidro. Os processos de laminação, tanto manual quanto à pistola, são usados para baixas quantidades de produção, principalmente em função dos pequenos investimentos dos moldes. Independentemente se o processo for manual ou à pistola, deve ser utilizado o processo de molde de superfície aberto. De baixo custo, quase não requer equipamentos específicos, sendo empregados apenas os seguintes:

- espátula, facas e tesoura;

-pistola para aplicação de gel coat;

$\bullet$ molde;

-pincéis;

-desmoldantes;

- dosadores;

-balança;

-roletes para compactação de laminados.

Inicia-se com a preparação do molde em superfície aberta, limpando-o e aplicando desmoldante, podendo ser álcool polivinílico (PVA) ou cera de carnaúba. Posteriormente deve ser aplicado gel coat na superfície do molde, com pincel ou com a pistola. A combinação é feita em geral com resina líquida (poliéster insaturado) com fibras de vidro, dando origem à peça moldada, equivalente à combinação de concreto com reforço de barras de aço. 
Quando da aplicação das fibras e ou remoção de bolhas, pode ser utilizado o pincel ou rolete para aplicação de três camadas de resinas. Não se recomenda mais de três aplicações pois o excesso de resina pode ocasionar exotermia, que leva ao empenamento da peça, queima do gel coat e esbranquiçamento da fibra (Figura 1.18).

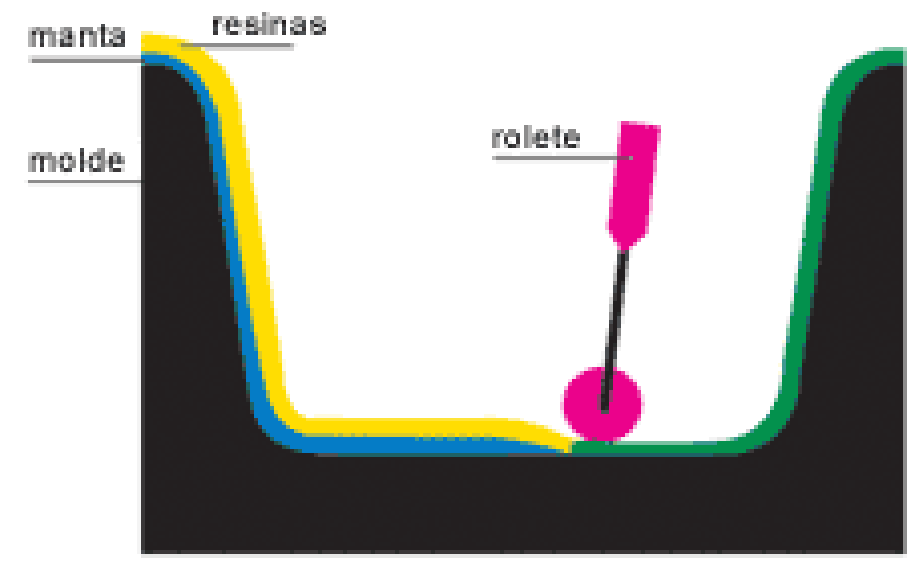

Figura 1.18- Laminação manual. Fonte: SAINT-GOBAIN-VETROTEX (2000)

Laminação à pistola (Spray-up): Sistema misto de laminação onde a deposição da fibra e resina se faz por equipamento de ar comprimido, sendo lançadas sobre um jato de resina direcionadas para a cavidade de um molde aberto. A preparação do molde é análoga à Laminação manual (Hand-lay-up), a aplicação da resina e das fibras de vidro são feitas simultaneamente com a utilização de uma pistola laminadora. A primeira demão deve ser de resina pura e as demais devem ser feitas com a mistura da fibra de vidro com a resina; cada camada deve ter aproximadamente $4 \mathrm{~mm}$ de espessura. Da mesma maneira que a laminação manual, somente um lado da peça fica liso.

Os custos de produção, como na laminação manual, também são baixos, apresentam maior rendimento e melhores resultados para peças mais complexas. Esse processo é muito utilizado para fabricação de piscinas, lanchas e banheiras de acrílico.

Enrolamento Filamentar (Filament Winding): Processo de laminação por enrolamento de fibras contínuas roving, que são impregnadas com resina e depositadas em um mandril, para fabricação de tubos, tanques e outros materiais de forma cilíndrica.

O processo consiste em utilizar como reforço filamentos contínuos de fibra de vidro (rovings), que ficam dispostos em prateleiras onde são desenrolados e impregnados com resina e aditivos por meio de imersão completa ou por cilindro de transferência. Dessa forma 
os filamentos impregnados de resina são enrolados em várias camadas sobre um mandril rotativo. Posteriormente acontece a polimerização ou mais conhecido como processo de cura em fornos ou com luzes infravermelhas, sempre com o mandril em rotação.

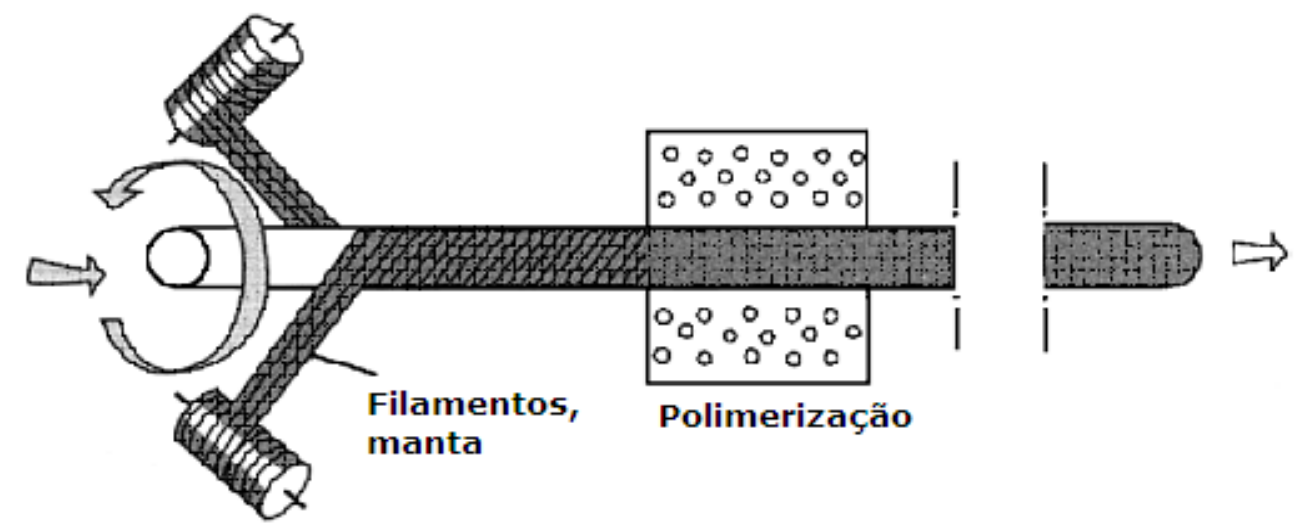

Figura 1.19- Processo de Filament Winding. Adaptado: Tsai, Stephen W. et al. (2003)

Pultrusão (Pultrusion): Processo de laminação contínua para fabricação de perfis lineares unidirecionais de seção transversal constante, onde a fibra contínua (roving) é impregnada com resina e o material é tracionado através de um molde de metal aquecido. A mistura fibra-resina tomará a geometria do molde. A temperatura do molde ativará a reação presente na mistura, ocorrendo o crosslink polimérico conforme o perfil do molde (Figura $1.20)$.

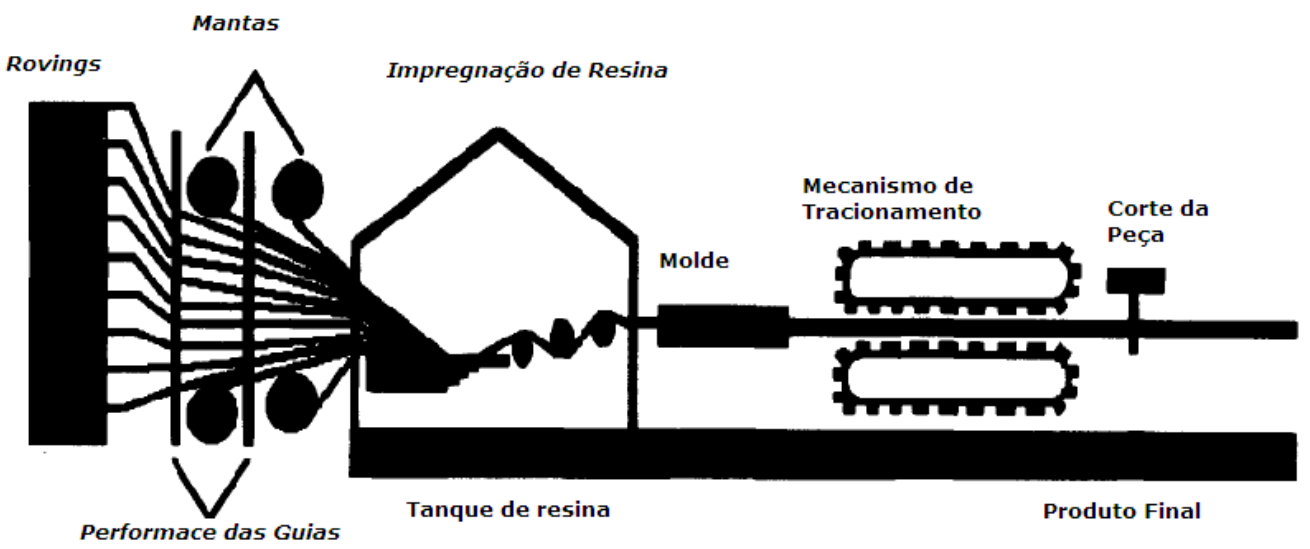

Figura 1.20 - Esquema do processo de Pultrusão. Adaptado: Handbook of Composites. Wilson, Brian A. (1998) 
RTM (Resin Transfer Molding): Modelagem por transferência de resina. É um processo de fabricação onde é injetada resina sob pressão na cavidade de um molde fechado em que as fibras já estão depositadas, formando o compósito. Permite a moldagem de componentes com forma complexa e grandes áreas com bom acabamento de superfície em ambos os lados, caracterizando-se ainda por permitir um alto ciclo de produção, uniformidade de espessura, apresentando uma perda pequena de matéria prima. Algumas aplicações desse processo são feitas no setor de transporte, como, por exemplo, cabines de caminhão, tratores e colheitadeiras

Centrifugação (Centrifugation): Processo de moldagem por centrifugação de diversas geometrias, com reforço por fibras picadas ou contínuas, e a resina aplicada juntamente nas paredes internas do molde metálico rotativo e cilíndrico. O processo de centrifugação é utilizado para obter estruturas ocas de grandes diâmetros, como, por exemplo, tubos e tanques para instalações químicas, petrolíferas e alimentícias, postes de iluminação elétrica e telefonia.

Laminação contínua: O processo de laminação contínua é utilizado para aplicações no setor da construção civil, como a produção de telhas onduladas e telhados de estufas em configurações lisas e onduladas. Faz-se a impregnação com resina e fibra de vidro, sendo utilizados rovings cortados ou contínuos sobre um filme de transporte. Em seguida deve ser feita a sobreposição desse material com um segundo filme. A moldagem ocorrerá de forma progressiva dentro da estufa com o a ajuda de moldes de perfil ao final da estufa. Antes do corte das bordas laterais e do corte transversal no tamanho desejado, os filmes são rebobinados.

SMC (Sheet Molding Compound): Moldagem por compressão utilizando folhas ou chapas de fibras pré-impregnadas. Na Europa e Estados Unidos, o compósito feito pelo processo de SMC é muito utilizado na indústria automobilística. É um processo dividido em três etapas:

- Preparação da pasta-matriz;

- Conformação do pré-impregnado;

- Prensagem ou injeção da peça final. 
Processo de moldagem a vácuo (Vacuum Molding): Utilizado para fabricação de peças de aparência lisa em ambos os lados. Este processo combina a injeção da resina introduzida no molde a baixa pressão e, após o fechamento do molde, cria-se vácuo. São produzidos neste processo, atualmente, peças como bandejas, correias protetoras para máquinas rotativas, caixas de distribuição elétrica e cadeiras escolares.

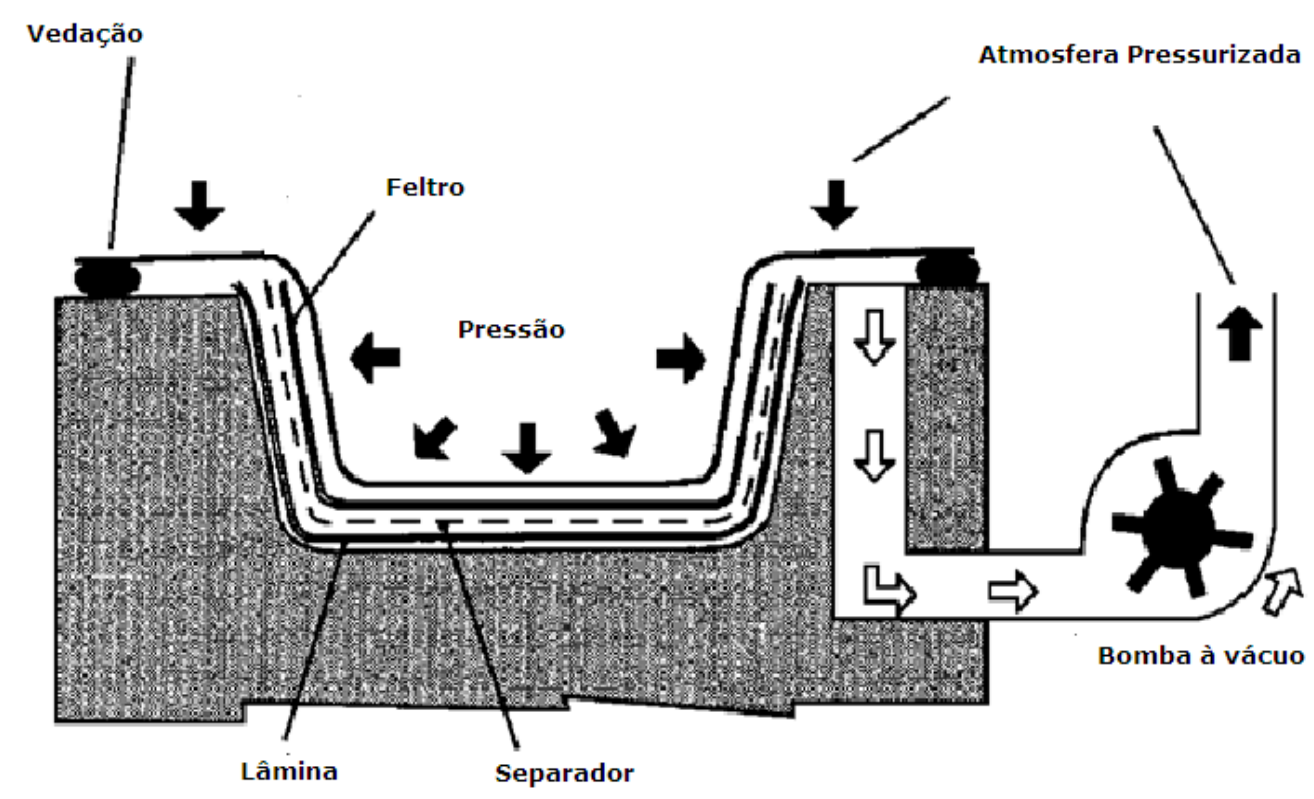

Figura 1.21 - Processo de moldagem a vácuo. Adaptado: Tsai, Stephen W. et al. (2003) 


\section{2- REVISÃO BIBLIOGRÁFICA}

\subsection{Fabricação das barras em GFRP}

Nesta pesquisa utilizam-se barras de GFRP fabricadas pelo processo de Pultrusão, é apresentada mais detalhadamente agora.

Pultrusion (Pultrusão): A palavra pultrusão é usada para descrever um processo de fabricação comercial para a produção de elementos compósitos de fibra reforçada.

W. Brandt Goldsworthy executou uma grande parte do processo de desenvolvimento e manufatura do equipamento em meados de 1950, para produzir elementos estruturais. A característica principal desse processo é a produção de barras ou elementos com uma dimensão predominante. É um método escolhido também pela economia e pela consistência do produto final (Figura 2.1).

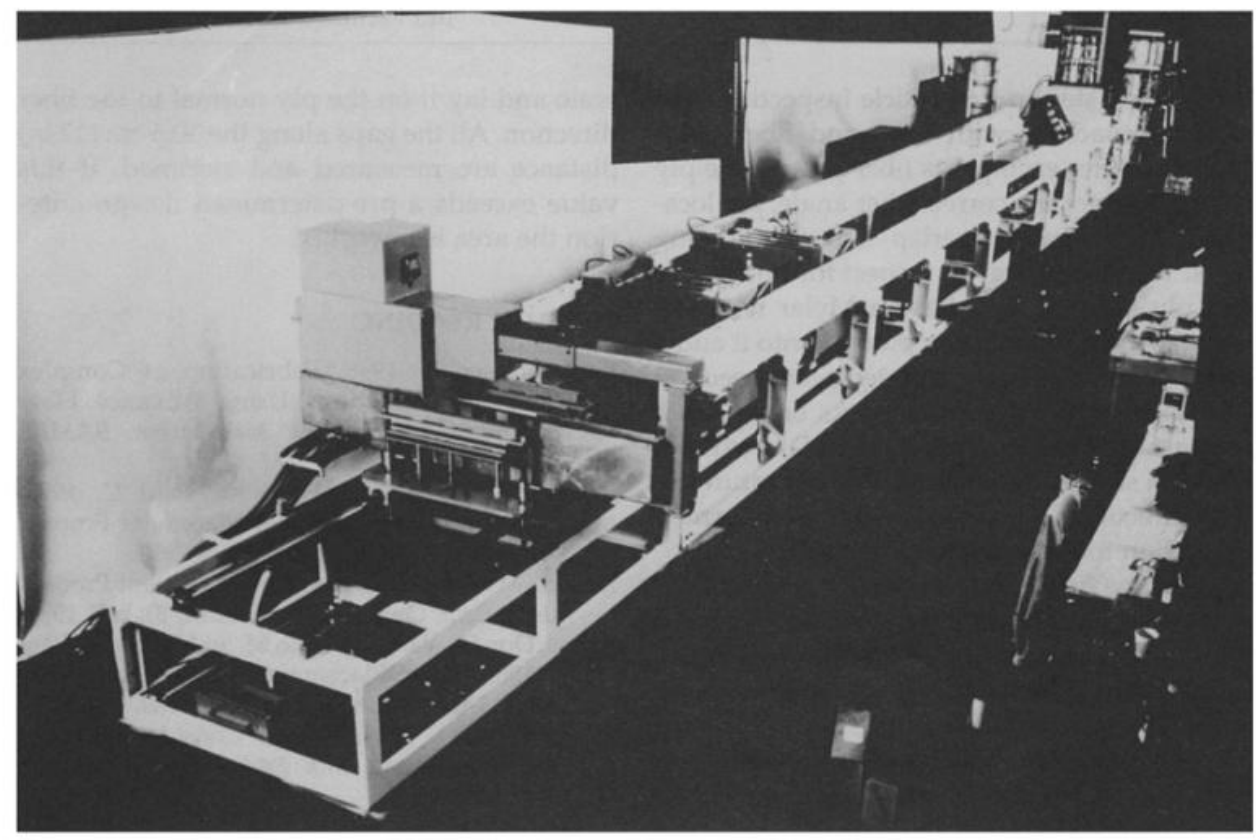

Figura 2.1- Máquina de Pultrusão. Fonte: Handbook of Composites. Wilson, Brian A. (1998) 
O processo de Pultrusão tira proveito da força da fibra na direção longitudinal para puxar o extrudado, formando, após o processo de cura, uma seção transversal constante e um elemento estrutural pertencente a um sistema de material compósito. A pultrusão pode produzir perfis ocos ou maciços, de diferentes formatos, podendo variar a taxa de vidro de 30 a $70 \%$ do peso final. Os perfis podem ser utilizados nos setores de energia elétrica, construção civil e mercado de bens de consumo.

A utilização desse processo tem expansão tanto nos EUA como ao redor do mundo utilizado por muitos fabricantes para produzir elementos estruturais simples, utilizando fibras longitudinais e resinas termorrígidas.

A capacidade de incorporar resistência tridimensional ocorreu primeiro em meados dos anos 60, quando se tornou possível incluir camadas de fibra envolvida circularmente. Reforços multidirecinais foram usados extensivamente em meados de 1970. A introdução de matrizes de resinas termoplásticas trouxeram o processo de pultrusão para o seguimento da indústria aeroespacial, como um método repetitivo e relativamente barato de produzir um elemento estrutural de seção transversal constante.

As principais vantagens da Pultrusão são as seguintes:

- A produção é contínua;

- Requisitos de mão de obra são baixos;

- A perda de material é baixa.

Não ocorreram variações no processamento até meados da década de 1960. A partir daí, vários pultrusores, tanto na Europa como nos EUA, desenvolveram o processo de adição de tecido em bandas ou folhas e fibras entrelaçadas, a fim de proporcionar resistência ao cisalhamento nos cantos das seções pultrudadas de formas complexas. O conceito foi desenvolvido para que um filamento sinuoso fosse adicionado à pultrusão, formando um aro envolvente pultrudado. Esse processo é usado principalmente com perfis tubulares ou placas. Não é possível adicionar o filamento sinuoso no processo para uma estrutura com curvatura côncava, tais como cantoneiras e vigas tipo 'I'. Durante a década de 1970 o conceito da pultrusão foi desenvolvido por Brandt Goldsworthy; três versões deste processo foram concebidas. A primeira versão, atualmente conhecida com 'pultrusão curvada', foi desenvolvida sob contrato da NASA pela Goldsworthy Engenharia e resultou em peças com raio constante. O processo típico de pultrusão é apresentado na Figura 2.2. 


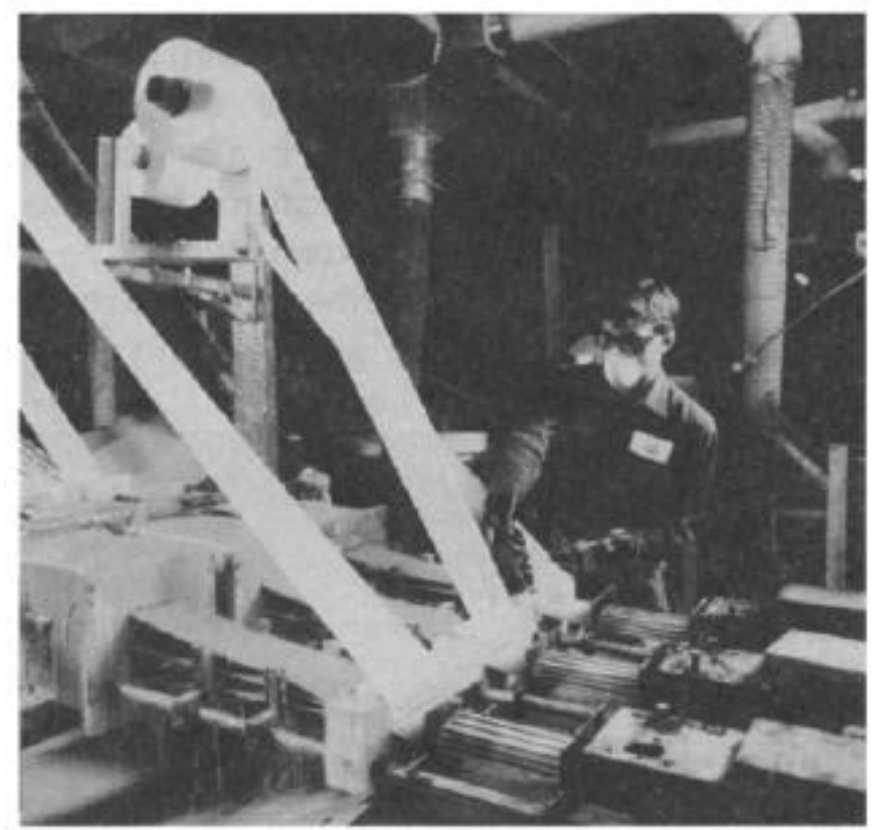

Figura 2.2- Material de reforço dos rovings sendo introduzidos na máquina de pultrusão. Fonte:

Handbook of Composites. Wilson, Brian A. (1998)

\subsection{Características das barras em FRP}

Barras de reforço comercialmente disponíveis, de Polímero Reforçado com Fibras (FRP) de aramida (AFRP), carbono (CFRP) e vidro (GFRP), são embebidas em matriz resinada. As barras têm diversos tipos de seção transversal (quadrado, redondo, cheio ou vazado). A Figura 2.3 apresenta algumas barras de reforço GFRP de seção transversal cheia e circular, disponíveis para a construção civil.

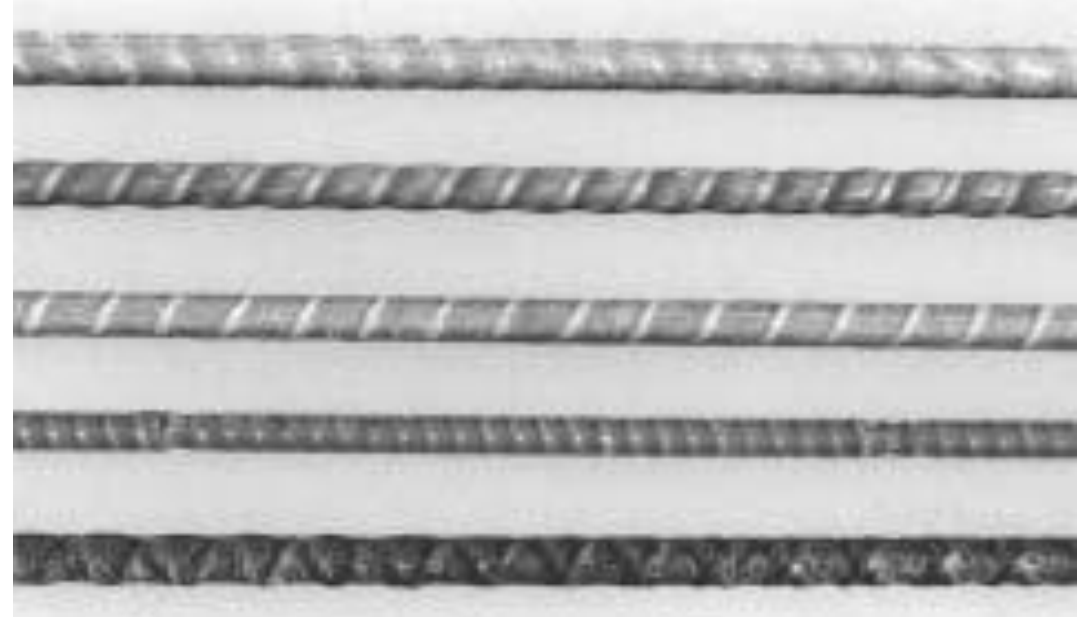

Figura 2.3- Barras de reforço em GFRP comercialmente disponíveis. Fonte: ACI440.1R-06 
As barras de reforço são produzidas através de vários processos de manufatura, com diferentes conformações superficiais. Cada método de manufatura produz uma diferente condição para a superfície da barra. A característica física da superfície da barra é uma importante propriedade mecânica de ligação com o concreto. Existe a barra lisa areada e não areada, existem três tipos de superfícies deformadas de barras disponíveis no mercado, como mostra a Figura 2.4. São elas:

- Trançada não areada ou Nervurada (a);

-Deformada areada ou revestida com areia (b);

-Trançada areada ou Torcida (c)

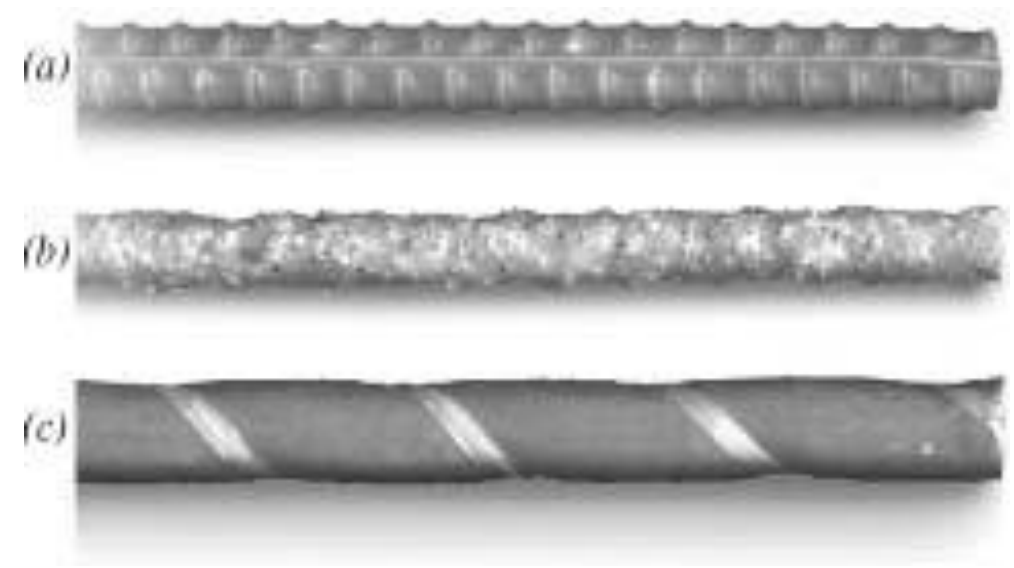

Figura 2.4- Barras de FRP com conformações superficiais diferentes, comercialmente disponíveis. Fonte: ACI440.1R-06

A classificação das barras de acordo com o diâmetro nominal seguem o padrão da norma ASTM, dada pela Tabela 2.1 
Tabela 2.1- Padrão ASTM - Barras Reforçadas. Fonte: ACI440.1R-06

\begin{tabular}{|c|c|c|c|}
\hline PADRÃO & $\begin{array}{c}\text { CONVERSÃO } \\
\text { MÉTRICA }\end{array}$ & $\begin{array}{c}\text { Diâmetro } \\
\text { Nominal (mm) }\end{array}$ & Área $\mathrm{Af}\left(\mathrm{mm}^{2}\right)$ \\
\hline $\mathrm{n}^{\circ} 02$ & nro 06 & 6,40 & 31,60 \\
\hline $\mathrm{n}^{\circ} 03$ & nro 10 & 9,50 & 71,00 \\
\hline $\mathrm{n}^{\circ} 04$ & nro 13 & 12,70 & 129,00 \\
\hline $\mathrm{n}^{\circ} 05$ & nro 16 & 15,90 & 199,00 \\
\hline $\mathrm{n}^{\circ} 06$ & nro 19 & 19,10 & 284,00 \\
\hline $\mathrm{n}^{\circ} 07$ & nro 22 & 22,20 & 387,00 \\
\hline $\mathrm{n}^{\circ} 08$ & nro 25 & 25,40 & 510,00 \\
\hline$n^{\circ} 09$ & nro 29 & 28,70 & 645,00 \\
\hline $\mathrm{n}^{\mathrm{o}} 10$ & nro 32 & 32,30 & 819,00 \\
\hline $\mathrm{n}^{\mathrm{o}} 11$ & nro 36 & 35,80 & 1006,00 \\
\hline
\end{tabular}

A partir da década de 90, japoneses, europeus, americanos, canadenses e mais recentemente os chineses começaram a optar por algumas obras onde o aço é substituído por barras de GFRP. Dentre os principais motivos estão:

- A região onde a obra é executada em relação à agressividade ambiental, regiões com incidência grande de neve e regiões próximas ou dentro das marés oceânicas;

- Fundações e lajes de pisos de áreas laboratoriais de equipamentos médicos de alta sensibilidade, onde não se podem usar materiais eletrocondutores, como o aço.

A Figura 2.5 mostra uma obra sendo executada com a utilização de barras em GFRP 


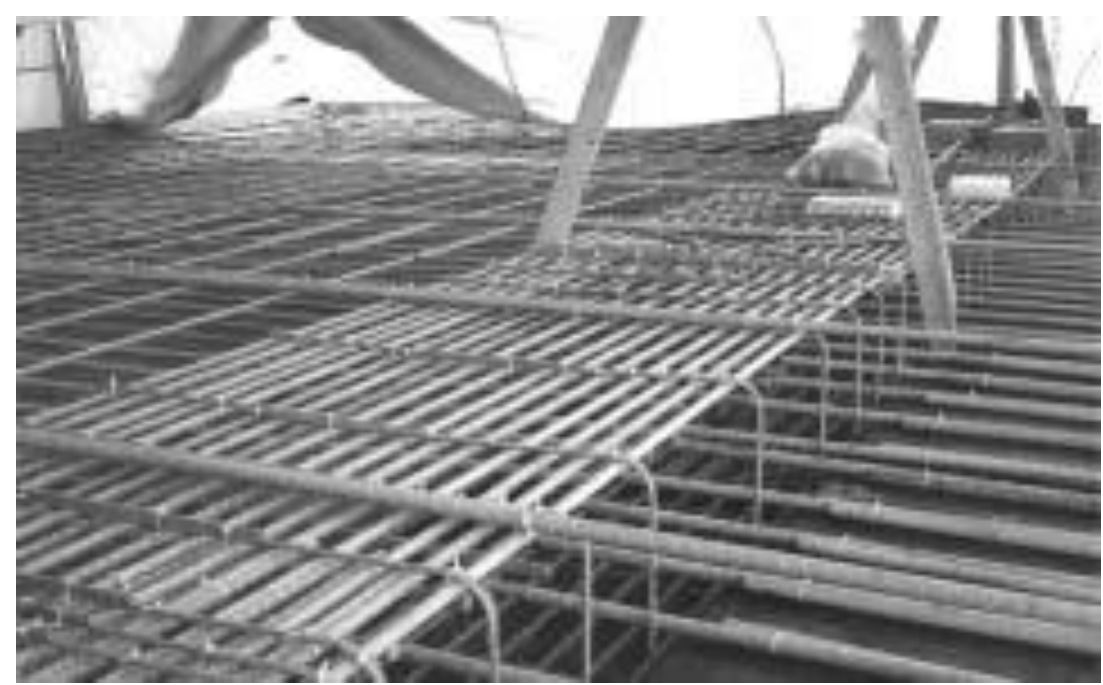

Figura 2.5 Barras de GFRP usadas na Winery in British Columbia em 1998. Fonte: ACI440.1R-06

A Tabela 2.2 faz uma comparação típica em termos das densidades das barras, coeficientes de expansão térmica, resistência à tração, tensão de escoamento nominal, módulo de elasticidade, deformação de escoamento e deformação de ruptura.

Tabela 2.2 - Propriedades das barras de FRP comparadas com as de aço. Fonte: ACI440.1R-06

\begin{tabular}{|c|c|c|c|c|c|c|}
\hline \multicolumn{3}{|c|}{ Propriedades das barras em FRP } & $\mathrm{AÇO}$ & GFRP & CFRP & AFRP \\
\hline \multicolumn{3}{|c|}{ Densidade das barras $\left(\mathrm{g} / \mathrm{cm}^{3}\right)$} & 7,90 & $\begin{array}{c}1,25 \mathrm{a} \\
2,10\end{array}$ & $\begin{array}{c}1,50 \mathrm{a} \\
1,60\end{array}$ & $\begin{array}{c}1,25 \mathrm{a} \\
1,40\end{array}$ \\
\hline \multirow{2}{*}{$\begin{array}{l}\text { Coeficiente de } \\
\text { expansão } \\
\text { térmica }\left(\times 10^{-}\right. \\
\left.{ }^{6}{ }^{\circ} \mathrm{C}\right)\end{array}$} & \multicolumn{2}{|c|}{ Direção longitudinal, $\alpha_{L}$} & 11,70 & $\begin{array}{l}6,00 \mathrm{a} \\
10,00\end{array}$ & $\begin{array}{c}-9,00 \mathrm{a} \\
0,00\end{array}$ & $\begin{array}{c}-6,00 \text { a } \\
-2,00\end{array}$ \\
\hline & \multicolumn{2}{|c|}{ Direção transversal, $\alpha_{T}$} & 11,70 & $\begin{array}{c}21,0 \mathrm{a} \\
23,0\end{array}$ & $\begin{array}{c}74,0 \text { a } \\
104,0\end{array}$ & $\begin{array}{c}60,0 \mathrm{a} \\
80,0\end{array}$ \\
\hline Tensão & & Escoamento (MPa) & $\begin{array}{c}276 \mathrm{a} \\
517\end{array}$ & & & \\
\hline Resistência & r & Tração (MPa) & $\begin{array}{c}483 a \\
690\end{array}$ & $\begin{array}{l}483 \mathrm{a} \\
1600\end{array}$ & $\begin{array}{l}600 \mathrm{a} \\
3690\end{array}$ & $\begin{array}{c}1720 a \\
2540\end{array}$ \\
\hline \multicolumn{3}{|c|}{ Módulo de elasticidade (GPa) } & 200,0 & 35 a 51 & $\begin{array}{c}120,0 \mathrm{a} \\
580,0\end{array}$ & $\begin{array}{l}41,0 \mathrm{a} \\
125,0\end{array}$ \\
\hline \multicolumn{3}{|c|}{ Deformação de escoamento (\%) } & $\begin{array}{c}0,14 \mathrm{a} \\
0,25\end{array}$ & & & \\
\hline \multicolumn{3}{|c|}{ Deformação de Ruptura (\%) } & $\begin{array}{c}6,0 \mathrm{a} \\
12,0\end{array}$ & 1,2 a 3,1 & 0,5 a 1,7 & 1,9 a 4,4 \\
\hline
\end{tabular}

Os principais fatores que alteram a resistência das barras de FRP à tração são as interações físicas e químicas da matriz com as fibras, a forma de distribuição das fibras na matriz, a porcentagem de fibras na matriz polimérica e, também, o controle de produção e qualidade das barras. 
Em relação às propriedades e dados fornecidos pelos fabricantes das barras de reforço FRP, em termos de resistência à tração e deformação das barras, tem-se, de acordo com o ACI440.1R-06:

$\varepsilon_{f u}=$ Deformação de ruptura de projeto da barra de reforço FRP

$\varepsilon_{f u}^{*}=$ Deformação garantida de ruptura da barra de reforço FRP, que é uma propriedade reportada ao fabricante da barra de reforço, ou seja, é a deformação média de ruptura das amostras de teste menos três vezes o desvio padrão, ou seja:

$$
\varepsilon_{f u}^{*}=\varepsilon_{u, a v e}-3 \sigma
$$

$\varepsilon_{u, a v e}=$ Deformação média de ruptura das amostras de teste

Chega-se então à equação 2.2:

$$
\varepsilon_{f u}=C_{E} \varepsilon_{f u}^{*}
$$

$C_{E}$ é o fator de redução ambiental dado pela Tabela 2.3.

$f_{f u}=$ Resistência à tração de projeto da barra de FRP considerando reduções de serviço (fatores ambientais), em MPa

$f_{f u}^{*}=$ Resistência garantida à tração da barra de FRP, em MPa, que é uma propriedade também reportada ao fabricante da barra de reforço, ou seja, é a resistência média à tração das amostras de teste menos três vezes o desvio padrão, ou seja:

$$
f_{f u}^{*}=f_{u, a v e}-3 \sigma
$$

$f_{u, a v e}=$ Resistência média à tração das amostras de teste

Chega-se então à equação 2.4:

$$
f_{f u}=C_{E} f_{f u}^{*}
$$

De novo, tem-se $C_{E}$ como o fator de redução ambiental dado pela Tabela 2.3. 
Tabela 2.3 - Fator de redução ambiental. Fonte: ACI440.1R-06

\begin{tabular}{|c|c|c|}
\hline Condições de exposição & Tipo de Fibra & $\begin{array}{c}\text { Fator de } \\
\text { redução devido } \\
\text { a condições } \\
\text { ambientais } \mathrm{C}_{E}\end{array}$ \\
\hline \multirow{3}{*}{$\begin{array}{c}\text { Concreto não exposto em contato com a terra } \\
\text { e água }\end{array}$} & Carbono & 1,0 \\
\hline & Vidro & 0,8 \\
\hline & Aramida & 0,9 \\
\hline \multirow{3}{*}{$\begin{array}{c}\text { Concreto exposto em contato com a terra e } \\
\text { água }\end{array}$} & Carbono & 0,9 \\
\hline & Vidro & 0,7 \\
\hline & Aramida & 0,8 \\
\hline
\end{tabular}

As barras de reforço FRP são avaliadas em diferentes graus de resistência à tração e módulo de elasticidade. As classes de resistência à tração são baseados na resistência à tração das barras. As resistências garantidas à tração das barras de FRP $f_{f u}^{*}$ são organizadas com incrementos de resistência de $69 \mathrm{MPa}$ em cada classe, a partir do grau mais baixo existente (414 MPa), ou seja:

- Classe F60: Correspondente a $f_{f u}{ }^{*}<483 \mathrm{MPa}$

- Classe F70: Correspondente a $f_{f u}{ }^{*}<552 \mathrm{MPa}$

-Classe F290: Correspondente a $f_{f u}{ }^{*}<2069 \mathrm{MPa}$

O módulo de elasticidade de projeto da barra de FRP é considerado também como a média dos valores reportados pelo fabricante (valor garantido) das amostras de teste, ou seja:

$$
E_{f}=E_{f, a v e}
$$

Com várias classificações de barras de reforço e diâmetros diferentes é necessário que se tenha uma fácil identificação da barra em relação ao fabricante, devendo ter as seguintes informações:

- Símbolo que identifique o fabricante;

-A letra indicativa do tipo de fibra ("G" para vidro, "A" para aramida, "C" para carbono ou "H" para híbrida); em seguida, o número correspondente ao diâmetro nominal da barra de acordo com padrão ASTM; 
-O grau de resistência;

- O módulo de elasticidade das barras, sendo que elas devem ter no mínimo o valor estabelecido na Tabela 2.4 .

Tabela 2.4 - Mínimo módulo de elasticidade para diferentes tipo de FRP.

Fonte: ACI440.1R-06

\begin{tabular}{|c|c|}
\hline Tipos de barras de reforço & Mínimo Módulo de elasticidade (MPa) \\
\hline GFRP & 39300 \\
\hline AFRP & 68900 \\
\hline CFRP & 110300 \\
\hline
\end{tabular}

- Outro fator importante a ser considerado nas barras de reforço FRP é de que suas propriedades mecânicas são superiores no eixo longitudinal (direção das fibras) e são ortotrópicos, podendo em alguns casos ser considerados transversalmente isotrópicos ou anisotrópicos.

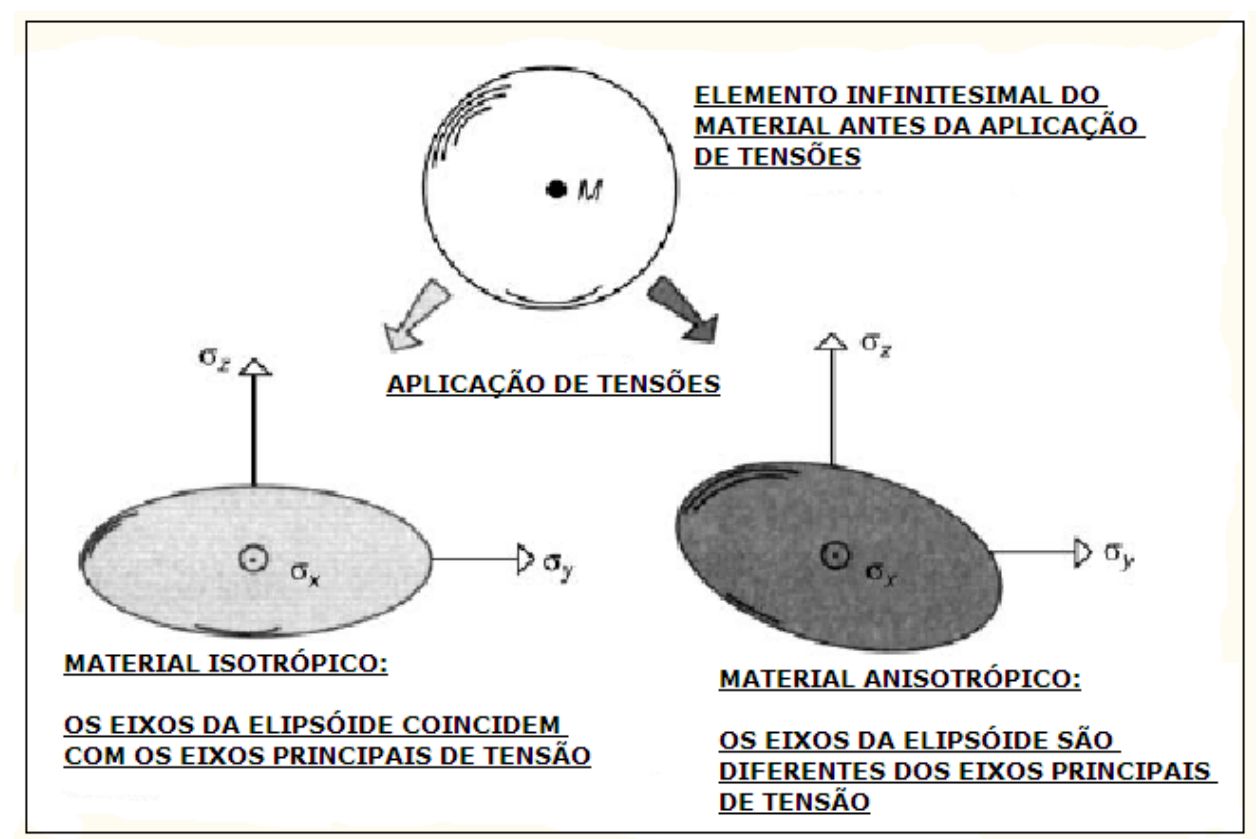

Fig.2.6 Esquema de deformação isotrópica e anisotrópica. Adaptado: Tsai, Stephen W. et al. (2003) 
No caso de compósitos híbridos, onde um único laminado pode ser constituído de lâminas com resina epóxi reforçada pela mistura de diversos tipos de fibras, as propriedades mecânicas são ainda mais diferenciadas nos três eixos de simetria do material.

Como se tratam de aplicações estruturais, a previsão de falha devida a um estado de tensões específico é outro fator importante a ser considerado no processo de fabricação das barras. Matthews e Rawlings (1994) definiram a "falha" de um componente como sendo o momento em que o mesmo não pode mais desempenhar a função para o qual foi projetado. As falhas internas podem ocorrer de diversas maneiras:

-Pela ruptura das fibras (transversal ou longitudinal):

-Fissuramento na matriz;

-Separação entre as fibras e a matriz;

-Delaminação (separação entre as camadas de um compósito laminado);

-Microflambagem que é uma deformação das fibras da lâmina quando submetida a esforços de compressão.

\subsection{Flexão em barras de aço e em barras de FRP}

\subsubsection{Tensão-deformação no aço e em barras de FRP}

Aço é definido como uma liga metálica composta principalmente de ferro e de uma porcentagem muito pequena de carbono (podendo chegar no máximo a $2 \%$ ). Os aços estruturais utilizados na construção civil possuem teores de carbono variando de $0,18 \%$ a 0,25\%. O aço apresenta grande resistência à tração e boa ductilidade. O tratamento mecânico do aço pode ser a quente, o que ocorre com os aços CA-25 e CA-50, e a frio ou encruamento, situação em que está incluído o aço CA-60.

A norma americana ACI440.1R-06 considera o dimensionamento básico na flexão das barras de FRP como reforço interno em estruturas de concreto análogo ao dimensionamento feito também pela norma americana ACI-318-05 para o reforço em aço convencional. Apesar de algumas hipóteses de cálculo, que são fundamentais para o cálculo das barras de aço no concreto, serem também aplicadas no cálculo de barras em FRP, deve-se observar que não existe patamar de escoamento nas barras de reforço de FRP, ou seja diferentemente do aço (Figura 2.7), nas barras de FRP a ruptura é frágil. 


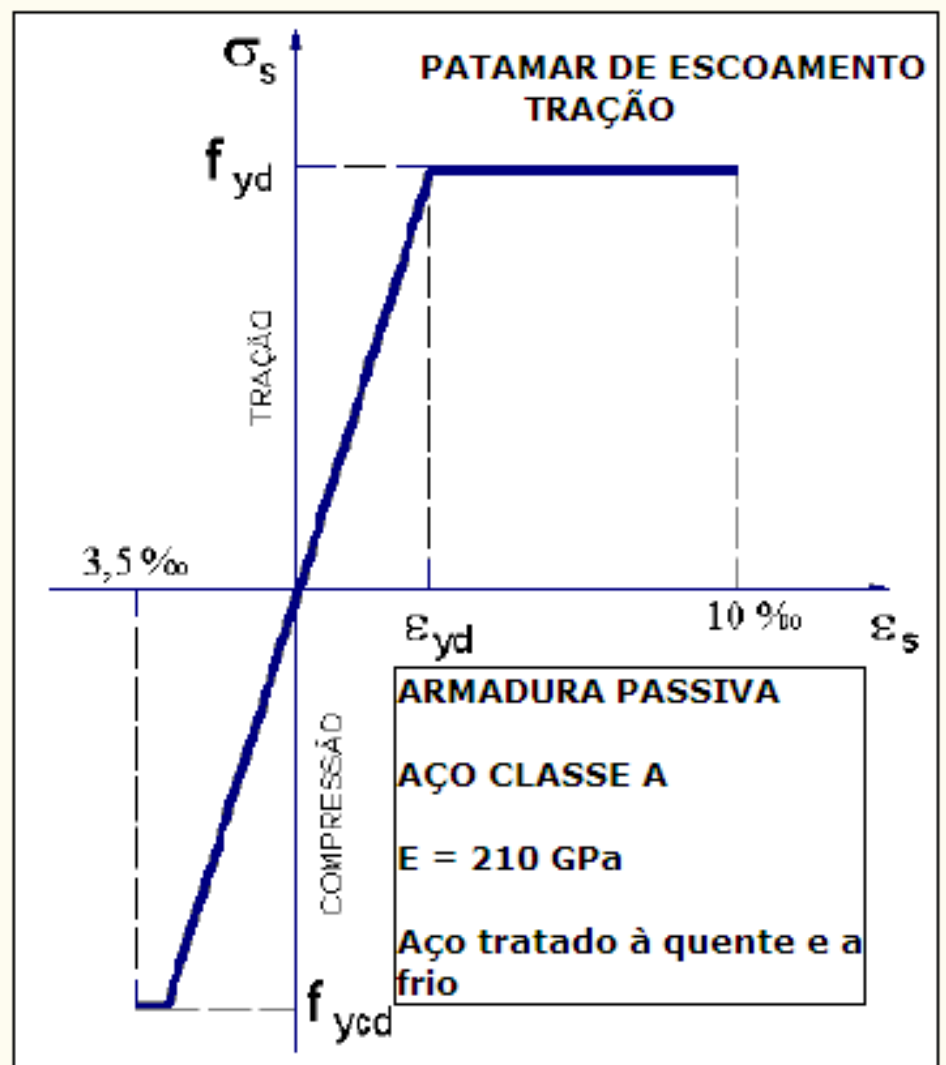

Figura 2.7- Digrama de cálculo (tensão-deformação) para o aço. Adaptado: NBR6118:2003

A Figura 2.8 faz uma comparação de diagramas do aço como armadura ativa (protensão), do aço como armadura passiva e do polímero reforçado com fibra de vidro (GFRP).

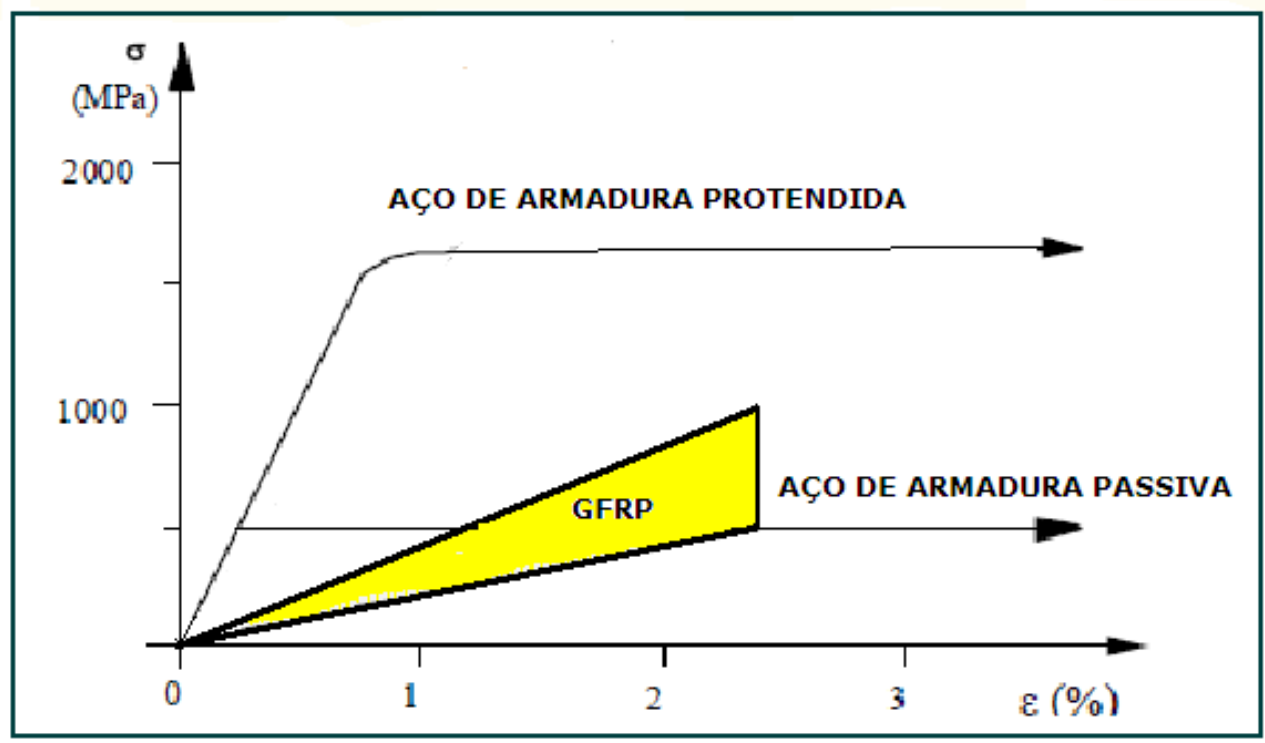

Figura 2.8 - Diagrama tensão-deformação do aço e GFRP. Adaptado: Pilakoutas, K. et al. (2002) 
Para uma viga de concreto armada com reforço em FRP para resistir à flexão, a rigidez, as características de aderência das barras, a resistência do tipo de fibra do material compósito e sobretudo a taxa de armadura empregada de forma balanceada são fatores essenciais para o equilíbrio da seção transversal. Duas vigas de concreto, reforçadas com barras em FRP e com barras de aço respectivamente e com mesmas condições de carregamento, certamente não terão a mesma taxa de armadura ou a mesma seção transversal, devido à maior rigidez de peças armadas com aço. Esse valor maior da taxa de armadura em peças armadas com FRP tem um impacto significativo sobre a distribuição de tensões ao longo da seção transversal do concreto reforçado (Figura 2.9).

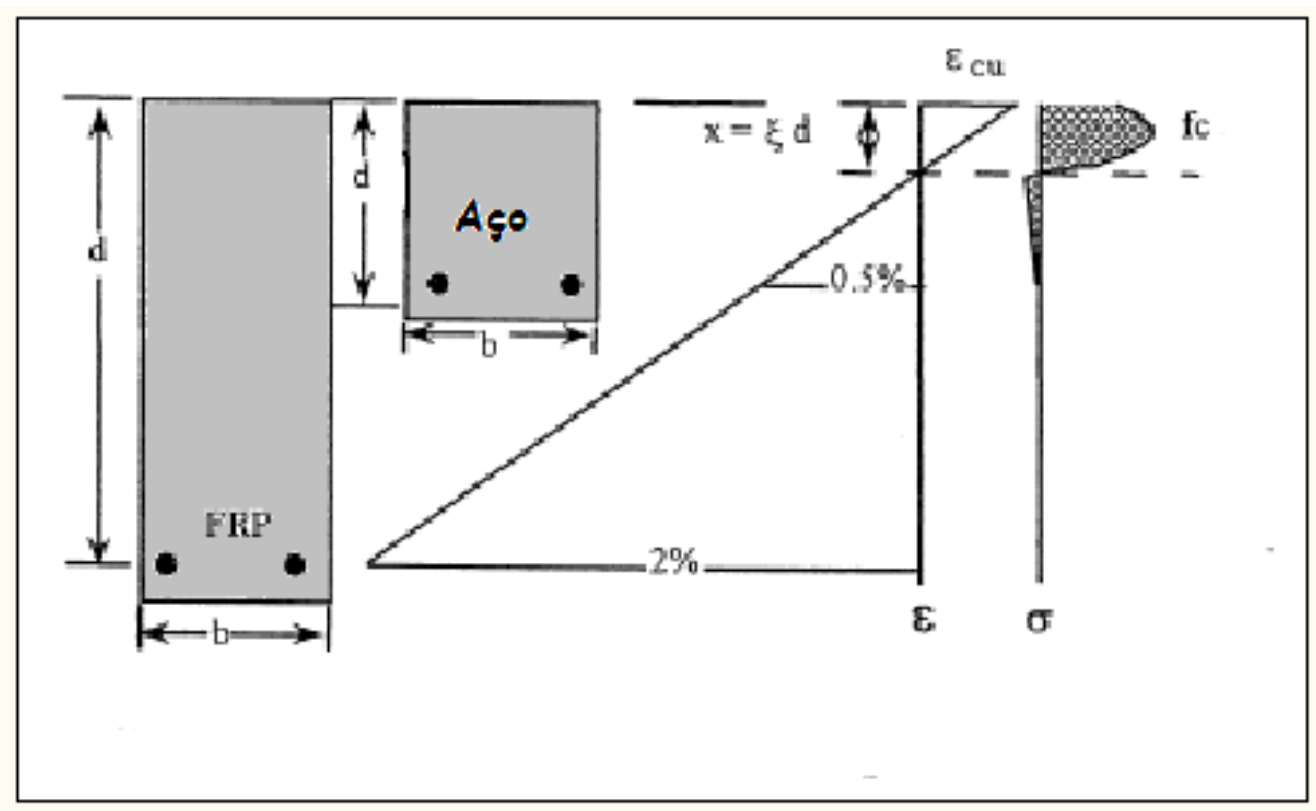

Figura 2.9 - Distribuição de deformações e tensões para duas seções transversais, armadas com FRP e aço respectivamente. Adaptado: Pilakoutas, K. et al. (2007)

A Figura 2.10 mostra que, para uma mesma taxa de armadura, a tensão de ruptura em peças armadas com aço é superior à de peças armadas em GFRP (Polímero Reforçado com Fibra de Vidro). 


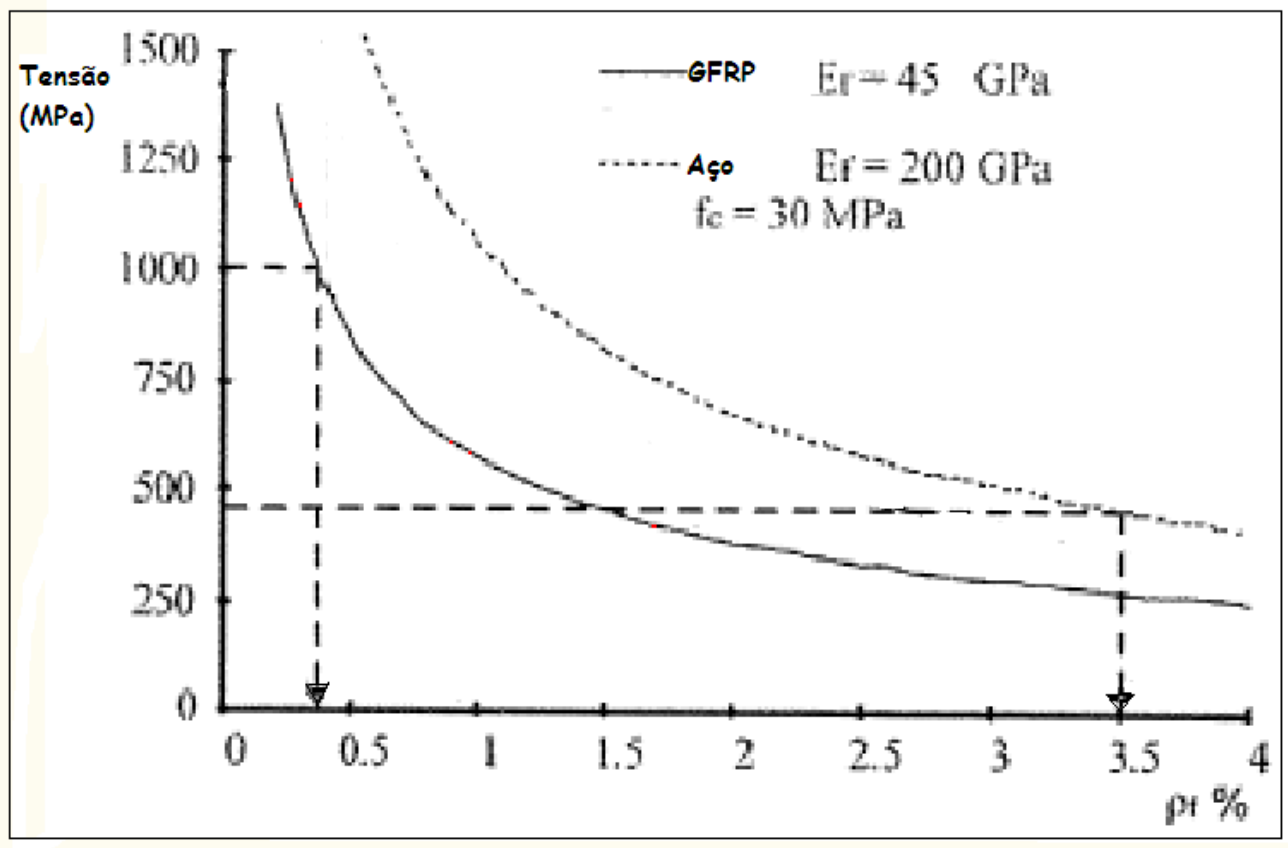

Figura 2.10 - Tensão na ruptura do concreto reforçado em relação à taxa de armadura de reforço.

Adaptado: Pilakoutas, K. et al. (2007)

\subsubsection{Propriedades mecânicas do concreto simples}

As propriedades mecânicas do concreto simples (sem armadura) são determinadas através de ensaios, executados de acordo com normas específicas da NBR. São elas:

- Resistência à compressão: Ensaio de compressão de corpos de prova cilíndricos ou prismáticos de concreto (ABNT NBR 5739:1994);

- Resistência à tração: Através de ensaios de tração direta, ensaio de tração na compressão diametral (spliting test) e determinação da resistência à tração na flexão em corpos de prova prismáticos (ABNT NBR 12142:1991) conforme a Figura 2.11; 


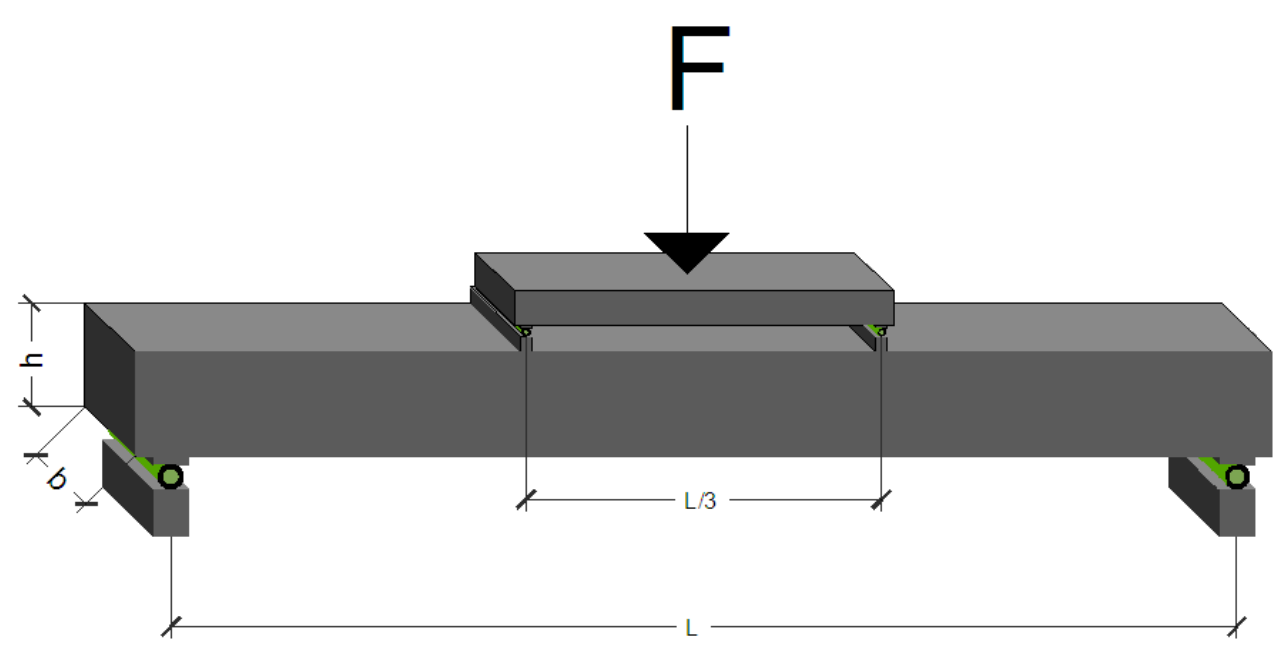

Figura 2.11- Ensaio de tração na flexão de uma viga de concreto de acordo com a ABNT NBR 12142:1991

- Módulo de elasticidade ou módulo de deformação longitudinal (E): É a relação entre a tensão $(\sigma)$ e a deformação do concreto $(\varepsilon)$. O módulo de deformação tangencial inicial (Figura 2.10) é obtido pelo método de ensaio segundo a ABNT NBR 8522:1984 (Determinação do módulo de deformação estática e diagrama tensão-deformação).

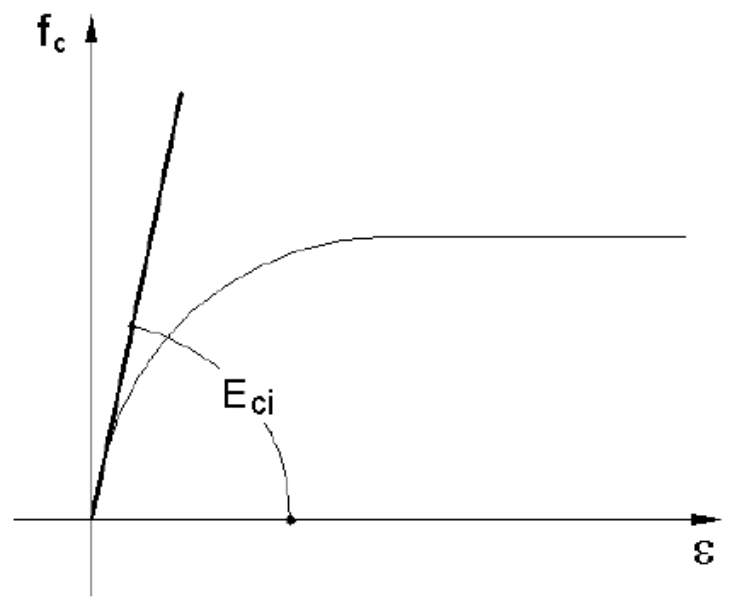

Figura 2.12- Módulo de deformação tangencial inicial do concreto. Adaptado ABNT NBR 6118:2003

Quando não existirem dados precisos sobre o concreto, para idade de referência de 28 dias, pode-se adotar o valor do módulo de elasticidade utilizando a expressão:

$$
\mathrm{E}_{c i}=5600 f_{c k}^{1 / 2}(M P a)
$$

O módulo de elasticidade secante a ser utilizado nas análises elásticas de projeto, especialmente para determinação de esforços solicitantes e verificação de estados limites de serviço, deve ser calculado pela expressão: 


$$
\mathrm{E}_{c s}=0,85 \mathrm{E}_{c i}
$$

Para análises no estado limite último, podem ser empregados o diagrama tensãodeformação da figura 2.13

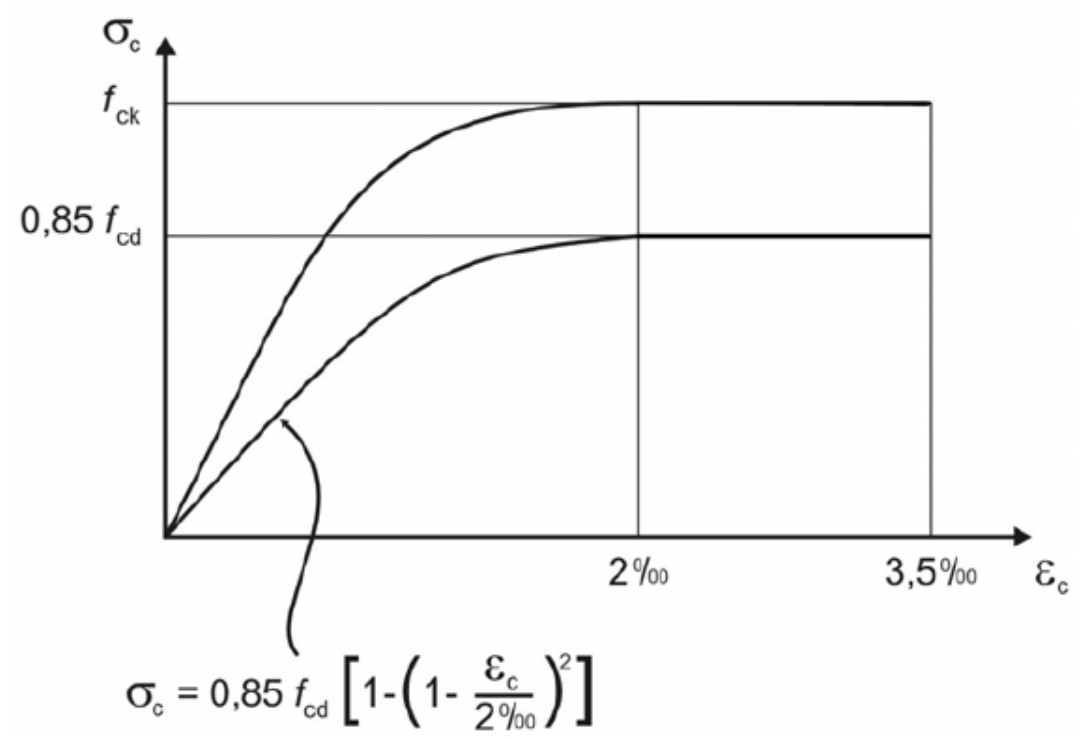

Figura 2.13 - Diagrama tensão deformação no estado limite. Fonte: ABNT NBR 6118:2003

\subsubsection{Agressividade ambienta segundo a ABNT NBR 6118:2003}

A Tabela 2.5 classifica a agressividade do ambiente de acordo com o tipo de ambiente onde a estrutura será exposta, podendo haver ou não, risco de deterioração da estrutura. 
Tabela 2.5 - Classe de agressividade ambiental. Adaptado: NBR 6118:2003

\begin{tabular}{|c|c|c|c|}
\hline $\begin{array}{c}\text { Classe de } \\
\text { agressividade } \\
\text { ambiental }\end{array}$ & Agressividade & $\begin{array}{l}\text { Classificação geral } \\
\text { do tipo de ambiente } \\
\text { para efeito de } \\
\text { projeto }\end{array}$ & $\begin{array}{c}\text { Risco de } \\
\text { deterioração da } \\
\text { estrutura }\end{array}$ \\
\hline \multirow{2}{*}{ I } & \multirow{2}{*}{ FRACA } & RURAL & \multirow{2}{*}{$\begin{array}{c}\text { INSIGNIFI- } \\
\text { CANTE }\end{array}$} \\
\hline & & SUBMERSA & \\
\hline II & MODERADA & $\begin{array}{c}\text { URBANA } \\
\text { (Ambientes } \\
\text { predominantes } \\
\text { secos) }\end{array}$ & PEQUENO \\
\hline \multirow[b]{2}{*}{ III } & \multirow[b]{2}{*}{ FORTE } & $\begin{array}{c}\text { MARINHA } \\
\text { (Ambientes } \\
\text { internos secos) }\end{array}$ & \multirow[b]{2}{*}{ GRANDE } \\
\hline & & $\begin{array}{l}\text { INDUSTRIAL } \\
\text { (Ambientes } \\
\text { predominantes } \\
\text { secos) }\end{array}$ & \\
\hline \multirow{2}{*}{ IV } & \multirow{2}{*}{ MUITO FORTE } & $\begin{array}{l}\text { INDUSTRIAL } \\
\text { (Ambientes } \\
\text { quimicamente } \\
\text { agressivos) }\end{array}$ & \multirow{2}{*}{ ELEVADO } \\
\hline & & $\begin{array}{c}\text { RESPINGOS DE } \\
\text { MARÉ }\end{array}$ & \\
\hline
\end{tabular}

$\mathrm{Na}$ Tabela 2.6, para cada classe de agressividade indicada na Tabela 2.5 estão associados fatores água/cimento e resistências características do concreto, que são diferentes para o concreto armado (com armadura passiva) e o concreto protendido (com armadura ativa). 
Tabela 2.6 - Correspondência entre classe de agressividade e qualidade do concreto.

Adaptado: NBR 6118:2003

\begin{tabular}{|c|c|c|c|c|c|}
\hline \multirow{2}{*}{ CONCRETO } & TIPO & \multicolumn{4}{|c|}{ CLASSE DE AGRESSIVIDADE } \\
\cline { 2 - 6 } & & I & II & III & IV \\
\hline \multirow{2}{*}{$\begin{array}{c}\text { Relação } \\
\text { água/cimento em } \\
\text { massa }\end{array}$} & $\begin{array}{c}\text { Concreto } \\
\text { Armado }\end{array}$ & $\leq 0,65$ & $\leq 0,60$ & $\leq 0,55$ & $\leq 0,45$ \\
\cline { 2 - 6 } & $\begin{array}{c}\text { Concreto } \\
\text { Protendido }\end{array}$ & $\leq 0,60$ & $\leq 0,55$ & $\leq 0,50$ & $\leq 0,45$ \\
\hline $\begin{array}{c}\text { Classe de } \\
\text { concreto (ABNT } \\
\text { NBR 8953) }\end{array}$ & $\begin{array}{c}\text { Concreto } \\
\text { Armado }\end{array}$ & $\geq \mathrm{C} 20$ & $\geq \mathrm{C} 25$ & $\geq \mathrm{C} 30$ & $\geq \mathrm{C} 40$ \\
\cline { 2 - 6 } & $\begin{array}{c}\text { Concreto } \\
\text { Protendido }\end{array}$ & $\geq \mathrm{C} 25$ & $\geq \mathrm{C} 30$ & $\geq \mathrm{C} 35$ & $\geq \mathrm{C} 40$ \\
\hline
\end{tabular}

Analisando a Tabela 2.7, tem-se o cobrimento nominal mínimo exigido pela norma NBR 6118:2003, que está intimamente relacionado com a classe de agressividade ambiental e com o tipo de estrutura e elemento estrutural a ser utilizado na construção.

Tabela 2.7 - Correspondência entre classe de agressividade ambiental e cobrimento nominal. Adaptado: NBR 6118:2003

\begin{tabular}{|c|c|c|c|c|c|}
\hline \multirow{3}{*}{$\begin{array}{c}\text { TIPO DE } \\
\text { ESTRUTURA }\end{array}$} & \multirow{3}{*}{$\begin{array}{c}\text { COMPONENTE } \\
\text { OU } \\
\text { ELEMENTO }\end{array}$} & \multicolumn{4}{|c|}{ CLASSE DE AGRESSIVIDADE AMBIENTAL } \\
\hline & & I & II & III & IV \\
\hline & & \multicolumn{4}{|c|}{ COBRIMENTO NOMINAL $(\mathrm{mm})$} \\
\hline \multirow{2}{*}{$\begin{array}{l}\text { CONCRETO } \\
\text { ARMADO }\end{array}$} & LAJE & 20 & 25 & 35 & 45 \\
\hline & VIGA/PILAR & 25 & 30 & 40 & 50 \\
\hline $\begin{array}{c}\text { CONCRETO } \\
\text { PROTENDIDO }\end{array}$ & TODOS & 30 & 35 & 45 & 55 \\
\hline
\end{tabular}




\subsubsection{Estádios de tensão e Domínios de deformação do concreto armado com aço}

Dada a Figura 2.11, supondo que a viga tenha armadura interna em aço, será analisado o que acontece ao longo de um determinado carregamento F.

Apesar da resistência do concreto à tração ser muito inferior à resistência à compressão, no início do carregamento o concreto resiste bem às tensões de tração, a linha neutra se concentra na parte inferior da viga e vai subindo para a região superior, conforme o aumento do carregamento. Nessa situação tem-se uma distribuição linear de tensões, onde é válida a lei de Hooke. Neste estágio de carregamento, denominado estádio 1, é possível calcular o momento de fissuração e termina quando a seção transversal sofre fissuração.

- No segundo estágio de carregamento, denominado estádio 2, o concreto não resiste mais à tração, sendo que a contribuição do concreto tracionado passa a ser desprezada, a região que sofre compressão acima da linha neutra permanece com distribuição linear de tensões, permanecendo válida a lei de Hooke. Com o aumento do carregamento as fissuras que antes se concentravam na região inferior da viga se deslocam para a região superior no sentido da borda comprimida. Esse estágio termina com o início da plastificação do concreto comprimido.

- No terceiro estágio de carregamento, denominado estádio 3, a zona comprimida se encontra plastificada e o concreto está na ruptura. Utiliza-se nessa etapa uma distribuição de tensões da forma parabólico-retangular, que segundo a NBR 6118:2003 pode ser aproximada por uma distribuição retangular equivalente. É nesse estágio que é feito o dimensionamento, com o cálculo da ruptura (Figura 2.14).

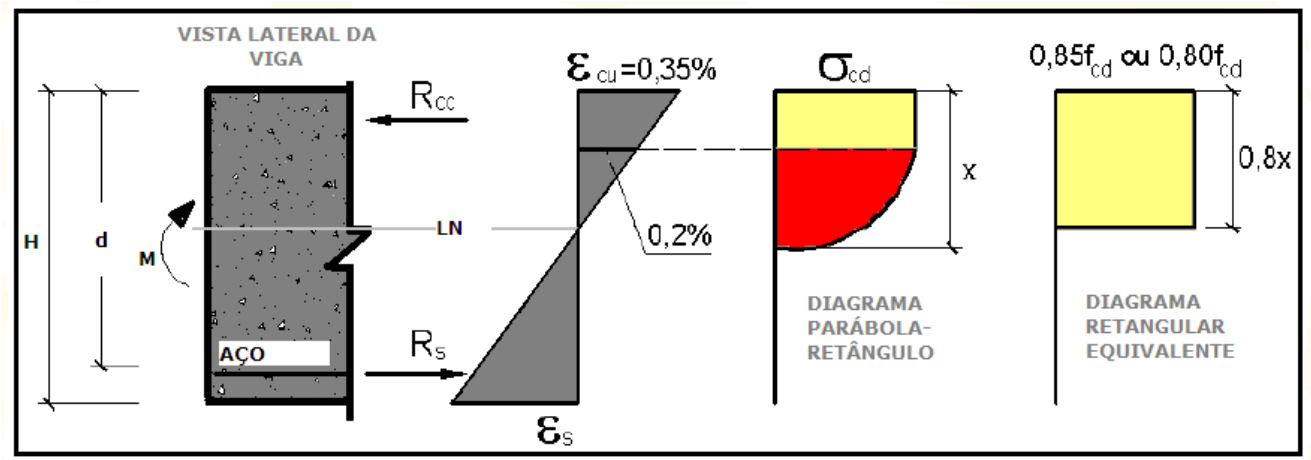

Figura 2.14 - Diagrama de deformação e de tensão no concreto na ruptura. Adaptado ABNT NBR 6118:2003 
Para o cálculo de dimensionamento tem-se os domínios de deformação, onde pelo menos um dos materiais (aço ou concreto) atinge o limite de deformação (Figura 2.15):

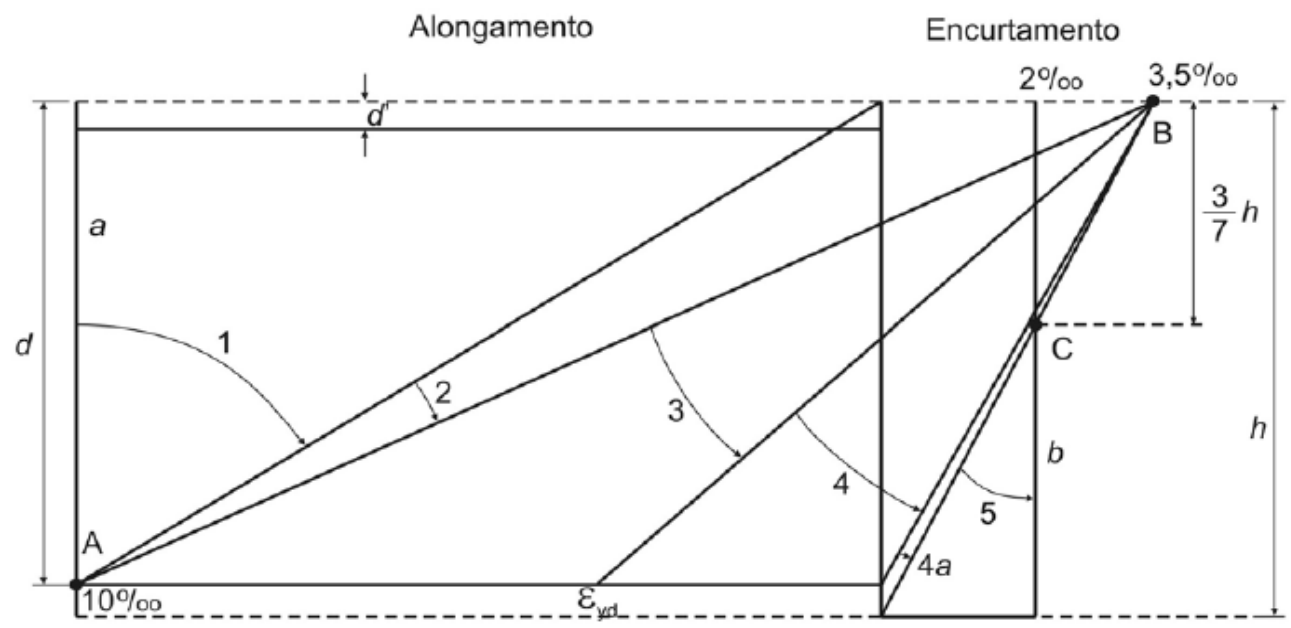

Figura 2.15 - Domínios de deformação na ruína. Fonte: ABNT NBR 6118:2003

- Ruína por deformação plástica excessiva do aço: Tração (uniforme ou não-uniforme) e flexão (simples ou composta) são situações que podem fazer o aço atingir alongamento máximo, produzindo na armadura longitudinal tracionada mais uma deformação específica de $1 \%\left(\varepsilon_{\mathrm{S}}=1 \%\right)$.

A linha correspondente ao alongamento constante e igual a $1 \%$ pode ser proveniente de tração simples ou excêntrica desde que a relação de área da armadura longitudinal mais tracionada da armadura longitudinal situada junto à borda superior da seção transversal seja tal que garanta o alongamento uniforme da seção. Essa situação pode ser observada na Figura 2.15 como sendo a reta $a$.

Se a tração excêntrica estiver presente em toda a seção de modo não uniforme, com $\varepsilon_{\mathrm{s}}=1 \%$ na armadura mais tracionada e deformação da borda superior $\left(\varepsilon_{\mathrm{s}}\right)$ variando de $1 \%$ a $0 \%$, temse neste caso, conforme a Figura 2.15, o domínio 1.

Quando a linha neutra entra na seção transversal, tem-se uma situação de flexão simples ou flexão composta, com força normal de tração ou de compressão, sendo que nesta situação tem-se alongamento $\varepsilon_{\mathrm{s}}=1 \%$ na armadura tracionada e compressão na borda superior do concreto $\left(\varepsilon_{\mathrm{c}}\right)$ variando de $0 \%$ a $0,35 \%$. Essa situação caracteriza-se pelo domínio 2, que é a última situação em que ocorre deformação plástica excessiva da armadura (Figura 2.15). 
- Ruína por ruptura do concreto comprimido na flexão: A linha neutra se localiza dentro da seção transversal. Na flexão a ruína ocorre com deformação específica do concreto $\left(\varepsilon_{c}\right)$ igual a $0,35 \%$ na borda comprimida. Quando a deformação do concreto na borda comprimida é de $0,35 \%$ e a deformação na armadura tracionada $\varepsilon_{\mathrm{s}}$ varia de $1 \%$ a $\varepsilon_{\mathrm{yd}}$, o concreto encontra-se na ruptura e o aço tracionado em escoamento, situação em que a seção é denominada subarmada. Há aproveitamento máximo dos dois materiais e a ruína ocorre com aviso, pois a peça apresenta grande fissuração e deslocamentos visíveis. Tem-se neste caso, o domínio 3.

Quando a deformação na armadura está entre $\varepsilon_{y d}$ e $0 \%$ e a deformação na borda comprimida permanece a mesma de $0,35 \%$, o concreto encontra-se na ruptura mas o aço tracionado não atinge o escoamento, sendo mal aproveitado e anti econômico. Neste caso, a seção é denominada superarmada, a ruína ocorre sem aviso, pois há pouca fissuração e os deslocamentos são menores. Tem-se neste caso, o domínio 4.

Da mesma forma, quando a linha neutra se aproxima da borda tracionada, ficando entre $\mathrm{d}$ e h, na região de cobrimento da armadura tracionada, pode-se dizer que as duas armaduras estão comprimidas, sendo a inferior também mal aproveitada. A ruína continua ocorrendo com a deformação do concreto em $0,35 \%$; é uma situação que ocorre na flexo-compressão, denominada de domínio $4 a$

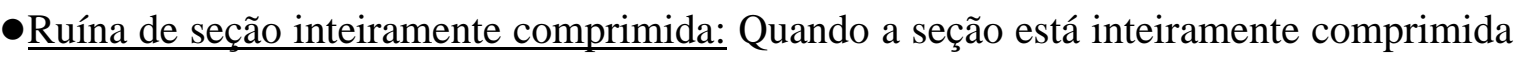
$(\mathrm{x}>\mathrm{h})$, com a deformação do concreto igual a $0,2 \%$ na linha distante $3 / 7 \mathrm{~h}$ da borda mais comprimida, tem-se o domínio 5. Na borda mais comprimida a deformação do concreto varia de $0,35 \%$ a $0,2 \%$, situação que só ocorre na compressão excêntrica. Se a deformação for uniforme de compressão, com encurtamento igual a $0,2 \%$, tem-se a reta $b$.

\subsubsection{Equacionamento para flexão simples no concreto armado com aço}

Na flexão simples são possíveis os domínios 2, 3 e 4, onde a linha neutra corta a seção transversal. No domínio 2 a ruína acontece, como visto anteriormente, com a deformação plástica excessiva do aço.

No domínio 3 a ruína acontece pela ruptura do concreto com o escoamento do aço, sendo a situação ideal de projeto. E no domínio 4 a ruína acontece pela ruptura do concreto sem que haja escoamento do aço, sendo uma situação que pode ser evitada aumentando a altura da 
seção transversal ou aumentando a resistência característica do concreto ou utilizando armadura dupla.

Considerando o equilíbrio de forças e momentos, de acordo com a Figura 2.16, tem-se:

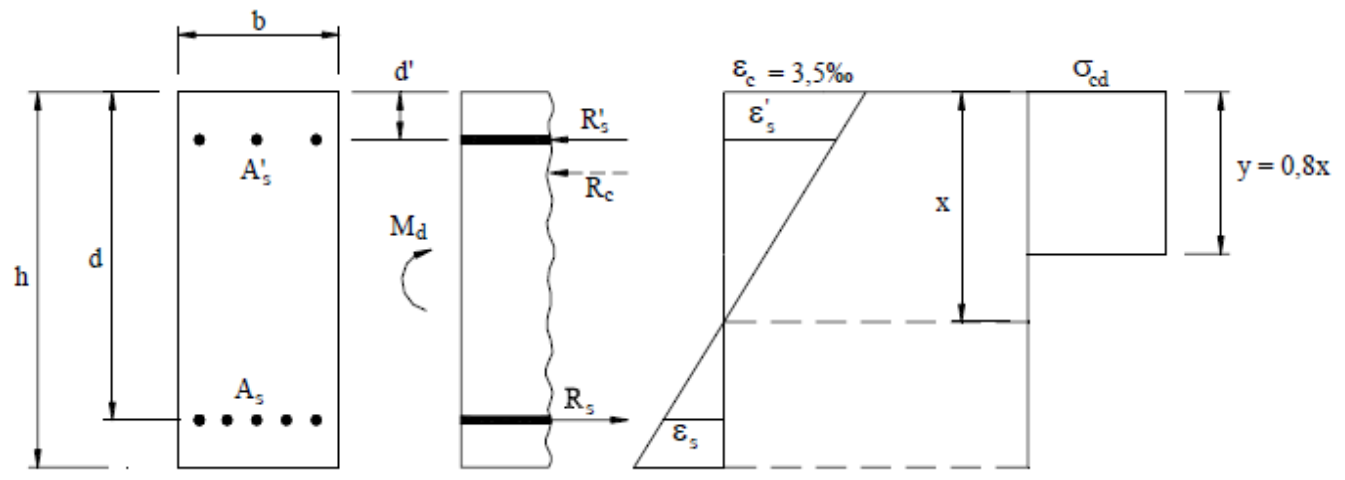

Figura 2.16 - Equilíbrio de forças e de momentos da viga na flexão simples.

$$
\begin{gathered}
0,68 b d \beta_{x} f_{c d}+\mathrm{A}_{s}^{\prime} \sigma_{s}^{\prime}-\mathrm{A}_{s} \sigma_{s}=0 \\
\mathrm{M}_{d}=0,68 b d^{2} \beta_{x} f_{c d}\left(1-0,4 \beta_{x}\right)+\mathrm{A}_{s}^{\prime} \sigma_{s}^{\prime}\left(d-d^{\prime}\right)
\end{gathered}
$$

Onde:

$b(m m)=$ largura da seção transversal da viga;

$d(m m)=$ altura útil da seção transversal;

$x(\mathrm{~mm})=$ distância da borda comprimida do concreto até a linha neutra;

$A_{s}\left(m m^{2}\right)=$ área da armadura longitudinal tracionada;

$A_{s}^{\prime}\left(m m^{2}\right)=$ área da armadura longitudinal comprimida;

$M_{d}(k N m)=$ momento fletor solicitante de cálculo;

$f_{c k}(M P a)=$ resistência característica do concreto;

$f_{c d}(M P a)=$ resistência de cálculo do concreto;

$f_{y k}(M P a)=$ resistência característica de escoamento do aço;

$f_{y d}(M P a)=$ resistência de cálculo de escoamento do aço;

$\gamma_{c}=1,40$ é o coeficiente de ponderação do concreto;

$\gamma_{s}=1,15$ é o coeficiente de ponderação do aço. 


$$
\begin{gathered}
\beta_{x}=\frac{x}{d} \\
f_{c d}=\frac{f_{c k}}{\gamma_{c}}
\end{gathered}
$$

Para o aço CA-50 tem-se:

$$
\sigma_{s}=\sigma_{s}^{\prime}=f_{y d}=\frac{f_{y k}}{\gamma_{s}}
$$

Pode-se utilizar armadura simples quando:

$$
M_{d, \text { máx }} \leq M_{d, \lim }
$$

$$
\text { Sendo que: } \quad M_{d, \lim }=\frac{b d^{2}}{k_{c, \lim }}
$$

$M_{d, \text { lim }}$ é o momento limite para armadura simples

$k_{c, \lim }$ corresponde ao limite entre os domínios 3 e 4

$$
k_{c, \lim }=\frac{1}{0,68 \beta_{x 34} f_{c d}\left(1-0,4 \beta_{x 34}\right)}
$$

Utiliza-se armadura dupla:

$$
M_{d, \lim }<M_{d, \text { máx }} \leq 1,2 M_{d, \lim }
$$

Quando

$$
M_{d, \text { máx }}>1,2 M_{d, \lim }
$$

pode ser necessário aumentar a altura da seção transversal da viga, pois em geral a largura é constante em toda a estrutura, ou utilizar o cálculo como seção "T".

\subsubsection{Equacionamento para flexão simples no concreto armado com FRP}

Pode-se dimensionar uma viga de concreto armada com FRP na flexão simples de três maneiras distintas:

•Dimensionamento quando a ruína ocorre devido à ruptura da barra de FRP (Figura 2.17). 


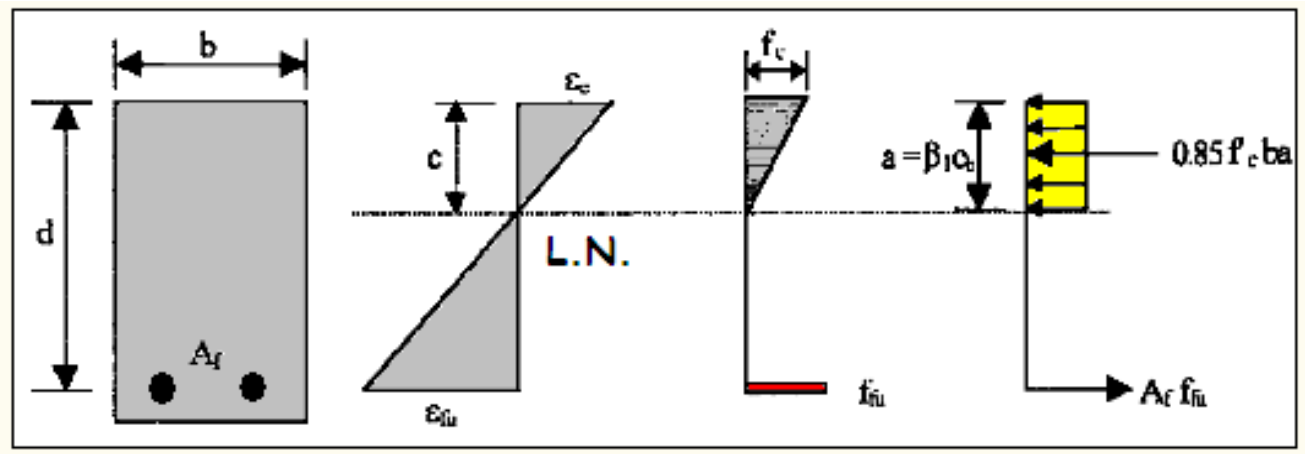

Figura 2.17 - Ruína governada pela ruptura da barra de FRP (tensão no concreto pode ser não linear). Adaptado: ACI440.1R-06

-Dimensionamento quando a ruína ocorre por esmagamento do concreto (Figura 2.18).

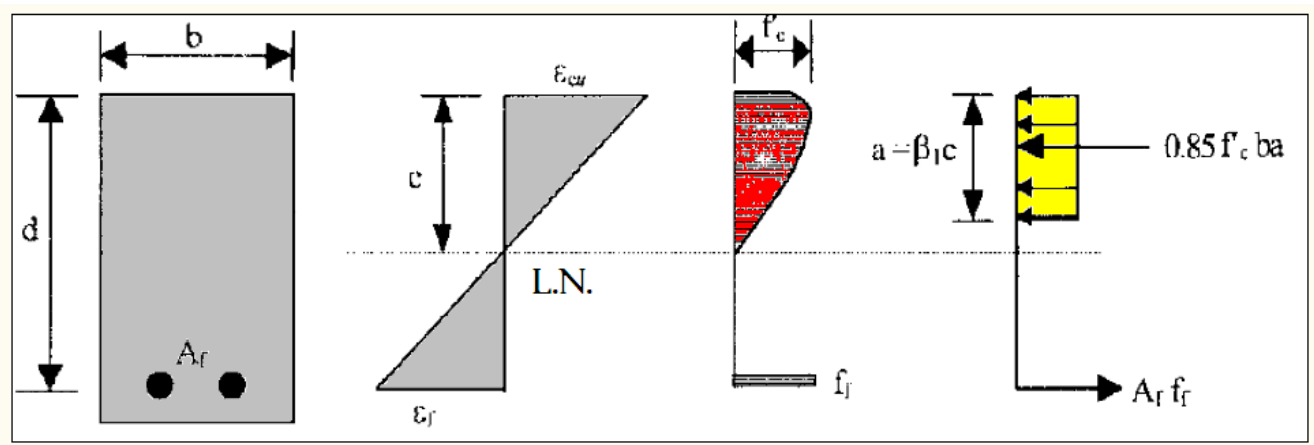

Figura 2.18 - Ruína governada pelo esmagamento do concreto. Adaptado: ACI440.1R-06

•Dimensionamento quando a ruína ocorre de forma balanceada, ou seja, a deformação da armadura e o esmagamento do concreto ocorrem simultaneamente (Figura 2.19).

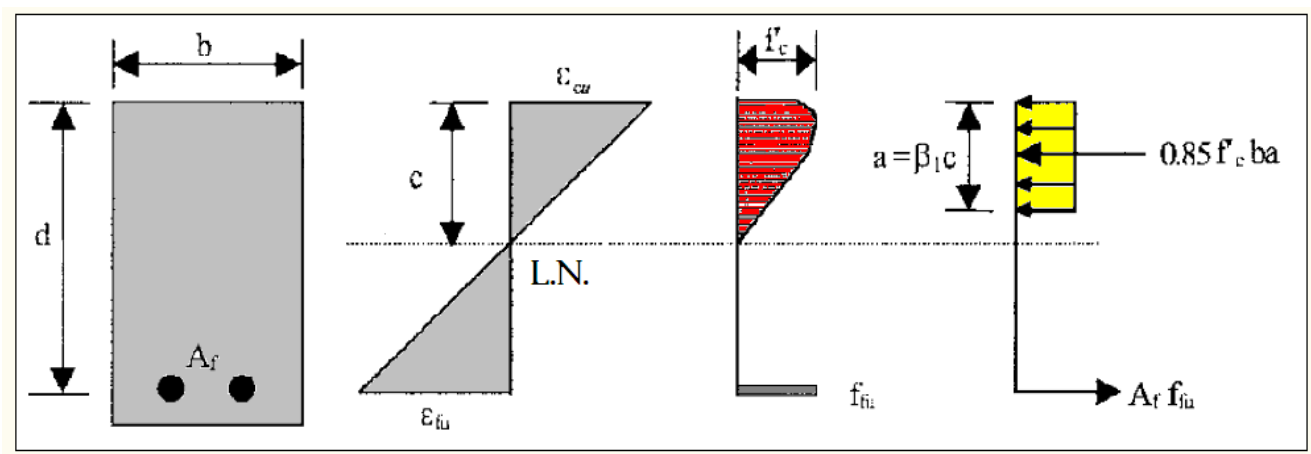

Figura 2.19 - Condição balanceada de ruína: ACI440.1R-06

Os cálculos da resistência das seções transversais devem ser realizados com base nas seguintes premissas: 
-Deformação no concreto e no reforço FRP é proporcional à distância do eixo neutro (isto é, uma seção plana antes do carregamento permanece plana após o carregamento);

-A máxima deformação de compressão utilizada no concreto é assumida como sendo 0,003 ;

-A resistência do concreto à tração é ignorada;

-O comportamento do reforço FRP à tração é elástico linear até a ruptura frágil;

-Perfeita ligação existente entre concreto e o reforço FRP.

A condição necessária e suficiente para que haja resistência à flexão é de que o momento resistente de projeto multiplicado por um fator de redução de resistência seja maior ou igual ao momento solicitante, ou seja:

$$
\phi M_{n} \geq M_{u}
$$

Onde:

$$
\begin{aligned}
& \phi=\text { fator de redução de resistência; } \\
& M_{n}(k N m)=\text { momento resistente; } \\
& M_{u}(k N m)=\text { momento solicitante. }
\end{aligned}
$$

Cálculo da taxa de armadura de reforço balanceado $\rho_{f b}$

$$
\rho_{f b}=0,85 \beta_{1} \frac{f_{c}^{\prime}}{f_{f u}} \frac{E_{f} \varepsilon_{c u}}{E_{f} \varepsilon_{c u}+f_{f u}}
$$

Em que: $f_{c}^{\prime}(\mathrm{MPa})$ é a resistência característica do concreto;

$f_{f u}(\mathrm{MPa})$ é dado pela equação 2.4;

$E_{f}(\mathrm{MPa})$ é o módulo de elasticidade de projeto da barra de FRP, onde

$E_{f}=E_{f, \text { ave }} ;$

$\varepsilon_{c u}$ é a deformação última do concreto;

$\beta_{1}$ é o fator de resistência do concreto dado pela equação:

$$
\beta_{1}=0,85-0,05\left(f_{c}^{\prime}-4000\right) / 1000, f_{c}^{\prime}(p s i)
$$


O cálculo da taxa de armadura da fibra é dado por:

$$
\rho_{f}=\frac{A_{f}}{b d}
$$

Em que:

$$
\begin{aligned}
& A_{f}\left(\mathrm{~mm}^{2}\right)=\text { área das barras pultrudadas (Tabela 2.1) } \\
& b(\mathrm{~mm})=\text { largura da viga } \\
& d(\mathrm{~mm})=\text { altura útil da viga }
\end{aligned}
$$

Calcula-se a relação $\rho_{f} / \rho_{f b}$ tem-se então:

- No caso de ruína governada pela ruptura da barra (Figura 2.17)

$$
\phi=0,55 \text { para } \rho_{f} \leq \rho_{f b}
$$

Nesse caso, o cálculo de $M_{n}$ é dado pela equação:

$$
M_{n}=A_{f} f_{f u}\left(d-\frac{\beta_{1} c_{b}}{2}\right)
$$

Onde $c_{b}(\mathrm{~mm})$ é a distância a partir da fibra de compressão extrema até a linha neutra, para condição balanceada de deformação, onde:

$$
c_{b}=\left(\frac{\varepsilon_{c u}}{\varepsilon_{c u}+\varepsilon_{f u}}\right) d
$$

$\varepsilon_{f u}$ é obtido através da equação 2.2 .

A armadura mínima no caso exclusivo de ruína da viga devido à ruptura da barra de FRP pode ser calculada de acordo com a equação 2.25 .

$$
A_{f, \min }=4,9 \frac{\sqrt{f_{c}^{\prime}}}{f_{f u}} b_{w} d \geq \frac{330}{f_{f u}} b_{w} d
$$

-No caso de ruína governada pela condição balanceada (Figura 2.19)

$$
\phi=0,30+0,25 \frac{\rho_{f}}{\rho_{f b}} \text { para } \rho_{f b}<\rho_{f}<1,4 \rho_{f b}
$$


Nesse caso, o cálculo de $M_{n}$ é dado pela equação:

$$
M_{n}=\rho_{f} f_{f}\left(1-0,59 \frac{\rho_{f} f_{f}}{f_{c}^{\prime}}\right) b d^{2}
$$

Em que $f_{f}$ é a tensão de tração no reforço FRP, dada por :

$$
f_{f}=\left(\sqrt{\left(\left(\frac{E_{f} \varepsilon_{c u}}{2}\right)^{2}+\frac{0,85 \beta_{1} f_{c}^{\prime}}{\rho_{f}} E_{f} \varepsilon_{c u}\right)}-0,5 E_{f} \varepsilon_{c u}\right) \leq f_{f u}
$$

- No caso de ruína governada pela ruptura do concreto (Figura 2.18)

$$
\phi=0,65 \text { para } \rho_{f} \geq 1,4 \rho_{f b}
$$

Quando $\rho_{f}>\rho_{f b}$ a ruína se dá pela ruptura do concreto e a distribuição de tensões no concreto pode ser aproximada pelo diagrama retangular de tensões, conforme as Figuras 2.18 e ou 2.19 .

A Figura 2.20 mostra e relação do fator de redução de resistência com a taxa de armadura de reforço FRP

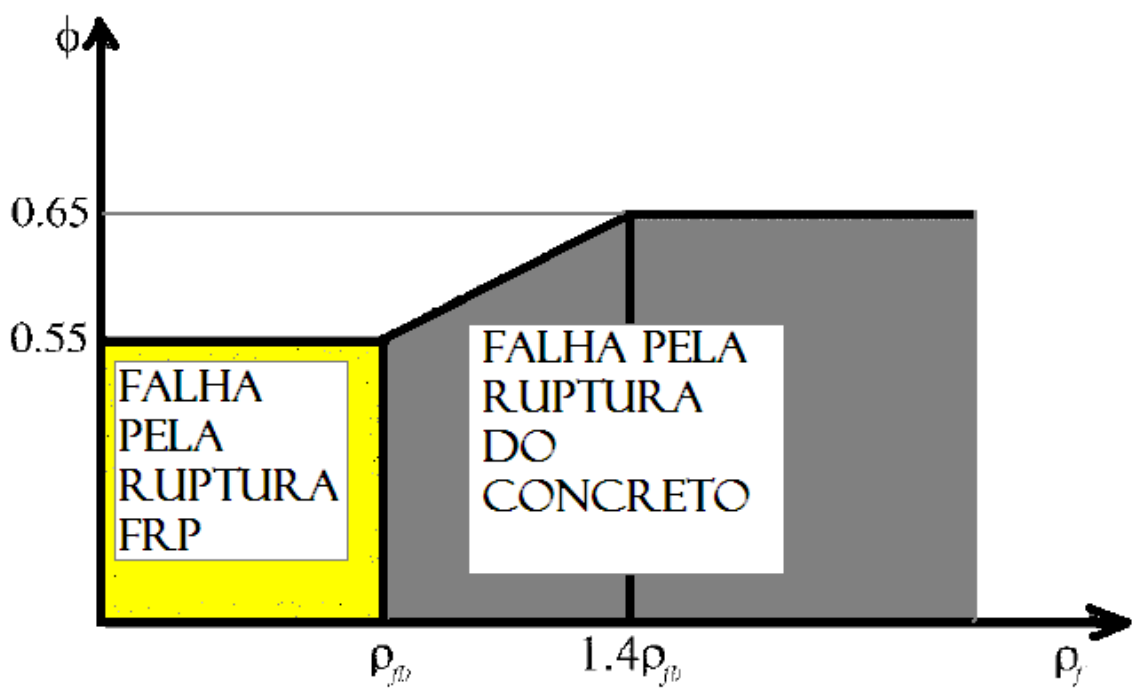

Figura 2.20 - Fator de redução de resistência em função da taxa de armadura de reforço FRP. Adaptado: ACI440.1R-06

Na Tabela 2.8 fez-se uma comparação entre barras de aço e barras de FRP. Para cada tipo de barra tem-se os respectivos valores das resistência à tração, módulo de elasticidade e taxa de armadura balanceada, para seções retangulares e $f_{c}^{\prime}=34,50 M P a$. 
Tabela 2.8 - Valores típicos da taxa de armadura balanceada para uma seção retangular com $f_{c}^{\prime}=\mathbf{3 4 , 5}$ MPa. Fonte: ACI440.1R-06

\begin{tabular}{|c|c|c|c|}
\hline $\begin{array}{c}\text { TIPO DE } \\
\text { BARRA }\end{array}$ & $\begin{array}{c}\text { RESISTÊNCIA DE } \\
\text { ESCOAMENTO OU } \\
\text { RESISTÊNCIA À } \\
\text { TRAÇÃO (MPa) }\end{array}$ & $\begin{array}{c}\text { MÓDULO DE } \\
\text { ELASTICIDADE } \\
(\text { GPa })\end{array}$ & $\rho_{\mathrm{fb}}$ \\
\hline AÇO & $\mathbf{4 1 4}$ & $\mathbf{2 0 0}$ & $\mathbf{0 , 0 3 3 5}$ \\
\hline GFRP & $\mathbf{5 5 2}$ & $\mathbf{4 1 , 4}$ & $\mathbf{0 , 0 0 7 8}$ \\
\hline AFRP & $\mathbf{1 1 7 2}$ & $\mathbf{8 2 , 7}$ & $\mathbf{0 , 0 0 3 5}$ \\
\hline CFRP & $\mathbf{2 0 7 0}$ & $\mathbf{1 5 2}$ & $\mathbf{0 , 0 0 2 0}$ \\
\hline
\end{tabular}

De acordo com o gráfico da Figura 2.21, tem-se uma comparação na flexão simples de três vigas de concreto armadas com aço convencional e com GFRP, em relação ao momento resistente e à curvatura na viga. A viga armada com aço (seção transversal 1) resiste bem em termos de curvatura até atingir o momento $M_{n}$ minorado pelo fator de redução de resistência. A partir deste momento, ocorre a ruína da viga e a curvatura dispara devido ao próprio escoamento do aço. Já as vigas armadas com GFRP (seção transversal 2 e 3) sofrem respectivamente ruptura por esmagamento do concreto e por ruptura da barra de GFRP; apesar dessas rupturas ocorrerem sem escoamento, com comportamento elástico linear e frágil, suas curvaturas são relativamente menores, quando comparadas com a viga armada com aço, para valores maiores que $\phi M_{n}$. 


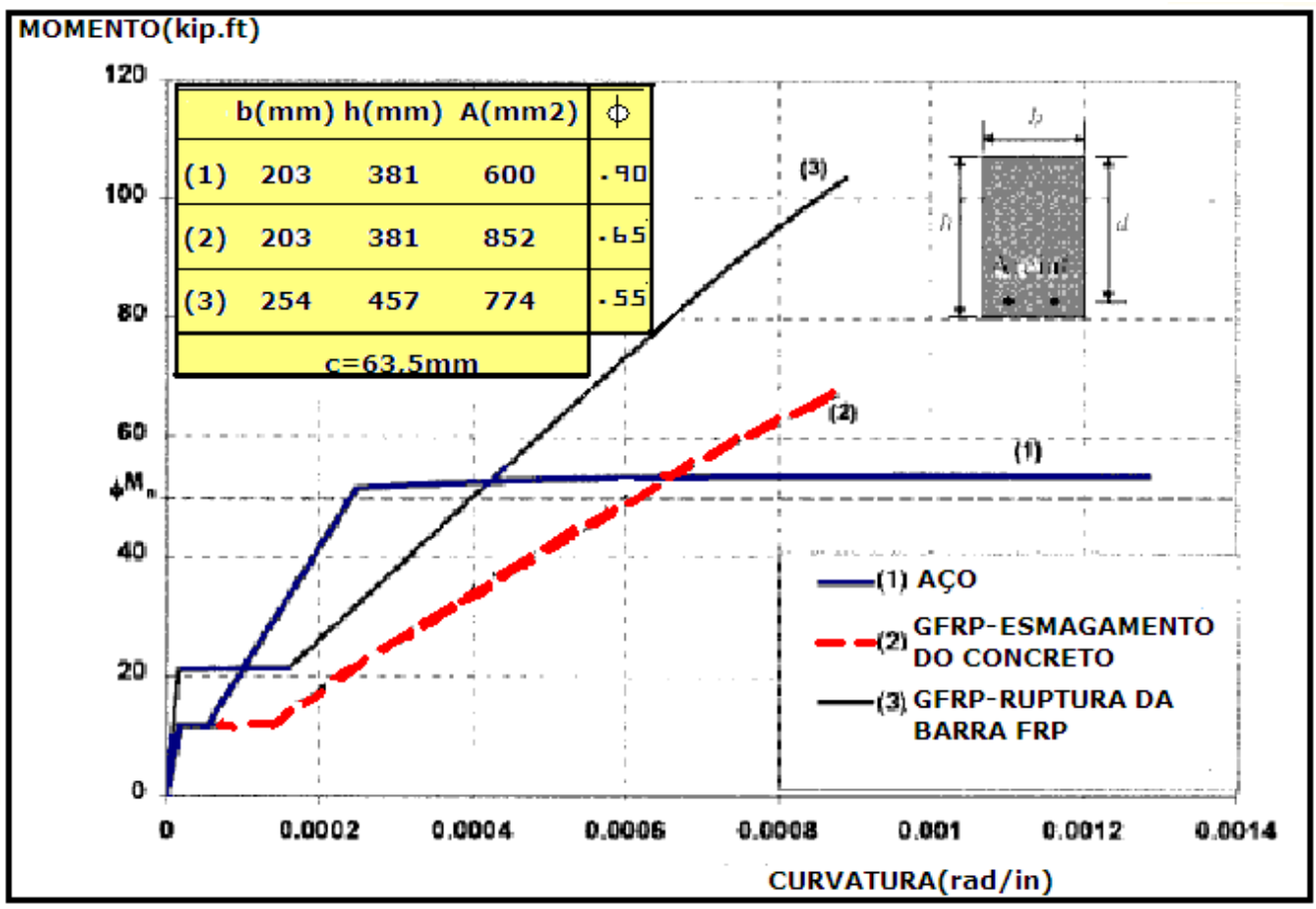

Fig.2.21- Relação teórica momento-curvatura para seções de concreto usando reforço em aço e GFRP.

Adaptado: ACI440.1R-06

\subsubsection{Considerações importantes sobre peças fletidas com FRP}

- Há a possibilidade de se ter em uma mesma seção transversal múltiplas camadas de reforço FRP (Figura 2.22) e ou combinações de diferentes tipos de FRP. Nos dois casos devem ser considerados, para efeito de cálculo, a distância do centro de gravidade da barra mais distante em relação a linha neutra e não o centro de gravidade médio de todas as barras, pois a fibra da barra mais tracionada é a mais desfavorável, porque diferentemente do aço não existe redistribuição de momento fletor nas barras FRP (não existe patamar de escoamento ou plastificação). As barras mais distantes da linha neutra sofrerão ruptura frágil antes das barras mais próximas da linha neutra. No caso de vários tipos diferentes de reforço FRP também deve ser verificada a compatibilidade das deformações, visto que são barras compostas por materiais distintos. 


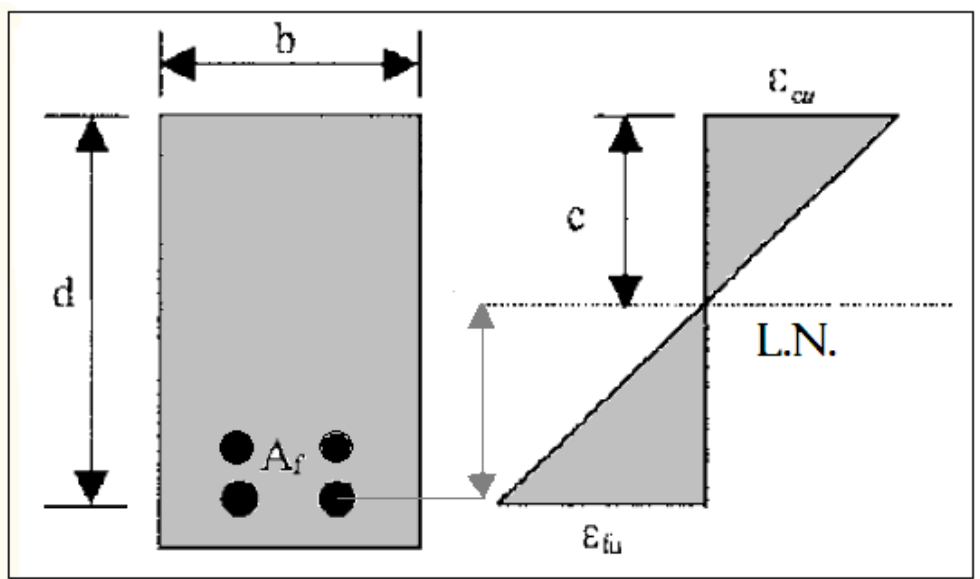

Figura 2.22 - Situação com mais de uma camada de reforço FRP. Adaptado: ACI440.1R-06

As armaduras em FRP de reforço longitudinal de compressão em vigas ("portaestribos"), principalmente em regiões de alta agressividade ambiental, podem ser utilizadas desde que haja confinamento das barras, visto que sua resistência à compressão é bem inferior quando comparada com a resistência à tração.

De acordo com a Figura 2.23, Nehdi et.al (2008) propuseram um novo modelo de testes para vigas de concreto com vão reduzido, reforçadas em FRP, onde a distância de cisalhamento $(a)$ deve estar no intervalo $\left(1,5<\frac{a}{d}<2,5\right)$, a capacidade última de carga de teste também é avaliada, utiliza-se o modelo proposto e investigam-se vários parâmetros comparando-se sua eficiência com outros modelos de projeto.

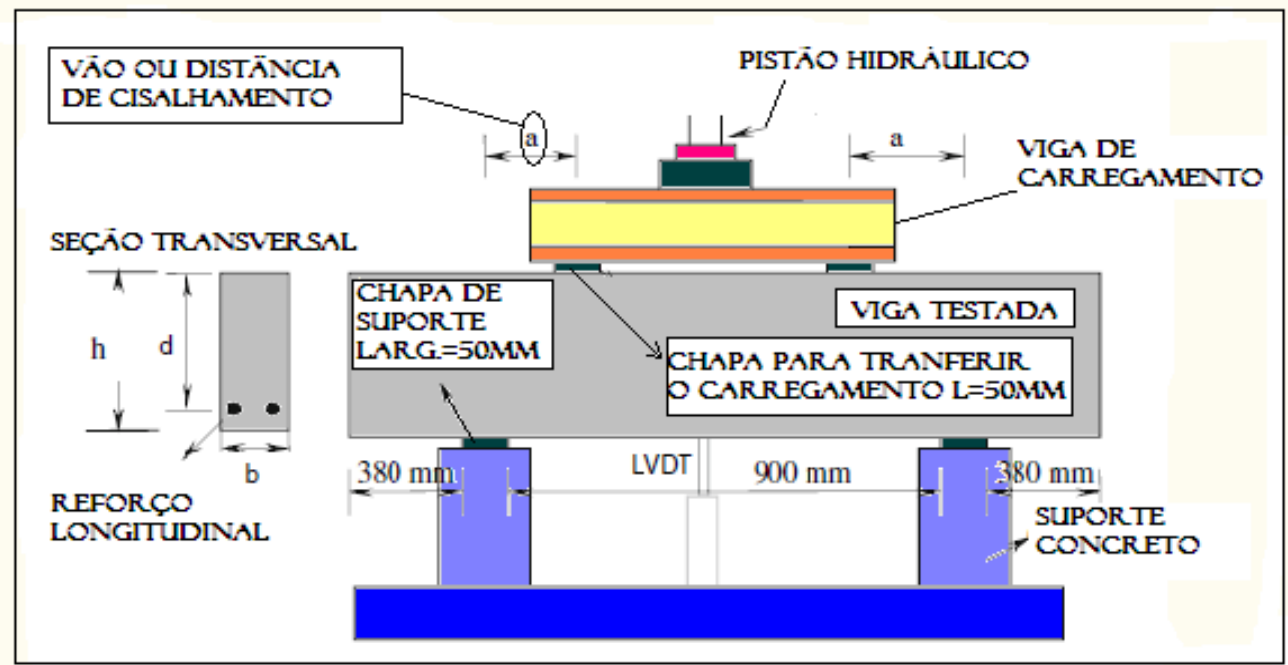

Figura 2.23 - Modelo proposto otimizado para viga com vão reduzido reforçada em FRP. Adaptado: Nehdi, M. et al. (2008) 
- Muruts e Nad (1998) estudaram barras laminadas de GFRP em concreto estrutural, com apresentação de modelos para resistência à tração e módulo de elasticidade das barras de GFRP, considerando o volume da fibra, da matriz e do compósito (conjunto) e suas respectivas deformações. Apresentaram formas de instrumentação para ensaios de arrancamento (pull-out tests) para analisar principalmente a resistência de aderência entre o concreto e a barra de GFRP.

- Um parâmetro importante para o incremento da resistência à tração entre as barras de FRP e os elementos de concreto é a aderência entre os dois, que depende muito da conformação física externa das barras, do tipo de adensamento do concreto, ou seja, sua resistência característica à compressão na região próxima às barras, cobrimento livre das barras, espaçamento das barras longitudinais, tamanho das barras e reforço transversal.

A Figura 2.24 mostra os tipos e métodos de ensaios de aderência entre barras de FRP e elementos de concreto.

- Método de arrancamento (Pull-out), item (a) da Figura 2.24, consiste em puxar ou arrancar literalmente a barra de FRP de dentro do concreto, sendo que o elemento encontra-se totalmente apoiado, testando dessa forma a sua aderência.

- Método de arrancamento indireto (Beam-end), item (b) da Figura 2.24, tem como finalidade também testar a aderência da barra de FRP que, associando os efeitos do braço alavanca e o peso parcial da viga, resultam em esforços de tração atuando na barra de FRP.

- Método da viga biapoiada ou flexão pura (Beam Anchorage), item (c) da Figura 2.24, que pode ser feito com barras ancoradas ou não, testando dessa forma a aderência na zona tracionada do concreto com as barras de FRP.

-Método da armadura com transpasse das barras na zona tracionada no centro do vão, onde atuam somente esforços de flexão pura (Splice), item (d) da Figura 2.24, também uma viga biapoiada com transpasse das barras de FRP na flexão pura, onde atuam esforços de tração nas barras de FRP e no concreto. 


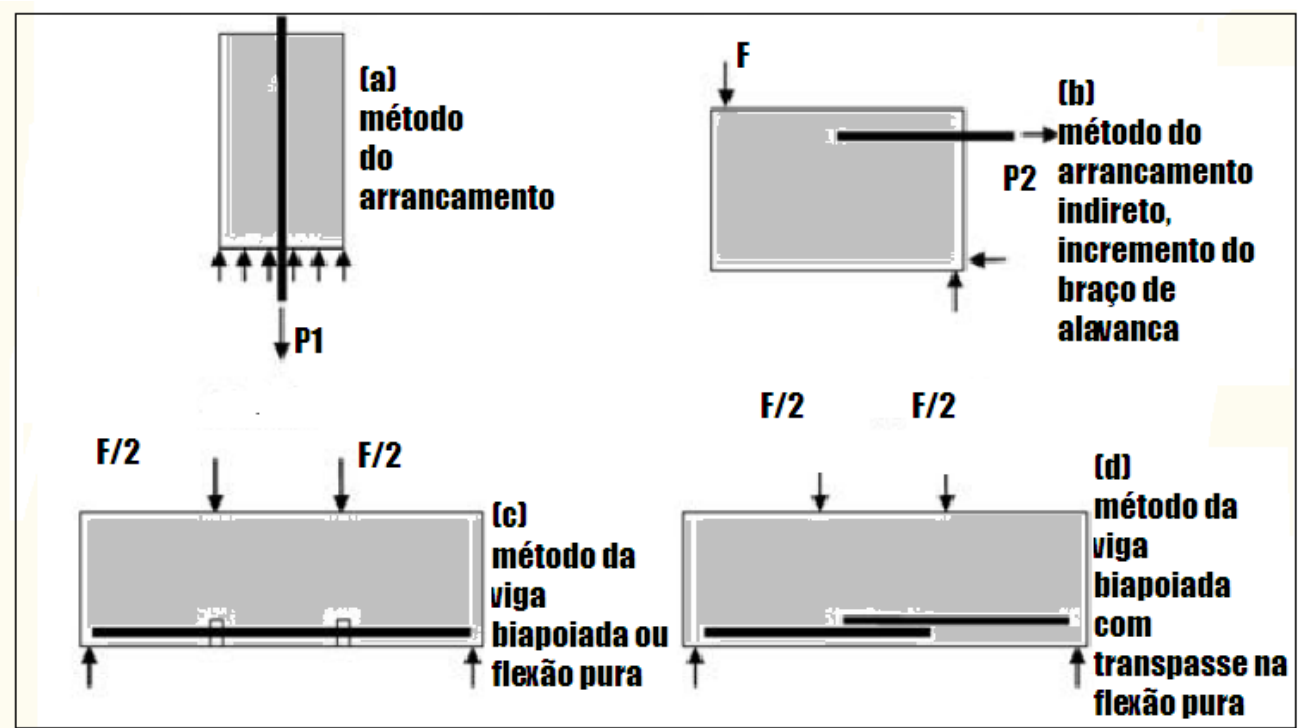

Figura 2.24 - Tipos de métodos de ensaio para testes de aderência entre barras de FRP e o concreto.

Adaptado: Fico (2007)

O ACI Structural Journal (2003) apresentou modelos de análise computacional em elementos finitos do comportamento de vigas de concreto com reforço interno hiperestático de FRP, suas deformações, características de carregamento, deslocamentos e modelos de ruptura (Figura 2.25).

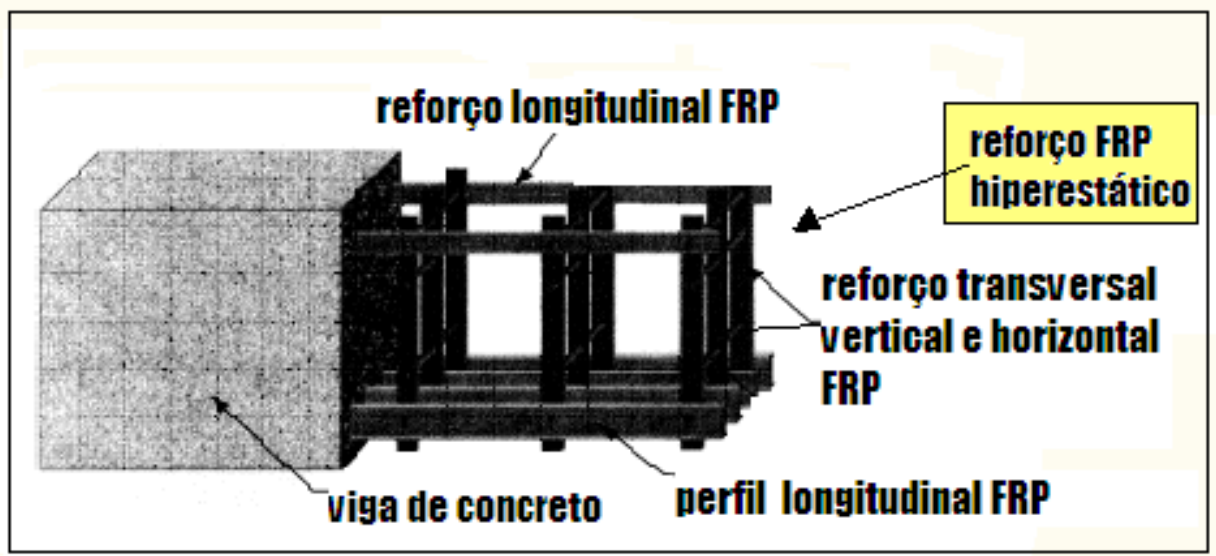

Figura 2.25 - Reforço interno hiperestático em FRP em vigas de concreto. Adaptado: ACI Structural Journal (2003)

Os objetivos da análise desses modelos foram de: 
- Investigar através de elementos finitos o comportamento de vigas de concreto curtas, médias e longas, armadas com estrutura espacial hiperestática em FRP, incluindo as características de carregamento e deslocamentos na ruptura;

- Avaliar os efeitos do cisalhamento em relação ao ponto de aplicação da carga (Figura 2.26) nos modelos de ruptura e estudar o estado de tensões da peça armada com reforço hiperestático na flexão;

-Desenvolver um procedimento alternativo para análise de vigas de concreto com reforço hiperestático em FRP, considerando múltiplos modelos de ruptura.

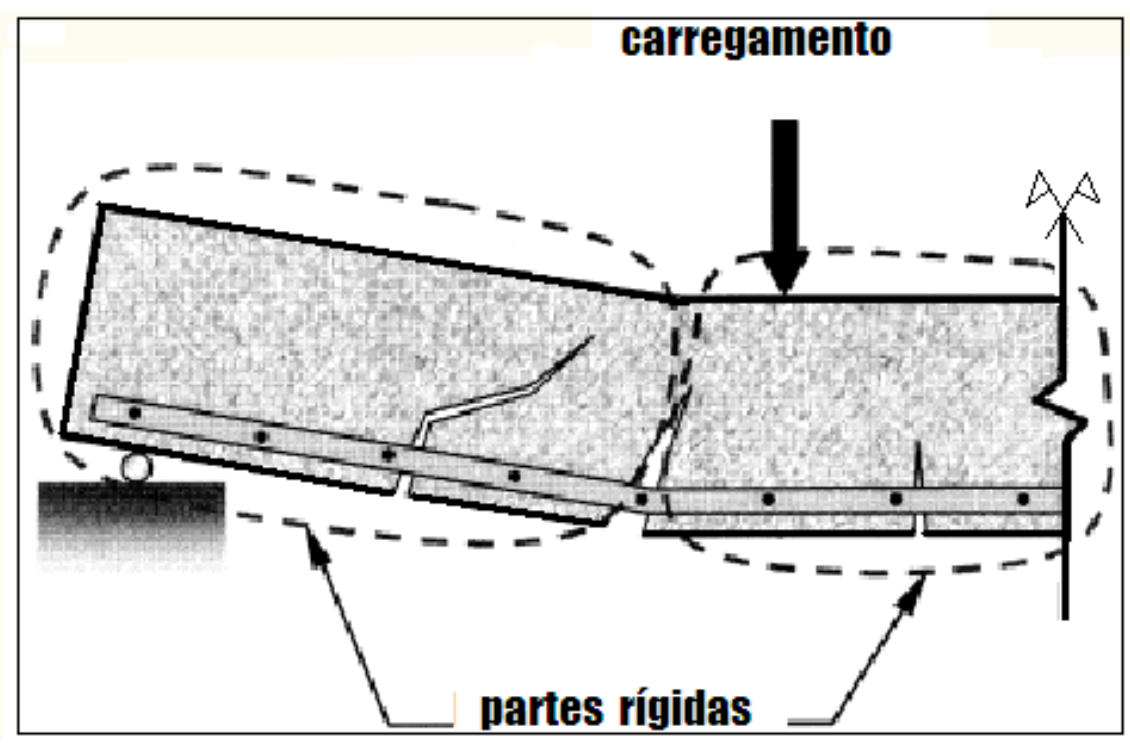

Figura 2.26 - Deformação e rotação das partes rígidas da viga. Adaptado: ACI Structural Journal (2003)

Os resultados obtidos nos modelos experimentais em elementos finitos são mostrados na Tabela 2.9. 
Tabela 2.9 - Resumo dos resultados dos experimentos em elementos finitos.

Adaptado: ACI Structural Journal (2003)

\begin{tabular}{|c|c|c|c|c|c||}
\hline \multirow{2}{*}{ VIGAS } & \multicolumn{2}{|c|}{ Total da capacidade de carga (KN) } & \multicolumn{2}{|c|}{$\begin{array}{c}\text { Força de tração em cada } \\
\text { barra principal (KN) }\end{array}$} \\
\cline { 2 - 6 } & $\begin{array}{r}\text { Experimen } \\
\text { tal }\end{array}$ & $\begin{array}{r}\text { Análise - } \\
\text { Flexão }\end{array}$ & $\begin{array}{c}\text { Análise em } \\
\text { elementos } \\
\text { finitos }\end{array}$ & $\begin{array}{c}\text { Análise- } \\
\text { Flexão }\end{array}$ & $\begin{array}{c}\text { Análise em } \\
\text { elementos } \\
\text { finitos }\end{array}$ \\
\hline CURTAS & 215.70 & 196,20 & 215,30 & 90,70 & 51,60 \\
\hline MÉDIAS & 143,20 & 130.80 & 161,90 & 90,70 & 76,50 \\
\hline LONGAS & 108,10 & 97,90 & 113,00 & 90,70 & 76,50 \\
\hline \hline
\end{tabular}

\subsection{Estados limites de serviço para vigas de concreto}

Define-se por momento de fissuração ao momento calculado quando as estruturas trabalham com seções ainda não fissuradas, no estádio 1, na iminência de mudança para o

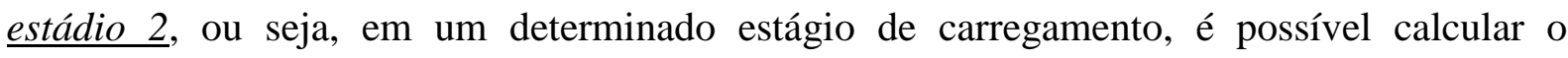
momento de fissuração pois as seções após este estágio estão fissuradas, fazendo com que o concreto não resista mais à tração, sendo que sua contribuição passa a ser desprezada.

Dessa forma tem-se então o momento de fissuração dado por:

$$
M_{r}=\alpha \frac{f_{c t} I_{c}}{y_{t}}
$$

Em que: $f_{c t}(M P a)=$ resistência do concreto à tração direta

De acordo com a ABNT NBR 6118:2003, tem-se:

•Na formação de fissuras:

$$
f_{c t}=f_{c t k, \mathrm{inf}}=0,21 f_{c k}^{2 / 3}
$$

•Na deformação excessiva:

$$
f_{c t}=f_{c t m}=0,30 f_{c k}^{2 / 3}
$$




$$
I_{c}=\frac{b h^{3}}{12} \text { é o momento de inércia da seção bruta }
$$

$y_{t}=$ distância do centro de gravidade da seção à fibra mais tracionada

$\alpha=1,50$ para seções retangulares

- Se o momento fletor solicitante correspondente a combinação rara de serviço for maior que momento resistente de fissuração, então há fissuras, ou seja:

$$
M_{d, \text { rara }}>M_{r} \text { (Há fissuras) }
$$

\subsubsection{Estados limites de serviço para vigas armadas com aço}

Como a seção transversal é composta por concreto e aço, que são dois materiais com características diferentes, é necessário homogeneizar a seção transversal, substituindo a área de aço por uma área correspondente de concreto.

- No estádio 1 , onde o concreto resiste à tração, o momento de inércia é dado pela equação 2.35, onde:

$$
I_{1}=\frac{b h^{3}}{12}+b h\left(x_{1}-\frac{h}{2}\right)^{2}+\left(\alpha_{e}-1\right) A_{s}\left(d-x_{1}\right)^{2}
$$

Em que: $b(\mathrm{~mm})=$ largura da seção transversal da viga;

$$
\begin{aligned}
& h(m m)=\text { altura da seção transversal da viga; } \\
& d(m m)=\text { altura útil da seção transversal da viga; } \\
& A_{s}\left(\mathrm{~mm}^{2}\right)=\text { área da seção transversal da armadura longitudinal de tração; } \\
& x_{1}(\mathrm{~mm})=\text { distância da fibra mais comprimida do concreto até a linha neutra, }
\end{aligned}
$$

onde:

$$
\begin{gathered}
x_{1}=\frac{\frac{b h^{2}}{2}+\left(\alpha_{e}-1\right) A_{s} d}{b h+\left(\alpha_{e}-1\right) A_{s}} \\
\alpha_{e}=\frac{E_{s}}{E_{c s}}
\end{gathered}
$$

Em que: $E_{s}=210 \mathrm{GPa}$ é o módulo de elasticidade do aço; 
$E_{c s}$ é o módulo de elasticidade do concreto dado pelas equações 2.7 e 2.6 respectivamente.

- No estádio 2, o concreto tracionado já está fissurado e portanto ele é desprezado no cálculo, onde:

$$
I_{2}=\frac{b x_{2}^{3}}{3}+\alpha_{e} A_{s}\left(d-x_{2}\right)^{2}
$$

Em que: $x_{2}(\mathrm{~mm})=$ distância da fibra mais comprimida do concreto até a linha neutra desprezando-se o concreto tracionado abaixo da linha neutra, onde:

$$
\frac{b}{2} x_{2}^{2}+\alpha_{e} A_{s} x_{2}-\alpha_{e} A_{s} d=0
$$

- Na verificação das deformações de uma estrutura deve-se considerar combinação quase permanente de ações e rigidez efetiva das seções.

- Para o cálculo da flecha imediata admite-se comportamento elástico linear e o momento de inércia é calculado segundo a NBR 6118:2003 pela equação 2.40.

$$
I=I_{e q}=\left(\frac{M_{r}}{M_{a}}\right)^{3} I_{c}+\left[1-\left(\frac{M_{r}}{M_{a}}\right)^{3}\right] I_{2}
$$

Em que: $M_{r}(k N m)=$ momento de fissuração;

$$
M_{a}(k N m)=\text { momento fletor na seção crítica, para combinação quase }
$$

permanente.

- Para o cálculo da flecha adicional diferida decorrente de cargas de longa duração em função da fluência, multiplica-se a flecha imediata por um fator dado pela NBR 6118:2003 segundo a equação 2.41 .

$$
\alpha_{f}=\frac{\Delta \xi}{1+50 \rho}
$$

Onde $\rho$ ' é a taxa de armadura de compressão (armadura dupla) dada por:

$$
\rho^{\prime}=\frac{A_{s}^{\prime}}{b d}
$$

Para $\rho^{\prime}=0$ tem-se armadura simples 
$\Delta \xi=\xi(t)-\xi\left(t_{0}\right)$ é a variação de um coeficiente em função do tempo em meses para flecha diferida; $\xi(t)$ é o valor do coeficiente em meses de quando se deseja o valor da flecha diferida e $\xi\left(t_{0}\right)$ é o valor do coeficiente em meses da data de aplicação da carga de longa duração, podendo ser obtido na Tabela 2.10 .

Tabela 2.10 - Valores do coeficiente $\xi$ em função do tempo. Fonte: ABNT NBR 6118:2003

\begin{tabular}{|c|c|c|c|c|c|c|}
\hline \hline TEMPO $(\mathrm{t})$ & 0 & 0,50 & 1 & 2 & 3 & 4 \\
\hline COEF. $\xi(t)$ & 0 & 0,54 & 0,68 & 0,84 & 0,95 & 1,04 \\
\hline TEMPO $(\mathrm{t})$ & 5 & 10 & 20 & 40 & $\geq 70$ & \\
\hline COEF. $\xi(t)$ & 1,12 & 1,36 & 1,64 & 1,89 & 2,00 & \\
\hline \hline
\end{tabular}

Obtém-se então o valor da flecha adicional diferida:

$$
a_{f}=\alpha_{f} a_{i}
$$

A flecha total é a soma da flecha imediata com a flecha adicional diferida:

$$
a_{t}=a_{i}\left(1+\alpha_{f}\right)
$$

O limite de deslocamento para a viga de concreto da Figura 2.11 armada com aço segundo a NBR 6118:2003 é de $a_{\lim }=\frac{l(m m)}{250}$,então:

$$
a_{t} \leq a_{\lim }=\frac{l}{250}
$$

Abertura de fissuras: O valor da abertura das fissuras pode sofrer influência de restrições às variações volumétricas da estrutura; além disso, essa abertura sofre também influência das condições de execução da estrutura.

Para cada elemento ou grupo de elementos das armaduras passiva e ativa aderente (excluindo-se os cabos protendidos que estejam dentro das bainhas), que controlam a fissuração do elemento estrutural, deve ser considerada uma área $\left(A_{c r i}\right)$ do concreto de 
envolvimento, constituída por um retângulo cujos lados não distam mais de $7,5 \phi$ do eixo da barra da armadura (Figura 2.27).

$\mathrm{Na}$ abertura de fissuras deve ser considerada a combinação frequente de ações. Segundo a NBR 6118:2003 a abertura de fissuras é o menor entre os dois valores:

$$
\begin{gathered}
w \leq w_{1}=\frac{\phi_{i} \sigma_{s i} 3 \sigma_{s i}}{12,5 \eta_{i} E_{s i} f_{c t m}} \\
w \leq w_{2}=\frac{\phi_{i} \sigma_{s i}}{12,5 \eta_{i} E_{s i}}\left[\frac{4}{\rho_{r i}}+45\right]
\end{gathered}
$$

Onde:

$\sigma_{s i}, \phi_{i}, E_{s i}, \rho_{r i}$ são definidos para cada área de envolvimento em exame;

$A_{c r i}$ é a área da região de envolvimento protegida pela barra $\phi_{i}$;

$E_{s i}$ é o módulo de elasticidade do aço da barra considerada, de diâmetro $\phi_{i}$;

$\phi_{i}$ é o diâmetro da barra que protege a região de envolvimento considerada;

$\rho_{r i}$ é a taxa de armadura passiva ou ativa aderente (que não esteja dentro da bainha) em relação a área da região de envolvimento $\left(A_{c r i}\right)$;

$\sigma_{s i}$ é a tensão de tração no centro de gravidade da armadura considerada, calculada no estádio 2.

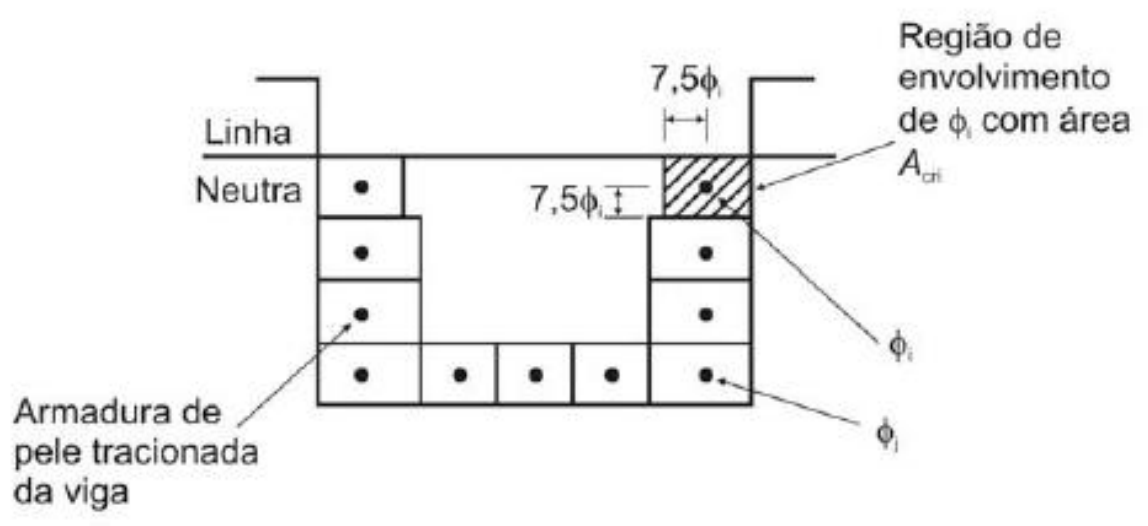

Figura 2.27 - Concreto de envolvimento da armadura. Fonte: ABNT NBR 6118:2003

- Pode-se calcular pela norma o valor de $\sigma_{s i}$ de forma refinada ou aproximada, respectivamente, conforme as equações: 
- No estádio 2 após calcular $x_{2}$ e $I_{2}$ e adotando $\alpha_{e}=15$ tem-se:

$$
\sigma_{s}=\frac{\alpha_{e} M_{d, \text { freq }}\left(d-x_{2}\right)}{I_{2}}
$$

- Adotando-se como braço de alavanca, ou seja, a distância da resultante de compressão do concreto até a resultante de tração da armadura longitudinal, o valor de igual a $0,8 d$ tem-se então:

$$
\sigma_{s}=\frac{M_{d, f r e q}}{0,8 d A_{s}}
$$

O valor limite, em função da classe de agressividade ambiental, da abertura máxima característica de fissuras $\left(w_{k}\right)$ se encontra na Tabela 2.11.

Tabela 2.11 - Exigências de durabilidade relacionadas à fissuração e à proteção da armadura, em

\begin{tabular}{|c|c|c|c|}
\hline $\begin{array}{l}\text { Tipo de } \\
\text { concreto } \\
\text { estrutural }\end{array}$ & $\begin{array}{c}\text { Classe de } \\
\text { agressividade } \\
\text { ambiental(CAA) }\end{array}$ & $\begin{array}{c}\text { Exigências relativas à } \\
\text { fissuração }\end{array}$ & $\begin{array}{l}\text { Combinações de } \\
\text { ações em serviço a } \\
\text { utilizar }\end{array}$ \\
\hline $\begin{array}{l}\text { Concreto } \\
\text { simples }\end{array}$ & $\begin{array}{c}\text { CAA- I à CAA- } \\
\text { IV }\end{array}$ & Não há & -- \\
\hline \multirow{3}{*}{$\begin{array}{l}\text { Concreto } \\
\text { armado }\end{array}$} & CAA- I & ELS-W wk $\leq 0,4 \mathrm{~mm}$ & \multirow{3}{*}{$\begin{array}{l}\text { Combinação } \\
\text { freqüente }\end{array}$} \\
\hline & $\begin{array}{c}\text { CAA-II e CAA- } \\
\text { III }\end{array}$ & ELS-W wk $\leq 0,3 \mathrm{~mm}$ & \\
\hline & CAA-IV & ELS-W wk $\leq 0,2 \mathrm{~mm}$ & \\
\hline
\end{tabular}
função das classes de agressividade ambiental. Fonte: ABNT NBR 6118:2003

\subsubsection{Estados limites de serviço para vigas armadas com FRP}

Os estados limites de serviço para elementos estruturais de concreto armados com FRP segundo o ACI são:

Controle de fissurações: 
A largura excessiva de fissuras é indesejável por razões estéticas ou para evitar fuga d'água que pode danificar ou deteriorar o concreto estrutural.

As barras de reforço FRP têm pequena rigidez após a fissuração, consequentemente deslocamentos admissíveis sob carregamento de serviço podem controlar o projeto. Em geral seções transversais projetadas com armadura de reforço em FRP, para ruína por esmagamento do concreto, satisfazem os critérios de limite de serviço para deslocamento e fissuração.

A limitação de serviço prevista no ACI 318-05 para o aço deve ser modificado para barras de FRP, pois a substituição de uma determinada área de aço pela mesma área em FRP resulta normalmente em deslocamentos e abertura de fissuras maiores, devido à menor rigidez das barras de FRP (Gao et al. 1998).

As barras de FRP são resistentes à corrosão e portanto a limitação da abertura máxima das fissuras pode ser desconsiderada quando a corrosão da armadura é o principal motivo para verificação do estado limite de serviço. Entretanto deve ser verificado em casos onde a estética do elemento estrutural é um fator importante e também para efeitos de cisalhamento.

A Sociedade Japonesa de Engenheiros Civis (JSCE-1997) somente considera a estética no estado limite de serviço, sendo a abertura máxima de fissuras igual a $0,5 \mathrm{~mm}$.

A Associação de Normas Canadense (CAN/CSA-S806-02) estabelece que para obras expostas em ambientes externos, a máxima abertura de fissuras é de 0,5mm, e para obras expostas em ambientes internos, a abertura máxima é de 0,7 mm.

O ACI 318-05 para o aço não se refere a reforços com FRP, entretanto, para efeitos de comparação, utiliza-se o controle de abertura de fissuras do reforço com aço que corresponde a aproximadamente 0,4 mm como limite máximo. O ACI 318-05 utiliza uma equação para controle de fissuras independente do tipo de reforço (aço ou FRP) com base em modelos físicos e não empíricos. Essa formulação considera entre outras variáveis o espaçamento das barras longitudinais principais e utiliza um coeficiente de aderência entre o reforço e o concreto, dada por:

$$
w=2 \frac{f_{f}}{E_{f}} \beta k_{b} \sqrt{\left(\left(d_{c}^{2}\right)+\left(\frac{s}{2}\right)^{2}\right)}
$$

Onde:

$s(m m)$ é o espaçamento das barras longitudinais principais; 
$d_{c}(m m)$ é a distância da fibra mais tracionada do concreto até o centro da barra de reforço;

$k_{b}$ é o coeficiente de aderência entre o reforço e o concreto;

$\beta$ é a razão entre a distância da linha neutra da seção transversal até a fibra tracionada extrema e a distância da linha neutra até o centro da barra tracionada. Para elementos de concreto reforçados com barras de aço, $\beta$ pode ser escrito da seguinte forma (Frosch,1999):

$$
\beta=1+0,0031 d_{c}
$$

O coeficiente de aderência entre o concreto e a barra varia de acordo com o tipo de reforço. Para barras de FRP com comportamento de aderência similar ao das barras de aço; tem-se $k_{b}=1$. Para barras de FRP com comportamento de aderência superior ao das barras de aço; tem-se $k_{b}<1$. Finalmente para barras de FRP com comportamento de aderência inferior ao das barras de aço; tem-se $k_{b}>1$. Gao et al. (1998) introduziram uma fórmula baseada em testes e resultados que indicaram que as características do vínculo das barras de GFRP podem variar em relação as barras de aço.

Segundo Bakis e Boothby (2004), para obras em ambientes internos pode ser incrementado $40 \%$ no coeficiente de aderência em barras de GFRP, e para ambientes externos, de $60 \%$. Em um período de 3 anos, em geral, para barras de FRP $k_{b}$ varia de 0,60 a 1,72, com um valor médio de 1,10 .

Em consenso, quando o coeficiente de aderência não é conhecido a partir de dados experimentais, adota-se $k_{b}=1,4$.

-Bakis e Ospina (2006) propuseram um modelo alternativo para controle de fissuras na flexão para elementos reforçados com FRP. O procedimento foi proposto devido às dificuldades práticas associadas na medição direta da fissuração, por conta da alta variabilidade do concreto fissurado. O modelo proposto tem aplicações em vigas prémoldadas de concreto e lajes e pode ser considerado como uma simplificação do ACI 440.1R06, e não como uma modificação. $\mathrm{O}$ objetivo principal é propor um controle de fissuração para barras de FRP em vigas de concreto em que o espaçamento máximo das barras longitudinais é fixado, no lugar do cálculo direto da abertura das fissuras. 
A equação de controle de fissuras aplicada a barras de aço proposta pelo ACI 318M-05 está diretamente ligada ao espaçamento entre barras e é definida por:

$$
s=380\left(\frac{280}{f_{s}}\right)-2,5 c_{c} \leq 300\left(\frac{280}{f_{s}}\right)
$$

Onde:

$s(m m)$ é o espaçamento entre as barras de aço longitudinais;

$f_{s}(M P a)$ é a tensão em serviço na barra de aço;

$c_{c}$ é o cobrimento livre entre o concreto e a armadura.

Embora o ACI 318M-05 não ligue explicitamente a equação 2.52 a uma abertura particular de fissuras, Frosch (1999) mostrou que a equação está relacionada a uma abertura que varia de $0,44 \mathrm{~mm}$ a $0,58 \mathrm{~mm}$. Então o espaçamento máximo entre barras é dado por:

$$
s=2 \sqrt{\left[\left(\frac{w E_{r}}{2 f_{r} \beta k_{b}}\right)^{2}-d_{c}^{2}\right]}
$$

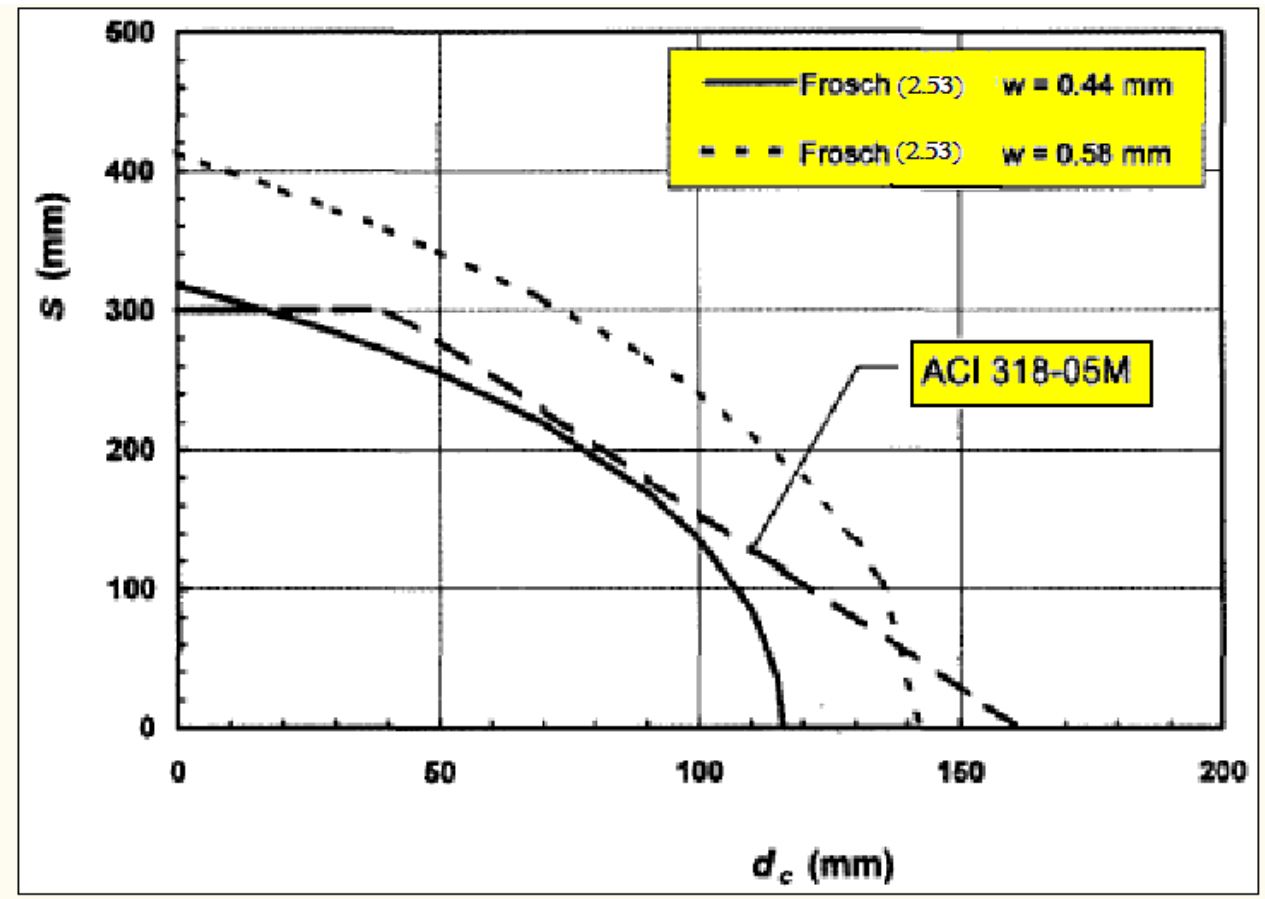

Figura 2.28 - Previsão de controle de fissuras da equação 2.52 segundo Frosch (1999). Adaptado: ACI 318M-05 
O ACI 440.1R-06 adota os limites de fissuração do Canadian High Bridge Design Code (2000), ou seja, faz a comparação diretamente pela largura máxima (equação 2.50) com a largura limite de $0,5 \mathrm{~mm}$ para condições de exposição exterior, e $0,7 \mathrm{~mm}$ para condições de exposição interior.

O objetivo a que se referem Bakis e Ospina (2006) é de manter o formato da equação 2.52 incluindo as variáveis dominantes identificadas pelo ACI 318M-05 juntamente com as propriedades relevantes das armadura em FRP, que influenciam na fissuração do elemento de concreto armado.

Utilizando a equação 2.52 como um ponto de partida, o espaçamento máximo entre barras longitudinais de FRP pode ser expresso da seguinte forma:

$$
s=380\left(\frac{280}{f_{r}}\right)\left(\frac{E_{r}}{200.000}\right)\left(\frac{w}{0,44}\right) \frac{1}{k_{b}}-2,5 c_{c} \leq 300\left(\frac{280}{f_{r}}\right)\left(\frac{E_{r}}{200.000}\right)\left(\frac{w}{0,44}\right) \frac{1}{k_{b}}
$$

Onde: $f_{r}(M P a)$ é o tensão de tração das barras de reforço FRP;

$E_{r}(M P a)$ é o módulo de elasticidade padronizado para barras de FRP, igual a

$200 \mathrm{GPa}$;

$w(m m)$ é a fissura máxima que foi padronizada em 0,44 mm;

$s(m m)$ é o espaçamento máximo a ser calculado.

Chega-se então à equação:

$$
s=1,2 \frac{E_{r} w}{f_{r} k_{b}}-2,5 c_{c} \leq 0,95 \frac{E_{r} w}{f_{r} k_{b}}
$$

Substituindo $w=0,7 \mathrm{~mm}$ e simplificando tem-se:

$$
s=0,8 \frac{E_{r}}{f_{r} k_{b}}-2,5 c_{c} \leq 0,7 \frac{E_{r}}{f_{r} k_{b}}
$$

A Figura 2.29 mostra, segundo Frosch (1999), o comportamento dos espaçamentos das barras longitudinais em relação ao cobrimento da armadura, sendo que, para a equação 2.53, existem três curvas fixadas com mesma abertura de fissuras $w=0,7 \mathrm{~mm}$. Uma delas é referente às barras de aço, as outras duas são de reforço em GFRP, com variação na distância da altura útil da seção transversal $(d)$, alterando dessa forma o valor de $\beta$, adotando-se 
$E_{r}=40 G P a, f_{r}=80 M P a$ e $k_{b}=1,4$. A quarta curva é relativa também às barras de reforço em GFRP, só que com abertura de fissuras $w=0,91 \mathrm{~mm}$. E por último, a curva proposta por Bakis e Ospina (2006), que é referente a equação 2.55, fornecendo uma representação razoável para o controle de fissuras devido à fixação do espaçamento entre barras de reforço GFRP.

No modelo proposto de Bakis e Ospina (2006) foi utilizada também uma aproximação para o parâmetro $\beta$, a equação 2.57 , na qual pode ser adotado $k=0,3$ :

$$
\beta=1+\frac{d_{c}}{d(1-k)}
$$

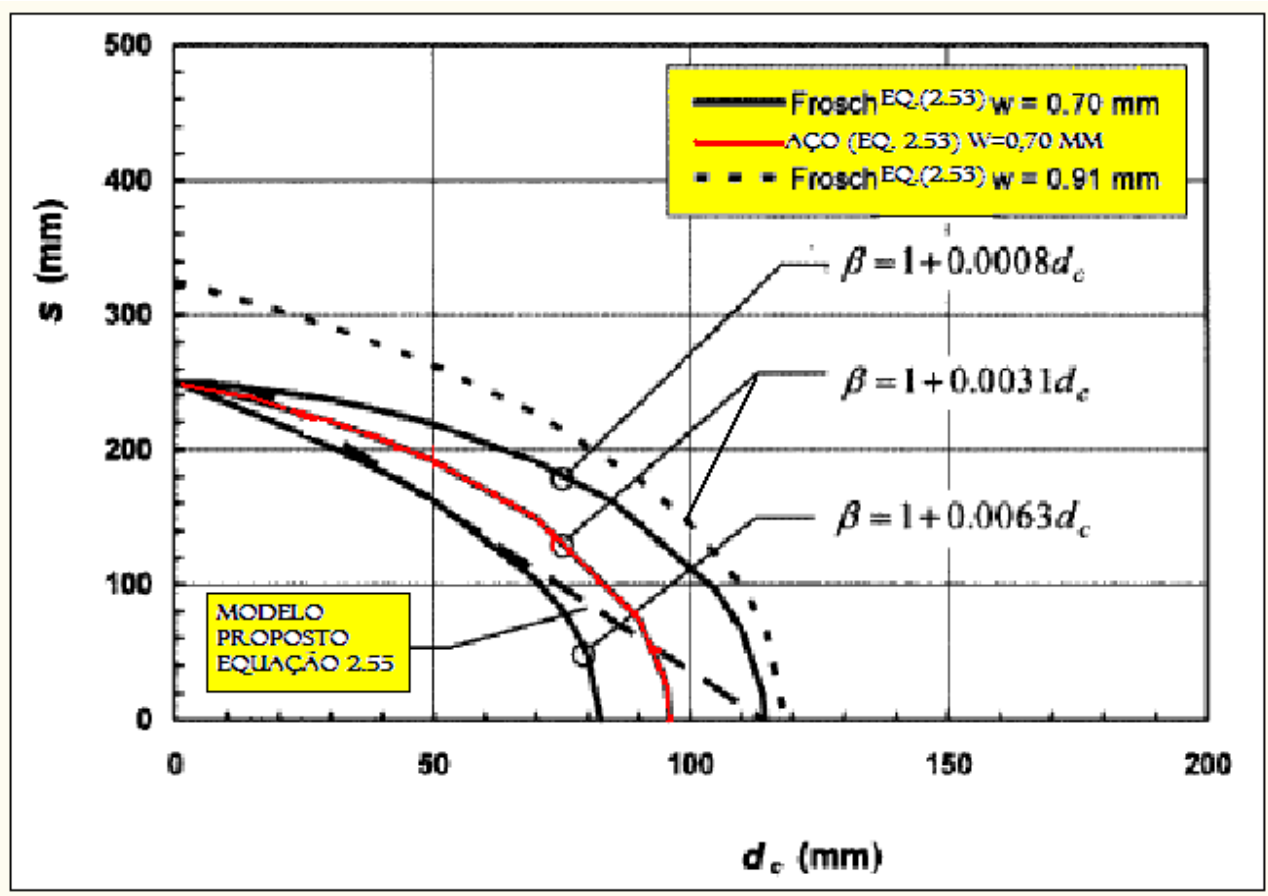

Figura 2.29 - Modelo proposto para controle de fissuras para o reforço GFRP em elementos de concreto. Adaptado: Bakis e Ospina (2006)

\section{Controle de deslocamentos:}

Os deslocamentos devem estar dentro de limites aceitáveis impostos pela utilização da estrutura. De acordo com o ACI 318-05, dois métodos são atualmente disponíveis para o controle de deslocamentos, o método direto e o indireto.

-Recomenda-se para projeto a altura mínina de viga de concreto dada pela Tabela 2.12. Os valores da tabela são baseados na equação 2.58 (Ospina et al. 2001). 
Tabela 2.12 - Altura mínima recomendada de viga. Adaptado: ACI 440.1R-06

\begin{tabular}{|c|c|c|c|c|}
\hline \hline & \multicolumn{4}{|c|}{ Altura mínima $=\mathrm{h}(\mathrm{mm})$} \\
\cline { 2 - 5 } & Biapoiada & $\begin{array}{c}\text { Um lado } \\
\text { contínuo }\end{array}$ & $\begin{array}{c}\text { Os dois lados } \\
\text { contínuos }\end{array}$ & Balanço \\
\hline Vigas & $1 / 10$ & $1 / 12$ & $1 / 16$ & $1 / 4$ \\
\hline $\mathrm{k}_{1}$ & 1,00 & 0,80 & 0,60 & 2,4 \\
\hline
\end{tabular}

$$
\frac{l}{h}=\frac{48 \eta}{5 k_{1}}\left(\frac{1-k}{\varepsilon_{f}}\right)\left(\frac{\Delta}{l}\right)_{\text {máx }}
$$

Onde: $\eta=\frac{d}{h}$;

$k_{1}$ é o parâmetro de cálculo devido às condições de contorno dadas pela Tabela 2.12;

$\left(\frac{\Delta}{l}\right)_{\text {máx }}$ é o limite de deslocamento para o carregamento de serviço.

$\varepsilon_{f}$ é a deformação no reforço FRP sob carregamento de serviço;

$k$ é definido pela equação 2.59 .

$$
\kappa=\sqrt{\left(2 \rho_{f} n_{f}+\left(\rho_{f} n_{f}\right)^{2}\right)}-\rho_{f} n_{f}
$$

Para a verificação do deslocamento da viga a longo prazo tem-se que calcular o momento de inércia bruto da seção transversal $I_{g}$, o momento de fissuração $M_{c r}$ e o momento de inércia transformado da seção fissurada $I_{c r}$, respectivamente, dados por:

$$
\begin{gathered}
I_{g}=\frac{b h^{3}}{12} \\
M_{c r}=\frac{2 f_{r} I_{g}}{h}
\end{gathered}
$$




$$
I_{c r}=\frac{b d^{3}}{3} k^{3}+\eta_{f} A_{f} d^{2}(1-k)^{2}
$$

Define-se $\beta_{d}$ como sendo um coeficiente de redução usado no cálculo do deslocamento, onde:

$$
\beta_{d}=\frac{1}{5}\left[\frac{\rho_{f}}{\rho_{f b}}\right] \leq 1,0
$$

Calculando-se o momento de inércia bruto da seção transversal fissurada, ocasionado pelo carregamento variável ou de curta duração $\left(w_{L L}\right)$ e pelo carregamento permanente ou de longa duração $\left(w_{D L}\right)$

Seja $M_{a}=M_{(D L+L L)}$, onde:

$$
\left(I_{e}\right)_{D L+L L}=\left(\frac{M_{c r}}{M_{a}}\right)^{3} \beta_{d} I_{g}+\left[1-\left(\frac{M_{c r}}{M_{a}}\right)^{3}\right] I_{c r} \leq I_{g}
$$

Seja também o deslocamento imediato devido ao carregamento permanente $\left(\Delta_{i}\right)_{D L}$ e o deslocamento imediato devido ao carregamento variável $\left(\Delta_{i}\right)_{L L}$, onde:

$$
\begin{gathered}
\left(\Delta_{i}\right)_{D L}=\frac{w_{D L}}{w_{D L+L L}}\left(\Delta_{i}\right)_{D L+L L} \\
\left(\Delta_{i}\right)_{L L}=\frac{w_{L L}}{w_{D L+L L}}\left(\Delta_{i}\right)_{D L+L L} \\
\left(\Delta_{i}\right)_{D L+L L}=\left(\Delta_{i}\right)_{D L}+\left(\Delta_{i}\right)_{L L}=\frac{5 M_{D L+L L} l^{2}}{48 E_{c}\left(I_{e}\right)_{D L+L L}}
\end{gathered}
$$

Sabendo-se que $w_{D L}(k N / m)$ e $w_{L L}(k N / m)$ e que $\lambda$ é o multiplicador para deslocamento dependente do tempo (ACI 318-08 recomenda $\xi=2,0$ para duração de 5anos), tem-se então $\lambda=0,6 \xi=1,20$

Finalmente o deslocamento total da viga é dada por: 


$$
\Delta_{L T}=\left(\Delta_{i}\right)_{L L}+\lambda\left[\left(\Delta_{i}\right)_{D L}+0,20\left(\Delta_{i}\right)_{L L}\right] \leq \frac{l}{240}
$$

Verificação da fadiga de tensão limite de ruptura:

Para a verificação da ruptura por fadiga em elementos de concreto, armados com FRP, deve ser verificado o comportamento do elemento estrutural devido ao carregamento variável e cíclico e posteriormente comparados os resultados com os limites de tensão de ruptura.

Seja $M_{s}=$ momento devido ao carregamento variável, onde:

$$
M_{s}=\frac{W_{D L}+0,20 W_{L L}}{W_{D L+L L}} M_{D L+L L}
$$

Seja $f_{f, s}=$ nível de tensão induzido no FRP pelo carregamento cíclico, onde:

$$
f_{f, s}=\frac{M_{s}}{A_{f} d(1-k / 3)} \leq 0,20 f_{f u} \text { para GFRP }
$$

Onde os limites de tensão de ruptura no reforço FRP são dados pela Tabela 2.13.

Tabela 2.13 - Limites de tensão de ruptura do reforço FRP. Adaptado: ACI 440.1R-06

\begin{tabular}{|c|c|c|c|}
\hline TIPO DE FIBRA & GFRP & AFRP & CFRP \\
\hline LIMITES DE TENSÃO & $0,20 \mathrm{f}_{\mathrm{fu}}$ & $0,30 \mathrm{f}_{\mathrm{fu}}$ & $0,55 \mathrm{f}_{\mathrm{fu}}$ \\
DE RUPTURA $\mathrm{f}_{\mathrm{f}, \mathrm{s}}$ & & & \\
\hline
\end{tabular}

- O deslocamento também pode ser calculado com a integração do diagrama de curvatura. Utilisando-se análise não linear, tendo como parâmetros a fissuração e as tensões pela fluência do concreto.

Os testes experimentais mostraram que o modelo proposto pelo Eurocode 2 pode ser considerado adequado para elementos em FRP. Então tem-se a seguir a equação para o cálculo do deslocamento, dada por: 


$$
f=f_{1} \beta_{1} \beta_{2}\left(\frac{M_{c r}}{M_{\text {máx }}}\right)^{m}+f_{2}\left[1-\beta_{1} \beta_{2}\left(\frac{M_{c r}}{M_{\text {máx }}}\right)^{m}\right]
$$

Onde: $f_{1}$ é o deslocamento da seção não fissurada;

$f_{2}$ é o deslocamento da seção transformada fissurada;

$\beta_{1}$ é o coeficiente de cálculo das propriedades de aderência das barras em FRP;

$\beta_{2}$ é o coeficiente de cálculo para o carregamento de curta e longa duração;

$M_{\text {máx }}$ é o máximo momento atuante;

$M_{c r}$ é o momento calculado de fissuração;

$m$ é o coeficiente de aderência prescrito pela CNR-DT 203/2006;

\subsection{Cisalhamento em vigas de concreto}

Os elementos estruturais de concreto com reforço interno em geral sofrem ação simultânea do momento fletor e da força cortante, exceto em regiões onde ocorre somente flexão pura. Quando se estuda a força cortante do elemento estrutural, considera-se o efeito associado do momento fletor.

Quando uma viga é carregada e se encontra no estádio 2, as seções fissuradas aparecem e a resultante de tração é resistida exclusivamente pelas barras longitudinais, a região próxima aos apoios ainda não se encontra fissurada, ou seja, essa região permanece no estádio 1. Com o aumento do carregamento surgem as fissuras inclinadas próximas aos apoios, que por sua vez são perpendiculares às tensões principais de tração. Nesse estágio praticamente toda a viga encontra-se no estádio 2, exceto as regiões muito próximas aos apoios.

O modelo clássico de treliça foi idealizado por Ritter e Mörsch, no início do século XX, e se baseia na analogia entre uma viga fissurada e uma treliça (Figura 2.30). 


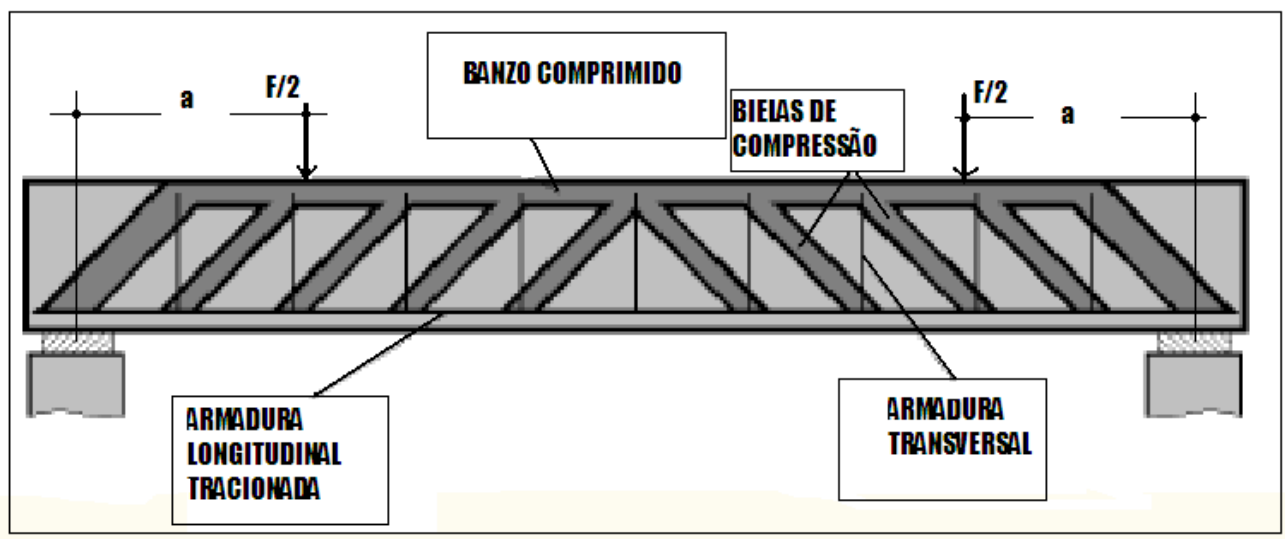

Figura 2.30 - Modelo clássico de analogia com a treliça segundo Ritter e Mörsch

Existe algumas imperfeições neste modelo; a inclinação das fissuras é menor que $45^{\circ}$, os banzos não são paralelos pois existe o arqueamento do banzo comprimido nas regiões próximas ao apoio e também a treliça é altamente hiperestática, ocorrendo engastamento das bielas no banzo comprimido.

Várias são as formas de ruína em vigas de concreto devido ao cisalhamento na flexão simples. São elas:

- Ruína por flexão: Nos domínios 2 e 3 a ruína ocorre após o escoamento da armadura, ocorrendo abertura de fissuras e deslocamentos excessivos. No domínio 4, a ruína se dá pelo esmagamento do concreto comprimido, não ocorrendo escoamento da armadura nem grandes deslocamentos, o que caracteriza uma ruína sem aviso;

- Ruína devida à deficiência de ancoragem no apoio: A falta ou deficiência de ancoragem no apoio pode provocar o colapso na junção da diagonal comprimida com o banzo tracionado, próximo ao apoio;

- Ruína por ruptura da armadura transversal: É a ruína decorrente da deficiência da armadura transversal em resistir as tensões de tração devidas à força cortante;

- Ruína do banzo comprimido: No caso também de deficiência da armadura transversal, as fissuras podem invadir a região comprimida pela flexão, diminuindo essa região e provocando sua ruptura; 
-Ruína por flexão localizada na armadura longitudinal: Na deformação da armadura transversal pode ocorrer grande fissuração, sendo que o deslocamento relativo das seções adjacentes podem levar a viga a um tipo de ruína que também decorre do cisalhamento.

- Ruína por esmagamento da biela: Para seções muito pequenas, as tensões principais de compressão podem atingir valores elevados, incompatíveis com a resistência do concreto à compressão;

\subsubsection{Cisalhamento em vigas de concreto armadas com aço}

Dada a Figura 2.31, onde a viga se encontra com carregamento $\mathrm{F}$ distribuído uniformemente ao longo da largura da viga, em uma região de espessura igual a $10 \mathrm{~mm}$, distante $\mathrm{a}=2 \mathrm{~h}=600 \mathrm{~mm}$ do centro do apoio esquerdo, produzindo esforços de cisalhamento, onde a relação a/d é aproximadamente igual a 2,5.

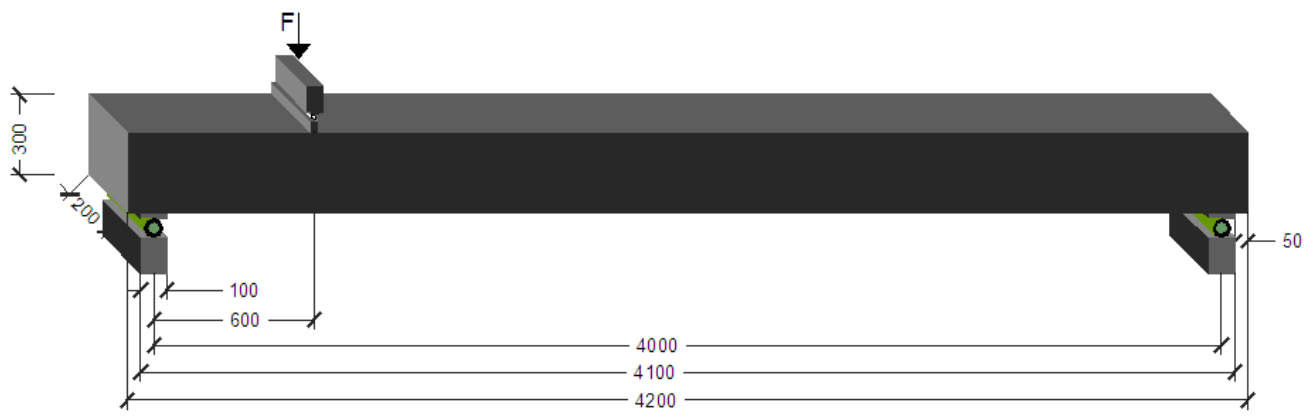

Figura 2.31 - Viga submetida a esforços de cisalhamento

Segundo a NBR 6118:2003, admitem-se dois modelos de cálculo, baseados na analogia com o modelo de treliça associado a mecanismos resistentes complementares, traduzidos por uma parcela adicional de cortante $\mathrm{V}_{\mathrm{c}}$. $\mathrm{O}$ primeiro modelo admite a parcela adicional de cortante $\mathrm{V}_{\mathrm{c}}$ constante, independente de $\mathrm{V}_{\mathrm{Sd}}$ (força cortante solicitante de cálculo), e bielas de compressão com inclinação de $45^{0}$. O segundo modelo considera as bielas com inclinação entre $30^{\circ}$ e $45^{\circ}$ e a parcela adicional de cortante $V_{c}$ diminuindo com o aumento de $V_{S d}$.

Nos dois modelos de cálculo devem ser considerados:

- A verificação da compressão na biela: 
- O cálculo da armadura transversal;

-O deslocamento do diagrama de força no banzo tracionado.

- Verificação da compressão na biela e da armadura de cisalhamento $A_{s w} / s$ para $F(k N)$ segundo o primeiro modelo da NBR 6118:2003. Independente da taxa de armadura transversal, deve ser verificada a seguinte condição:

$$
\begin{gathered}
V_{S d}=V_{S d, f a c e} \leq V_{R d 2} \\
V_{R d 2}=0,27 \alpha_{v} f_{c d} b_{w} d
\end{gathered}
$$

Onde: $V_{R d 2}(k N)$ é a força cortante resistente de cálculo, relativa à ruína da biela; $V_{S d}(k N)$ é a força cortante solicitante de cálculo na região de apoio $\left(V_{S d, f a c e}\right)$; $\alpha_{v}=\left(1-f_{c k}(M P a) / 250\right)$.

- Para o cálculo da armadura transversal também deve ser satisfeita a seguinte condição:

$$
V_{S d} \leq V_{R d 3}=V_{c}+V_{s w}
$$

Onde: $V_{R d 3}(k N)$ é a força cortante resistente de cálculo, relativa à ruína por tração diagonal; no cálculo da armadura transversal considera-se $V_{R d 3}=V_{S d}$;

$V_{c}(k N)$ é a parcela adicional de força cortante absorvida por mecanismos complementares ao da treliça (resistência ao cisalhamento da seção sem armadura transversal);

$V_{s w}(k N)$ é a parcela de força absorvida pela armadura transversal.

- Para o cálculo da armadura transversal mínima tem-se:

$$
V_{S d, \text { min }}=V_{s w, \text { min }}+V_{c}
$$

Onde: 


$$
\begin{aligned}
& V_{s w, \text { min }}=0,9 \rho_{s w, \text { min }} b_{w} d f_{y w d} \\
& a_{s w, \text { min }}=\frac{A_{s w, \text { min }}}{s}=\rho_{s w, \text { min }} b_{w}
\end{aligned}
$$

$\rho_{s w, \min }(\%)$ é dado pela Tabela 2.14

Tabela 2.14 - Valores da taxa de armadura mínima. Adaptado ABNT NBR 6118:2003

\begin{tabular}{|c|c|c|c|c|c|c|c|}
\hline \multirow{2}{*}{ AÇO } & \multicolumn{7}{|c|}{ CONCRETO } \\
\cline { 2 - 8 } & C20 & C25 & C30 & C35 & C40 & C45 & C50 \\
\hline CA-25 & 0,1768 & 0,2052 & 0,2317 & 0,2568 & 0,2807 & 0,3036 & 0,3257 \\
\hline CA-50 & 0,0884 & 0,1026 & 0,1159 & 0,1284 & 0,1404 & 0,1580 & 0,1629 \\
\hline CA-60 & 0,0737 & 0,0855 & 0,0965 & 0,1070 & 0,1170 & 0,1265 & 0,1357 \\
\hline \hline
\end{tabular}

$$
V_{c}=0,6 f_{c t d} b_{w} d
$$

É necessário que se verifique, no detalhamento dos estribos, limites de diâmetro mínimo e máximo, espaçamento longitudinal mínimo e máximo, número de ramos de estribos e ancoragem, dados pelas prescrições indicadas na NBR 6118:2003, item 18.3.3.2.

- Para verificação da ancoragem tem-se o comprimento de ancoragem básico dado por:

$$
l_{b}=\frac{\phi_{l} f_{y d}}{4 f_{b d}}
$$

Onde:

$$
\begin{gathered}
f_{y d}=\frac{\sigma_{s}}{\gamma_{s}} \\
f_{c t d} \frac{0,21 f_{c k}^{2 / 3}}{\gamma_{c}}
\end{gathered}
$$




$$
f_{b d}=\eta_{1} \eta_{2} \eta_{3} f_{c t d}
$$

A área necessária das barras a ancorar é dada por:

$$
\begin{gathered}
A_{s, \text { nec }}=\frac{\alpha_{1} l_{b} A_{s, \text { calc }}}{l_{b, \text { disp }}} \\
A_{s, \text { calc }}=\frac{R_{s}}{f_{y d}} \\
R_{s}=\frac{a_{l}}{d} V_{\text {Sd,face }}=\frac{V_{S d, \text { face }}}{2\left(V_{\text {Sd,face }}-V_{c}\right)} V_{\text {Sd,face }}
\end{gathered}
$$

\subsubsection{Cisalhamento em vigas de concreto armadas com FRP}

O cálculo é similar ao feito para o aço no ACI 318-05, exceto pelas diferenças das propriedades mecânicas das barras de FRP, que afetam a resistência ao cisalhamento. Algumas considerações iniciais que podem ser utilizadas para os projetos de reforço com FRP para o cisalhamento são:

-Barras de FRP têm relativamente baixo módulo de elasticidade;

-Barras de FRP têm baixa resistência transversal ao cisalhamento;

-Barras de FRP têm alta resistência à tração, mas não tem ponto de escoamento;

-A resistência à tração da barra FRP na curvatura é significativamente menor do que a parcela relativa à armadura em linha reta.

O fator de redução de resistência ao cisalhamento dado pelo ACI 318-05 para o aço é também utilizado para o reforço em FRP, onde:

$$
\Phi V_{n} \geq V_{u}
$$

Onde $\Phi=0,75$ é o fator de redução de resistência ao cisalhamento;

$V_{n}$ é a resistência nominal ao cisalhamento;

$V_{u}$ é o esforço cortante solicitante 
O ACI 318-05 considera para o reforço em aço:

$$
V_{n}=V_{C}+V_{s}
$$

Onde:

$V_{c}$ é a resistência ao cisalhamento devida ao concreto;

$V_{s}$ é a resistência ao cisalhamento devida ao reforço em aço

Comparando uma seção reforçada em aço com área igual do reforço longitudinal em FRP na flexão, depois da fissuração, a seção reforçada em FRP tem uma menor profundidade para a linha neutra por causa da menor rigidez axial das barras. A região de compressão da seção transversal é reduzida e as larguras das fissuras são maiores; como consequência a resistência ao cisalhamento fornecido pelo intertravamento de agregados da diagonal fissurada é menor. A resistência ao cisalhamento do concreto é influenciada pela resistência de tração das barras longitudinais na flexão. Dessa forma a contribuição do reforço longitudinal FRP à resistência ao cisalhamento ainda não foi determinada, por causa da menor rigidez axial das barras de FRP na direção transversal, ou seja, a contribuição é bem menor que a do aço.

Dessa forma a parcela de contribuição vertical transversal às barras longitudinais de FRP não pode ser adicionada, no cálculo da resistência total de cisalhamento.

Kong e Evans(2001), além de analisarem o melhor posicionamento da carga concentrada em vigas de concreto para o ensaio de cisalhamento, também investigaram o comportamento das componentes de cisalhamento na flexão de uma viga de concreto reforçada com aço (Figura 2.32). 


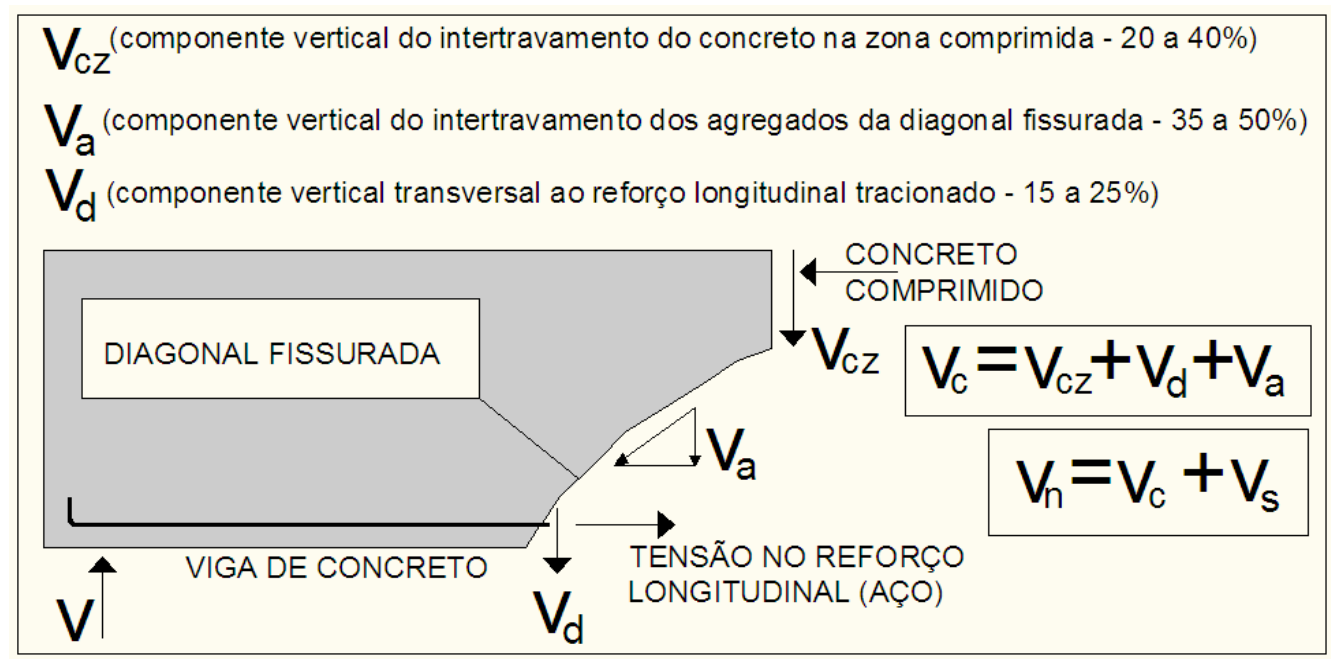

Figura 2.32 - Componentes de $V_{n}$ para a viga de concreto reforçada com aço. Adaptado Kong e Evans (2001)

Pela Figura 2.32 observa-se que para o reforço em FRP, diferentemente do aço, as componentes verticais $V_{d}$ e $V_{a}$ que fazem parte da parcela de resistência ao cisalhamento do concreto não são consideras pelo ACI 318-05, e consequentemente pelo ACI 440.1R-06.

Portanto, para as barras de FRP, a resistência ao cisalhamento na flexão em uma determinada seção transversal é composta pela soma da componente vertical devida ao intertravamento da zona comprimida de concreto $\left(V_{c z}\right)$ adicionada à parcela de resistência da armadura transversal das barras $\operatorname{FRP}\left(V_{f}\right)$, ou seja, para as vigas de concreto reforçadas com FRP tem-se $V_{c}=V_{c z}$, onde:

$$
V_{n}=V_{c}+V_{f}
$$

Dessa forma a tensão de cisalhamento no reforço de FRP deve ser limitado ao controle da largura de fissuras devidas ao cisalhamento.

Para o cálculo da resistência do concreto ao cisalhamento $V_{c}$, tem-se:

$$
V_{c}=\frac{2}{5} \sqrt{f_{c}^{\prime}} b_{w} c
$$

Onde $c=k d$, sendo que $c$ é a distância extrema da fibra comprimida até a linha neutra e $\kappa$ é calculado de acordo com a equação 2.59 , onde $\eta_{f}$ é a razão do módulo de elasticidade da fibra em relação ao módulo de elasticidade do concreto: 


$$
\eta_{f}=E_{f} / E_{c}=E_{f} /\left(4750 \sqrt{f_{c}^{\prime}}\right)
$$

Substituindo $c$ em 2.87 tem-se:

$$
V_{c}=\left(\frac{1}{5} k\right) 2 \sqrt{f_{c}^{\prime}} b_{w} d
$$

A equação reescrita 2.89 é uma simplificação do ACI 318-05 para o reforço em aço, modificada pelo fator $\left(\frac{1}{5}\right) k$, para o cálculo em FRP, no sistema de unidades SI.

Para o cálculo da contribuição da armadura transversal ao cisalhamento em FRP, utiliza-se o mesmo equacionamento para o aço dado pelo ACI 318-05; então chega-se à seguinte equação:

$$
V_{f}=\frac{A_{f v} f_{f v} d}{s}
$$

O nível de tensão na armadura de reforço transversal de cisalhamento $\left(f_{f v}\right)$ deve ser limitado pelo controle da largura das fissuras de cisalhamento e manter a integridade do concreto, evitando a ruína por ruptura da armadura transversal. Na equação 2.91 tem-se o nível de tensão permitido no reforço transversal de cisalhamento FRP.

$$
f_{f v}=0,004 E_{f} \leq f_{f b}
$$

Em que: $f_{f v}=$ Resistência à tração das barras transversais de cisalhamento em FRP;

$f_{f b}=$ Resistência de projeto à tração da barra FRP em relação a sua curvatura, dada pela equação:

$$
f_{f b}=\left(0,05 \frac{r_{b}}{d_{b}}+0,3\right) f_{f u} \leq f_{f u}
$$

$r_{b}(m m)$ é o raio da curvatura da viga;

$d_{b}(\mathrm{~mm})$ é o diâmetro da barra de reforço FRP dado pela Tabela 2.1;

$f_{f u}$ é calculada pela equação 2.4 . 
$f_{f b}=0,3 f_{f u}$ para $\frac{r_{b}}{d_{b}}=0$, ou seja quando a razão entre o raio de curvatura da barra $\left(r_{b}\right)$ e o diâmetro da barra $\left(d_{b}\right)$ for igual a zero. A mínima razão $\frac{r_{b}}{d_{b}}$ recomendada para estribos verticais $\left(90^{\circ}\right)$ é de $\frac{r_{b}}{d_{b}}=3$.

Quando se utiliza o reforço transversal em FRP perpendicular ao eixo axial da viga, o espaçamento requerido dos estribos e a área do reforço podem ser calculados pela equação 2.93.

$$
\frac{A_{f v}}{s}=\frac{\left(V_{u}-\Phi V_{c}\right)}{\Phi f_{f v} d}
$$

Quando o reforço transversal em FRP é inclinado, a resistência de cisalhamento da barra é calculada da seguinte forma:

$$
V_{f}=\frac{A_{f v} f_{f v} d}{s}(\operatorname{sen} \alpha+\cos \alpha)
$$

Podem ser considerados dois tipos de ruptura no cisalhamento em vigas com reforço transversal em FRP:

- Controle pelo esmagamento do concreto: Estudos feitos por Nagasaka et al. (1993) indicaram que, para seções de concreto reforçadas com FRP, a transição para a ruptura por esmagamento no modelo de falha ocorre para valores médios de $V_{c}=0,3 f_{c}^{\prime} b_{w} d$, mas podem ser inferiores, chegando a $V_{c}=0,18 f_{c}^{\prime} b_{w} d$. A relação entre a ruptura e falha por esmagamento não foi totalmente compreendida ainda. O mais recomendado pelo ACI é o limite de $V_{c}=8 \sqrt{f_{c}^{\prime}} b_{w} d$, devendo também o controle de fissuras de cisalhamento ser limitado, com valores abaixo do correspondente à falha por esmagamento. 


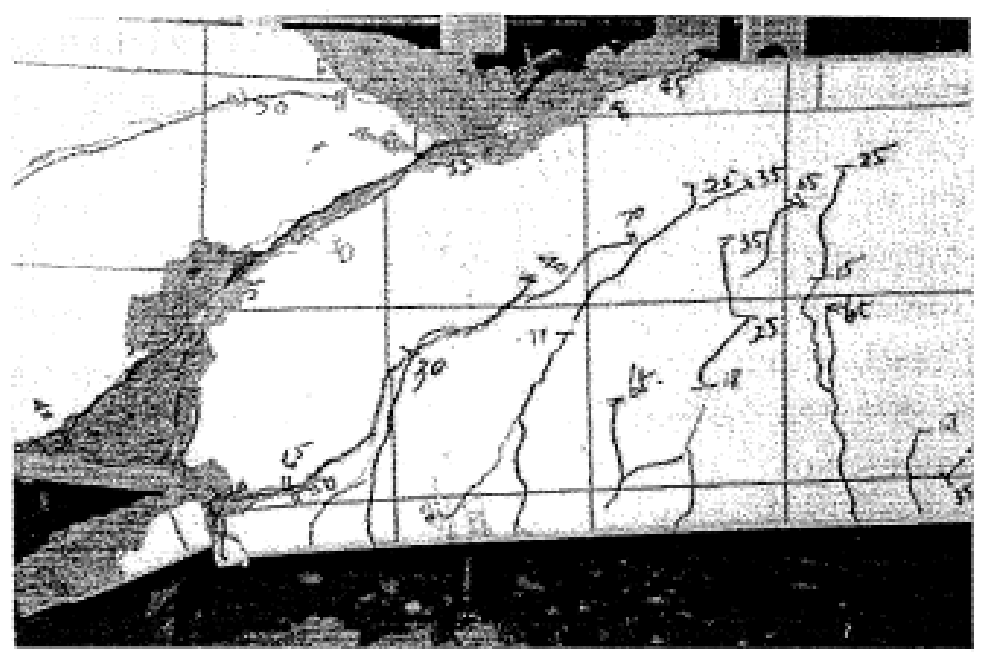

Figura 2.33 - Ruptura no cisalhamento pelo esmagamento do concreto. Fonte: Pilakoutas et al. (2007)

Pilakoutas et al. (2007), estudaram algumas aproximações, inicialmente desenvolvidas no Japão, sobre o valor da resistência do concreto ao cisalhamento. O princípio dessas aproximações é de assumir perfeita aderência entre as barras de reforço e o concreto, para uma melhor aproximação das deformações, independente do tipo de reforço utilizado, maximizando a ação entre o reforço e o concreto, transferindo e interagindo as forças e deformações, apesar de características e propriedades diferentes dos materiais interligados. Partindo desta consideração tem-se para as deformações que $\varepsilon_{F R P}=\varepsilon_{s}(a c ̧ o)$ e, analogamente, tem-se para as forças: $F_{F R P}=F_{s}(a c ̧ o)$. Chega-se a uma área equivalente de aço dada por $A_{e}=A_{F R P} E_{F R P} / E_{s}$.

- Controle pela ruptura do reforço de cisalhamento em FRP: É um modelo mais frágil com deslocamentos maiores.

Limites da tensão-deformação do reforço transversal de cisalhamento:

-Canadian Highway Bridge Design Code (Canadian Standards Association 2000) prescrevem como limite de tensão deformação no reforço de cisalhamento em FRP o valor de $0,002 \mathrm{~mm} / \mathrm{mm}$.

- O Eurocrete Project prescreve como limite da deformação em reforço transversal o valor de $0,0025 \mathrm{~mm} / \mathrm{mm}$. 
-O ACI 318-05 considera o limite de deformação de 0,00275 mm/mm; em nenhum caso a deformação efetiva no reforço de cisalhamento FRP deve exceder 0,004 mm/mm.

Armadura mínima: O ACI 318-05 requer uma mínima armadura de cisalhamento quando:

$$
V_{u}>\frac{\Phi V_{c}}{2}
$$

A armadura mínima de cisalhamento $\left(A_{f v, \text { min }}\right)$ é independente da resistência do concreto. Para uma mínima armadura de reforço de cisalhamento FRP, pode-se ter o espaçamento dos estribos rearranjados da seguinte forma:

$$
s \leq \frac{A_{f v, \text { min }} f_{f v}}{0,35 b_{w}}
$$

De acordo com o ACI 318-05, se no reforço em aço é utilizada a armadura mínima, esta fornece uma resistência proporcional ao cisalhamento que varia desde $1,5 V_{c}$, quando $f_{c}^{\prime}=17 M P a$, até $1,25 V_{c}$, quando $f_{c}^{\prime}=69 M P a$.

Para a armadura mínima de cisalhamento em FRP, a equação 2.96 é a mais recomendada. Por exemplo, no caso de viga armada com reforço longitudinal em GFRP, a resistência proporcional ao cisalhamento fornecida pela armadura mínima na equação 2.96 pode exceder $3 V_{c}$. Mas se houver decréscimo da espessura da armadura longitudinal, deve-se ter um concreto com maior resistência característica.

- Detalhamento da armadura transversal de cisalhamento: O ACI 440.1R-06 adota para reforço de cisalhamento FRP o mesmo que a ACI 318-05 adota para o aço. Então o máximo espaçamento limite de estribo vertical FRP é dado por $s \leq\left\{\frac{d(\mathrm{~mm})}{2}\right\}$ ou $s \leq\left\{24^{\prime \prime}=600 \mathrm{~mm}\right\}$.

\subsubsection{Verficação da ancoragem nas barras em FRP}


Analisar se a ancoragem da barra de FRP por aderência é suficiente.

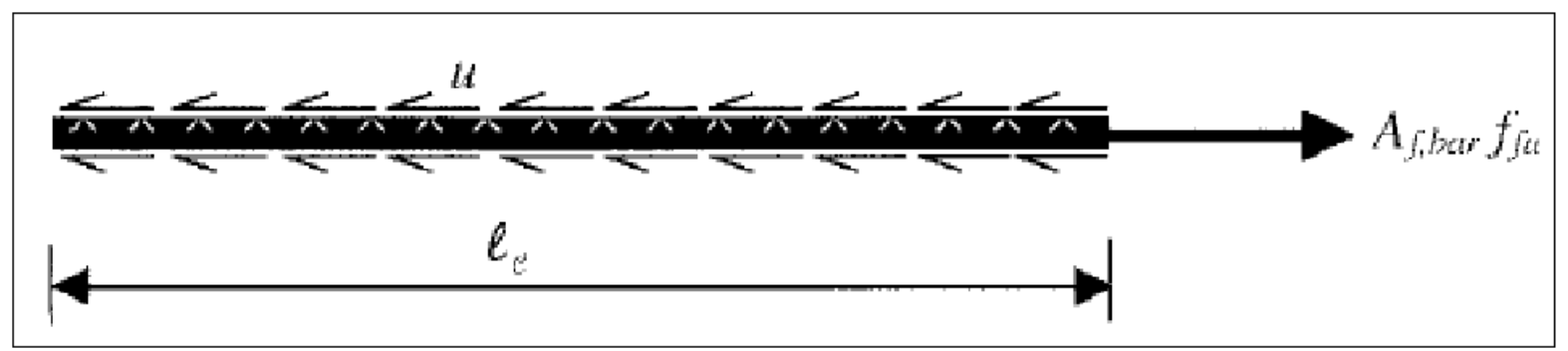

Figura 2.34 - Transferência de força através da aderência. Fonte: ACI 440.1R-06

A Figura 2.34 mostra a condição de equilíbrio da barra de FRP de comprimento $l_{e}$, envolta no concreto. A força na barra é resistida pela tensão de aderência $u$ agindo na superfície da barra. Pelo equilíbrio de forças tem-se:

$$
l_{e} \pi d_{b} u=A_{f, b a r} f_{f}
$$

Wambeke e Shield (2006), utilizando uma metodologia de ensaio igual à do aço, fizeram 269 testes de ligação de aderência em vigas. A maioria das barras representadas no banco de dados era composta de GFRP, onde 82 testes resultaram em rupturas, baseado nos trabalhos de Ehsani et al.(1996a), Daniali(1992), Shield et al.(1997,1999) e Tighiouart et al. (1999). Através de regressão linear chegou-se na seguinte equação para o sistema de unidades SI:

$$
\frac{u}{0,083 \sqrt{f_{c}^{\prime}}}=4,0+0,3 \frac{C}{d_{b}}+100 \frac{d_{b}}{l_{e}}
$$

Através das equações 2.97 e 2.98 chega-se à expressão de $f_{f e}$ (tensão que pode ser atingida pela barra para o comprimento incorporado $l_{e}$ ) no sistema de unidades SI.

$$
\begin{gathered}
f_{f e}=\frac{0,083 \sqrt{f_{c}^{\prime}}}{\alpha}\left(13,6 \frac{l_{e}}{d_{b}}+\frac{C}{d_{b}} \frac{l_{e}}{d_{b}}+340\right) \leq f_{f u} \\
C=\min \left(d_{c}, \frac{1}{2} c-o-c \text { spacing }\right)
\end{gathered}
$$

$l_{e}=$ comprimento incorporado do reforço FRP (Figura 2.34) 


$$
\begin{aligned}
& \alpha=1,0 p / h \leq 12^{\prime \prime} \\
& \alpha=1,5 p / h>12^{\prime \prime} \\
& d_{b}(m m) \text { é o diâmetro da barra FRP } \\
& \text { Limite de }\left(\frac{C}{d_{b}}\right)_{\text {máx }}=3,5
\end{aligned}
$$$$
\text { Recomenda-se: } 20<\frac{l_{e}}{d_{b}}<100
$$

Quando $f_{f e}>f_{f u}$, deve-se adotar então: $f_{f e}=f_{f u}$

Se $f_{f e}>f_{f}$, então a resistência da barra à flexão não é limitada pela aderência.

- Verificar a ancoragem na região de momento positivo: Pode ser feita de acordo com o ACI 318-05, com alterações no caso de comprimento de ancoragem para barras em FRP. Nas barras retas ou contínuas, a tensão desenvolvida $\left(f_{f r}\right)$ deve obedecer à equação 2.28 e à tensão dada pela equação 2.99. O comprimento incorporado para barras retas é definido no sistema SI de unidades por:

$$
l_{d}=\frac{\alpha \frac{f_{f r}}{0,083 \sqrt{f_{c}^{\prime}}}-340}{13,6+\frac{C}{d_{b}}} d_{b}
$$

Como a ruína é governada pelo esmagamento do concreto, tem-se $f_{f r}=f_{f}$.

Por causa do fator de redução de resistência em comparação com o aço, no ACI 318-05 tem-se a seguinte condição para o comprimento $l_{d}$ :

$$
l_{d} \leq 1,3 \frac{\phi M_{n}}{V_{u}}+l_{a}
$$


Em que $l_{a}$ é o comprimento adicional incorporado para o apoio ou pelo ponto de inflexão, devendo ser a maior profundidade efetiva ou $12 d_{b}$. Se $l_{a}=0$ não há inclusão de comprimento adicional. 


\section{3 - MODELOS DE CÁLCULO}

O objetivo da aplicação destes modelos comparativos de vigas pré-moldadas é obter subsídios para a aplicação de barras de reforço de GFRP, em relação ao Estado Limite de Serviço (ELS), em obras realizadas em regiões de alta agressividade ambiental. Nem todos os parâmetros da norma americana foram inseridos, uma vez que alguns coeficientes internos que contam com efeitos sísmicos e com a neve estão embutidos nos cálculos. O principal objetivo do trabalho foi comparar os modelos de cálculo de norma para estruturas utilizadas em ambientes agressivos e comparar os resultados entre o uso da armadura de aço e a armadura longitudinal e transversal de GFRP para uma mesma tipologia de elemento estrutural.

Ainda que esses estudos estejam avançando, no Brasil ainda existe certa reação quanto ao uso e aplicação desses materiais, a despeito de inúmeras vantagens que se pode obter quando utilizados de forma criteriosa e em aplicações específicas. Como é possível notar, ainda hoje, no Brasil, as fundações e lajes de pisos de áreas laboratoriais de equipamentos médicos de alta sensibilidade carecem de norma que elimine o uso de materiais eletrocondutores como o aço. Este é um dos exemplos de aplicações possíveis, além do uso em ambientes de alta agressividade ambiental ou industrial.

\subsection{Modelo-1- cálculo de acordo com a NBR 6118:2003}

Será analisado o modelo da Figura 3.1 na flexão simples, ou seja, uma viga de concreto com seção transversal $(200 \mathrm{~mm} \times 300 \mathrm{~mm})$ biapoiada, exposta em ambiente altamente agressivo, cujo comprimento entre apoios é de $3000 \mathrm{~mm}$, submetida a um carregamento $\mathrm{F}$ transmitido por uma viga de carregamento em duas regiões da viga distantes $1000 \mathrm{~mm}$. 


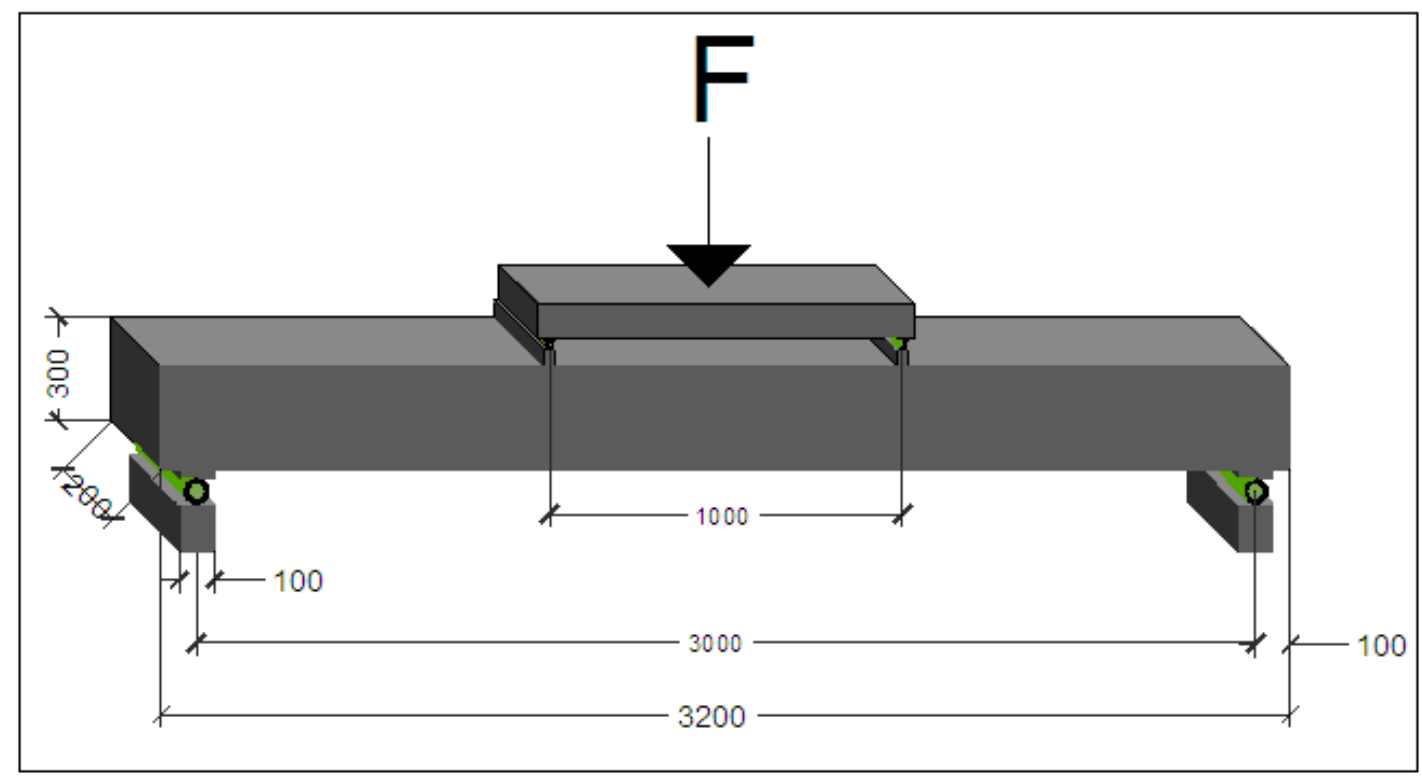

Figura 3.1 - Viga $200 \mathrm{~mm} \times 300 \mathrm{~mm}$ submetida à flexão em ambiente altamente agressivo

De acordo com a Tabela 2.5, para ambiente com alta agressividade e risco de deterioração elevado a classe de agressividade ambiental é IV.

Pelas Tabelas 2.6 e 2.7 deve ser utilizado um concreto com resistência característica mínima $f_{c k}=40 \mathrm{MPa}$ e cobrimento nominal mínimo $c=50 \mathrm{~mm}$.

Adota-se inicialmente como armadura longitudinal tracionada $A_{s}=2 \phi 10 \mathrm{~mm}$; $A_{s}^{\prime}=2 \phi 8 \mathrm{~mm}$ como portaestribo e $\phi_{t}=5 \mathrm{~mm}$ como diâmetro da armadura transversal.

Os coeficientes de ponderação da resistência do concreto e aço foram adotados iguais: $\gamma_{c}=\gamma_{s}=1,00$.

Calcula-se inicialmente a altura útil da seção transversal, resultando em $240 \mathrm{~mm}$.

Ainda, segundo a norma brasileira, utilizando a equação 2.14 , calcula-se o $M_{d, \lim }$, resultando em 104,73kNm.

Em seguida, são calculados $\beta_{x}$ e $M_{k}$ utilizando as equações de compatibilidade para armadura simples, 2.8 e 2.9 respectivamente.

Tem-se que: $\beta_{x}=0,060$ (Domínio 2)

$$
M_{d}=M_{k}=18,39 k N m<M_{d, \text { lim }}(\text { passa })
$$

Em seguida, calcula-se $V_{k}$ e $F$ segundo as características apresentadas na Figura 3.1 
Pelo equilíbrio de forças estáticas da viga, tem-se que: $V_{k}=19,11 k N$ e $F=33,42 k N$ para o domínio 2.

Para um carregamento produzindo $M_{d, \text { máx }}=1,2 M_{d, \mathrm{lim}}=125,68 \mathrm{kNm}$, ele corresponderia ao limite da seção transversal, ou seja, domínio 4, onde $\beta_{x}=0,60$ e $F=124 k N$.

A partir do resultado anterior verifica-se a compressão na biela (equação 2.72 e 2.73 ) e a armadura transversal de cisalhamento $A_{s w} / s$.

Para $F=33,42 k N, V_{S d, f a c e}=19,04 k N<V_{R d 2}=435,46 k N$ (passa).

Então com a equação 2.74 chega-se a $V_{S d, \text { min }}=97,12 k N>V_{S d, \text { face }}$. Tem-se, utilizando estribo de 2 ramos, $a_{s w, \min }=\phi 5 m m \mathrm{c} / 13 \mathrm{~cm}$. Adota-se $a_{s w}=\phi 5 m m \mathrm{c} / 13 \mathrm{~cm}$.

Verifica-se a ancoragem e por último é feita a verificação dos estados limites de serviço (ELS).

- Verificação dos Estados Limites de Serviço (ELS)

\section{Cálculo da flecha imediata e da flecha diferida}

Calcula-se pela NBR6118:03 o momento de inércia equivalente. Para isso é necessário obter primeiramente o momento de fissuração $M_{r}$ e o momento de inércia no estádio II $\left(I_{2}\right)$. Somando-se a flecha imediata e a flecha diferida chega-se a flecha total $a_{t}$, sendo o deslocamento limite dado por $l / 250$. Utiliza-se para isso as equações 2.30 a 2.45 .

\section{Cálculo da abertura de fissuras}

Calcula-se primeiramente: A taxa de armadura $\rho_{\mathrm{ri}}, \sigma_{\mathrm{s}}$ aproximado e $\sigma_{\mathrm{s}} \mathrm{I}_{2}$ no estádio II.

Finalmente, o menor de dois valores $w_{k}$. Utiliza-se para isso as equações 2.46 a 2.49.

Após a verificação dos estados limites de serviço (ELS), chega-se ao detalhamento da viga do modelo 1 (Figura 3.2) utilizando-se reforço interno em aço segundo a NBR 6118:2003. 


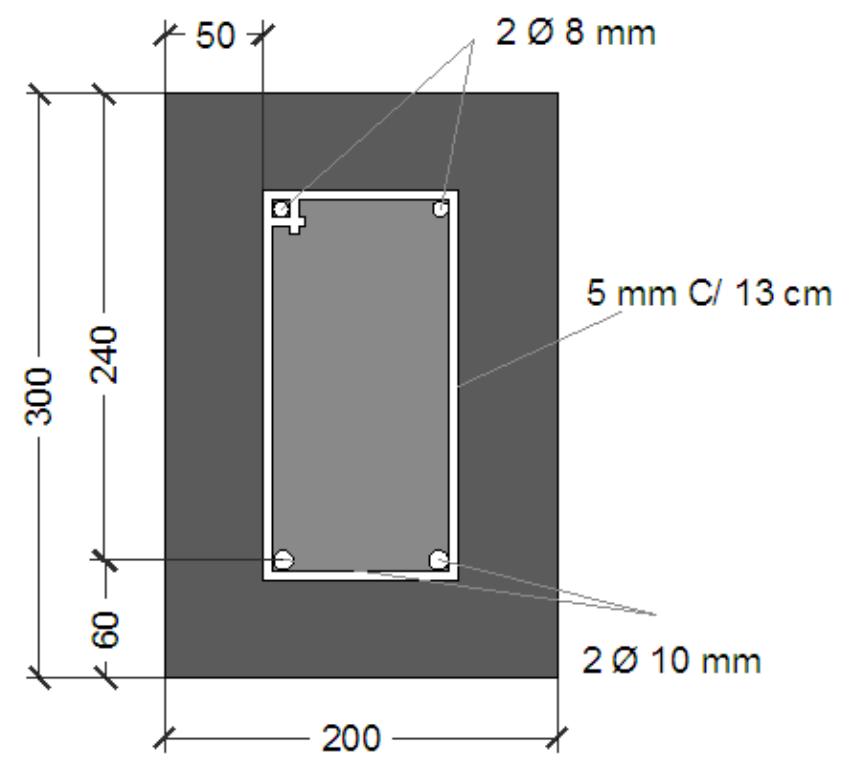

Figura 3.2 - Detalhamento final da viga submetida à flexão simples, com armadura convencional para um carregamento de $\mathrm{F}=33,42 \mathrm{kN}$ (domínio 2) em ambiente altamente agressivo

\subsection{Modelo-1- cálculo de acordo com o ACI 440.1R-06}

- Para o mesmo modelo da viga do item 3.1 na flexão simples (Figura 3.1), com as mesmas dimensões e condições ambientais (alta agressividade e risco de deterioração elevado) e também com o mesmo carregamento $F=33,42 k N$, calcula-se a seguir a armadura longitudinal principal tracionada em GFRP $e$ verifica-se o estado limite de serviço.

-Adota-se também a mesma resistência característica do concreto $f_{c}^{\prime}=40 M P a$ e cobrimento mínimo da armadura em GFRP $(\operatorname{cov} e r=25,4 m m=1 ")$;

-Adota-se inicialmente de acordo com a Tabela 2.1 para a armadura principal tracionada em GFRP $4 \phi 6,4 \mathrm{~mm} ; 2 \phi 6,4 \mathrm{~mm}$ para portaestribo e $\phi 9,5 \mathrm{~mm}$ para a armadura de cisalhamento;

-Calcula-se a altura útil da seção transversal $\left(d_{c}=c+\phi_{t}+\phi_{l} / 2=38,10 \mathrm{~mm}\right)$; 
-Como o carregamento é o mesmo do item 3.1, utiliza-se o mesmo momento solicitante, ou seja, $M_{u}(k N)=M_{k}=18,39 k N$;

-Calcula-se a resistência de projeto considerando reduções de serviço $\left(f_{f u}\right)$, utiliza-se a equação 2.4, onde $C_{E}$ é o fator de redução devido às condições ambientais (Tabela 2.3). Para fibra de vidro em concreto exposto a terra e água, $C_{E}=0,70 ; f_{f u}^{*}(M P a)=f_{u, a v e}-3 \sigma$ é a resistência à tração garantida das barras GFRP, que é uma propriedade reportada ao fabricante da barra de reforço. Neste modelo adota-se $f_{f u}^{*}=620,6 M P a$;

- Calcula-se o fator de resistência do concreto $\beta_{1}$, dado pela equação 2.20 , e a taxa de reforço balanceado $\rho_{f b}$, dado pela equação 2.19. Para esse cálculo adota-se o módulo de elasticidade de projeto da barra de FRP ( $\left.E_{f}=44800 M P a\right)$;

-Para o cálculo da taxa de armadura utiliza-se a equação 2.21. Calcula-se a relação $\rho_{f} / \rho_{f b}$ que resulta em: $\rho_{f} / \rho_{f b}=0,17$. Como $\rho_{f}<\rho_{f b}$ tem-se a ruína da viga governada pela ruptura da barra, que não é o ideal, pois a ruptura é frágil e os deslocamentos são maiores;

- Adota-se armadura principal: $3 \phi 12,7 \mathrm{~mm}$;

Pela Tabela 2.1, tem-se:

$A_{f}=387 \mathrm{~mm}^{2}$ e $d_{c}=41,25 \mathrm{~mm} ; d=h-d_{c}=258,75 \mathrm{~mm}$

Como $\rho_{f}<\rho_{f b}$ tem-se novamente a ruína da viga governada pela ruptura da barra. $\mathrm{O}$ passo seguinte consiste em analisar o estado limite de utilização. Usa-se fator de redução de resistência $\phi=0,55$, onde $M_{n}$ é o momento resistente à flexão.

Chega-se a $\phi M_{n}=21,79 k N m>M_{u}=18,39 k N m$ (Passa)

-Em seguida verifica-se a largura de fissura no estado limite de serviço;

Utilizam-se as equações $2.59,2.69$ e 2.70 , onde $M_{(D L+L L)}=18,39 \mathrm{kNm}$.

Dessa forma, tem-se: $f_{f}=193,30 M P a$. Calcula-se o gradiente de deformação e a abertura de fissura para ambiente altamente agressivo, dados pelas equações 2.57 e 2.50 , respectivamente, tem-se $w=0,83 \mathrm{~mm}>0,5 \mathrm{~mm}$ (Não Passa), onde $k_{b}=1,6$ e $s=58,75 \mathrm{~mm}$ 
são o coeficiente de vinculação entre FRP e o concreto e o espaçamento transversal, respectivamente, conforme prescreve o ACI.

- Adota-se novamente armadura principal: $3 \phi 19,1 \mathrm{~mm}$;

Pela Tabela 2.1 tem-se:

$A_{f}=852 \mathrm{~mm}^{2}, d_{c}=44,45 \mathrm{~mm}$ e $d=255,55 \mathrm{~mm}$

Obtém-se $\rho_{f} / \rho_{f b}=1,186$. Como $\rho_{f b}\left\langle\rho_{f}\left\langle 1,4 \rho_{f b}\right.\right.$, tem-se a condição balanceada de ruína, ou seja, ruína governada pela ruptura da barra e esmagamento do concreto. Neste caso utilizase como um fator de redução de resistência a equação 2.26. Através das equações 2.28 e 2.27, respectivamente, calcula-se o momento resistente $M_{n}$. Então tem-se:

$$
\phi M_{n}=46,27 k N m>M_{u}=18,39 k N m \text { (Passa) }
$$

-Em seguida verifica-se novamente a largura de fissura no estado limite de serviço;

Pela equação 2.70 chega-se a $f_{f}=90,50 \mathrm{MPa}$, em que $k_{b}=1,6$ e $s=55,55 \mathrm{~mm}$ é o coeficiente de vinculação entre FRP e o concreto e o espaçamento transversal, respectivamente, conforme prescreve o ACI.

Tem-se: $w=0,41 \mathrm{~mm}<0,5 \mathrm{~mm}$ ( Passa)

-Verifica-se o deslocamento a longo prazo da viga, calcula-se o momento de inércia da seção bruta e o momento crítico de fissuração. Utilizando-se as equações 2.60 a 2.68 tem-se:

$$
\Delta_{L T}=9,63 m m \leq \frac{l}{240}=\frac{3000}{240}=12,5 \mathrm{~mm}(\text { Passa })
$$

-Verifica-se também a fadiga de tensão limite para as barras de GFRP, utilizando-se as equações 2.69 e 2.70 , têm-se:

$$
f_{f, s}=26,71 M P a \leq 0,20 f_{f u}=86,88 M P a(\text { Passa })
$$

-Verifica-se o espaçamento máximo $\left(s_{\text {máx }}\right)$ entre as barras de GFRP para o controle de fissuras, utilizando-se da equação 2.55 no modelo proposto por Bakis e Ospina (2006), temse:

$$
s=\left(b-2 d_{c}\right) / 2=55,55 m m<s_{\text {máx }}=99,74 m m<129,31 \mathrm{~mm}(\text { Passa })
$$


-Verifica-se também o cobrimento mínimo entre as barras de GFRP, de acordo com o ACI 318-05 (adota-se o mesmo valor utilizado para barras de aço), tem-se:

$$
c_{\text {livre }}=s-d_{b}=55,55-19,10=36,45 \mathrm{~mm}>1 "=25,4 \mathrm{~mm}(\text { Passa })
$$

\section{- Cálculo da armadura transversal de cisalhamento em GFRP.}

-Deve ser verificada a condição da equação 2.85 , onde na região próxima ao apoio tem-se: $V_{u}=18,73 \mathrm{kN}$.

Seja $\kappa=c / d$, onde $c=50,85 \mathrm{~mm}$ é a distância da fibra mais comprimida até a linha neutra. Pela equação 2.89 tem-se a contribuição de resistência ao cisalhamento do concreto dado por $V_{c}=25,73 k N$.

-Verifica-se segundo o ACI 318-05 se a armadura mínima transversal de cisalhamento é requerida (utiliza-se a equação 2.95).

$$
V_{u}>\frac{\Phi V_{c}}{2}=9,65 k N(\text { É requerida) }
$$

Para $\phi=9,5 \mathrm{~mm} ; A_{f v}=2 \times 71=142 \mathrm{~mm}^{2} \quad($ Tabela 2.1$)$

- Para que a equação 2.91 seja satisfeita é necessário adotar a mínima razão recomendada entre o raio de curvatura da barra de GFRP e o seu diâmetro, na equação 2.92. Para estribos verticais a razão é de $\frac{r_{b}}{d_{b}}=3$. Então $f_{f b}=0,45 f_{f u}$, tem-se então: $f_{f v}=179,20 M P a \leq f_{f b}=195,49 M P a \quad$ (passa)

- Para que o diâmetro adotado da armadura transversal forneça uma armadura mínima de reforço de cisalhamento em GFRP, deve-se ter respectivamente o espaçamento dos estribos calculado através da equação 2.96, resultando no intervalo $s \leq 364 \mathrm{~mm}$.

Considerando o limite de intervalo do espaçamento para armadura mínima, calculado pela equação 2.96, adota-se armadura com espaçamento limite de estribo vertical GFRP dado por: $s \leq\left\{\frac{d}{2}=127,78 \mathrm{~mm}\right\}$ ou $s \leq\left\{24^{\prime \prime}=600 \mathrm{~mm}\right\}$, então $s=120 \mathrm{~mm}$ 
- Cálculo da contribuição ao cisalhamento do estribo vertical adotado $\left(V_{f}\right)$

Substituindo $s=120 \mathrm{~mm}$ na equação 2.90 tem-se: $V_{f}=54,19 \mathrm{kN}$

Finalmente $V_{n}=V_{c}+V_{f}$, então $\Phi V_{n}=59,94 k N>V_{u}=18,73 k N$ (Passa)

- Para efeito de análise de cálculo (desprezando-se a interferência do diâmetro transversal no cálculo da altura útil da viga) faz-se a interação novamente diminuindo o diâmetro transversal, adotando pela Tabela 2.1 o diâmetro mínimo fornecido dado por $\phi=6,40 \mathrm{~mm}$; $A_{f v}=2 \times 31,60=63,20 \mathrm{~mm}^{2}$.

-Para que o diâmetro adotado na armadura transversal $(\phi=6,40 \mathrm{~mm})$ forneça uma armadura mínima de reforço de cisalhamento em GFRP, deve-se ter o espaçamento dos estribos calculado através da equação 2.96, resultando no intervalo $s \leq 161 \mathrm{~mm}$. Adota-se então armadura com espaçamento limite de estribo vertical GFRP dado por: $s \leq\left\{\frac{d}{2}=127,78 \mathrm{~mm}\right\}$ ou $s \leq\left\{24^{\prime \prime}=600 \mathrm{~mm}\right\}$, chega-se a $s=120 \mathrm{~mm}$.

-Verifica-se a contribuição ao cisalhamento $\left(V_{f}\right)$ do novo estribo vertical adotado. Para $s=120 \mathrm{~mm}$, na equação 2.90 tem-se: $V_{f}=24,41 k N$

Finalmente tem-se $V_{n}=V_{c}+V_{f}=50,44 k N, \quad$ então $\Phi V_{n}=37,83 k N>V_{u}=18,73 k N$ (Passa).

-Em seguida verifica-se se a tensão requerida da barra pode ser incrementada e se a ancoragem por aderência é suficiente:

Utilizando-se da equação 2.100 , tem-se $C=27,78 \mathrm{~mm}$

$l_{e}=$ comprimento de aderência da barra GFRP.

$\alpha=1,0 \mathrm{p} / \mathrm{h} \leq 305 \mathrm{~mm}, d_{b}=19,1 \mathrm{~mm}$ e adota-se $l_{e}=\frac{l}{2}=1500 \mathrm{~mm}$

Como resultado da equação 2.99 tem-se $f_{f e}=799,10 \mathrm{MPa}>f_{f u}=434,42 \mathrm{MPa}$.

Então deve ser adotado: $f_{f e}=f_{f u}=434,42 M P a>f_{f}=394,15 M P a$

Dessa forma a resistência da barra na flexão não é limitada pela aderência ou ligação de superfície. 
É necessário verificar a condição de ancoragem na região de momento positivo:

Tem-se $l_{a}=0$, não há inclusão de comprimento adicional no apoio. Considerando-se $f_{f r}=f_{f}=394,15 M P a$ e substituindo-se os valores nas equações 2.101 e 2.102, respectivamente, tem-se:

$$
l_{d}=521 \mathrm{~mm}<3211 \mathrm{~mm}(\text { Passa })
$$

-Finalmente tem-se o detalhamento da viga (Figura 3.3) feita com reforço longitudinal e transversal em GFRP.

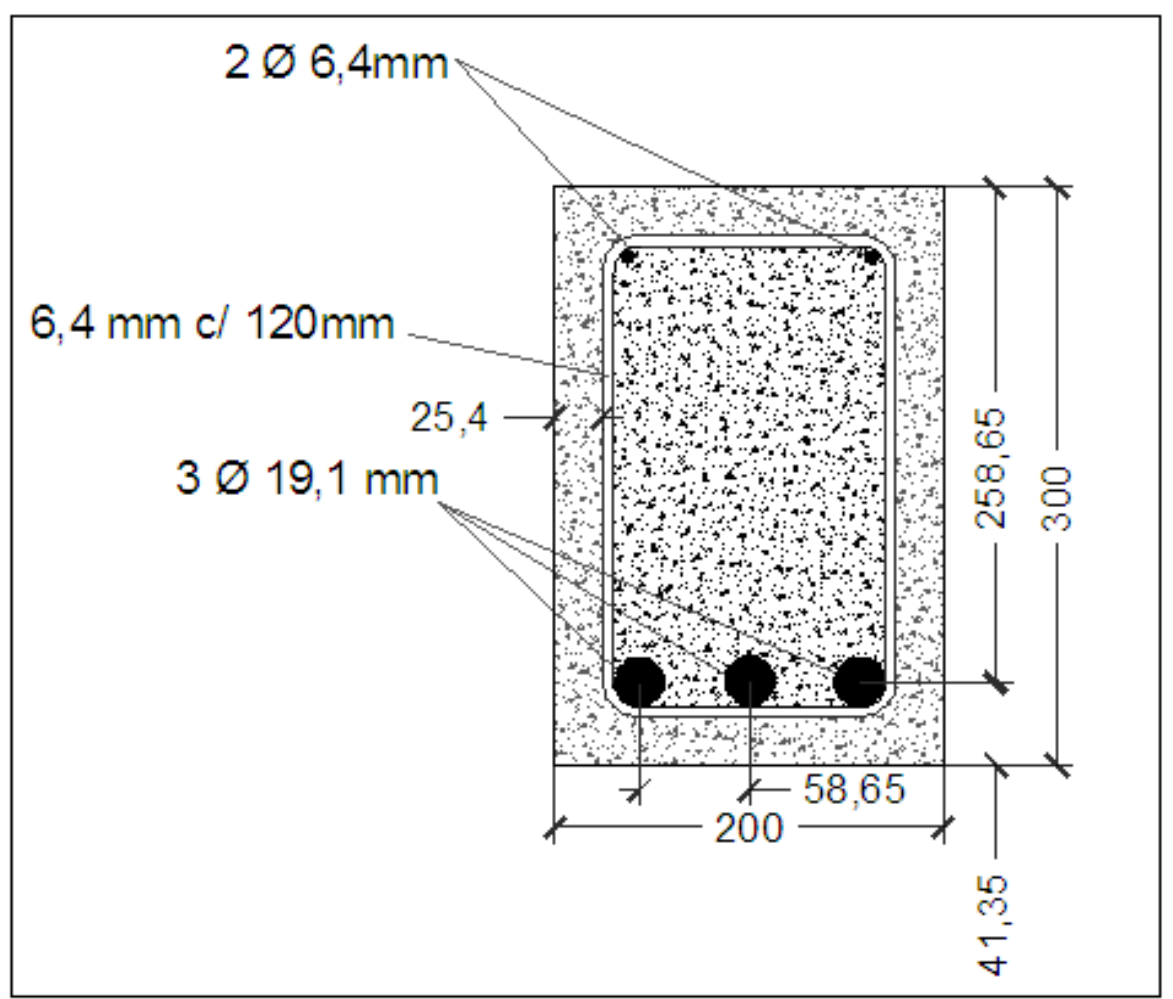

Figura 3.3 - Detalhamento final da viga submetida à flexão simples, com armadura em GFRP e um

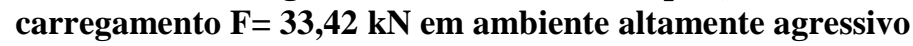

- Tem-se a Tabela 3.1 que compara alguns resultados analíticos obtidos da viga (modelo 1) no centro do vão, calculados através da formulações teóricas pela ABNT NBR 6118:2003 e pelo ACI 440.1R-06, respectivamente. 
Tabela 3.1 - Resultados obtidos da viga (flexão simples) no centro do vão através das equações.

\begin{tabular}{|c|c|c|}
\hline VIGA & NBR 6118:2003 & ACI440.1R-06 \\
\hline Seção transversal (mm) & $200 \times 300$ & $200 \times 300$ \\
\hline $\mathrm{d}(\mathrm{mm})$ & 240 & 255,55 \\
\hline$\overline{d^{\prime}(m m)}$ & 60 & 44,45 \\
\hline Comprimento livre (mm) & 3000 & 3000 \\
\hline $\mathrm{F}(\mathrm{kN})$ & 33,42 & 33,42 \\
\hline$\overline{\mathrm{M}_{\mathrm{k}}(\mathrm{kNm})}$ & 18,39 & 18,39 \\
\hline$A_{s}$ e $A_{f}\left(m^{2}\right)$ & 157 & 852 \\
\hline$A_{\mathrm{sw}}$ e $A_{f v}\left(m^{2}\right)$ & 39,27 & 63,2 \\
\hline $\mathrm{s}(\mathrm{mm})$ & 130 & 120 \\
\hline $\mathrm{x}$ e c $(\mathrm{mm})$ & 14,4 (Domínio 2) & 50,85 \\
\hline $\begin{array}{l}\text { Abertura máxima de } \\
\text { fissuras }(\mathrm{mm})\end{array}$ & $0,37(\leq 0,20)$ & $0,41(\leq 0,50)$ \\
\hline $\begin{array}{l}\text { Deslocamento máximo } \\
(\mathrm{mm})\end{array}$ & $3,39(<12,00)$ & $9,63(<12,5)$ \\
\hline
\end{tabular}

\subsection{Modelo-2- cálculo de acordo com a NBR 6118:2003}

Agora será analisado o modelo da Figura 3.4, uma viga de concreto com seção transversal (200mmx300mm) biapoiada, exposta em ambiente altamente agressivo, cujo comprimento entre apoios é de $4000 \mathrm{~mm}$, submetida a um carregamento $\mathrm{F}$ transmitido em uma região da viga distante $600 \mathrm{~mm}$ do apoio esquerdo. 


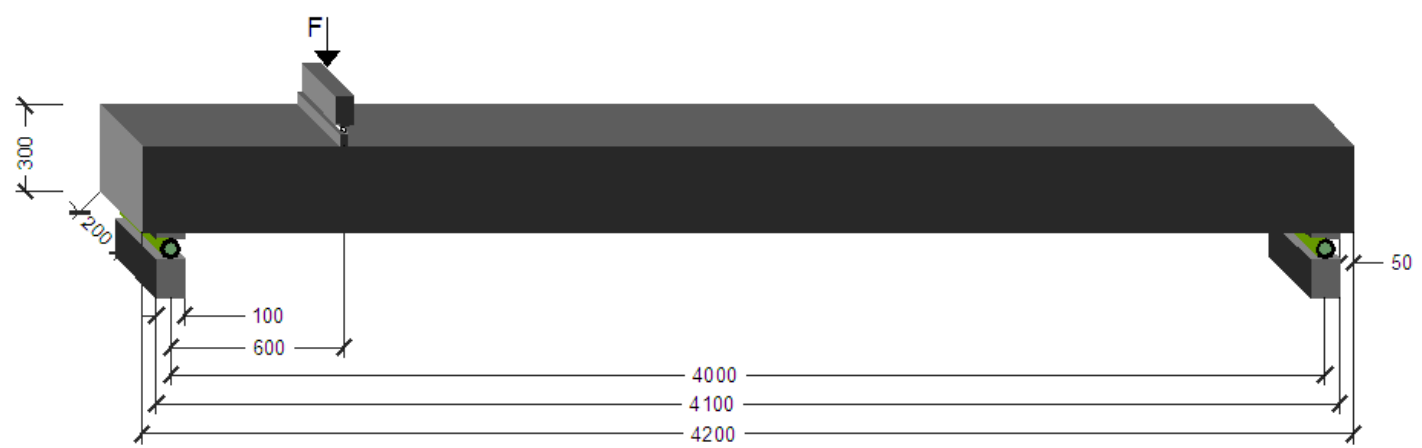

Figura 3.4 - Viga $200 \mathrm{~mm}$ x $300 \mathrm{~mm}$ submetida ao cisalhamento em ambiente altamente agressivo

Da mesma maneira, de acordo com a Tabela 2.5, para ambiente com alta agressividade e risco de deterioração elevado, a classe de agressividade ambiental é IV.

Também pelas Tabelas 2.6 e 2.7 deve ser utilizado o concreto com resistência característica mínima $f_{c k}=40 M P a$ e cobrimento nominal mínimo $c=50 \mathrm{~mm}$.

Adota-se inicialmente como armadura longitudinal tracionada $A_{s}=3 \phi 12,7 \mathrm{~mm}$; $A_{s}^{\prime}=2 \phi 8 \mathrm{~mm}$ como portaestribos e $\phi_{t}=5 \mathrm{~mm}$ como o diâmetro da armadura transversal.

Os coeficientes de ponderação da resistência do concreto e aço foram adotados iguais, ou seja: $\gamma_{c}=\gamma_{s}=1,00$

Calcula-se inicialmente a altura útil da seção transversal, resultando em 238,65mm .

Ainda, segundo a norma brasileira, utilizando a equação 2.14 , calcula-se o $M_{d, \text { lim }}$, resultando em $103,60 \mathrm{kNm}$.

Em seguida, são calculados $\beta_{x}$ e $M_{k}$ utilizando as equações de compatibilidade para armadura simples 2.8 e 2.9 respectivamente.

Tem-se que: $\beta_{x}=0,14$ (Domínio 2)

$$
M_{d}=M_{k}=40,96 k N m<M_{d, \lim }(\text { passa) }
$$

Em seguida, calcula-se $V_{k}$ e $F$ segundo as características apresentadas na Figura 3.4.

Pelo equilíbrio de forças estáticas da viga, tem-se que: $V_{k}=77,33 k N$ e $F=77,33 k N$ para o domínio 2.

Para um carregamento produzindo $M_{d, \text { máx }}=1,2 M_{d, \mathrm{lim}}=124,32 \mathrm{kNm}$, ele corresponderia ao limite da seção transversal, ou seja, domínio 4, onde $\beta_{x}=0,60$ e $F=240,78 \mathrm{kN}$. 
A partir do resultado anterior verifica-se a compressão na biela (equações 2.72 e 2.73 ) e a armadura de transversal de cisalhamento $A_{s w} / s$.

Para $F=77,33 k N, V_{S d, \text { face }}=77,26 k N<V_{R d 2}=433,10 k N$ (passa).

Então com a equação 2.74 chega-se a $V_{S d, \text { min }}=96,60 k N>V_{S d, \text { face }}$. Tem-se, utilizando estribo de 2 ramos, $a_{s w, \text { min }}=\phi 5 \mathrm{~mm} \mathrm{c} / 13 \mathrm{~cm}$. Adota-se $a_{s w}=\phi 5 m m \mathrm{c} / 13 \mathrm{~cm}$.

Na verificação da ancoragem, com o resultado obtido para $A_{s, \text { nec }}$, tem-se a necessidade de ancorar as 3 barras longitudinais de tração até os apoios, com comprimento total de $435 \mathrm{~cm}$ cada, sendo que elas devem ter ganchos verticais de $12,5 \mathrm{~cm}$.

- Verificação dos Estados Limites de Serviço (ELS)

\section{$\underline{\text { Cálculo da flecha imediata e da flecha diferida }}$}

Calcula-se pela NBR6118:03 o momento de inércia equivalente. Para isso é necessário obter primeiramente o momento de fissuração $M_{r}$ e o momento de inércia no estádio II $\left(I_{2}\right)$. Somando-se a flecha imediata e a flecha diferida chega-se a flecha total $a_{t}$, onde o deslocamento limite é dado por $l / 250$. Utiliza-se para isso as equações 2.30 a 2.45.

\section{$\underline{\text { Cálculo da abertura de fissuras }}$}

Calcula-se primeiramente: A taxa de armadura $\rho_{\mathrm{ri}}, \sigma_{\mathrm{s}}$ aproximado e $\sigma_{\mathrm{s}} \mathrm{I}_{2}$ no estádio II.

Finalmente chega-se ao menor de dois valores $w_{k}$. Utiliza-se para isso as equações 2.46 a 2.49 .

Após a verificação dos estados limites de serviço (ELS), chega-se ao detalhamento da viga do modelo 2 (Figura 3.4), utilizando reforço interno em aço segundo a NBR 6118:2003. 


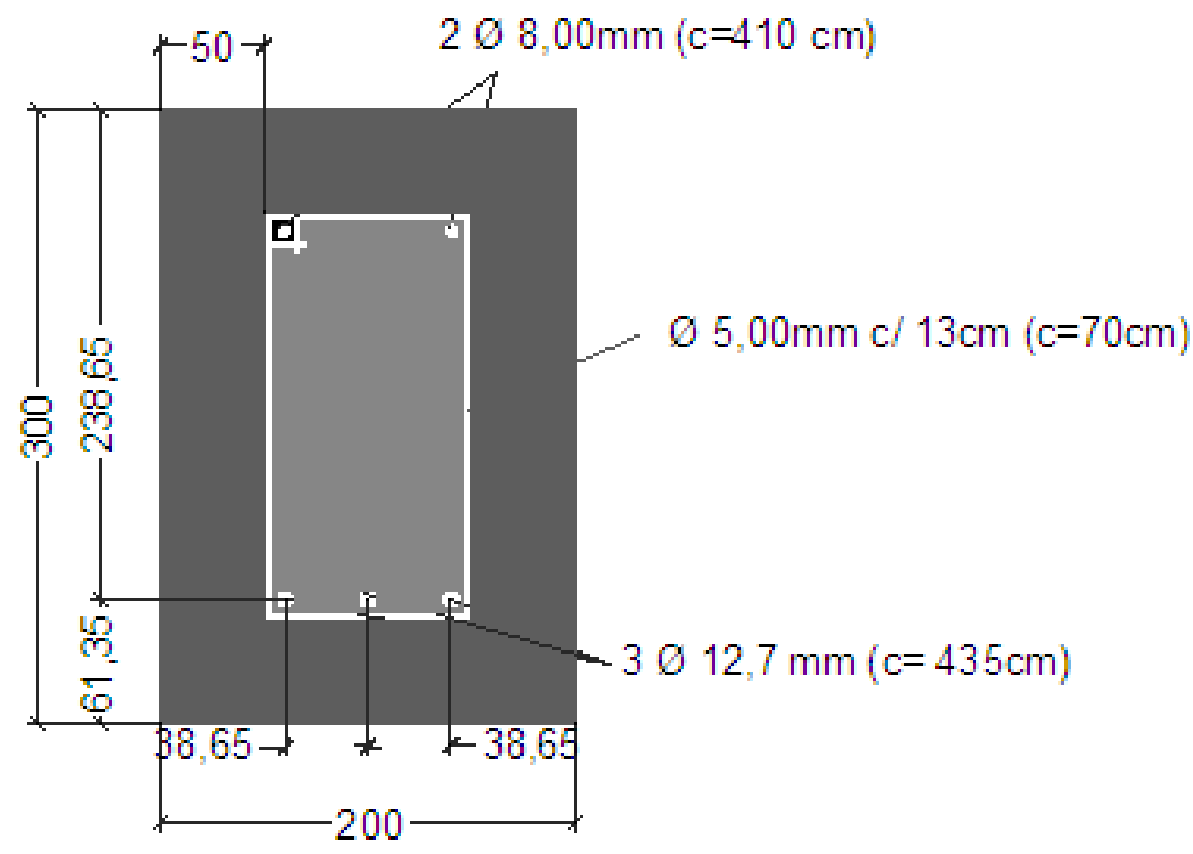

Figura 3.5 - Detalhamento final da viga submetida ao cisalhamento, com armadura convencional para um carregamento de $\mathrm{F}=77,33 \mathrm{kN}$ (domínio 2) em ambiente altamente agressivo

\subsection{Modelo-2- Cálculo de acordo com o ACI 440.1R-06}

Para o mesmo modelo da viga do item 3.3 (Figura 3.4), com as mesmas dimensões e condições ambientais (alta agressividade e risco de deterioração elevado) e também com o mesmo carregamento $F=33,42 k N$, calcula-se a seguir a armadura longitudinal principal tracionada em GFRP e verifica-se o estado limite de serviço.

-Adota-se também a mesma resistência característica do concreto $f_{c}^{\prime}=40 M P a$ e cobrimento mínimo da armadura em GFRP $(\operatorname{cov} e r=25,4 m m=1 ")$;

- Adota-se inicialmente, de acordo com a Tabela 2.1, para a armadura principal tracionada em GFRP $3 \phi 19,1 \mathrm{~mm} ; 2 \phi 6,4 \mathrm{~mm}$ para portaestribo e $\phi 9,5 \mathrm{~mm}$ para a armadura de cisalhamento;

-Calcula-se a altura útil da seção transversal $\left(d_{c}=c+\phi_{t}+\phi_{l} / 2=44,45 \mathrm{~mm}\right)$; 
-Como o carregamento é o mesmo do item 3.3, utiliza-se o mesmo momento solicitante, ou seja, $M_{u}(k N)=M_{k}=40,96 k N$;

-Calcula-se a resistência de projeto considerando reduções de serviço $\left(f_{f u}\right)$, utilizando-se a equação 2.4, onde $C_{E}$ é o fator de redução devido às condições ambientais (Tabela 2.3). Para fibra de vidro em concreto exposto a terra e água, $C_{E}=0,70 ; f_{f u}^{*}(M P a)=f_{u, a v e}-3 \sigma$ é a resistência à tração garantida das barras GFRP, que é uma propriedade reportada ao fabricante da barra de reforço. Neste modelo adota-se $f_{f u}^{*}=620,6 M P a$;

- Calcula-se o fator de resistência do concreto $\beta_{1}$ dado pela equação 2.20 e a taxa de reforço balanceado $\rho_{f b}$ dado pela equação 2.19. Para esse cálculo adota-se o módulo de elasticidade de projeto da barra de FRP $\left(E_{f}=44800 M P a\right)$;

-Para o cálculo da taxa de armadura utiliza-se a equação 2.21. Calcula-se a relação $\rho_{f} / \rho_{f b}$ que resulta em: $\rho_{f} / \rho_{f b}=1,186$. Como $\rho_{f b}<\rho_{f}<1,4 \rho_{f b}$, tem-se a ruína da viga governada pela ruptura da barra e esmagamento do concreto.

Chega-se a $\phi M_{n}=46,27 k N m>M_{u}=40,96 k N m$ (Passa)

-Em seguida verifica-se a largura de fissura no estado limite de serviço;

Utilizam-se as equações $2.59,2.69$ e 2.70 , onde $M_{(D L+L L)}=40,96 \mathrm{kNm}$.

Dessa forma, tem-se: $f_{f}=201,48 M P a$. Calculando-se o gradiente de deformação e a abertura de fissura para ambiente altamente agressivo dados pelas equações 2.57 e 2.50, respectivamente, tem-se $w=0,91 \mathrm{~mm}>0,5 \mathrm{~mm}$ (Não Passa), onde $k_{b}=1,6$ e $s=55,45 \mathrm{~mm}$ são o coeficiente de vinculação entre FRP e o concreto e o espaçamento transversal, respectivamente, conforme prescreve o ACI.

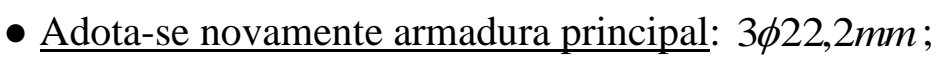

Pela Tabela 2.1 tem-se:

$A_{f}=1161 \mathrm{~mm}^{2}$ e $d_{c}=46 \mathrm{~mm}$ e $d=254 \mathrm{~mm}$ 
Como $\rho_{f} / \rho_{f b}=1,627$, tem-se a ruína da viga governada pelo esmagamento do concreto. Utilizando o fator de redução de resistência da equação 2.29 e através das equações 2.28 e 2.27, respectivamente, calcula-se o momento resistente $M_{n}$. Então tem-se:

$$
\phi M_{n}=56,02 k N m>M_{u}=40,96 k N m \text { (Passa) }
$$

-Em seguida verifica-se novamente a largura de fissura no estado limite de serviço;

Tem-se: $w=0,71 \mathrm{~mm}>0,5 \mathrm{~mm}$ ( Não Passa e deve ser realizada nova iteração de cálculo)

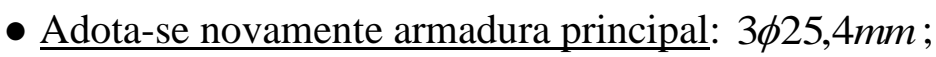

Pela Tabela 2.1 tem-se:

$A_{f}=1530 \mathrm{~mm}^{2}$ e $d_{c}=47,6 \mathrm{~mm}$ e $d=252,4 \mathrm{~mm}$

Como $\rho_{f} / \rho_{f b}=2,156$, tem-se a ruína da viga governada pelo esmagamento do concreto. Utilizando o fator de redução de resistência da equação 2.29 e através das equações 2.28 e 2.27, respectivamente, calcula-se o momento resistente $M_{n}$. Então tem-se:

$$
\phi M_{n}=61,09 k N m>M_{u}=40,96 K N m(\text { Passa })
$$

-Em seguida verifica-se novamente a largura de fissura no estado limite de serviço;

Tem-se: $w \cong 0,5 \mathrm{~mm}$ (Passa)

-Verifica-se o deslocamento a longo prazo da viga, calcula-se o momento de inércia da seção bruta e o momento crítico de fissuração, utiliza-se as equações 2.60 a 2.68, tem-se:

$$
\Delta_{L T}=27,26 \mathrm{~mm}>\frac{l}{240}=\frac{4000}{240}=16,67 \mathrm{~mm} \text { (Não passa). Pelo resultado obtido dever-se-ia }
$$
aumentar a altura da viga para $400 \mathrm{~mm}$, que é o que prescreve o ACI como prédimensionamento, sendo $h=\frac{l}{10}=\frac{4000}{10}=400 \mathrm{~mm}$. Mas nesse estudo considera-se esse resultado favorável. Continua-se com a mesma seção transversal para que se faça a análise final no capítulo 4.

-Verifica-se também a fadiga de tensão limite para as barras de GFRP, utiliza-se as equações 2.69 e 2.70 , tem-se:

$$
f_{f, s}=29,52 M P a \leq 0,20 f_{f u}=86,88 M P a(\text { Passa })
$$


-Verifica-se também o espaçamento máximo $\left(s_{\text {máx }}\right)$ entre as barras de GFRP para o controle de fissuras, utilizando a equação 2.55 no modelo proposto por Bakis e Ospina (2006), tem-se:

$$
s=\left(b-2 d_{c}\right) / 2=52,40 m m<s_{\text {máx }}=63,89 \mathrm{~mm}<100,85 \mathrm{~mm} \text { (Passa) }
$$

-Verifica-se o cobrimento mínimo entre as barras de GFRP de acordo com o ACI 318-05 (adota-se o mesmo valor utilizado para barras de aço) tem-se:

$$
c_{\text {livre }}=s-d_{b}=52,40-25,4=27 m m>1 "=25,4 m m(\text { Passa })
$$

\section{-Cálculo da armadura transversal de cisalhamento em GFRP.}

- Deve ser verificada a condição da equação 2.85 , onde na região próxima ao apoio tem-se: $V_{u}=68,50 \mathrm{kN}$.

Seja $\kappa=c / d$, onde $c=65,12 \mathrm{~mm}$ é a distância extrema da fibra comprimida até a linha neutra. Pela equação 2.89 tem-se a contribuição de resistência ao cisalhamento do concreto dado por $V_{c}=32,95 \mathrm{kN}$.

-Verifica-se de acordo com o ACI 318-05 se a armadura mínima transversal de cisalhamento é requerida (utilizando a equação 2.95).

$$
V_{u}>\frac{\Phi V_{c}}{2}=12,36 k N(\text { É requerida) }
$$

Para $\phi=9,5 \mathrm{~mm} ; A_{f v}=2 \times 71=142 \mathrm{~mm}^{2} \quad($ Tabela 2.1)

-Para que a equação 2.91 seja satisfeita é necessário adotar a mínima razão recomendada entre o raio de curvatura da barra de GFRP e o seu diâmetro na equação 2.92. Para estribos verticais a razão é de $\frac{r_{b}}{d_{b}}=3$. Então $f_{f b}=0,45 f_{f u}$, tem-se então $f_{f v}=179,20 M P a \leq f_{f b}=195,49 M P a$ (passa)

- Para que o diâmetro adotado da armadura transversal forneça uma armadura mínima de reforço de cisalhamento em GFRP, deve-se ter o espaçamento dos estribos calculado através da equação 2.96, resultando no intervalo $s \leq 364 \mathrm{~mm}$. 
Adota-se armadura mínima com espaçamento limite de estribo vertical GFRP dado por: $s \leq\left\{\frac{d}{2}=126,20 \mathrm{~mm}\right\}$ ou $s \leq\left\{24^{\prime \prime}=600 \mathrm{~mm}\right\}$, então $s=120 \mathrm{~mm}$

•Cálculo da contribuição ao cisalhamento do estribo vertical adotado $\left(V_{f}\right)$

Substituindo $s=120 \mathrm{~mm}$ na equação 2.90 tem-se: $V_{f}=53,52 \mathrm{kN}$

Finalmente $V_{n}=V_{c}+V_{f}$, então $\Phi V_{n}=64,85 k N<V_{u}=68,50 k N$ (Não passa)

- Deve-se então diminuir o espaçamento das barras transversais. Para isso adota-se $s=110 \mathrm{~mm}$.

É feita então nova iteração, calcula-se a nova contribuição ao cisalhamento da armadura transversal após a redução do espaçamento:

Substituindo $s=110 \mathrm{~mm}$ na equação 2.90 tem-se: $V_{f}=58,39 \mathrm{kN}$

Finalmente $V_{n}=V_{c}+V_{f}$, então $\Phi V_{n}=68,51 k N>V_{u}=68,50 k N$ (Passa)

-Em seguida deve ser verificado se a tensão requerida da barra pode ser incrementada e se a ancoragem por aderência é suficiente:

Utilizando-se a equação 2.100 tem-se $C=26,20 \mathrm{~mm}$

$l_{e}=$ comprimento de aderência da barra GFRP.

$\alpha=1,0 \mathrm{p} / \mathrm{h} \leq 305 \mathrm{~mm}, d_{b}=25,4 \mathrm{~mm}$ e adotando-se $l_{e}=\frac{l}{2}=2000 \mathrm{~mm}$

Como resultado da equação 2.99 tem-se $f_{f e}=783,23 M P a>f_{f u}=434,42 M P a$, então deve-se adotadar: $f_{f e}=f_{f u}=434,42 M P a>f_{f}=277,96 M P a$

Dessa forma a resistência da barra não é limitada pela aderência ou ligação de superfície.

É necessário verificar a condição de ancoragem na região de momento positivo:

Tem-se $l_{a}=0$, não há inclusão de comprimento adicional no apoio. Considerando-se $f_{f r}=f_{f}=277,96 \mathrm{MPa}$ e substituindo-se os valores nas equações 2.101 e 2.102, respectivamente, tem-se:

$$
l_{d}=329 \mathrm{~mm}<1159 \mathrm{~mm}(\text { Passa) }
$$


- Finalmente tem-se o detalhamento da viga (Figura 3.6) feita com reforço longitudinal e transversal em GFRP.

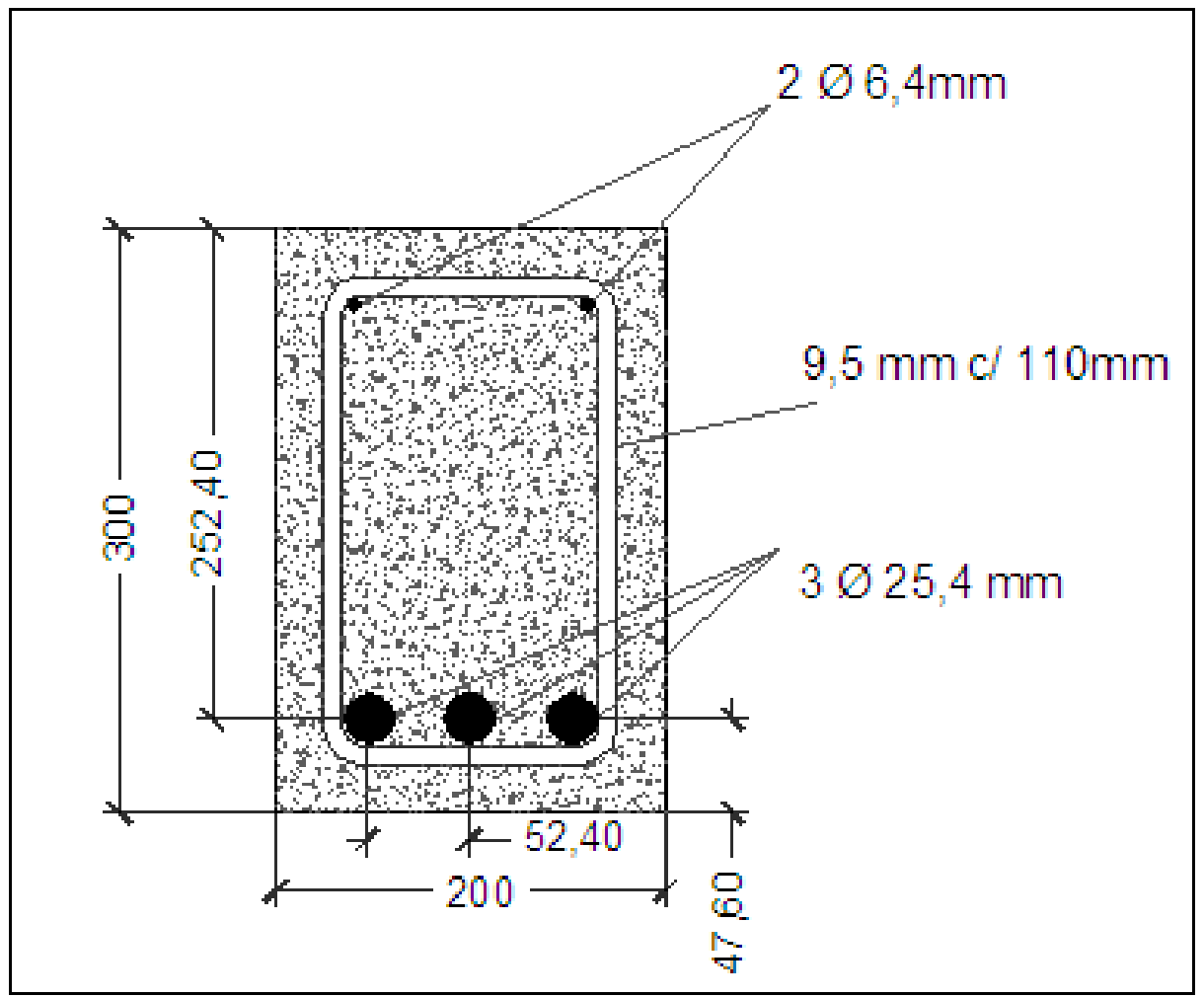

Figura 3.6 - Detalhamento final da viga submetida ao cisalhamento, com armadura em GFRP e um carregamento $F=77,33 \mathrm{kN}$ em ambiente altamente agressivo

- Na Tabela 3.2 comparam-se alguns resultados analíticos obtidos da viga (modelo 2) na região de máxima solicitação, calculados através das formulações teóricas, pela ABNT NBR 6118:2003 e pelo ACI 440.1R-06, respectivamente. 
Tabela 3.2 - Resultados obtidos da viga (cisalhamento) através das equações.

\begin{tabular}{|c|c|c|}
\hline VIGA & NBR 6118:2003 & ACI440.1R-06 \\
\hline Seção transversal (mm) & $200 \times 300$ & $200 \times 300$ \\
\hline $\mathrm{d}(\mathrm{mm})$ & 238,65 & 252,4 \\
\hline $\mathrm{d}^{\prime}(\mathrm{mm})$ & 61,35 & 47,6 \\
\hline Comprimento livre (mm) & 4000 & 4000 \\
\hline $\mathrm{F}(\mathrm{kN})$ & 77,33 & 77,33 \\
\hline $\mathrm{M}_{\mathrm{k}}(\mathrm{kNm})$ & 40,96 & 40,96 \\
\hline$A_{s}$ e $A_{f}\left(m^{2}\right)$ & 380 & 1530 \\
\hline$A_{s w}$ e $A_{f v}\left(m^{2}\right)$ & 39,27 & 142 \\
\hline $\mathrm{s}(\mathrm{mm})$ & 130 & 110 \\
\hline $\mathrm{x} \mathrm{e} \mathrm{c}(\mathrm{mm})$ & 33,41(Domínio 2) & 65,66 \\
\hline $\begin{array}{l}\text { Abertura máxima de fissuras } \\
\qquad(\mathrm{mm})\end{array}$ & $0,26(\leq 0,20)$ & $0,5(\leq 0,50)$ \\
\hline $\begin{array}{l}\text { Deslocamento máximo } \\
\qquad(\mathrm{mm})\end{array}$ & $12,54(<16,00)$ & $27,26(<16,67)$ \\
\hline
\end{tabular}

\subsection{Análise dos modelos pelo método dos elementos finitos}

Como no início do trabalho adotou-se como referência a comparação entre modelos cuja seção transversal das vigas e carregamento fossem os mesmos, tanto para as vigas armadas em aço como para as vigas armadas em GFRP. Para a análise em elementos finitos introduziu-se também o mesmo carregamento, igual ao utilizado no cálculo analítico; também utilizou-se na simulação as mesmas armaduras que foram calculadas através das equações anteriores. 
Foram feitas quatro simulações, sendo duas de flexão com armadura em aço e GFRP (Figura 3.1) e duas de cisalhamento também com armadura em aço e GFRP (Figura 3.4), utilizando-se do software "solid edge versão 21 acadêmica", onde os modelos de flexão possuem a mesma seção transversal e a mesma armadura, das Figuras 3.2 e 3.3 respectivamente. Os modelos de cisalhamento possuem a mesma seção transversal e a mesma armadura das Figuras 3.5 e 3.6 respectivamente.

Para análise dos modelos em elementos finitos foi utilizado o software "ansys versão 9 acadêmica”. Através do método dos elementos finitos foi possível obter resultados de deformação, deslocamento e tensões máximas devido ao carregamento de flexão e de cisalhamento.

- Adotou-se para os modelos de flexão e cisalhamento como base de entrada de dados elementos geométricos predominantemente tetraédricos, para a simulação estática. A entrada de dados relativa às características dos materiais que foram utilizados na simulação podem ser vistos na Tabela 3.3.

Para efeito de simulação as barras transversais em GFRP foram consideradas com seção retangular com área equivalente à área calculada analiticamente pelo ACI 4401R.06. As propriedades dos materiais utilizados na simulação (Tabela 3.3) para as barras GFRP foram retiradas da Tabela 2.2, onde em alguns casos foi adotada uma média entre valores máximo e mínimo. 
Tabela 3.3 - Entrada de dados para a simulação em elementos finitos dos modelos da vigas

\begin{tabular}{|c|c|c|c|}
\hline \multirow[b]{2}{*}{ PROPRIEDADES } & \multicolumn{3}{|c|}{ MATERIAIS } \\
\hline & CONCRETO & AÇO CA50 & GFRP \\
\hline $\begin{array}{c}\text { MÓDULO DE } \\
\text { ELASTICIDADE (Pa) }\end{array}$ & $3 e^{10}$ & $2 e^{11}$ & $4,3 \mathrm{e}^{10}$ \\
\hline COEF. POISSON & 0,18 & 0,30 & 0,26 \\
\hline $\begin{array}{c}\text { DENSIDADE } \\
\left(\mathbf{k g} / \mathbf{m}^{3}\right)\end{array}$ & 2300 & 7850 & 1670 \\
\hline $\begin{array}{c}\text { COEF. EXPANSÃO } \\
\text { TÉRMICA }\left(/^{\circ} \mathrm{C}\right)\end{array}$ & $1,4 \mathrm{e}^{-5}$ & $1,2 \mathrm{e}^{-5}$ & $8 e^{-6}$ \\
\hline $\begin{array}{c}\text { RESIST. ÚLTIMA A } \\
\text { TRAÇÃO (Pa) }\end{array}$ & $5 e^{6}$ & $4,6 e^{8}$ & $2,41 \mathrm{e}^{8}$ \\
\hline $\begin{array}{l}\text { RESIST. ÚLTIMA A } \\
\text { COMPRESSÃO (Pa) }\end{array}$ & $4,1 \mathrm{e}^{7}$ & 0 & $1,93 e^{8}$ \\
\hline $\begin{array}{c}\text { RESIST. } \\
\text { ESCOAMENTO A } \\
\text { TRAÇÃO }(\mathbf{P a})\end{array}$ & 0 & $2,5 \mathrm{e}^{8}$ & \\
\hline \begin{tabular}{c|} 
RESIST. \\
ESCOAMENTO A \\
COMPRESSÃO $(\mathbf{P a})$
\end{tabular} & 0 & $2,5 \mathrm{e}^{8}$ & \\
\hline
\end{tabular}

\subsubsection{Resultados obtidos nos modelos de flexão}

Após a entrada de dados geraram-se duas malhas de elementos geométricos predominantemente tetraédricos, uma para o modelo flexão em aço e outra para o modelo flexão em GFRP. Os elementos geométricos para o concreto podem ser vistos na Figura 3.7 e da armadura na Figura 3.8, tendo-se então a malha de elementos finitos do conjunto concreto e armadura para o início da simulação em elementos finitos na flexão. 


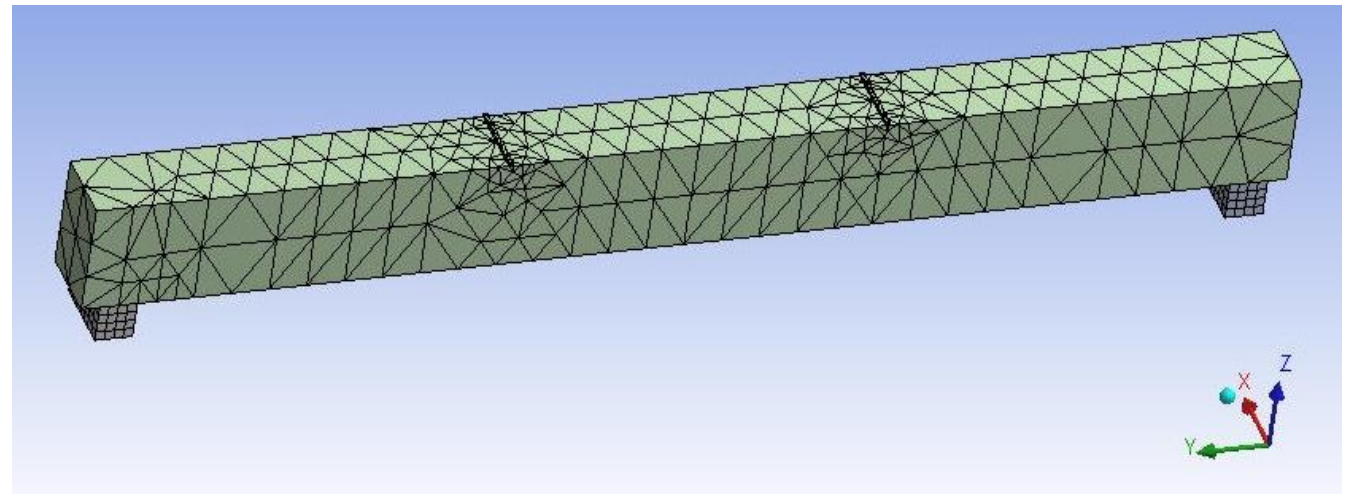

Figura 3.7 - Malha de elementos finitos para os elementos do concreto da viga na flexão

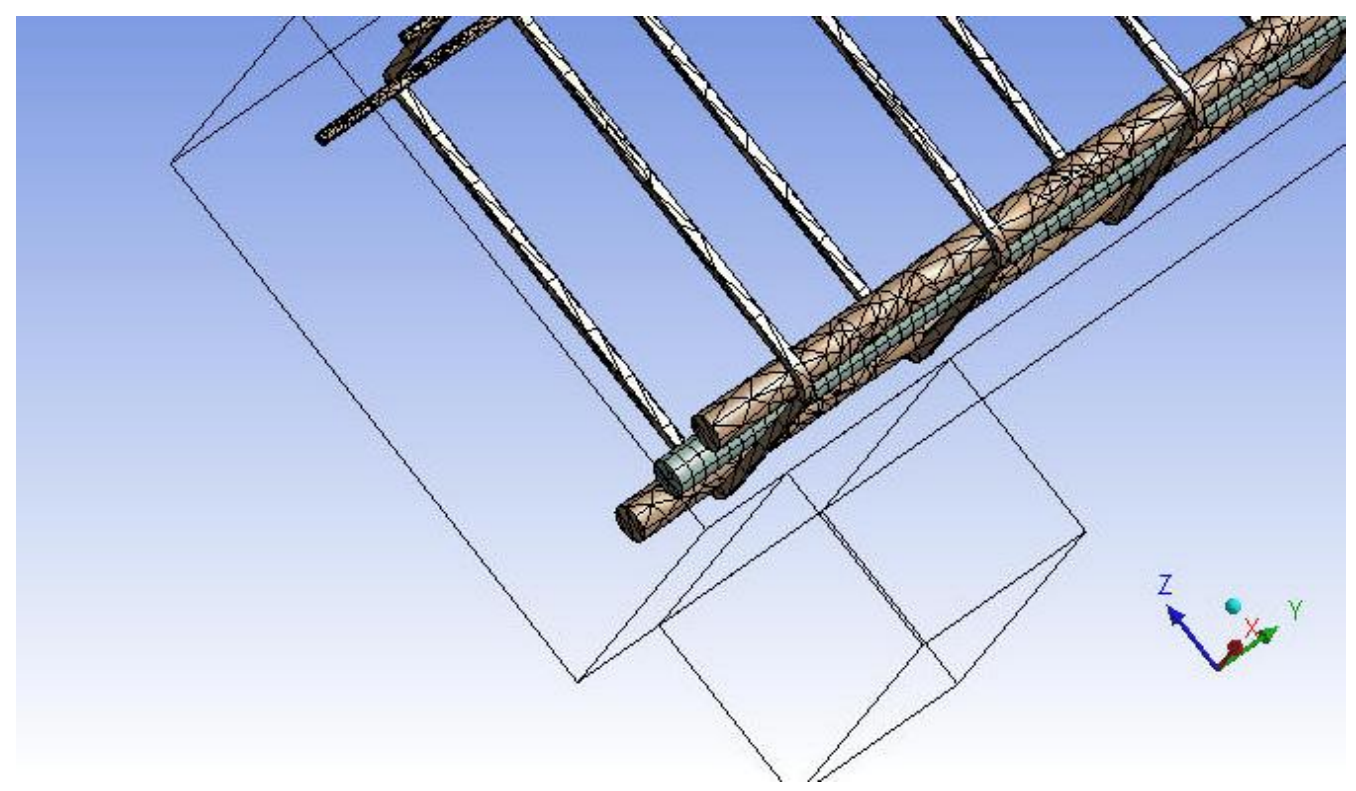

Figura 3.8 - Malha de elementos finitos para os elementos da armadura na flexão

Fez-se uma adaptação de carregamento nos modelos de flexão, onde o carregamento concentrado $\mathrm{F} / 2=16,71 \mathrm{kN}$ é distribuído uniformemente ao longo da largura da viga, em uma região de espessura igual a $10 \mathrm{~mm}$, criando uma pressão uniforme $\mathrm{P}=8,36 \mathrm{MPa}$, aplicado em duas regiões distintas da viga distantes entre si L/3 (Figura 3.1).

- Devido a esse carregamento, na flexão, que se encontra no domínio 2 para a viga armada em aço (Figura 3.2), tem-se que o deslocamento máximo global do conjunto viga armada é o mesmo da armadura com aço (Figuras 3.9a e 3.9b respectivamente). 


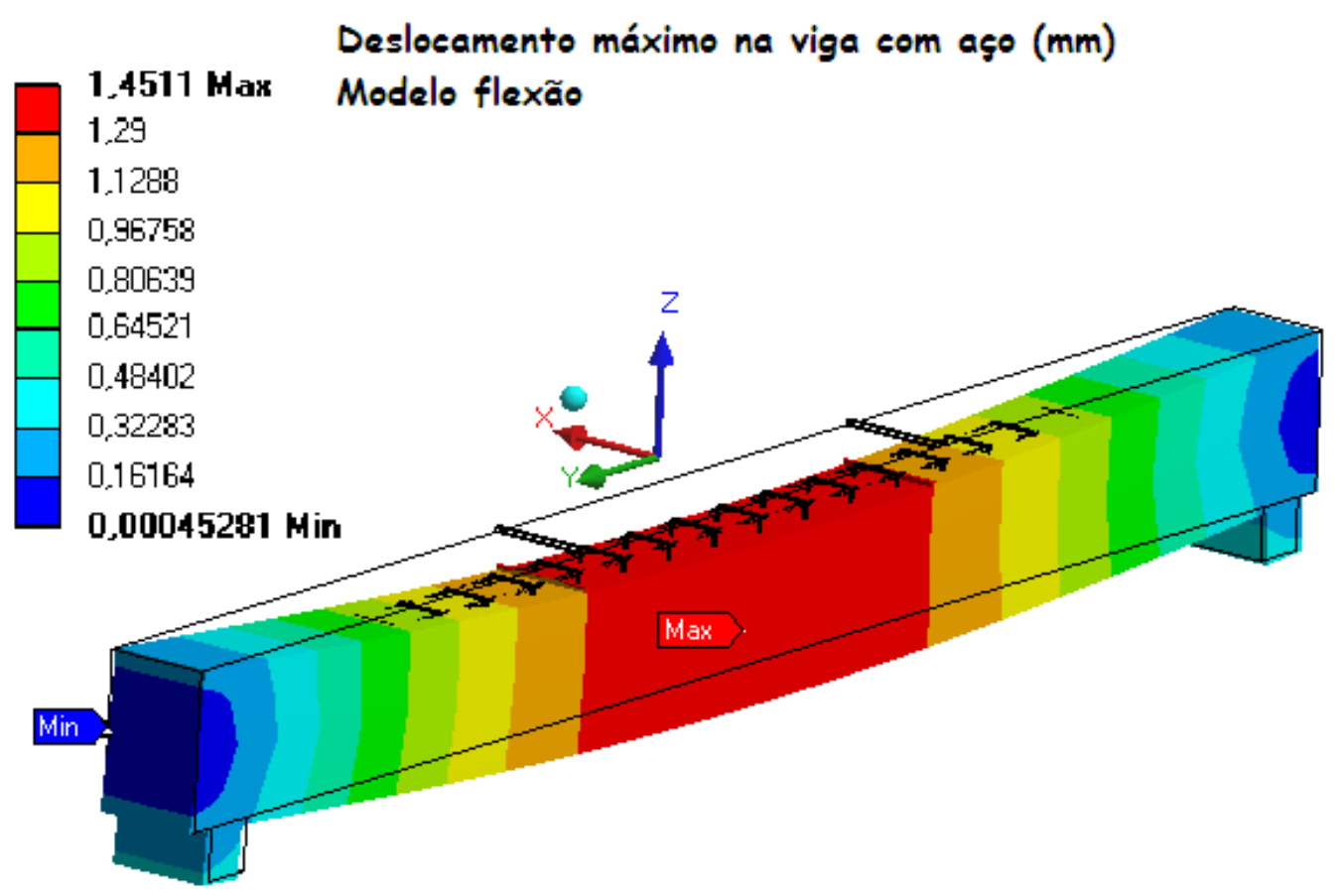

Figura 3.9a - Deslocamento máximo na viga armada com aço na flexão

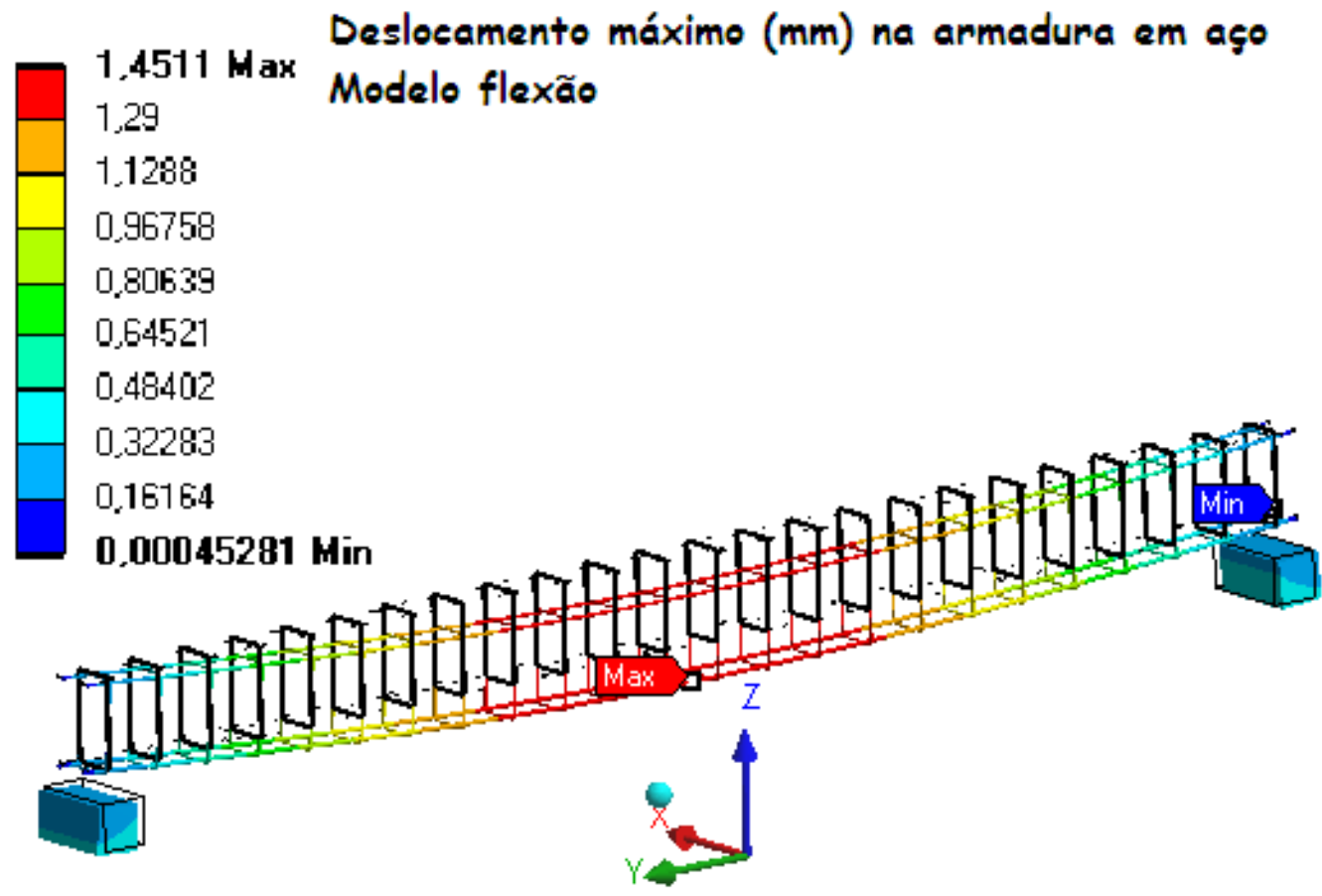

Figura 3.9b - Deslocamento máximo na armadura em aço na flexão

Para o mesmo carregamento na flexão para a viga da Figura 3.3, com a utilização de barras em GFRP, tem-se também que o deslocamento máximo global do conjunto viga armada é igual ao deslocamento da armadura em GFRP (Figuras 3.10a e 3.10b respectivamente). 


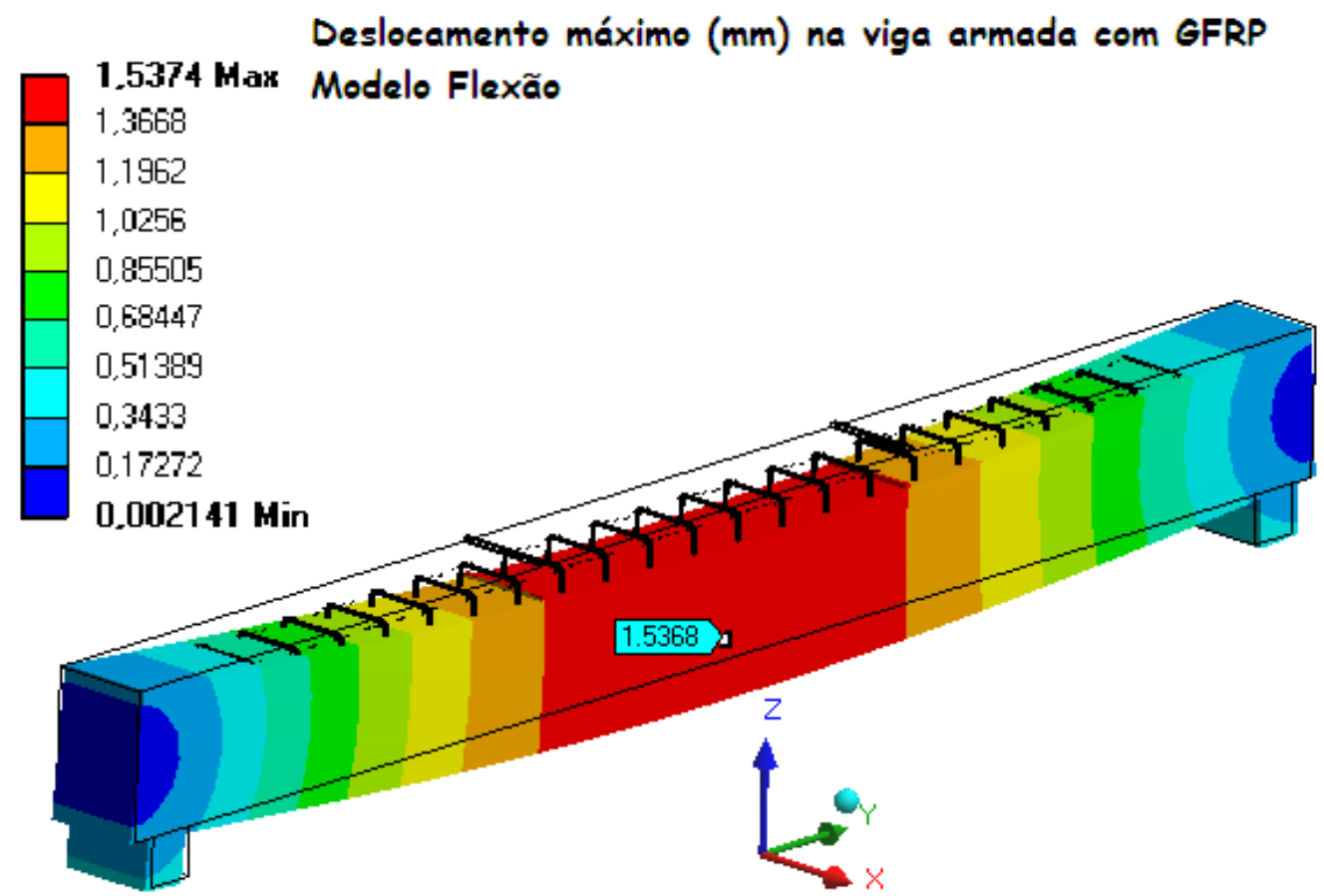

Figura 3.10a - Deslocamento máximo na viga armada com GFRP na flexão

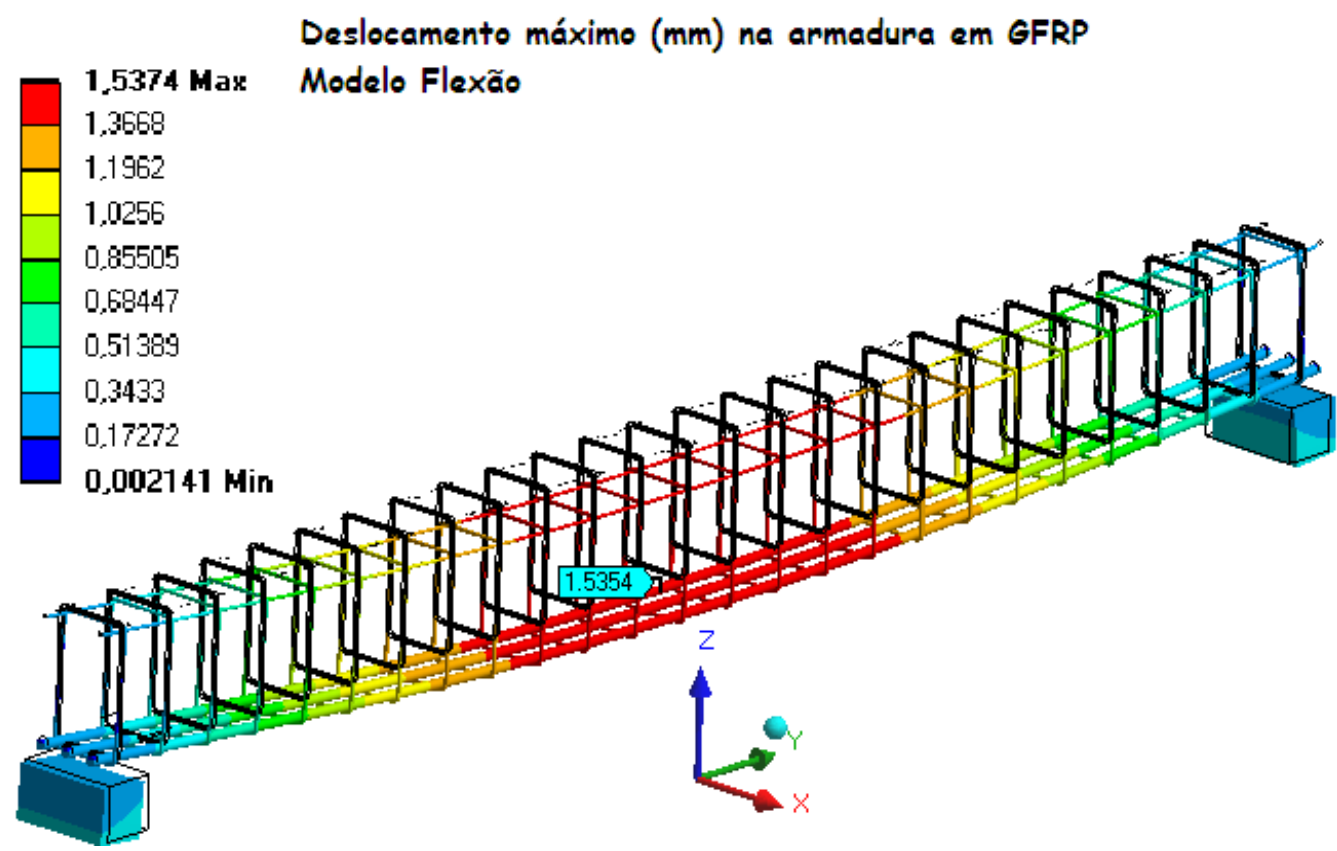

Figura 3.10b - Deslocamento máximo na armadura em GFRP na flexão

A deformação máxima $(\mathrm{mm} / \mathrm{mm})$ da viga armada com aço e da armadura podem ser vistas nas Figuras 3.11a e 3.11b respectivamente. 


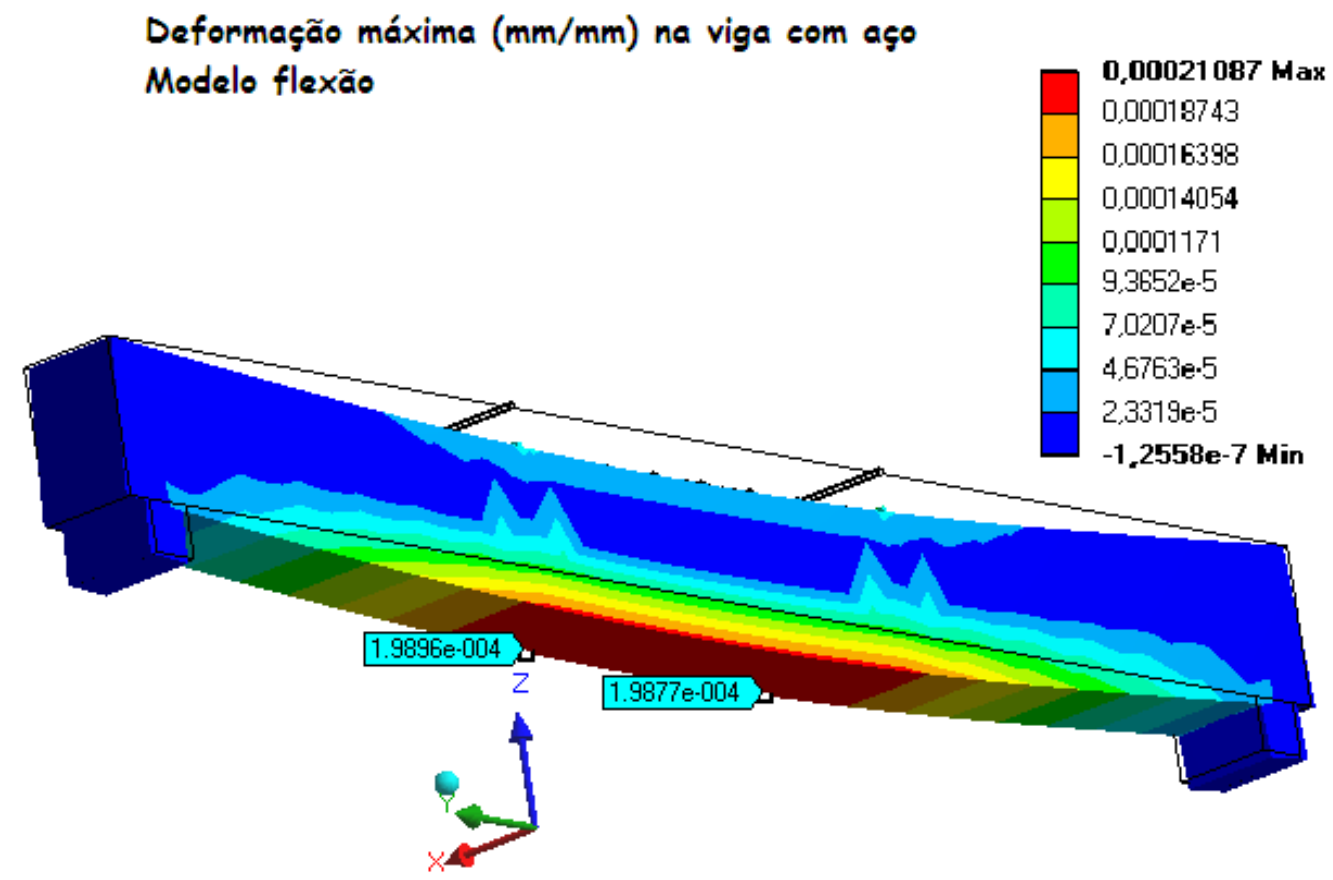

Figura 3.11a - Deformação máxima na viga armada em aço na flexão

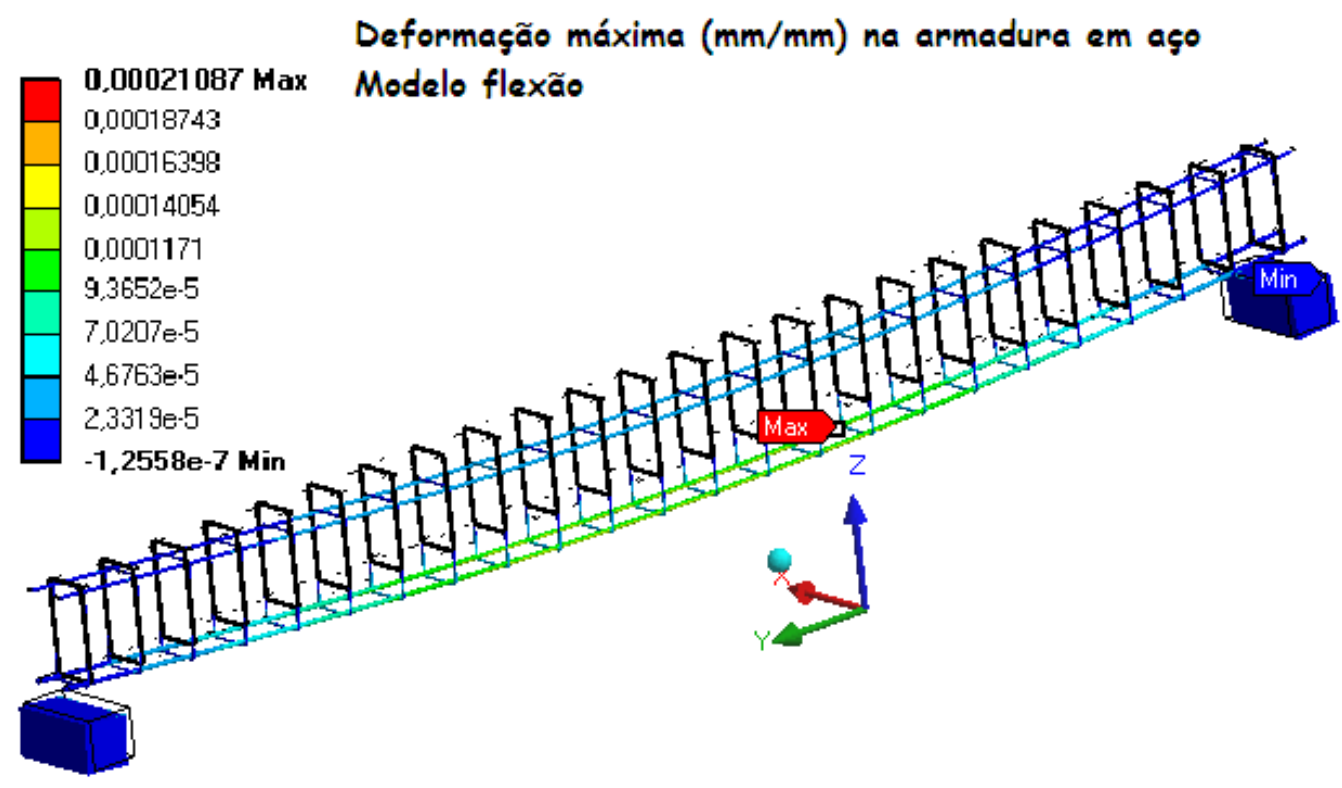

Figura 3.11b - Deformação máxima na armadura em aço na flexão

A deformação máxima $(\mathrm{mm} / \mathrm{mm})$ da viga armada com GFRP e da armadura em GFRP podem ser vistas nas Figuras 3.12a e 3.12b respectivamente. Observa-se que a máximadeformação do conjunto não se encontra na região tracionada da viga, e sim na região próxima ao apoio. 


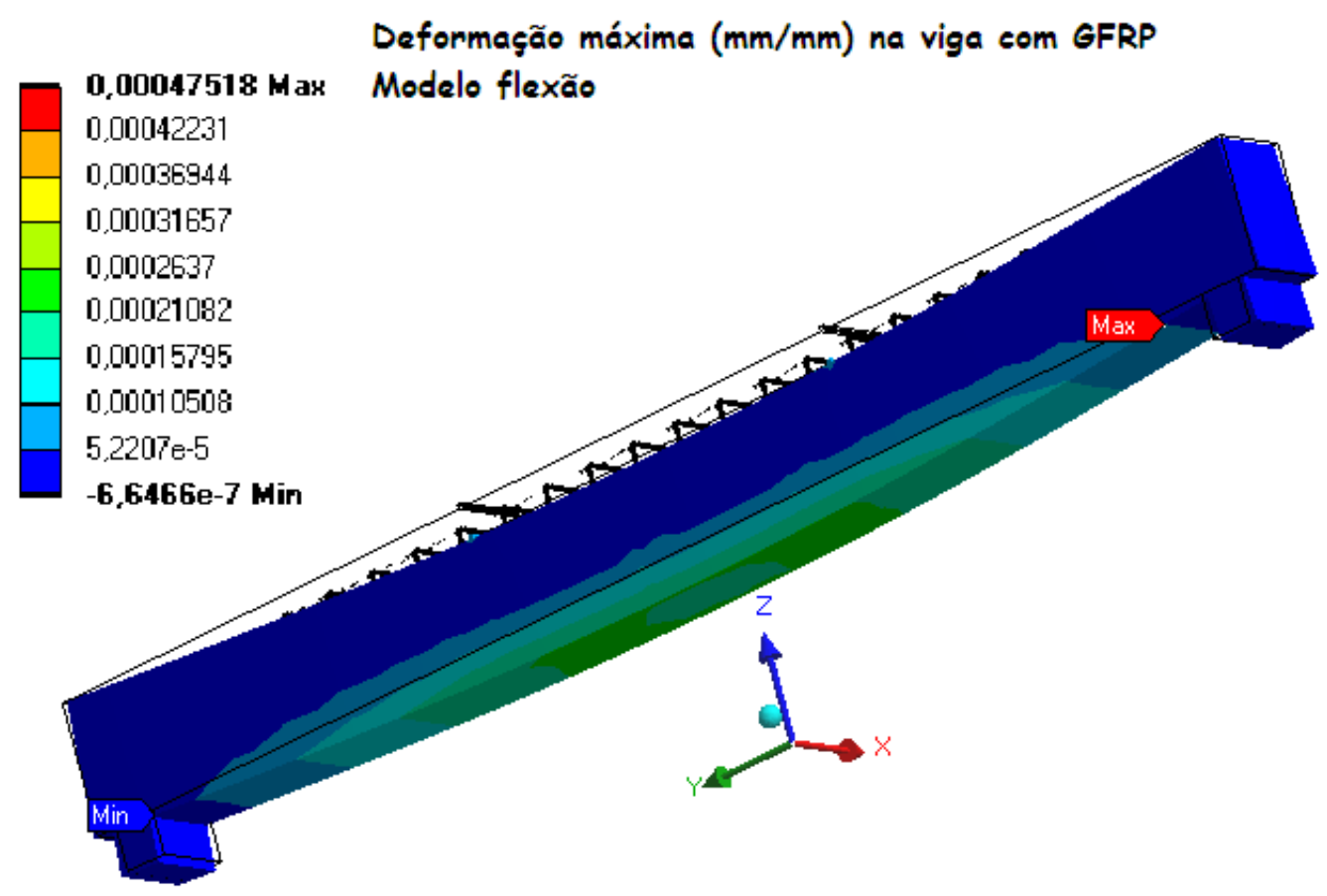

Figura 3.12a - Deformação máxima na viga armada com GFRP na flexão

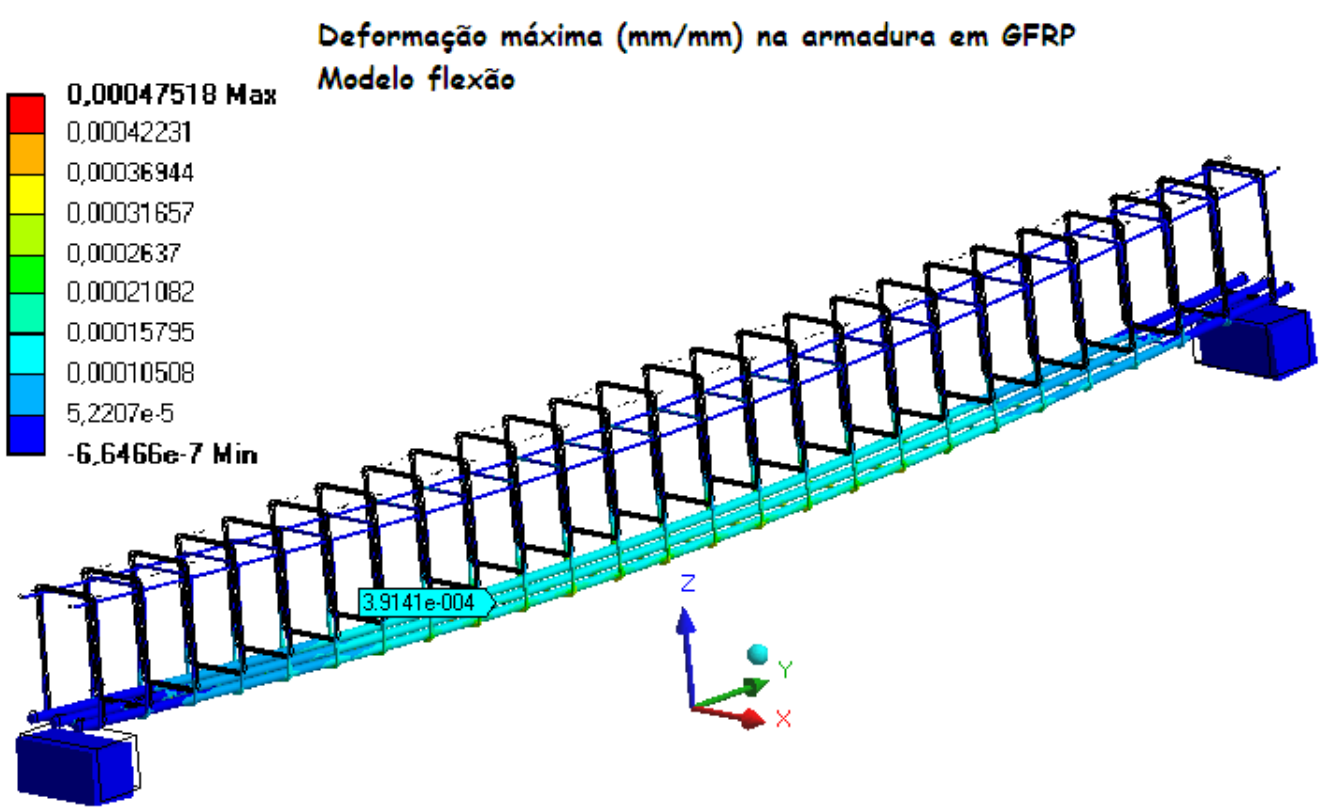

Figura 3.12b - Deformação máxima na armadura em GFRP na flexão

As tensões máximas de tração e compressão (MPa) na viga armada com aço podem ser vistas na Figura 3.13. Observa-se que as máximas tensões de tração e compressão estão dentro de suas respectivas zonas de tração e compressão, respectivamente. 


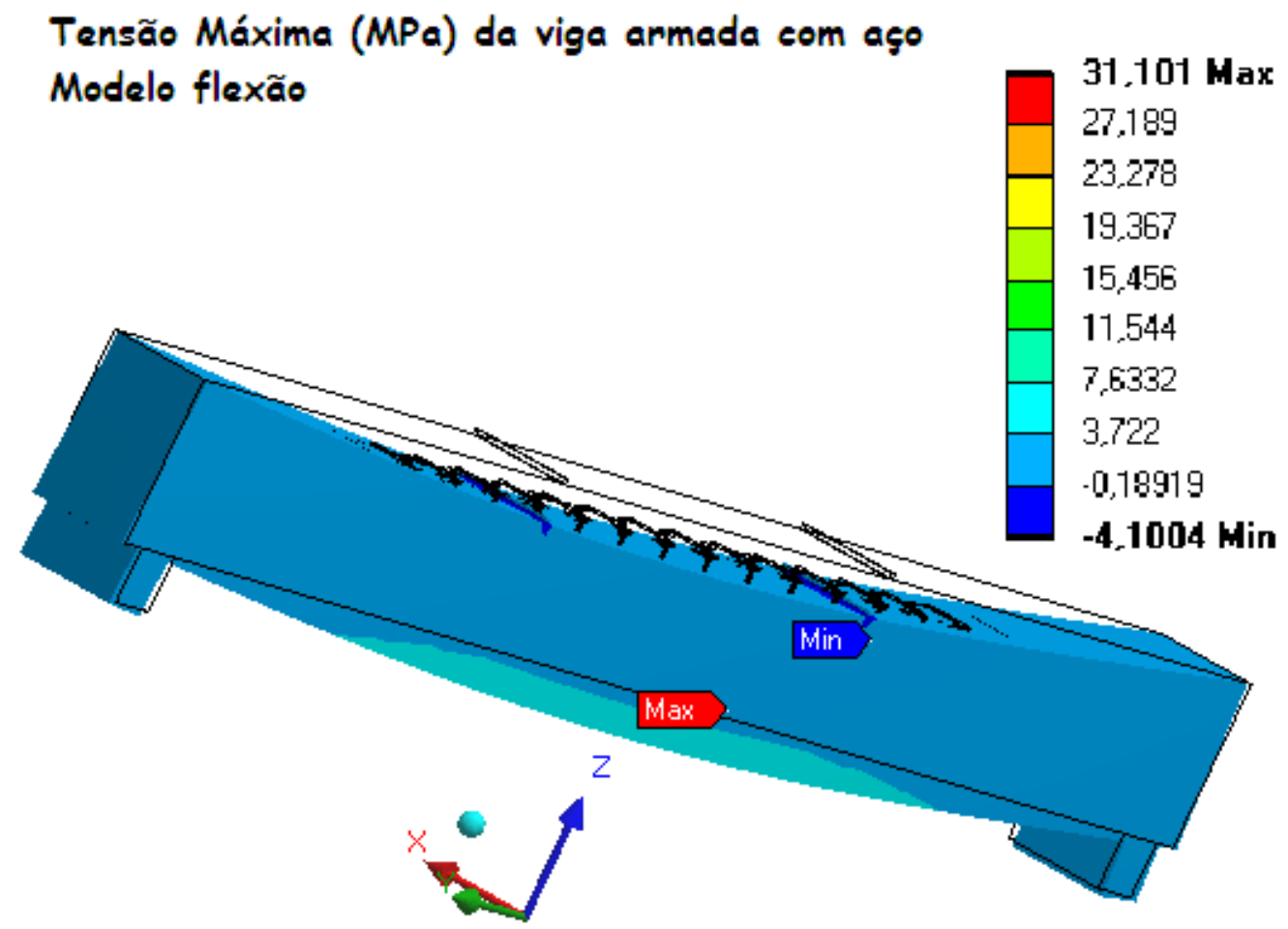

Figura 3.13 - Tensão máxima de tração e compressão da viga armada com aço na flexão

A tensão máxima de tração (MPa) na viga armada em GFRP, onde os valores da tensão na armadura em GFRP são os mesmos, podem ser vistos na Figura 3.14a. 


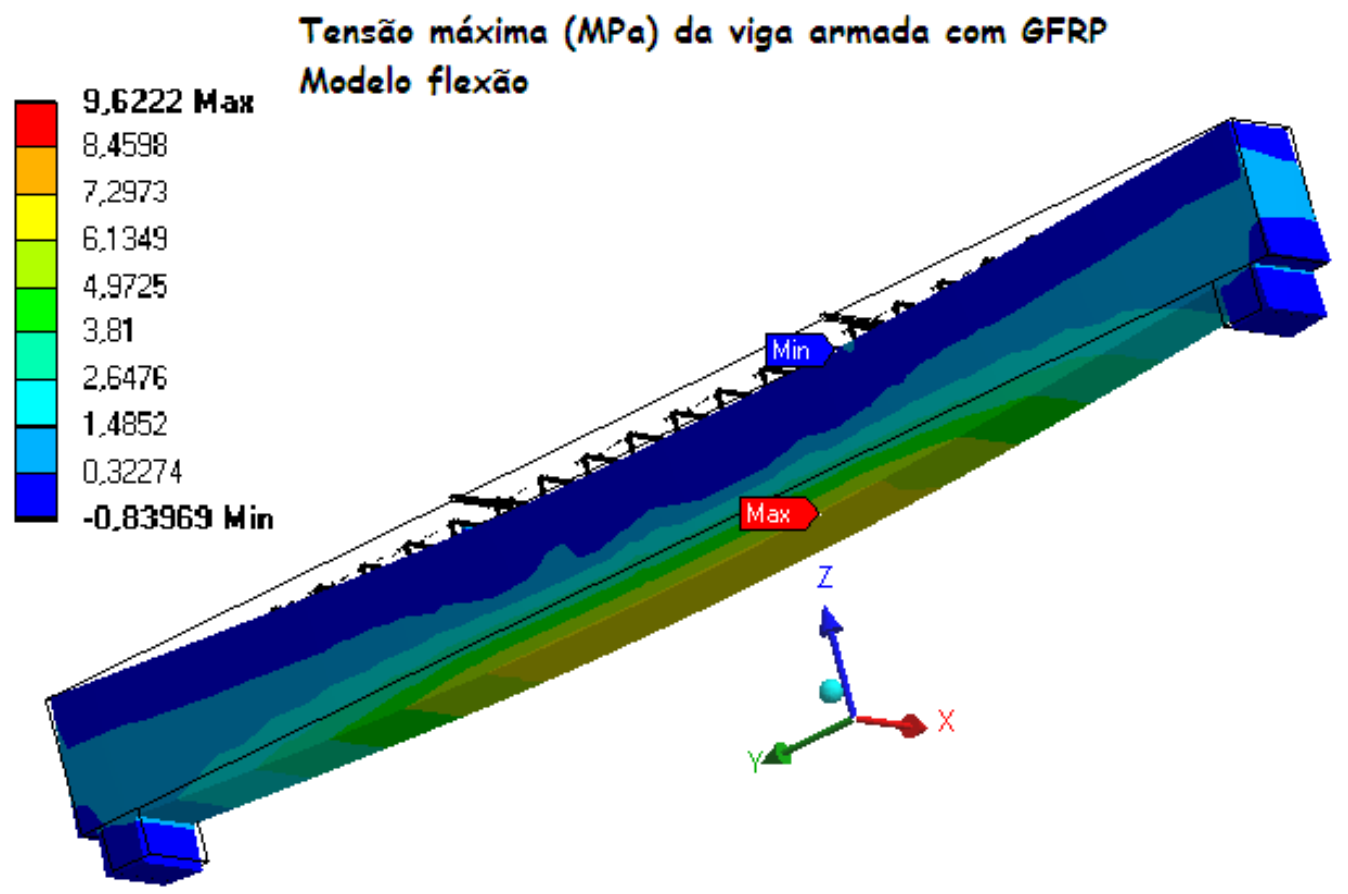

Figura 3.14a - Tensão máxima de tração e compressão da viga armada com GFRP na flexão

A Figura 3.14b mostra a máxima tensão da viga armada em GFRP. Observa-se que através do método dos elementos finitos pode-se encontrar o ponto de máxima tensão (interna ou externamente) analisando-se todos os elementos do concreto e da armadura.

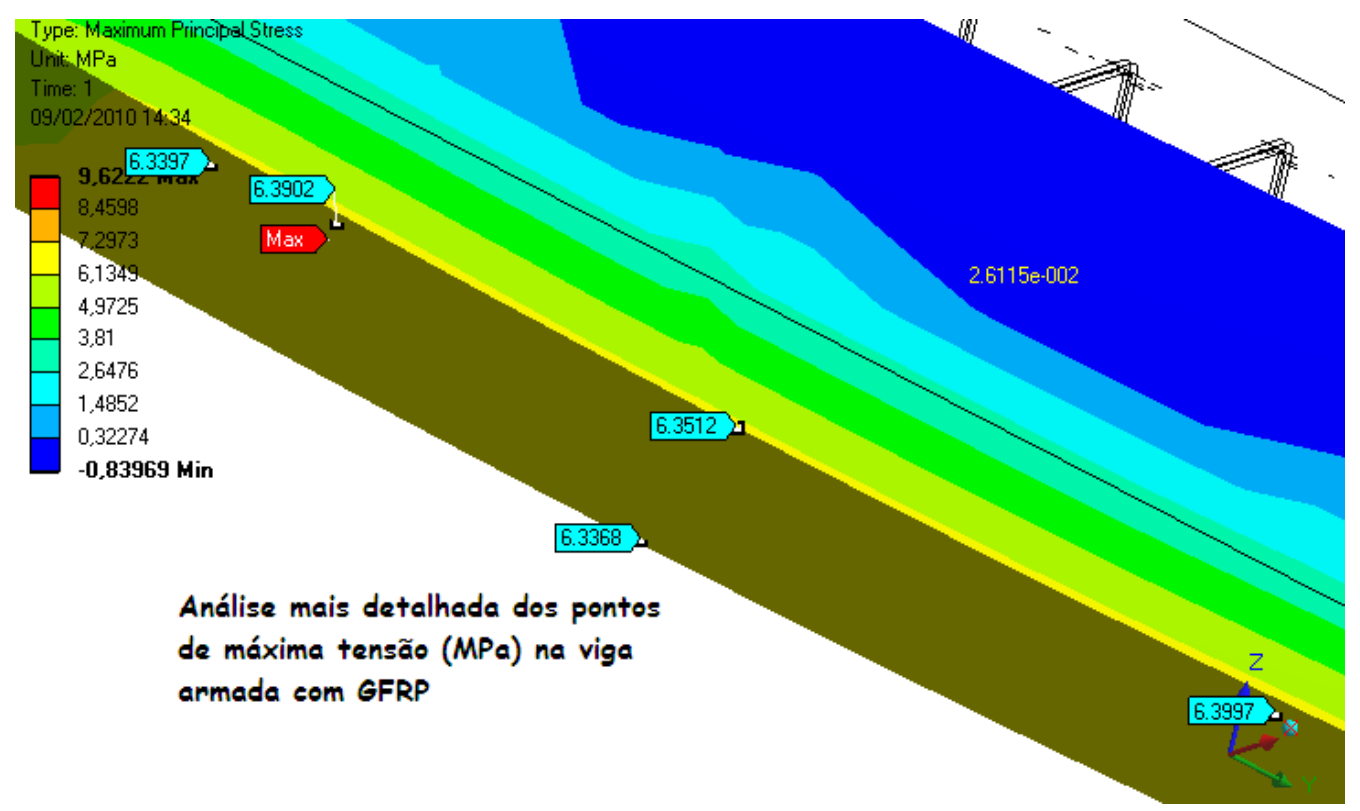

Figura 3.14b - Análise mais detalhada do ponto de máxima tensão na viga armada em GFRP 


\subsubsection{Resultados obtidos nos modelos de cisalhamento}

Da mesma forma, no modelo cisalhamento, após a entrada de dados geraram-se duas malhas de elementos geométricos predominantemente tetraédricos, uma para o modelo cisalhamento em aço e outra para o modelo cisalhamento em GFRP. Os elementos geométricos para o concreto podem ser vistos na Figura 3.15 e da armadura na Figura 3.16, tendo-se então a malha de elementos finitos do conjunto concreto e armadura para o início da simulação em elementos finitos no cisalhamento.

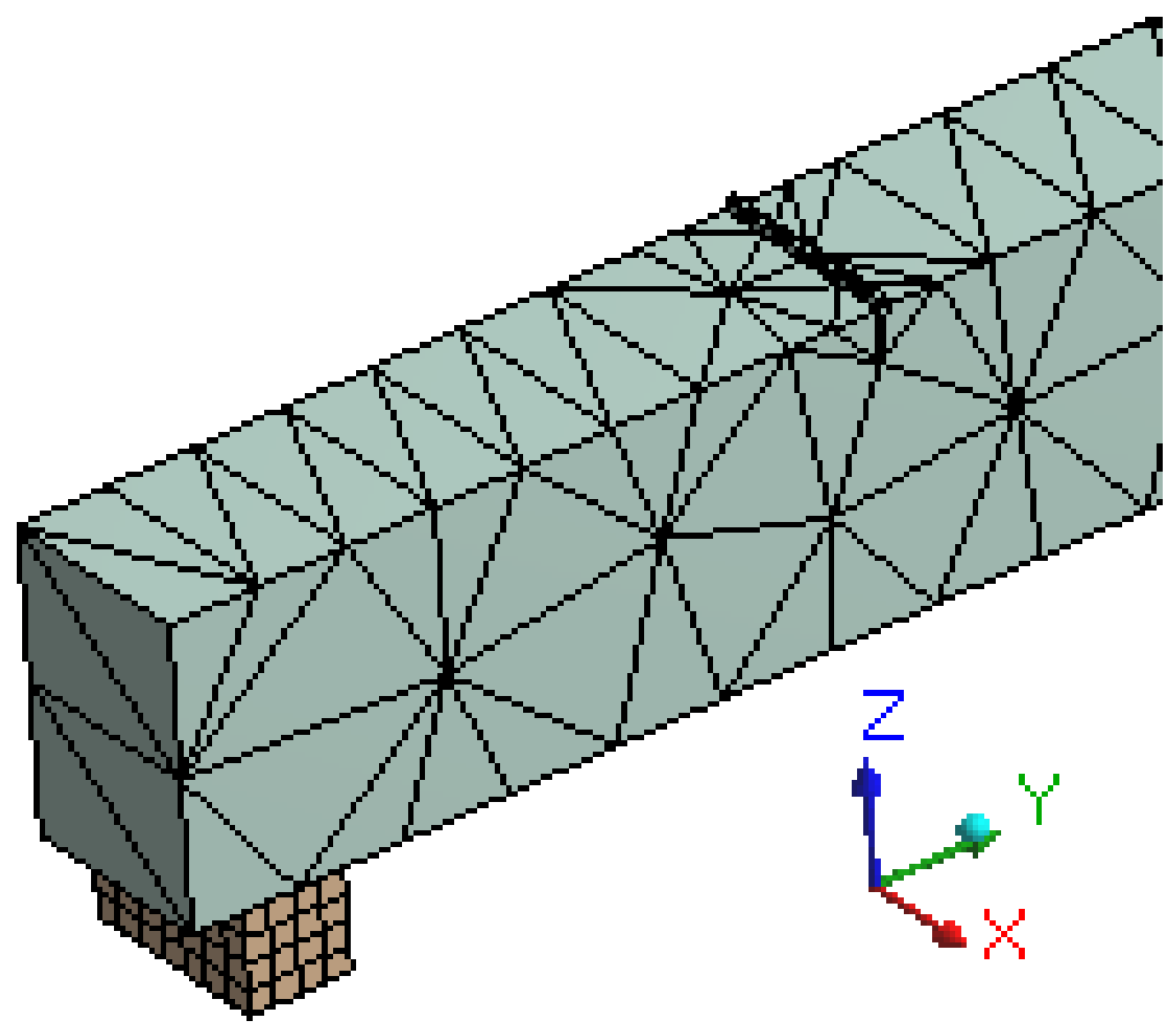

Figura 3.15 - Malha de elementos finitos para os elementos do concreto da viga no cisalhamento 


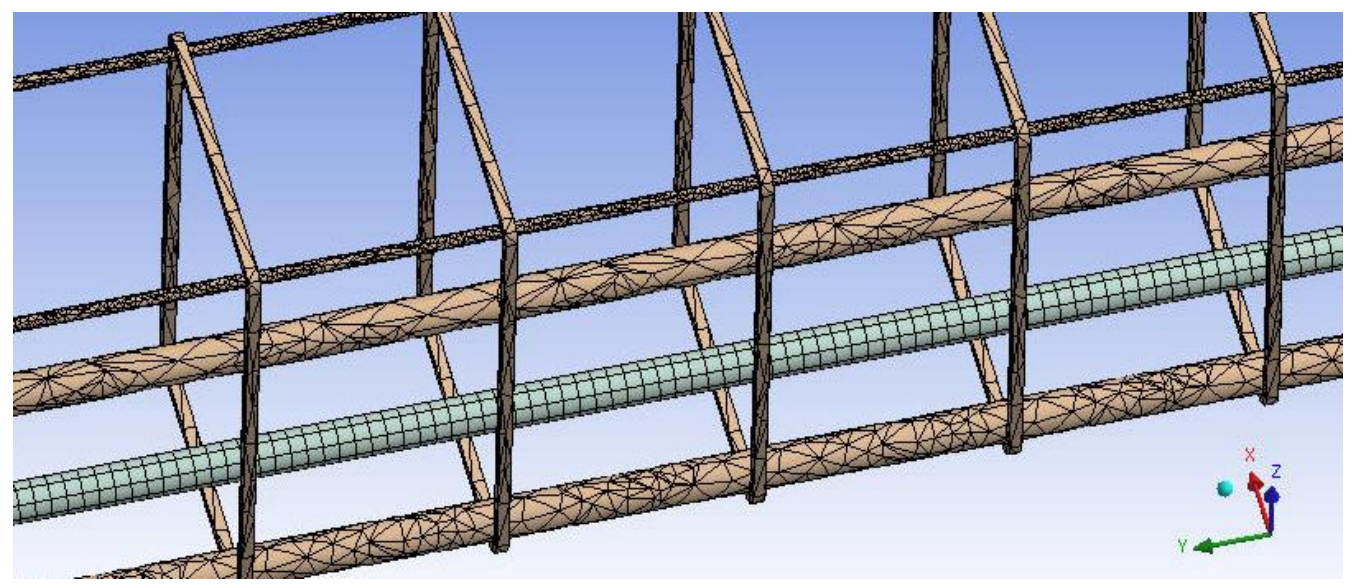

Figura 3.16 - Malha de elementos finitos para os elementos da armadura no cisalhamento

Fez-se também numa adaptação de carregamento nos modelos de cisalhamento, onde o carregamento concentrado $\mathrm{F}=77,33 \mathrm{kN}$ é distribuído uniformemente ao longo da largura da viga, em uma região de espessura igual a $10 \mathrm{~mm}$, criando uma pressão uniforme $\mathrm{P}=38,67$ $\mathrm{MPa}$, aplicado em uma região distinta da viga, distante do apoio esquerdo $600 \mathrm{~mm}$ (Figura 3.4).

- Devido a esse carregamento no cisalhamento, que se encontra também no domínio 2 para a viga armada em aço (Figura 3.5), tem-se que o deslocamento máximo global do conjunto viga armada é a mesmo da armadura em aço (Figuras 3.17a e 3.18b respectivamente).

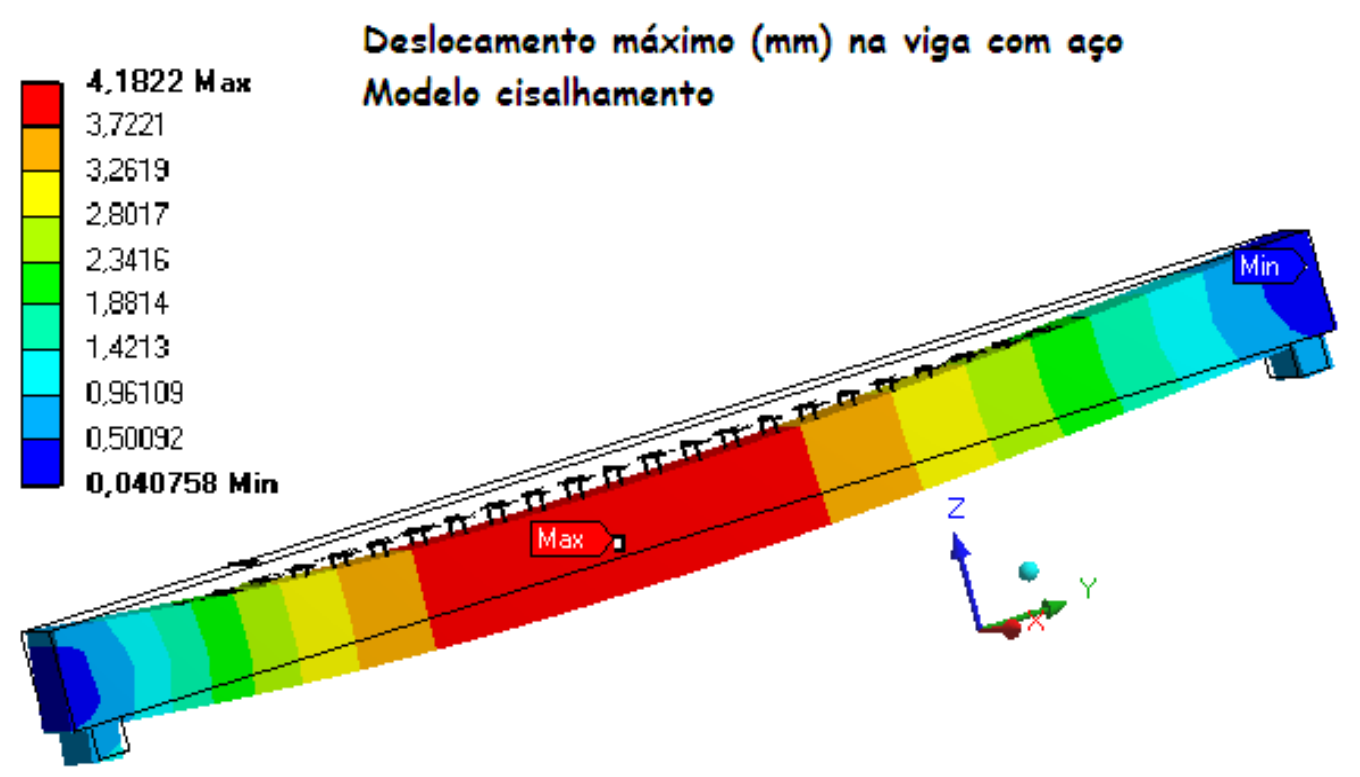

Figura 3.17a - Deslocamento máximo na viga armada com aço no cisalhamento 


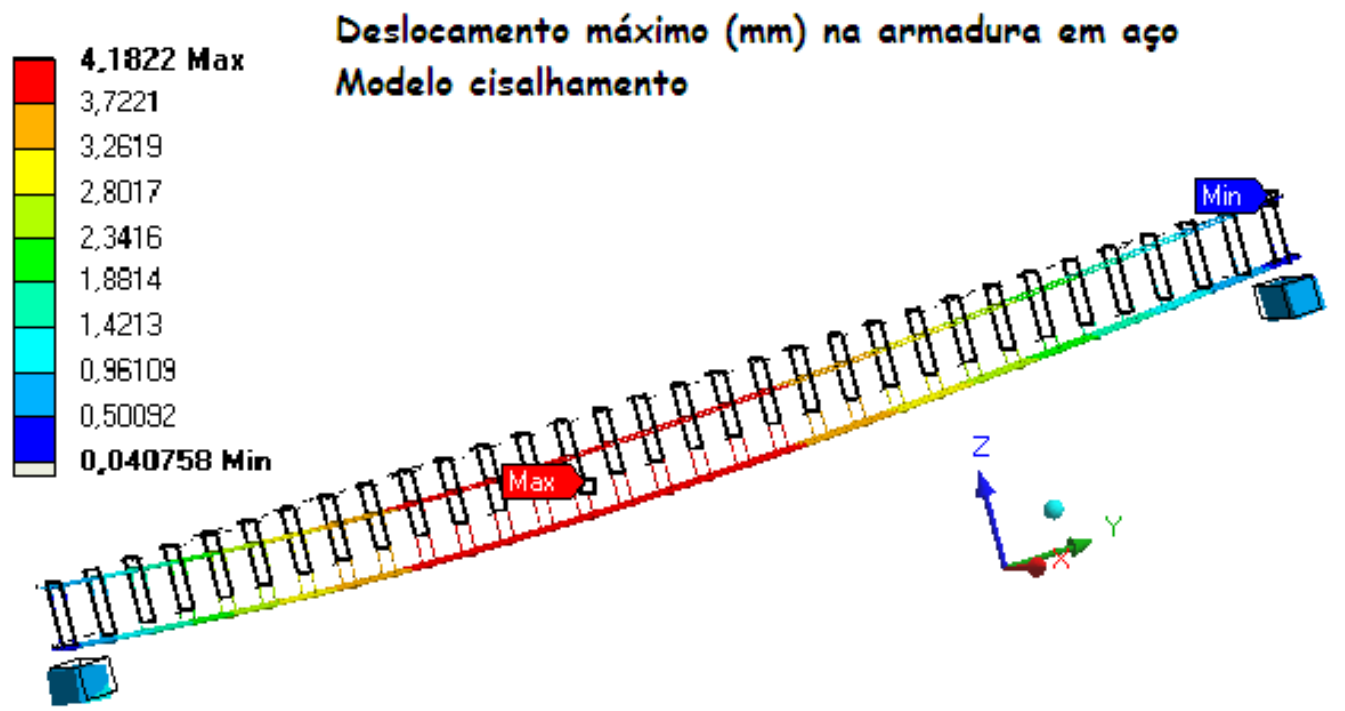

Figura 3.17b - Deslocamento máximo na armadura em aço no cisalhamento

- Para o mesmo carregamento no cisalhamento para a viga da Figura 3.6, com a utilização de barras em GFRP tem-se também que o deslocamento máximo global do conjunto viga armada é igual ao deslocamento da armadura em GFRP (Figuras 3.18a e 3.18b respectivamente).

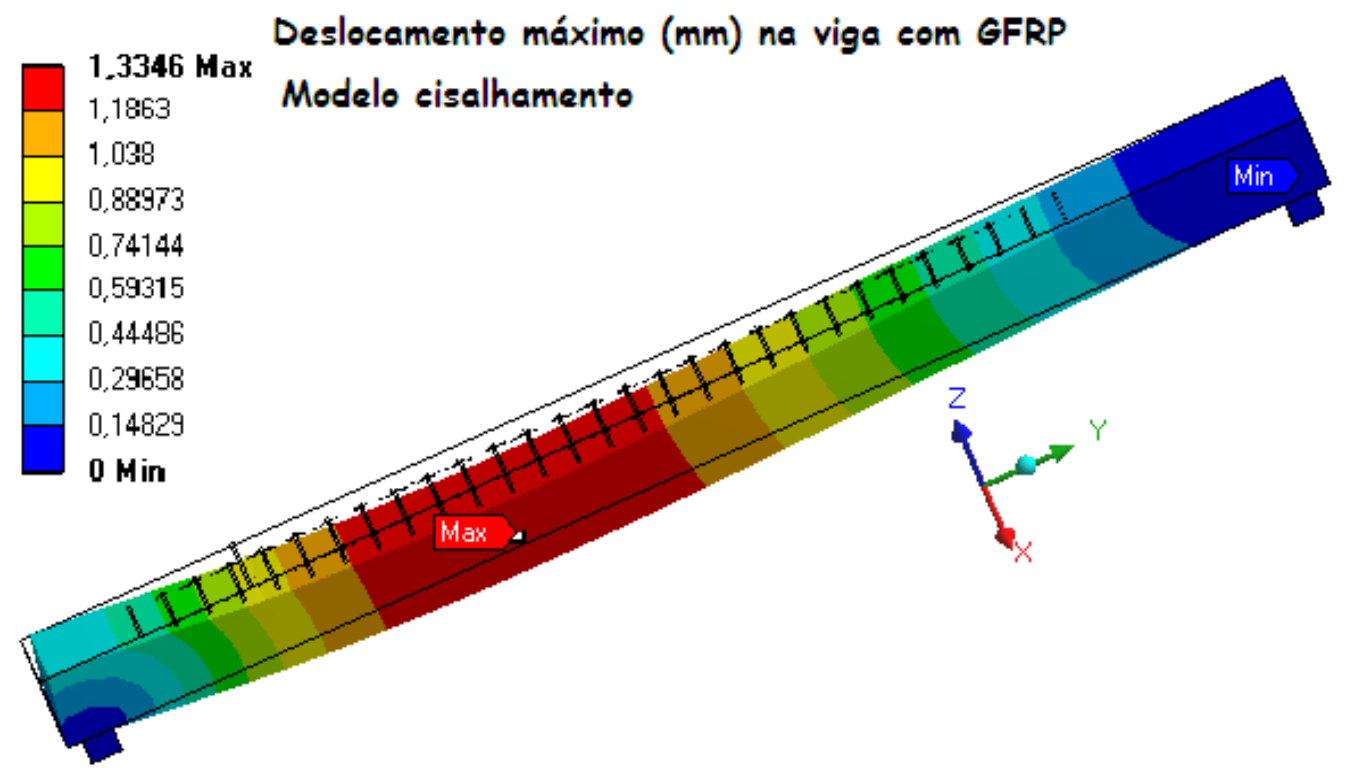

Figura 3.18a - Deslocamento máximo na viga armada com GFRP no cisalhamento 


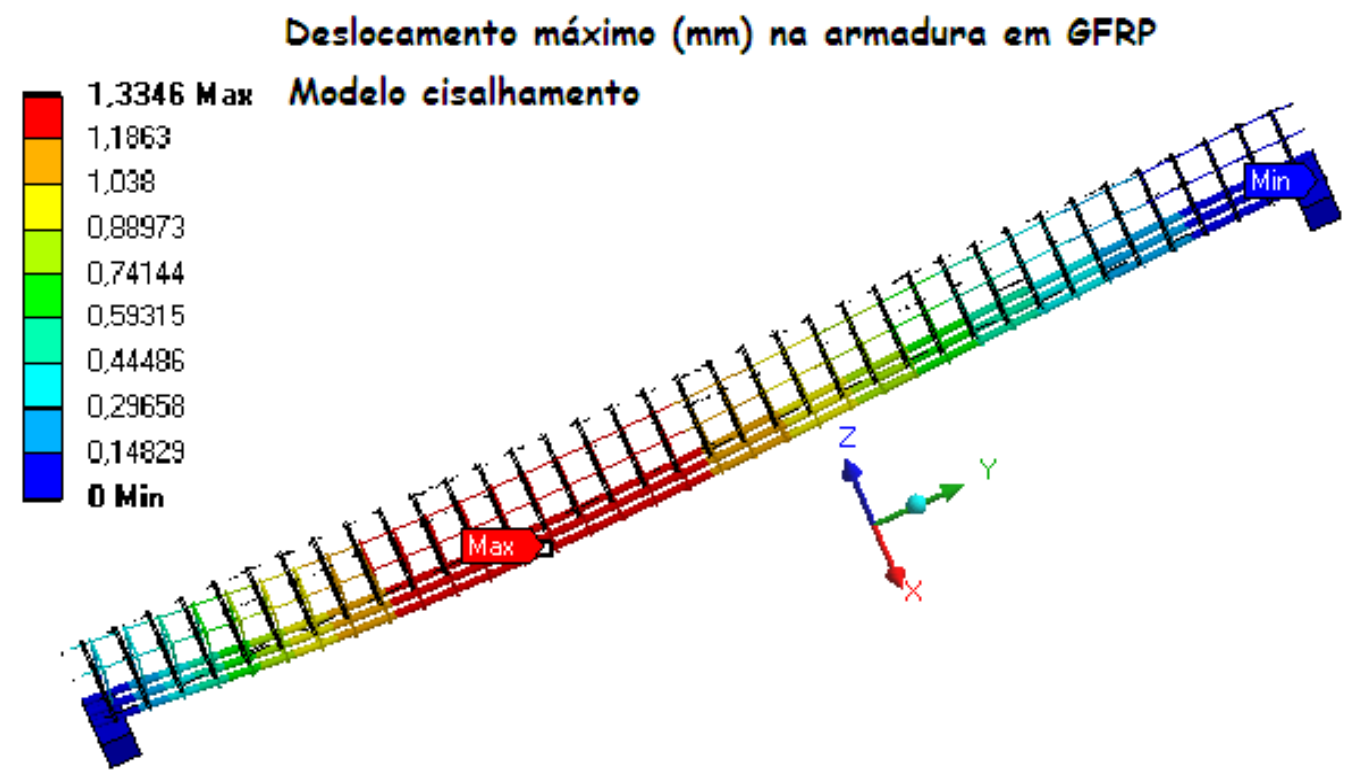

Figura 3.18b - Deslocamento máximo na armadura em GFRP no cisalhamento

A deformação máxima $(\mathrm{mm} / \mathrm{mm})$ no conjunto viga armada em aço e na armadura em aço é dado também pelas Figuras 3.19a e 3.19b, respectivamente.

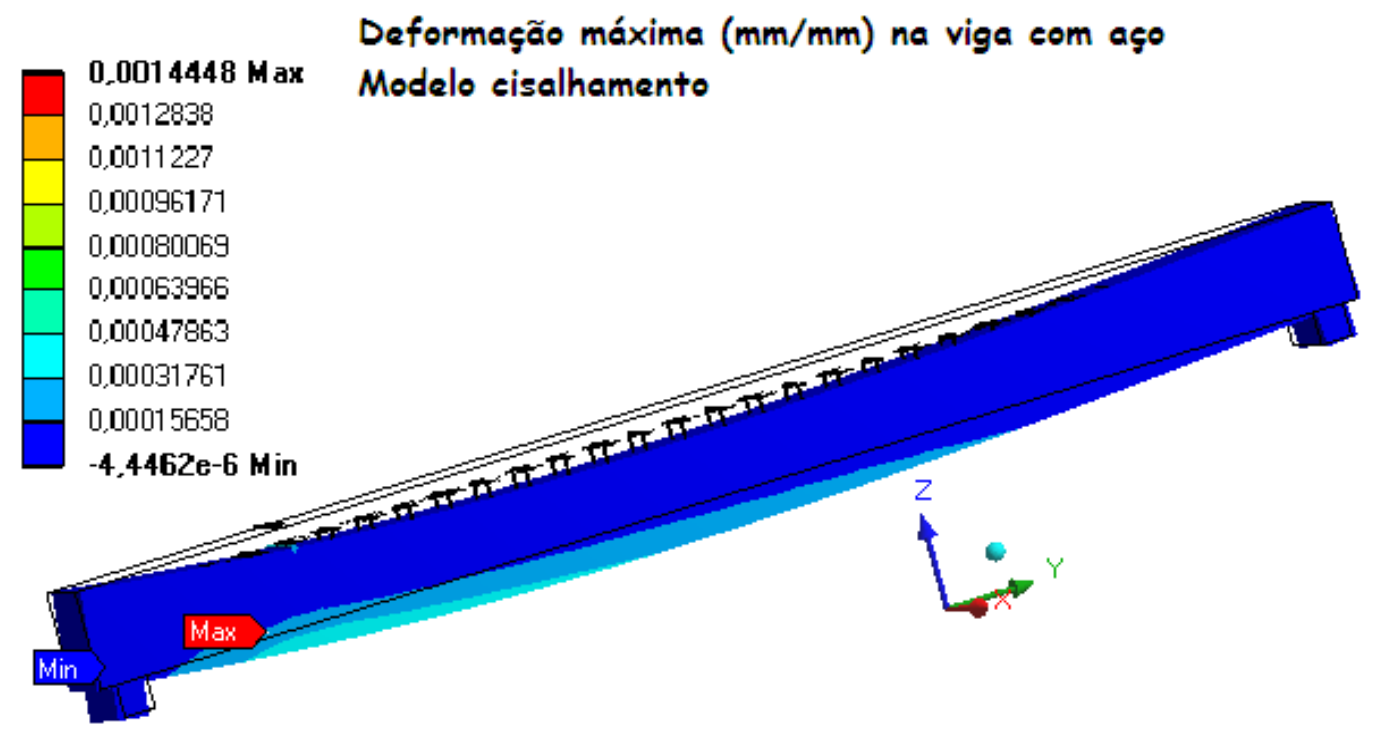

Figura 3.19a - Deformação máxima na viga armada com aço no cisalhamento 


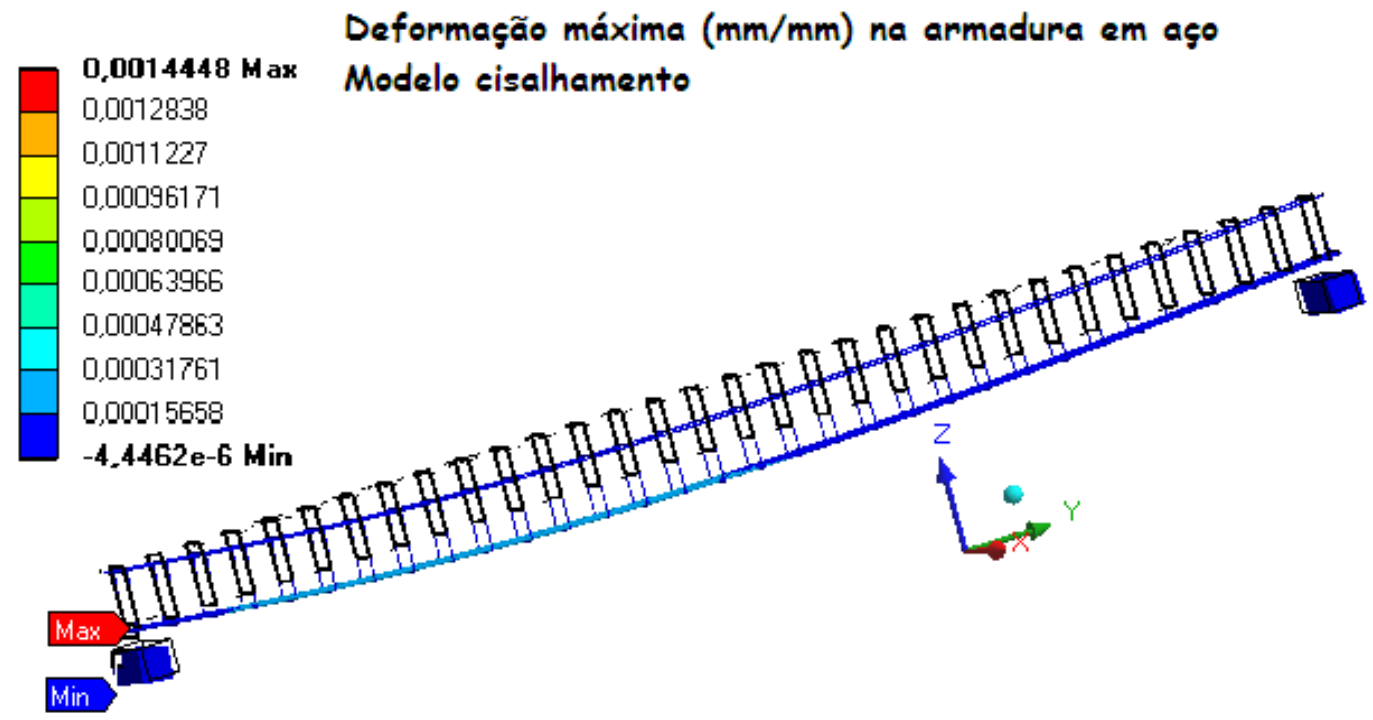

Figura 3.19b - Deformação máxima na armadura em aço no cisalhamento

A deformação máxima ( $\mathrm{mm} / \mathrm{mm})$ na viga armada em GFRP e nas barras em GFRP é dada pelas Figuras 3.20a e 3.20b, respectivamente.

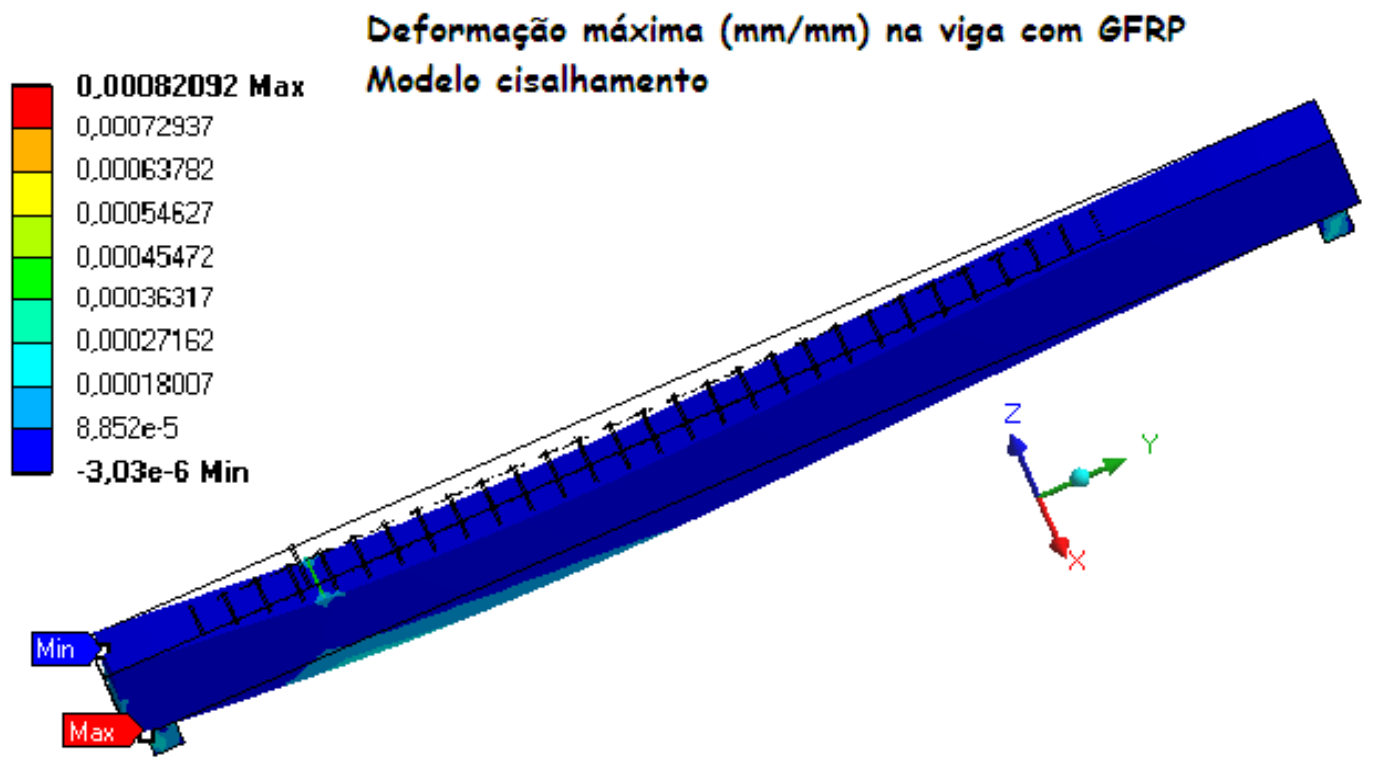

Figura 3.20a - Deformação máxima na viga armada com GFRP no cisalhamento 


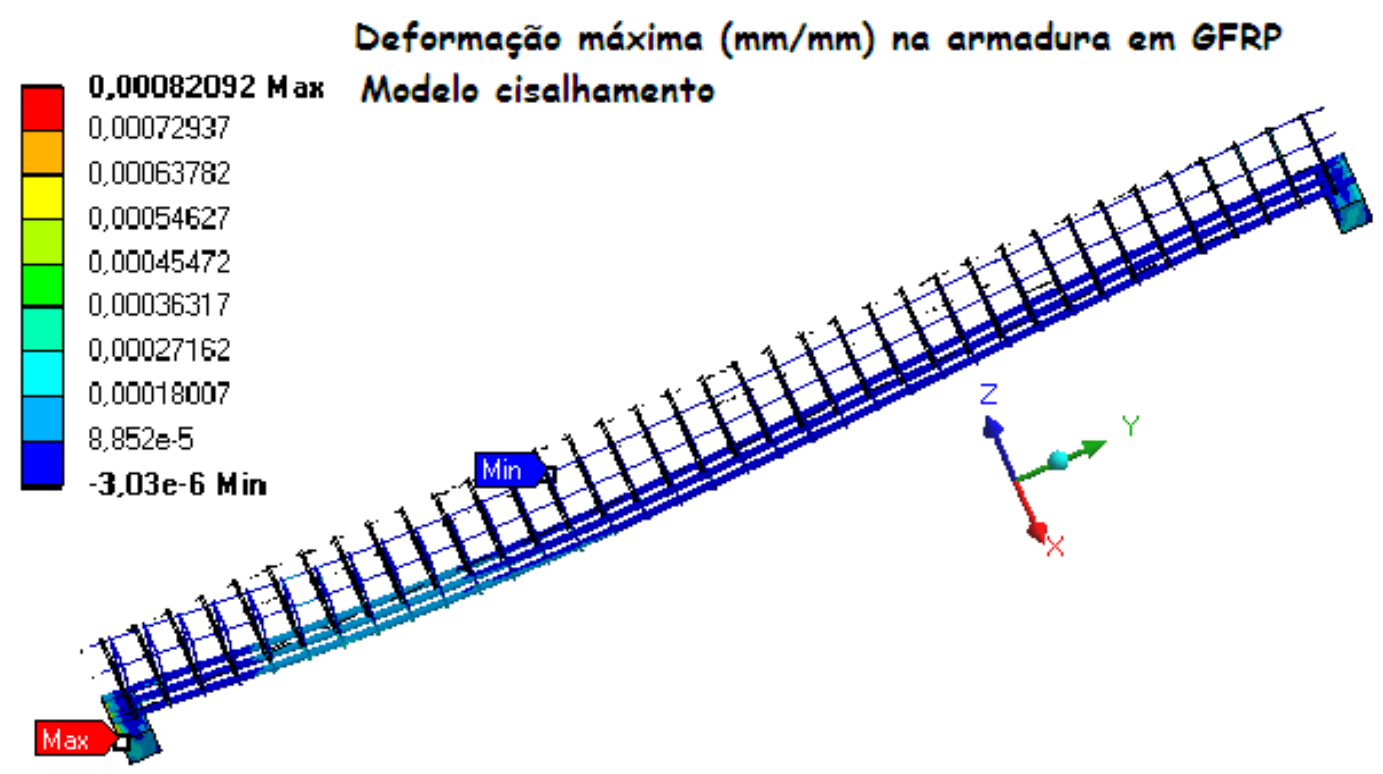

Figura 3.20b - Deformação máxima na armadura em GFRP no cisalhamento

A tensão máxima de tração (MPa) na viga armada com aço, pode ser vista na Figura 3.21. Observa-se também a máxima tensão de compressão localizada na zona comprimida do concreto, próxima à região de aplicação da carga.

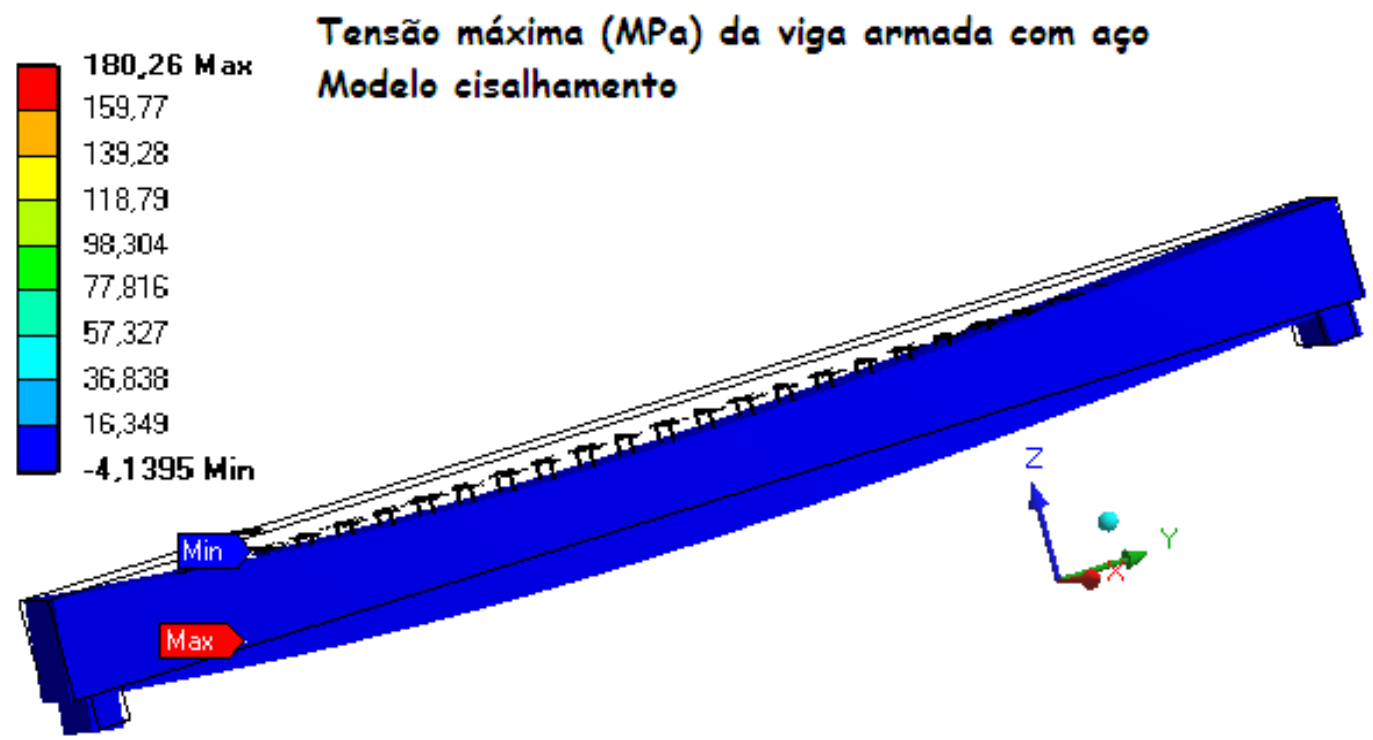

Figura 3.21 - Tensão máxima de tração e compressão da viga armada com aço no cisalhamento

A tensão máxima de tração (MPa) na viga armada com GFRP, pode ser vista na Figura 3.22. Observa-se também a máxima tensão de compressão localizada na zona comprimida do concreto, próxima à região de aplicação da carga. 


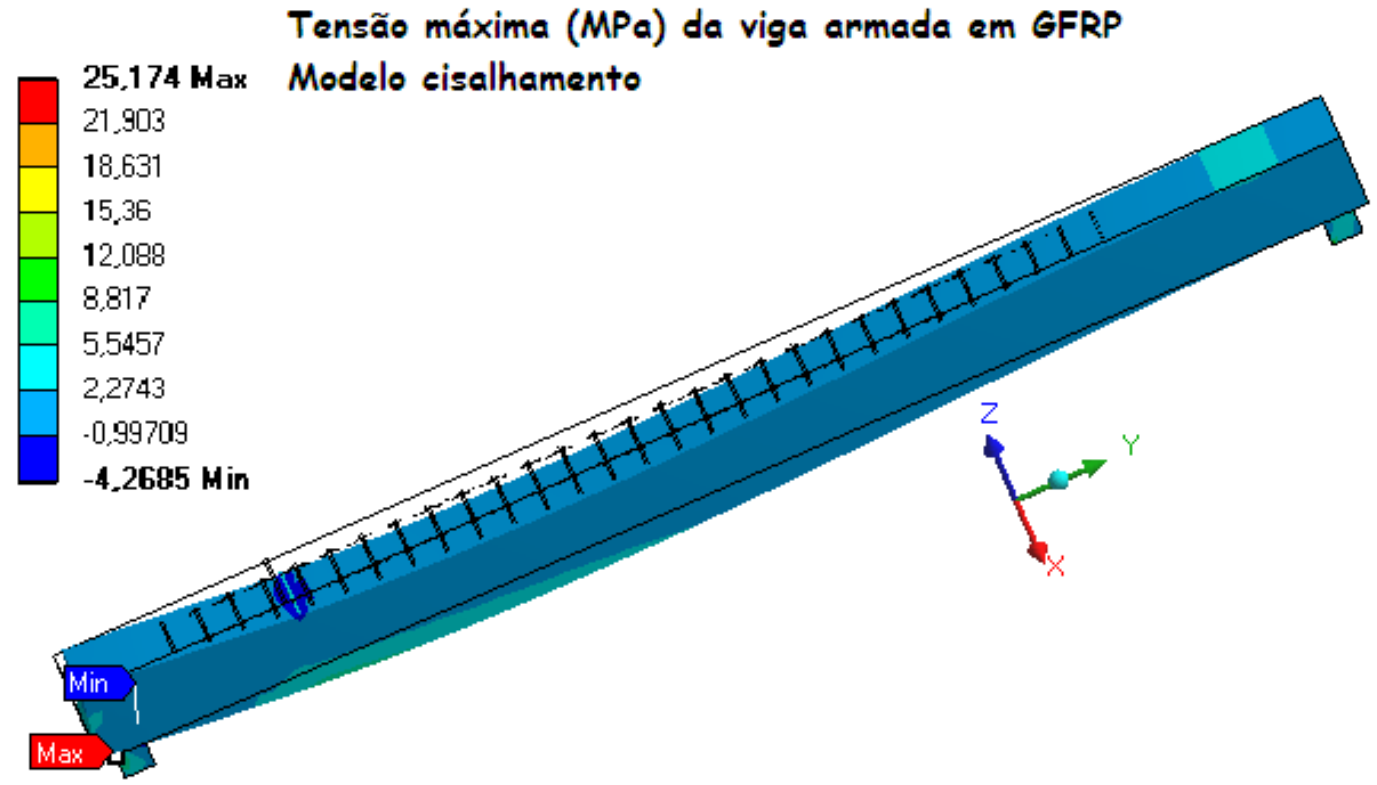

Figura 3.22 - Tensão máxima de tração e compressão da viga armada com GFRP no cisalhamento 


\section{4- ANÁLISE DE RESULTADOS}

\subsection{Modelo de Flexão}

\subsubsection{Através das equações}

Foram comparadas aqui duas situações na flexão simples, onde na primeira foi executado o cálculo analítico segundo a ABNT NBR 6118:2003, utilizando-se armadura em aço. No segundo caso foi executado o cálculo de acordo com o Instituto Americano do Concreto (ACI 440.1R - 06) utilizando barras em GFRP. Ambos os casos referem-se a um mesmo carregamento, mesma seção transversal de concreto e meio altamente agressivo, de acordo com a Figura 3.1.

Para uma armadura em aço adotada e verificada no ELS (Figura 3.2) chegou-se por análise estática a um estado de tensões e deformações no domínio 2, cujo carregamento encontrado foi de $\mathrm{F}=33,42 \mathrm{kN}$. Determinou-se também que, para um carregamento aplicado de intensidade $\mathrm{F}=124 \mathrm{kN}$, chegar-se-ia ao domínio 4, onde dever-se-ia aumentar a altura da viga, caso a armadura fosse a mesma.

Utilizando-se do mesmo carregamento $\mathrm{F}=33,42 \mathrm{kN}$ e mesma seção transversal de concreto, foi calculada a armadura principal longitudinal tracionada em GFRP, através da condição balanceada de ruína, ou seja, ruína governada pela ruptura da barra e esmagamento do concreto, e posteriormente calculada também a armadura transversal em GFRP, sendo que em todos os cálculos foram verificados o ELS (Figura 3.3).

Analisando a Tabela 3.1 de resultados analíticos dessa situação, chegou-se a algumas conclusões:

- Apesar da rigidez da barra em GFRP ser menor que a rigidez da barra em aço, principalmente após a fissuração, nota-se pelas Figuras 3.2 e 3.3 que, por se tratar de ambiente altamente agressivo, a viga armada em aço necessita o dobro do cobrimento livre em relação à viga armada em GFRP. Dessa forma a inércia do conjunto total da armadura em aço se torna 
inferior ao conjunto da armadura em GFRP, consequentemente há um ganho considerável relativo de rigidez na armadura em GFRP.

- Na flexão simples as verificações do deslocamento máximo (ELS) tiveram resultados satisfatórios em ambos os casos, ou seja, com armaduras diferentes, porém para a deformação máxima o resultado para a viga com armadura em aço não ficou dentro dos limites estabelecidos pela norma brasileira, o que não ocorreu com a deformação máxima para a viga armada em GFRP, que ficou dentro dos limites estabelecidos pelo ACI.

\subsubsection{Através do método dos elementos finitos}

Na Tabela 4.1 encontram-se os valores do deslocamento máximo, deformação máxima e tensão máxima na viga armada e também na armadura, bem como a sua localização aproximada, obtidos pelo método dos elementos finitos para a flexão simples com armadura em aço e com armadura em GFRP.

Tabela 4.1 - Resultados pelo método dos elementos finitos na flexão em aço e GFRP

\begin{tabular}{|c|c|c|c|}
\hline M.E.F. & C/AÇO CA50 & C/GFRP & LOCAL \\
\hline $\begin{array}{c}\text { DELOCAMENTO } \\
\text { MÁX. (mm) }\end{array}$ & 1,4511 & 1,5374 & $\begin{array}{l}\text { Região inferior da viga } \\
\text { (centro do vão) }\end{array}$ \\
\hline $\begin{array}{c}\text { DESLOCAMENTO } \\
\text { MÁX. } \\
\text { ARMADURA (mm) }\end{array}$ & 1,4511 & 1,5374 & $\begin{array}{l}\text { Face inferior da barra } \\
\text { longitudinal tracionada } \\
\text { (centro do vão) }\end{array}$ \\
\hline $\begin{array}{c}\text { DEFORMAÇÃO } \\
\text { MÁX. (mm) }\end{array}$ & 0,6326 & 0,7911 & $\begin{array}{l}\text { Região inferior da viga } \\
\quad \text { (centro do vão) }\end{array}$ \\
\hline $\begin{array}{c}\text { DEFORMAÇÃO } \\
\text { MÁX. } \\
\text { ARMADURA (mm) }\end{array}$ & 0,6326 & 1,1742 & $\begin{array}{l}\text { Face inferior da barra } \\
\text { longitudinal tracionada } \\
\text { (centro do vão) }\end{array}$ \\
\hline $\begin{array}{l}\text { TENSÃO MÁX. } \\
\text { (MPa) }\end{array}$ & 31,101 & 9,6222 & $\begin{array}{l}\text { Região inferior da viga } \\
\quad \text { (centro do vão) }\end{array}$ \\
\hline $\begin{array}{c}\text { TENSÃO MÁX. } \\
\text { ARMADURA (MPa) }\end{array}$ & 31,101 & 9,6222 & $\begin{array}{l}\text { Região inferior da viga } \\
\text { (centro do vão) }\end{array}$ \\
\hline
\end{tabular}


Analisando a Tabela 4.1 nota-se que os deslocamentos nas armaduras em GFRP e no aço estão muito próximas. No entanto, as barras em GFRP como também a viga armada em GFRP sofrem deformações máximas maiores em relação à viga armada com aço. Comparando-se os resultados em elementos finitos da Tabela 4.1 com os resultados analíticos da Tabela 3.1, tem-se que tanto na norma brasileira ABNT NBR 6118:2003 como no ACI440.1R-06 os deslocamentos estão dentro dos limites aceitáveis, o que não acontece com as deformações, pois ambos os casos não estão dentro dos limites estabelecidos, o que de certa forma beneficia a armadura em GFRP, pois em se tratando de ambiente altamente agressivo, o aço teria maiores problemas devido à corrosão na armadura.

No caso das tensões máximas no modelo em GFRP, elas são menores que as máximas tensões nas barras em aço, o que já era esperado, ocorrendo devido à maior área de superfície diametral das barras em GFRP, consequentemente maior inércia em relação às barras de aço.

O gráfico da Figura 4.1 mostra de maneira aproximada na flexão simples a tensão (MPa) em função da deformação $\left(\mathrm{mm} / \mathrm{mm} \times 10^{-4}\right)$ das vigas armadas em aço e GFRP pelo método dos elementos finitos, e a faixa de variação da deformação máxima do aço e GFRP no cálculo analítico.

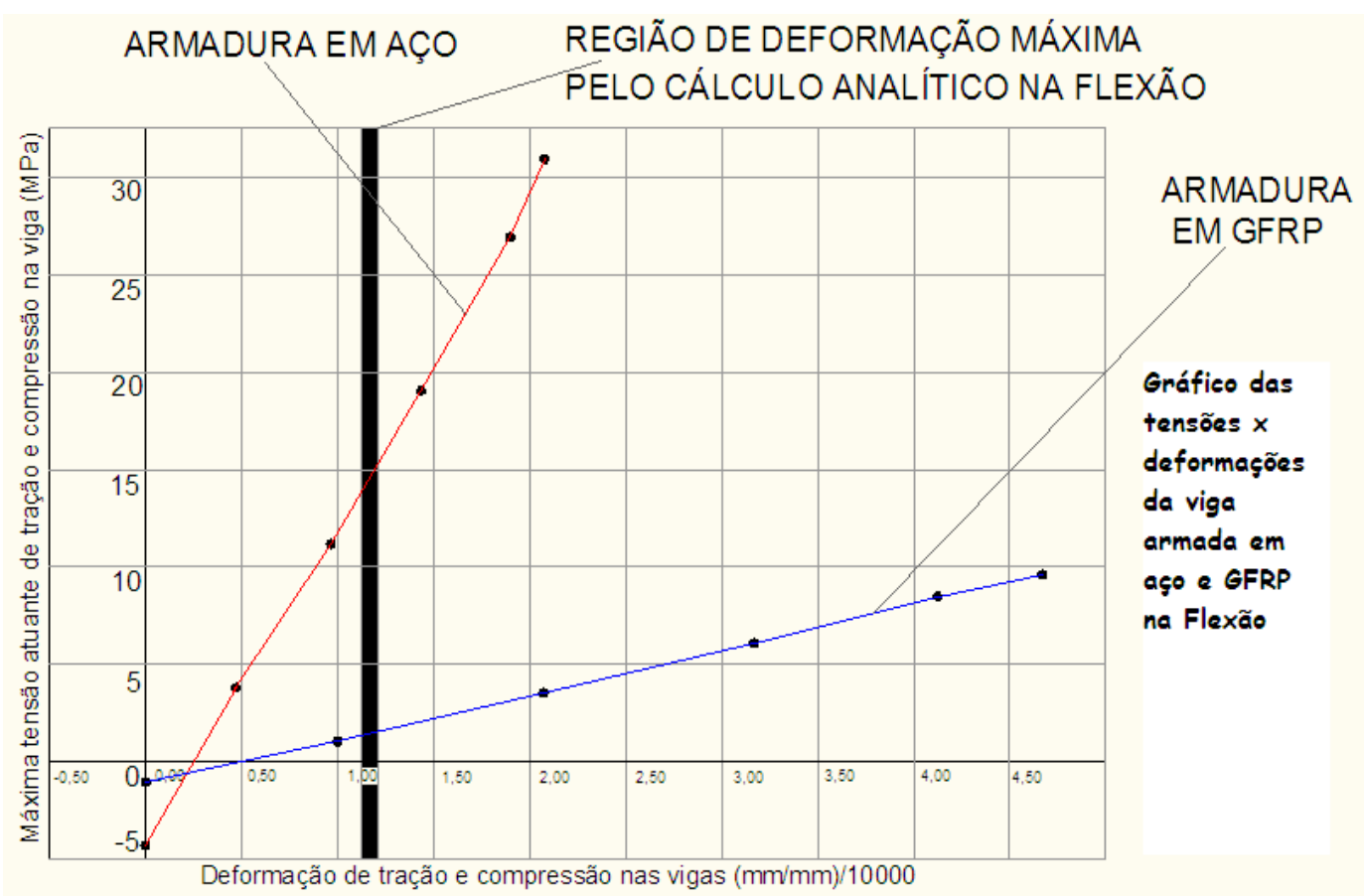

Figura 4.1 - Comparação tensão x deformação entre o aço e GFRP na flexão 


\subsection{Modelo de cisalhamento}

\subsubsection{Através das equações}

Também foram comparadas duas situações no cisalhamento, onde na primeira foi executado o cálculo analítico segundo a ABNT NBR 6118:2003, utilizando-se armadura em aço. No segundo caso foi executado o cálculo com base no ACI 440.1R - 06 utilizando barras em GFRP, em ambos os casos para um mesmo carregamento, mesma seção transversal de concreto e considerando o meio altamente agressivo, de acordo com a Figura 3.4.

Para uma armadura de aço adotada e verificada no ELS (Figura 3.5) chegou-se por análise estática a um estado de tensões e deformações no domínio 2, cujo carregamento encontrado foi de $\mathrm{F}=77,33 \mathrm{kN}$. Determinou-se também que para um carregamento aplicado de intensidade $\mathrm{F}=240,78 \mathrm{kN}$, chegar-se-ia ao domínio 4, onde dever-se-ia aumentar a altura da viga, caso a armadura fosse a mesma.

Utilizando-se do mesmo carregamento $\mathrm{F}=77,33 \mathrm{kN}$ e mesma seção transversal de concreto, foi calculada a armadura principal longitudinal tracionada em GFRP, através da condição de ruína da viga governada pelo esmagamento do concreto, e posteriormente calculada também a armadura transversal em GFRP, sendo que em todos os cálculos foram verificados o ELS (Figura 3.6).

Analisando a Tabela 3.2 de resultados analíticos do modelo em cisalhamento, nota-se que na armadura em aço o deslocamento máximo está dentro dos limites da NBR 61118:2003, o que não acontece com a viga armada em GFRP. No caso da deformação máxima é a armadura em GFRP que está dentro dos limites, o que não acontece com a armadura em aço. 


\subsubsection{Através do método dos elementos finitos}

Na Tabela 4.2 encontram-se os valores do deslocamento máximo, deformação máxima e tensão máxima na viga armada e também na armadura, bem como a sua localização aproximada, obtidos pelo método dos elementos finitos, para o cisalhamento com armadura em aço e com armadura em GFRP.

Tabela 4.2 - Resultados pelo método dos elementos finitos no cisalhamento em aço e GFRP

\begin{tabular}{|c|c|c|c|}
\hline M.E.F. & C/AÇO CA50 & C/GFRP & LOCAL \\
\hline $\begin{array}{l}\text { DEFLEXÃO MÁX. } \\
(\mathbf{m m})\end{array}$ & 4,1822 & 1,3346 & $\begin{array}{c}\text { Região inferior da viga } \\
\text { (próximo à aplicação } \\
\text { da carga) }\end{array}$ \\
\hline $\begin{array}{l}\text { DEFLEXÃO MÁX. } \\
\text { ARMADURA (mm) }\end{array}$ & 4,1822 & 1,3346 & $\begin{array}{c}\text { Estribo na região } \\
\text { próxima à aplicação da } \\
\text { carga }\end{array}$ \\
\hline $\begin{array}{l}\text { DEFORMAÇÃO } \\
\text { MÁX. (mm/mm) }\end{array}$ & 5,7792 & 3,2837 & $\begin{array}{c}\text { Região inferior da viga } \\
\text { (próximo ao apoio } \\
\text { esquerdo) }\end{array}$ \\
\hline $\begin{array}{c}\text { DEFORMAÇÃO } \\
\text { MÁX. ARMADURA } \\
(\mathbf{m m} / \mathbf{m m})\end{array}$ & 5,7792 & $\mathbf{3 , 2 8 3 7}$ & $\begin{array}{c}\text { Região inferior da viga } \\
\text { (próximo ao apoio } \\
\text { esquerdo) }\end{array}$ \\
\hline $\begin{array}{l}\text { TENSÃO MÁX. } \\
\text { (MPa) }\end{array}$ & 180,26 & 25,174 & $\begin{array}{c}\text { Região inferior da viga } \\
\text { (próximo ao apoio } \\
\text { esquerdo) }\end{array}$ \\
\hline $\begin{array}{c}\text { TENSÃO MÁX. } \\
\text { ARMADURA (MPa) }\end{array}$ & 180,26 & 25,174 & $\begin{array}{c}\text { Região inferior da viga } \\
\text { (próximo ao apoio } \\
\text { esquerdo) }\end{array}$ \\
\hline
\end{tabular}

Analisando a Tabela 4.2 (modelo cisalhamento) os deslocamentos estão bem menores do que aqueles calculados analiticamente. As deformações ao contrário estão bem acima dos valores encontrados analiticamente, o que de certa forma favorece mais uma vez a armadura em GFRP, por se tratar de ambiente altamente agressivo, sendo que as deformações na 
armadura em aço foram superiores às da armadura em GFRP, no cálculo em elementos finitos.

No caso das tensões máximas no modelo em GFRP, elas são menores que as máximas tensões nas barras em aço, o que já era esperado também, devido à maior superfície diametrical das barras em GFRP.

O gráfico da Figura 4.2 mostra de maneira aproximada no cisalhamento a tensão (MPa) em função da deformação $\left(\mathrm{mm} / \mathrm{mm} \times 10^{-4}\right)$ das vigas armadas em aço e GFRP, pelo método dos elementos finitos, e a faixa de variação da deformação máxima do aço e GFRP, no cálculo analítico.

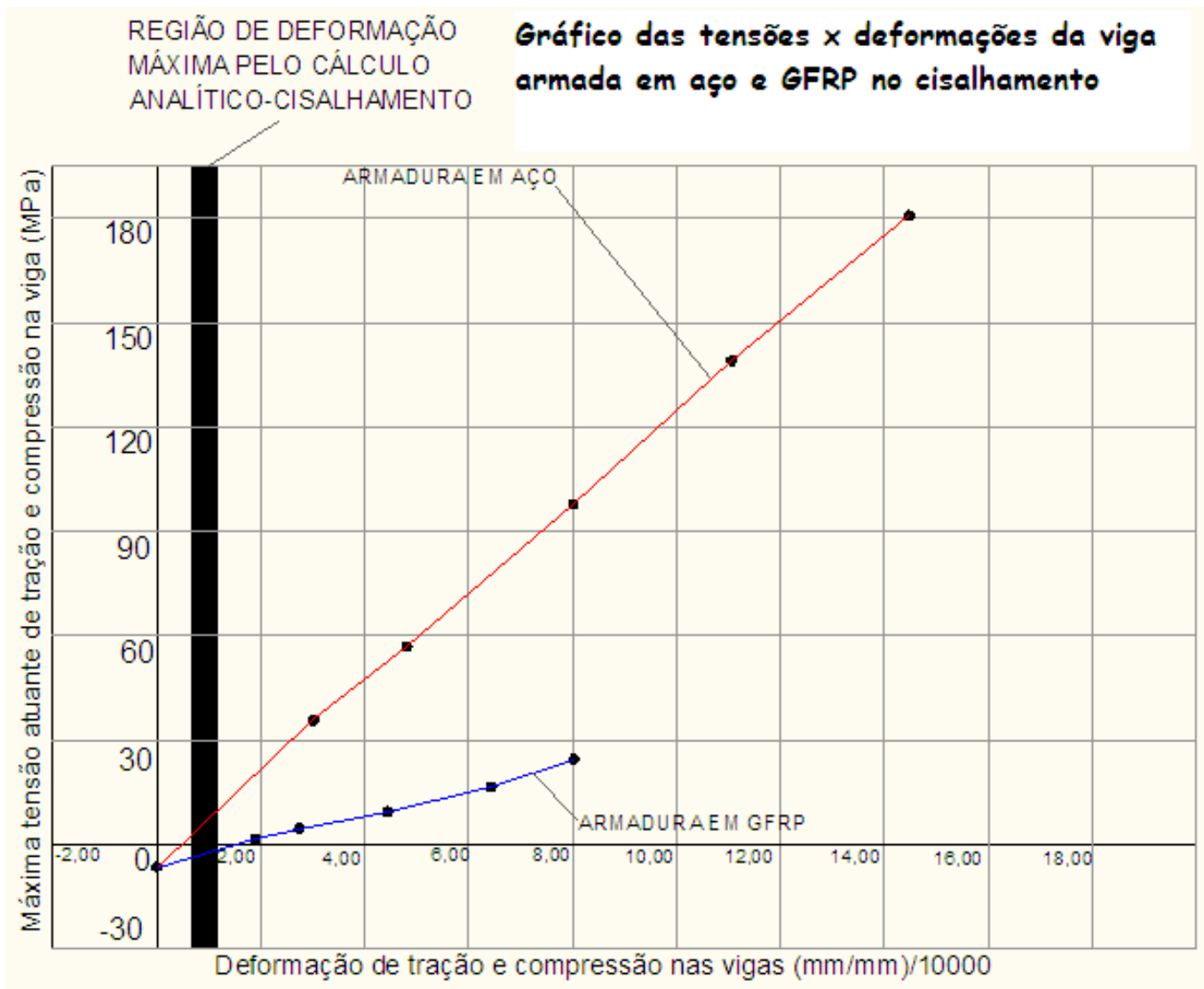

Figura 4.2 - Comparação tensão x deformação entre o aço e GFRP no cisalhamento

Pode-se notar (Figura 4.2) que, ao contrário da flexão, no cisalhamento as deformações na viga armada em GFRP são relativamente bem menores do que as deformações na viga armada em aço. 


\section{5- CONSIDERAÇÕES FINAIS}

Da motivação do início do trabalho até análise dos resultados finais tentou-se seguir o melhor possível as normas envolvidas. Em relação à simulação em elementos finitos, os modelos de cálculo também foram feitos com todas as entradas de dados possíveis para que os resultados pudessem futuramente ser comparados à análise experimental. O motivo de se comparar a ABNT NBR 6118:2003 somente com a norma americana o ACI 440.1R-06 foi de poder dar um padrão sistemático para o trabalho e não se desviar do objetivo inicial, ou seja, analisar um elemento de construção, no caso a viga, em meio altamente agressivo com armadura interna em aço e GFRP, na flexão e no cisalhamento.

Apesar de não ter sido encontrada até agora na literatura a análise por elementos finitos de uma viga com armadura transversal interna em GFRP, com os resultados obtidos neste trabalho pode-se melhor interpretar algumas situações reais de carregamento em que atuem tensões de flexão e cisalhamento.

Quando se comparam alternativas em elementos construtivos, principalmente em ambientes altamente agressivos, cuja situação de projeto talvez impossibilite aumentar a seção transversal da viga e muito menos modificar o carregamento externo, resta então mudar a armadura de reforço interno da viga de concreto.

\subsection{Flexão simples}

A viga armada em aço na flexão simples trabalha muito bem em termos de deslocamentos e deformações, para solicitações abaixo das solicitações de ruptura, e consequente, escoamento do aço, conforme já ilustrado na Figura 2.21. Para solicitações maiores a viga armada em GFRP se comporta melhor em termos de curvatura e consequentemente seus deslocamentos e deformações são menores.

Como toda a simulação na flexão simples foi feita no domínio 2 , ou seja, é a última situação em que ocorre deformação plástica excessiva da armadura, a partir do domínio 3, que 
é a situação ideal de projeto para o dimensionamento de vigas armadas em aço, onde a armadura se encontra tracionada e em escoamento, os resultados podem ser diferentes, ocasionado deslocamentos e deformações maiores quando comparados com vigas armadas em GFRP. Pode-se notar isso também no cálculo analítico (Tabela 3.1) onde a deformação máxima e o deslocamento máximo são menores para a viga armada em aço no domínio 2. Como uma possível continuidade deste trabalho, além da análise experimental, seria adequado analisar, também de maneira analítica e através do Método dos Elementos Finitos, vigas armadas em aço no domínio 3, comparando com vigas armadas em GFRP, utilizando o mesmo carregamento e mesma seção transversal.

\subsection{Cisalhamento}

A viga armada em aço no cisalhamento, apesar de se encontrar no domínio 2, apresenta deslocamentos e deformações relativamente bem maiores do que a viga armada em GFRP, conforme mostrado na Tabela 4.2. A maior taxa de armadura em peças armadas em FRP tem um impacto significativo sobre a distribuição de tensões ao longo da seção transversal, que no caso específico do cisalhamento fica evidente. Interessante também notar que no cálculo analítico do modelo cisalhamento, a deformação e deslocamento máximo na viga armada com aço continuam sendo menores, quando comparados com a viga armada em GFRP (Tabela $3.2)$.

Sabendo-se que o ACI 440.1R-06 considera que a tensão de cisalhamento no reforço GFRP deve ser limitada pelo controle da largura de fissuras e que o dimensionamento analítico no cisalhamento utilizando o controle pelo esmagamento do concreto produz deslocamentos menores comparados com armadura em aço, os resultados obtidos em elementos finitos são altamente satisfatórios.

Também uma possível continuidade deste trabalho seria analisar experimentalmente o modelo de cisalhamento e comparar com os resultados já obtidos. 


\section{REFERÊNCIAS BIBLIOGRÁFICAS}

Al-Sunna, R.; Pilakoutas, K.; Waldron, P. e Al-Hadeed, T. (2003). Deflection of FRP Reinforced Concrete Beams.

Alves Filho; Avelino (2006). Elementos Finitos. A base da tecnologia CAE.

American Concrete Institute. ACI Structural Journal (2002). Shear Tests of FRPReinforced Concrete Beams Without Stirrups. New York: ACI.

American Concrete Institute. ACI Structural Journal (2003). Analysis of fiberreinforced polymer composite grid reinforced concrete beams. New York: $\mathrm{ACl}$.

American Concrete Institute. ACI 440.1R-06 (2006). - Guide for the Design and Construction of Structural Concrete Reinforced with FRP bars. N. York: ACI.

American Concrete Institute. ACI 318-08 (2008). - Building Code Requirements for Structural Concrete (ACI 318-08) and commentary. New York: $\mathrm{ACI}$.

American Concrete Institute. ACI 318-05 (2005) - Building Code Requirements for Structural Concrete (ACI 318-05) and commentary. New York: ACI.

American Concrete Institute Committee 318 (2005). Metric Building Code Requirements for Reinforced Concrete and Commentary (ACI 318M-05). Mich..

American Composites Manufacturers Association (2009). ACMA - USA, Disponível em <http://www.acmanet.org.br>. Acesso em 10 de Março de 2009.

Antunes, Helena M. C. Carmo e E. Souza, João C. A. de Oliveira (2006). Introdução à Análise Matricial de Estruturas. SET/EESC/USP. 
Associação Brasileira de Normas Técnicas (2003). NBR 6118:2003 - Projeto de Estruturas de Concreto. Rio de Janeiro: ABNT.

Associação Brasileira de Normas Técnicas (2001). NBR 9062:2001 - Projeto e execução de estruturas de concreto pré-moldado. Rio de Janeiro: ABNT.

Associação Brasileira de Materiais Compósitos (2009). ABMACO - Disponível em <http://www.abmaco.org.br>. Acesso em 15/03/2009.

ASTM Standard (2001). Standard terminology for composite materials. ASTM International. West Conshohocken, Pa., USA.

Bakis, C. E. e Boothby, T. E. (2004). Evaluation of Crack Width and Bond Strength in GFRP Reinforced Beams Subjected to Sustained Loads.

Bakis, Charles E. e Ospina, Carlos E. (2006). Indirect crack control procedure for FRP- reinforced concrete beams and one-way slabs.

Callister Jr., W. D. (2002). Ciência e Engenharia de Materiais: Uma Introdução. Tradução de Sérgio Murilo Stamile Soares, 5 ed. Rio de Janeiro.

CAN/CSA-S6-00 (2000). Canadian High Bridge Design Code. Canadian Standard Association (CSA) International. Toronto, Ontário, Canadá.

CAN/CSA-S6-02 (2002). Design and Construction of Building Components with Fibre- Reinforced Polymers, Canadian Standards Association. CAN/CSA-S80202. Ontário, Canadá.

Carvalho, Roberto C. e Figueiredo Filho, Jasson R. de. (2004). Cálculo e detalhamento de estruturas usuais de concreto armado. Segundo a NBR 6118:2003. 
CNR-DT 203/2006 (2006). Guide for the Design and Construction of Concrete Structures Reinforced with Fiber-Reinforced Polymer Bars. Roma, Itália.

CONSIGLIO NAZIONALE DELLE RICERCHE (2007). Istruzioni per la Progettazione, l'Esecuzione ed il Controllo di Strutture di Calcestruzzo Armato con Barre di Materiale Composito Fibrorinforzato. Roma.

Correia, J.R.; Branco, F.A. e Ferreira, J.G. (2007). Comportamento mecânico de perfis pultrudidos de fibra de vidro (GFRP) e das sua ligações. Lisboa.

Daniali, S. (1992). Development Length for Fiber- Reinforced Plastic Bars. Advanced Composite Materials in Bridges and Structures.

Daniel, I. M.; Ishai, O. (1994). Engineering Mechanics of Composite Materials, New York, Oxford University Press.

Ehsani, M. R.; Saadatmanesh, H.; e Tao, S. (1996). Design Recommendation for Bond of GFRP Rebars to Concrete. Journal of Structural Engineering.

EN 1992-1-1 Eurocode 2 (2004). Design of concrete structures - Part 1-1: General rules and rules for buildings.

Fico, Raffaello (2007). Limit states design of concrete structures reinforced with FRP bars. Ph.D. Thesis.

Frosch, R. J. (1999). Another Look at Cracking and Crack Control in Reinforced Concrete, ACI Structural Journal.

Gao, D.; Benmokrane, B. e Masmoud, R. (1998). A Calculating Method of Flexural Properties of FRP - Reinforced Concrete Beam, Techical Report. Canadá.

Gay, D.; Hoa, S. V. e Tsai, S. W. (2003). Composite Materials (Design and applications). Part I: Principles of Construction. 
Hughes Bros. Inc. (2001). Mechanical Properties of GFRP rebar.

Hull, D. (1981). An introduction to composite materials. London, Cambridge University Press.

Hyer, M. W. (1998). Stress analysis of fiber- reinforced composite materials. Boston.

JSCE - Japan Society of Civil Engineers (1997). Recommendation for Design and Construction of Concrete Structures Using Continuous Fiber Reinforcing Materials. Tokio.

Leonhardt, F. e Mönnig, E. (1982). Construções de Concreto. Princípios Básicos do dimensionamento de Estrututras de Concreto Armado. Vol. 1.

Kong, F.K. e Evans, R.H. (2001). Reinforced and Prestresse Concrete. Third Edition - chapter 6.

Mattews, F.L. e Rawlings, R. D. (1994). Composite materials: engineering and science.1.ed. New York, Chapman-Hall.

Micali, Roberto M.; Ortenzi, Altibano e Carvalho, Jonas de. (2009). Comportamento de vigas pré-moldadas de concreto submetidas ao cisalhamento - Estudo comparado com armadura convencional e com polímero reforçado com fibras de vidro, EESC - USP.

Micali, Roberto M.; Ortenzi, Altibano e Carvalho, Jonas de. (2009). Comportamento de vigas pré-moldadas de concreto submetidas à flexão com armadura interna em GFRP, EESC - USP.

Muruts, Mulu e Nad, Ludovit. (1998). Laminated glass fiber reinforced plastic (GFRP) bars in concrete structures, Budapest.

Nagasaka, T.; Fukuyama, H. e Tanigaki, M. (1993). Shear Performance of Concrete Beams Reinforced with FRP Stirrups. 
Nehdi, M.; Omeman, Z. e El-Chabib, H. (2008). Optimal efficiency factor in strutand-tie model for FRP-reinforced concrete short beams with $(1,5<a / d<2,5)$.

Ortenzi, Altibano (2007). A fibra de vidro em matrizes poliméricas e cimentícias e seu uso estrutural em construção civil - o estado - da - arte. Dissertação de mestrado.São Carlos: UFSCAR.

Ospina, Carlos E. e Nanni, Antonio (2007). CURRENT FRP-REINFORCED CONCRETE DESIGN TRENDS IN ACI 440.1R.

Ospina, Carlos E.; Alexander, S. e Cheng, J. J. (2001). Behaviour of Concrete Slabs with Fibre-Reinforced Polymer Reinforcement. Structural Engineering Report. Alberta, canadá.

Owens Corning (2009). Disponível em <http://www.owenscorning.com.br>. Acesso em 30/04/2009.

Pilakoutas, k.; Guadagnini, M.; Neocleous, K. e Taerwe, L. (2007). Design Guidelines for FRP reinforced concrete structures.

Pilakoutas, k.; Guadagnini, M. e Neocleous, K. (2002). Design Philosophy Issues of Fiber Reinforced Polymer Reinforced Concrete Structures. Journal of Composites for Construction.

Pinheiro, Libânio M.; Muzardo, Cassiane D. e Santos, Sandro P. (2004). Estruturas de concreto. SET/EESC/USP.

SAINT-GOBAIN-VETROTEX (2000). Vetrotex Glass Fibre. Chambéry: VETROTEX.

Savassi, Walter. (1996). Introdução ao Método dos Elementos Finitos: Em análise linear de estruturas. São Carlos: EESC. 
Shield, C.; French, C.; e Retika, A. (1997). Thermal and Mechanical Fatigue Effects on GFRP Rebar- Concrete Bond. Proceedings of the Third International Symposium on Non-Metallic (FRP) Reinforcement for Concrete Structures, Tokyo, Japan.

Shield, C.; French, C.; e Hanus, J. (1999). Bond of GFRP Rebar for Consideration in Bridge Decks. Fourth International Symposium on Fiber Reinforced Polymer Reinforcement for Reinforced Concrete Structures.

Tavares, Danusa Haick (2006). Análise teórica e experimental de vigas de concreto armadas com barras não metálicas de GFRP. Dissertação de mestrado. São Carlos: EESC/USP.

Toledo, Raquel de; Abreu, Aline F. De e Jungles Antonio E. (1999). A Difusão de Inovações Tecnológicas na Indústria da Construção Civil. Universidade Federal de Santa Catarina. Florianópolis: UFSC.

Tighiouart, B.; Benmokrane, B.; e Mukhopadhyaya, P. (1999). Bond Strength of Glass FRP Rebar Splices in Beams Under Static Loading. Construction and Building Materials, V.13.

Uomoto, T. et al. (2002). Use of Fiber Reinforced Polymer Composites as reinforcing Material for Concrete. Journal of Materials in Civil Engineering.

Wambeke, B. e Shield. C. (2006). Development Length of Glass Fiber Reinforced Polymer Bars in Concrete. ACI Structural Journal.

Wilson, Brian A. (1998). Handbook of Composites. Edited by S.T. Peters. Published by Chapman \& Hall, London. 